UNIVERSIDADE DE SÃO PAULO

ESCOLA POLITÉCNICA

FABIO SISMOTTO EL HAGE

A ESTRUTURA TARIFÁRIA DE USO DAS REDES DE DISTRIBUIÇÃO DE ENERGIA ELÉTRICA NO BRASIL: ANÁLISE CRÍTICA DO MODELO VIGENTE E NOVA PROPOSTA METODOLÓGICA

São Paulo, 2011 


\title{
A ESTRUTURA TARIFÁRIA DE USO DAS REDES DE DISTRIBUIÇÃO DE ENERGIA ELÉTRICA NO BRASIL: ANÁLISE CRÍTICA DO MODELO VIGENTE E NOVA PROPOSTA METODOLÓGICA
}

\author{
Tese apresentada à Escola Politécnica da \\ Universidade de São Paulo para a obtenção \\ do título de Doutor em Engenharia.
}

Área de concentração: Sistemas de Potência

Orientador: Prof. Dr. Nelson Kagan

São Paulo, 2011 
Autorizo a reprodução e divulgação total ou parcial deste trabalho, por qualquer meio convencional ou eletrônico, para fins de estudo e pesquisa, desde que citada a fonte

Catalogação na publicação

Serviço de Biblioteca e Documentação

Escola Politécnica da Universidade de São Paulo

Este exemplar foi revisado e alterado em relação à versão original, sob responsabilidade única do autor e com a anuência de seu orientador.

São Paulo, 14 de fevereiro de 2011.

Assinatura do autor

Assinatura do orientador

FICHA CATALOGRÁFICA

El Hage, Fabio Sismotto

A estrutura tarifária de uso das redes de distribuição de ener-

gia elétrica no Brasil: análise crítica do modelo vigente e nova proposta metodológica / F.S. El Hage. -- ed.rev. -- São Paulo, 2011.

153 p. + anexos

Tese (Doutorado) - Escola Politécnica da Universidade de São Paulo. Departamento de Engenharia de Energia e Automação Elétricas.

1. Distribuição de energia elétrica (Tarifas) - Brasil 2. Custo econômico I. Universidade de São Paulo. Escola Politécnica. Departamento de Engenharia de Energia e Automação Elétricas II. t. 
Às minhas amadas esposa e filha,

por serem a razão e a luz da minha vida.

À minha mãe,

por ter se dedicado tanto à minha formação para a vida.

À minha família,

por me apoiar, sempre! 


\section{AGRADECIMENTOS}

Em primeiro lugar, agradeço a meu orientador, Prof. Nelson Kagan, por ter proporcionado um produtivo ambiente de confiança e liberdade.

Agradeço ao Prof. Carlos Barioni, pelos sempre apropriados direcionamentos dados ao estudo.

Agradeço aos Professores Lucas Ferras e Carlos Marcio Tahan, pelas intensas e produtivas discussões.

Agradeço ao amigo Mauro Machado, por contestar e induzir a reflexões mais profundas.

Agradeço aos amigos Fernando Orsatti e Rodrigo Carareto, pelas fortes contribuições em matemática aplicada.

Agradeço aos colegas Marco Delgado e Saulo Castilho, pela oportunidade de aplicação efetiva dos resultados da pesquisa no âmbito do projeto de $P \& D$ estratégico sobre o tema da estrutura tarifária.

Por fim, agradeço aos amigos Alden Antunes, André Méffe, Denis Antonelli, Ricardo Wada, Cristiano Silveira e Sérgio Fujimoto, que contribuíram de forma importante para o amadurecimento do trabalho. 


\section{RESUMO}

O trabalho discute a questão da precificação eficiente em sistemas de distribuição de energia, abordando desde a teoria econômica clássica aplicada aos modelos de produção e transporte da energia, passando por uma avaliação crítica da atual metodologia de estrutura tarifária vigente no Brasil, até o detalhamento de uma proposta consistente e simplificadora de estrutura de preços para a atividade da distribuição de energia.

A teoria de monopólios naturais é o pano de fundo para uma discussão integrada dos modelos clássicos de estrutura de preços para o transporte da energia elétrica. Nesta avaliação do "estado da arte", são abordadas as teorias da precificação linear, da precificação não linear e da precificação de ponta.

A atual metodologia nacional de cálculo da estrutura tarifária de uso das redes de distribuição, aplicada pela Agência Nacional de Energia Elétrica - ANEEL, é revisitada sob uma visão técnica crítica. Como resultado, são desconstruídos alguns conceitos e processos vigentes pela constatação de uma excessiva complexidade operacional aliada a uma carência de fundamentação econômica e matemática.

Por fim, é proposta uma metodologia simplificadora para a estrutura de preços de uso das redes de distribuição de energia, objetivando maior eficiência econômica, maior simplicidade operacional na aplicação e sólida fundamentação teórica, reduzindo arbitrariedades e subjetividades existentes na atual metodologia.

Palavras chave: 1.Distribuição de energia. 2.Estrutura Tarifária. 3.Tarifa de Uso. 4.Energia-Custos marginais 


\section{ABSTRACT}

The present work discusses the question of efficient pricing on electric power distribution systems. The subject is approached from the discussion of the classical economic theory applied to energy production and transport models, passing through a critical evaluation of the current rate structure used in Brazil, to the description of a consistent and simplified proposal for the electric power distribution rate design.

The theory of natural monopolies is the background of an integrated discussion on classical rate design models concerning the electric energy transportation activity. By the classical problem analysis, some theories commonly approached are linear pricing, non linear pricing and peak load pricing.

The current Brazilian methodology used for the rate design of the usage of distribution networks, applied by the National Regulatory Agency (ANEEL), is revisited under a critical technical vision. As a result, some concepts are reassessed due to the observed excessive operational complexity allied to the lack of economical and statistical foundation.

Finally, a simplified methodology for the rate structure of the usage of electrical distribution networks is proposed. The methodology aims, at the same time, greater economic efficiency, simpler operational application and a solid theoretical foundation, thereby reducing arbitrariness and subjectivity found in the current methodology.

Keywords: 1.Power distribution. 2.Rate structure. 3.Usage tariffs. 4.Energy marginal costs. 


\section{LISTA DE ILUSTRAÇÕES}

Figura 1 - Fluxograma de informações para o cálculo dos custos de capacidade ....... 10

Figura 2 - Fluxograma de informações para o cálculo das tarifas de referência ........... 11

Figura 3 - Precificação a custos médios em um mercado monoproduto ......................... 13

Figura 4 - Representação da tarifa em duas partes...................................................... 17

Figura 5 - Situação de forte monotonicidade em $\mathrm{R}$ da função demanda. A preços iguais, a demanda do consumidor grande será sempre maior que a demanda do

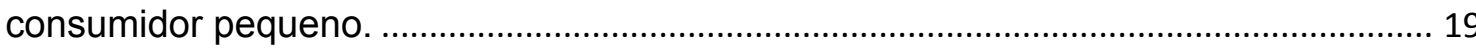

Figura 6 - Perda de bem-estar social em ambos os sub-mercados devido à precificação à custos médios. ............................................................................................. 20

Figura 7 - Excedente dos consumidores tipo grande e tipo pequeno para precificação ao custo marginal.

Figura 8 - Princípio econômico da tarifação em multi-partes: "Trade-off" entre exclusão de consumidores pequenos e a perda de bem-estar devido a preços marginais elevados.

Figura 9 - Esquema de tarifação multi-parte compatível com incentivos ........................ 23

Figura 10 - Curva de triagem dada pela Equação (7) ................................................... 26

Figura 11 - Comparação de alternativas tecnológicas de geração através das curvas de triagem. Nota-se a dominância da região de menor custo a partir da

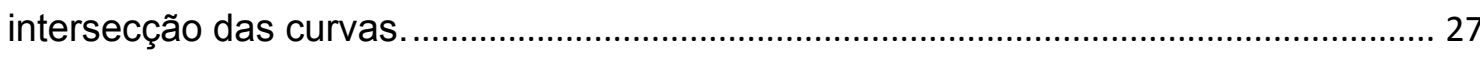

Figura 12 - Demandas $\mathrm{q}_{1}$ e $\mathrm{q}_{2}$ a preços iguais ........................................................... 30

Figura 13 - "Firm peak case": A preços diferentes, a demanda máxima continua

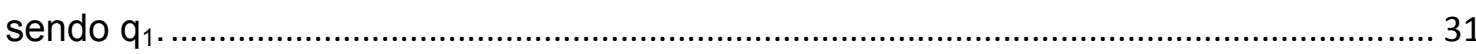

Figura 14 - "Shifting peak case": A preços diferenciados, a demanda menor se

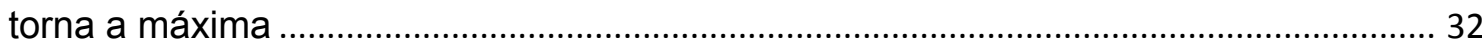

Figura 15 - Solução ótima para o problema de inversão da ponta documentada por

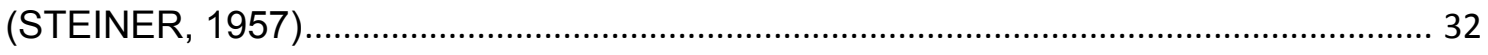

Figura 16 - Curva de custos totais de uma rede composta por apenas uma SE.......... 44

Figura 17 - Curvas de curto prazo para consecutivas expansões de capacidade........ 45

Figura 18 - Curvas de custos totais e marginais de curto e longo prazos. ..................... 46

Figura 19 - Curvas de custos de curto prazo mais rígidas. ............................................ 47

Figura 20 - Curvas de custos totais e marginais de curto e longo prazos. ..................... 47

Figura 21 - Curva de custos totais de curto prazo de uma rede simplificada ................. 48

Figura 22 - Função demanda e os custos marginais de curto e longo prazos.............. 50

Figura 23 - Representação simplificada de um sistema de distribuição com três

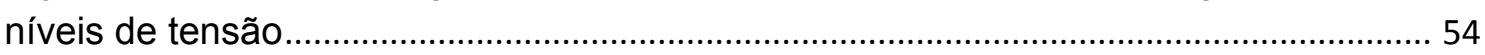

Figura 24 - Previsão de investimentos em expansão (Ii) e de variações de

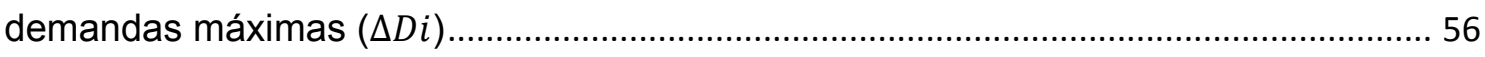

Figura 25 - Exemplo de diagrama de fluxo simplificado para a determinação do

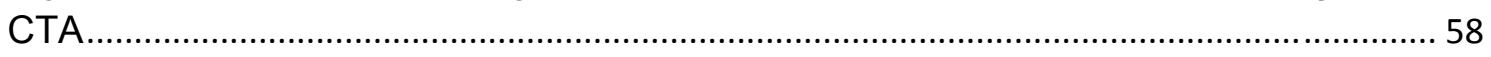

Figura 26 - Diagrama contendo as curvas de consumidores-tipo e redes-tipo .............. 60

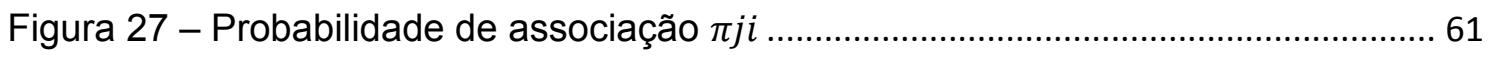

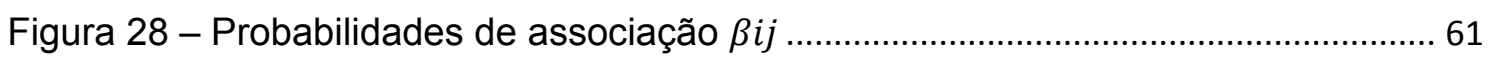


Figura 29 - Caso exemplo, com três consumidores-tipo atendidos por uma rede-tipo 62

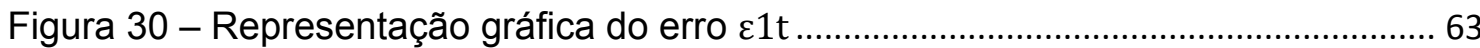

Figura 31 - Variáveis $D j(T M)$ e $D J M A X$ utilizadas no cálculo do fator de

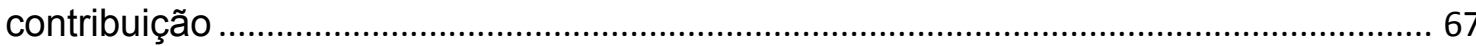

Figura 32 - Representação gráfica do problema de associações entre consumidores e redes

Figura 33 - Exemplo de um alimentador que atende a dois consumidores e tem duas fontes energéticas, um gerador e uma transformação de um nível a montante. . 74 Figura 34 - Curvas de carga utilizadas no exemplo da Figura 33 ................................... 75

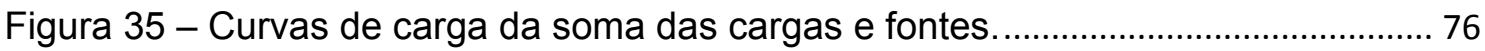

Figura 36 - Curvas estimadas e reais das fontes $G$ e $F$................................................ 77

Figura 37 - Modelamento do problema das probabilidades de associação para o nível de baixa tensão (BT) da DME-PC. Foram consideradas curvas agregadas dos consumidores das classes residencial (RES), comercial (COM), industrial (IND), rural (RUR), subterrâneo (AS) e iluminação pública (IP). Fonte: Aneel-Tardist.............. 79 Figura 38 - Exemplo de um sistema determinístico, com uma única fonte de alimentação

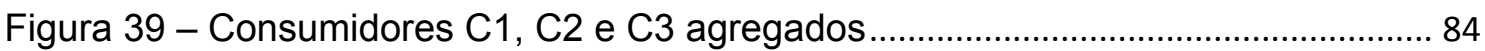

Figura 40 - Exemplo de um sistema determinístico, com uma única fonte de

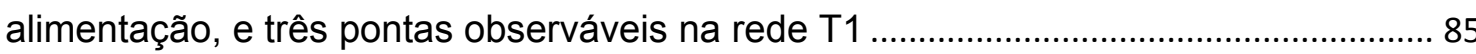

Figura 41 - Proporção de uso da rede T1 em cada um dos instantes de ponta ............ 87

Figura 42 - Exemplo de determinação das retas de curta (CU), média (MU) e longa (LU) utilização a partir de regressões lineares dos custos de cada cliente-tipo

Figura 43 - Interpretação gráfica dos custos de capacidade no contexto da atual metodologia

Figura 44 - Análise de regressão entre o custo de capacidade e o fator de carga para o horário de ponta. Dados da campanha de medidas da ESCELSA 2009. Fonte: ANEEL

Figura 45 - Análise de regressão entre o custo de capacidade e o fator de carga para o horário de ponta. Dados da campanha de medidas da RGE 2008. Fonte: ANEEL

Figura 46 - Análise de regressão entre o custo de capacidade e o fator de carga para o horário de ponta. Dados da campanha de medidas da ELEKTRO 2002. Fonte: ANEEL

Figura 47 - Modelo econômico de (DRÈZE, 1964) …..................................................... 102

Figura 48 - Exemplo de carga periódica ilustrado por (DRĖZE, 1964)......................... 103

Figura 49 - Exemplo de curvas de carga agregadas para duas empresas hipotéticas, Empresa 1 e Empresa 2.

Figura 50 - Modelo econômico proposto para os custos totais de uma distribuidora. 106 Figura 51: Sistema para atendimento a dois tipos de consumidores em um mesmo nível de tensão.

Figura 52 - Contexto metodológico no qual serão definidas as variáveis e processos da metodologia proposta.

Figura 53 - Exemplo de diagrama simplificado de fluxo de energia com três níveis: 
Figura 54: Curvas de carga de um consumidor de média tensão, representando 32 dias ininterruptos de medição

Figura 55: Média e desvio padrão dos 288 pontos armazenados durante os 32 dias de medição. Média em azul e desvio padrão em vermelho

Figura 56: Grupo de curvas de dias úteis, contendo 22 dias de medição, além da curva média

Figura 57: Grupo de curvas de finais de semana, contendo 10 dias de medição, além da média.

Figura 58: Curvas de médias e desvios de cada um dos 288 pontos para dias úteis.

Média em azul e desvio padrão em vermelho

Figura 59: Curvas de médias e desvios de cada um dos 288 pontos para os finais de semana. Média em azul e desvio padrão em vermelho

Figura 60: Inferência do formato da curva média da população de determinada modalidade. As linhas tracejadas representam o erro amostral.....

Figura 61 - Modalidades Azul e Verde atualmente empregadas nos sistemas de distribuição brasileiros

Figura 62 - Possível curva de custos da geração a diesel

Figura 63 - Interpretação gráfica das opções da modalidade Azul da EDF

Figura 64 - Modalidades A1, A2, ... An de uma das faixas da tarifa Verde francesa.127 Figura 65 - Mecanismo proposto de ajuste regulatório das sinalizações entre ponta e fora-ponta com base nos custos marginais de curto e longo prazos, e na análise da dinâmica do mercado através da observação da curva agregada do sistema....... 133 Figura 66 - Visualização gráfica das três modalidades tarifárias, F1, F2 e F3............. 136 Figura 67 - Curva da tarifa de uso do sistema de distribuição, em função apenas da demanda máxima registrada

Figura 68 - Esquema de tarifação com 3 modalidades, de tal forma que o mercado é dividido em 3 faixas de consumo com igual número de consumidores.

Figura 69 - Distribuição de freqüências dos fatores de carga no posto de ponta para todos os consumidores A4 de uma distribuidora nacional. ............................................. 140

Figura 70 - Caso do Monopólio Natural Permanente ...................................................... 154

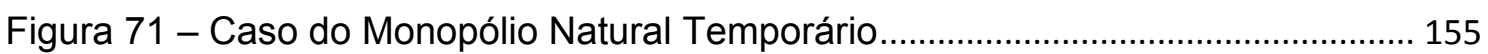

Figura 72 - Definição das regiões de economias e deseconomias de escala .............. 157

Figura 73 - Representação gráfica dos excedentes do consumidor e do produtor .... 160

Figura 74 - Interpretação gráfica do custo fixo, variável e total .................................... 161

Figura 75 - Resultados para a precificação à custos médios, com a ilustração dos excedentes do consumidor, EC, do produtor, EP e do "peso-morto", que é a perda de bem-estar social.

Figura 76 - Curva de custos caracterizando Economias de Escala no âmbito da

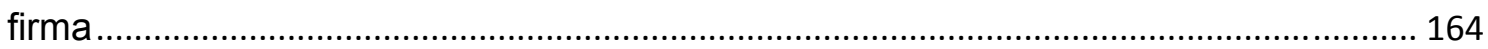

Figura 77 - Economias de Escala x Sub-aditividade da função custo ............................. 167

Figura 78 - Uma firma monopolista fixa seu preço acima do custo marginal ................ 171

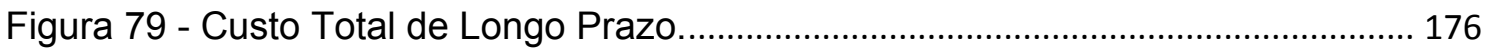

Figura 80 - Custo de Total de Longo Prazo................................................................. 178

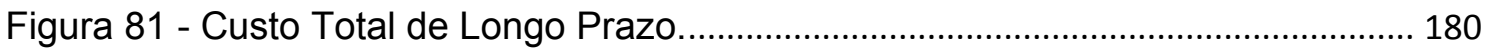

Figura 82 - Custo Total de Longo Prazo................................................................................. 182 
Figura 83 - Custo Total de Longo Prazo

Figura 84: Agrupamentos resultantes - Método k-médias. ........................................... 187

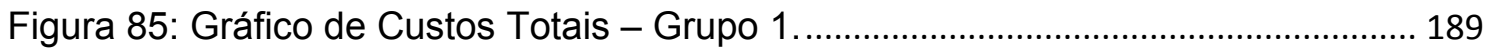

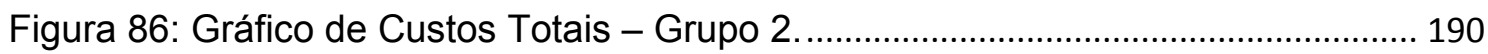

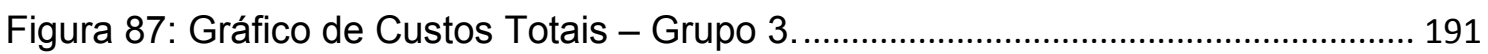

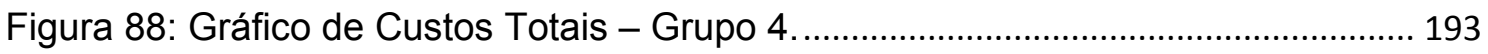

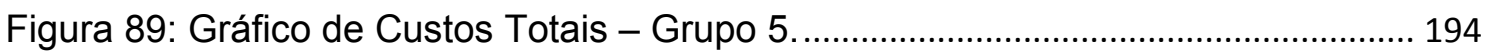

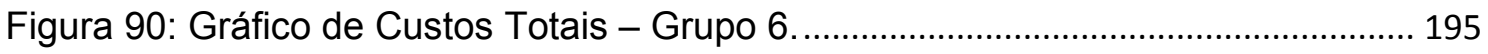

Figura 91 - Representação gráfica das variáveis $\pi j i$................................................... 198

Figura 92 - Representação gráfica das variáveis $\beta i j$................................................... 198

Figura 93 - Na figura, está indicada uma curva de referência. A curva "com erro" é um exemplo de curva com pequena distância euclidiana em relação à curva de referência. Apesar da pequena distância euclidiana, vê-se que a forma da curva não mantida. A linha tracejada em indica uma faixa em torno da curva de referência de forma que os erros amostrais para cada uma das variáveis é igual a 0,2 ............. 205

Figura 94 - Função densidade de probabilidade da distribuição normal com média 0 e desvio padrão unitário

Figura 95 - Histograma da população com distribuição uniforme entre 0 e $1 \mathrm{com}$ 20.000 elementos

Figura 96 - Verificação do teorema do limite central. Distribuição da média amostral para 5000 amostras aleatórias, para amostras de tamanhos iguais a 20, 50 e 100 elementos.

Figura 97 - Para 50.000 amostras calculou-se a média amostral e o número de vezes em que a média amostral esteve a uma distância de menos de $10 \%$ da média da população.

Figura 98 - Distribuições das populações geradas para simulação do caso multidimensional.

Figura 99 - Curva média para uma população de 5893 consumidores. Estão indicadas as faixas correspondentes a erros amostrais de 20 e $40 \%$

Figura 100 - Histograma para o valor de emax para amostras de 694 elementos. Ao centro, o limite de erro determinado pelo erro amostral requerido (20\%).

Figura 101 - Histograma para o valor de emax para amostras estratificadas de 205 elementos. Ao centro, o limite de erro determinado pelo erro amostral requerido $(20 \%)$ 


\section{LISTA DE TABELAS}

Tabela 1 - Dados de demanda ativa, em base horária, de uma rede-tipo $i$ qualquer .. 68

Tabela 2 - Identificação dos instantes de ponta $h$ da rede-tipo $i$....................................... 68

Tabela 3 - Dados de demanda ativa, em base horária, de um consumidor-tipo $j$

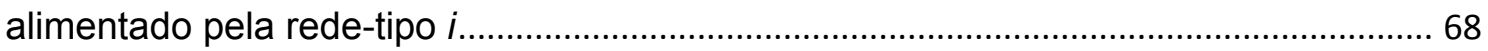

Tabela 4 - Vetor de Fatores de Contribuição do consumidor-tipo j .................................. 69

Tabela 5 - Resultado das probabilidades de associação obtidas a partir da otimização do sistema apresentado em (39). As estatísticas de teste de hipótese nula (T-Statistic) foram calculadas ao nível de $95 \%$ de confiabilidade. R2 é coeficiente de correlação dos ajustamentos

Tabela 6 - Resultados da estimativa das probabilidades de associação para o caso da Figura 37. São apresentadas as estimativas das variáveis $(\pi j i)$, seus desvios $(\sigma j i)$, as estatísticas dos testes de hipótese nula (t-stat) e suas correspondentes probabilidades (Prob).

Tabela 7 - Resultados dos coeficientes de correlação não ajustados da estimativa. .. 80 Tabela 8 - Proporção de Receitas Faturadas aplicando-se Cmg do nível às demandas coincidentes dos consumidores

Tabela 9 - Proporção de Receitas Faturadas aplicando-se o Custo de Capacidade dos consumidores às respectivas demandas máximas do posto da ponta ..................... 85

Tabela 10 - Custos de capacidade calculados, em $\mathrm{R} \$ / \mathrm{kW}$.ano........................................ 86

Tabela 11 - Receitas obtidas através da aplicação dos custos de capacidade às demandas máximas dos consumidores-tipo, em ambos os postos tarifários ................ 87

Tabela 12 - Demandas coincidentes dos consumidores nos horários de ponta............ 88

Tabela 13 - Receitas supostamente faturadas por demandas coincidentes nos

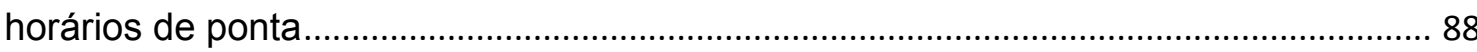

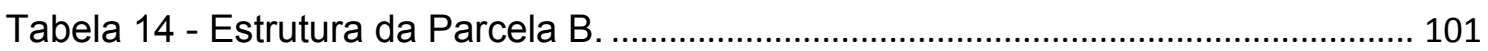

Tabela 15 - Custos Marginais Isolados (denominados custos marginais de expansão) utilizados pela ANEEL no $2^{\circ}$ ciclo de revisões tarifárias. Fonte: ANEEL. . 141 Tabela 16 - Resultado da aplicação da metodologia proposta ao sistema da CPFL Paulista, utilizando-se dados de curvas de carga e fluxo de energia do segundo ciclo de revisões tarifárias da empresa. Fonte de dados: ANEEL.

Tabela 17 - Tarifas finais (Anexo II) da CPFL Paulista nos dois cenários: Metodologia proposta e resultados do Tardist. Fonte de dados: ANEEL. ..................... 142 Tabela 18 - Resultado da aplicação da metodologia proposta ao sistema da RGE, utilizando-se dados de curvas de carga e fluxo de energia do segundo ciclo de revisões tarifárias da empresa. Fonte de dados: ANEEL

Tabela 19 - Tarifas finais (Anexo II) da RGE nos dois cenários: Metodologia proposta e resultados do Tardist. Fonte de dados: ANEEL.

Tabela 20 - Resultado da aplicação da metodologia proposta ao sistema da ESCELSA, utilizando-se dados de curvas de carga e fluxo de energia do segundo ciclo de revisões tarifárias da empresa. Fonte de dados: ANEEL.

Tabela 21 - Tarifas finais (Anexo II) da ESCELSA nos dois cenários: Metodologia proposta e resultados do Tardist. Fonte de dados: ANEEL. 
Tabela 22 - Calendário de Revisão Tarifária - 2007. Fonte: ANEEL. ........................... 173

Tabela 23 - Calendário de Revisão Tarifária - 2008. Fonte: ANEEL. ............................ 173

Tabela 24 - Calendário de Revisão Tarifária - 2009. Fonte: ANEEL. ............................. 175

Tabela 25 - Dados da função de custos de longo prazo - Total. ..................................... 176

Tabela 26 - Dados das Distribuidoras - Nordeste. Dados a preços constantes de

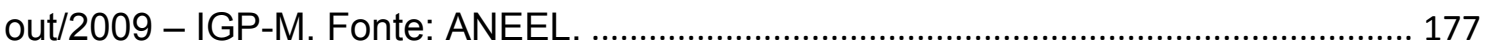

Tabela 27 - Dados da função de custos de longo prazo - Total. ..................................... 178

Tabela 28: Custos médios - Nordeste. Fonte: ANEEL. ............................................... 178

Tabela 29 - Dados das Distribuidoras - Norte/ Centro-Oeste. Fonte: ANEEL.............. 179

Tabela 30 - Dados da função de custos de longo prazo - Total. ..................................... 180

Tabela 31: Custos médios - Norte/Centro-Oeste. Fonte: ANEEL. ................................... 180

Tabela 32 - Dados das Distribuidoras - Sul. Fonte: ANEEL. .......................................... 181

Tabela 33 - Dados da função de custos de longo prazo - Total. .................................... 182

Tabela 34 - Custos médios - Sul. Fonte: ANEEL. ......................................................... 183

Tabela 35 - Dados das Distribuidoras - Sudeste. Fonte: ANEEL. ................................. 184

Tabela 36 - Dados da função de custos de longo prazo - Total. ..................................... 185

Tabela 37 - Custos marginais de curto prazo e custos médios - Sudeste. Fonte:

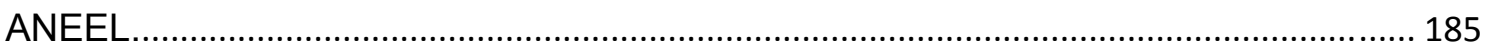

Tabela 38 - Custos marginais de operação e custos médios - Grupo 1 ........................ 188

Tabela 39 - Dados da função de custos de longo prazo - Grupo 1 ............................... 188

Tabela 40 - Custos marginais de operação e custos médios - Grupo 2 …..................... 189

Tabela 41: Dados da função de custos de longo prazo - Grupo 2 . ................................ 190

Tabela 42 - Custos marginais de operação e custos médios - Grupo 3......................... 190

Tabela 43 - Dados da função de custos de longo prazo - Grupo 3 ................................ 191

Tabela 44 - Custos marginais de operação e custos médio - Grupo 4 ........................... 191

Tabela 45 - Dados da função de custos de longo prazo - Grupo 4 ............................... 192

Tabela 46 - Custos marginais de operação e custos médio - Grupo 5.......................... 193

Tabela 47 - Dados da função de custos de longo prazo - Grupo 5 ................................. 194

Tabela 48 - Custos marginais de operação e custos médios - Grupo 6........................ 194

Tabela 49 - Dados da função de custos de longo prazo - Grupo 6................................ 195

Tabela 50 - Características das populações geradas para simulação de caso

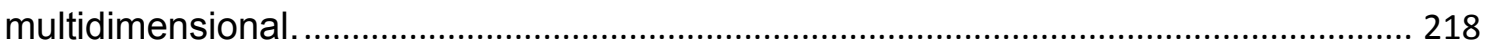

Tabela 51 - Definição dos estratos utilizados e número de amostras para cada estrato. 


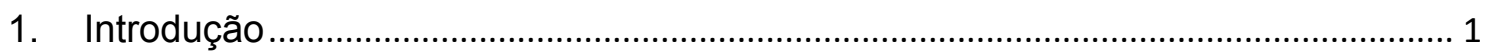

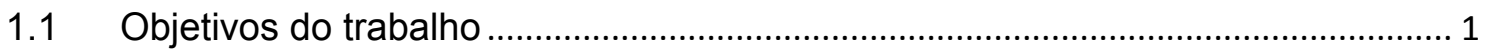

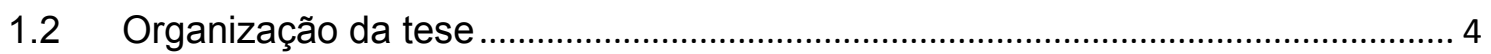

1.3 Contribuições explícitas do trabalho.................................................................. 5

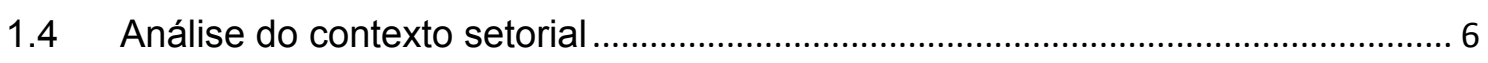

1.5 Histórico e visão geral sobre a estrutura tarifária brasileira................................... 8

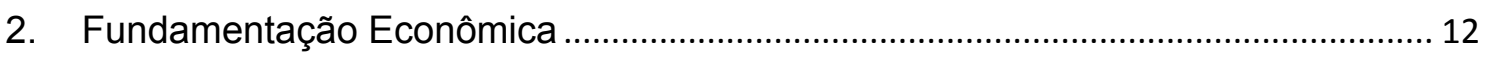

2.1 Modelos de precificação em monopólios naturais ................................................ 12

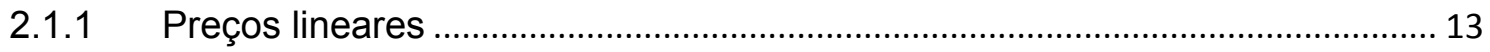

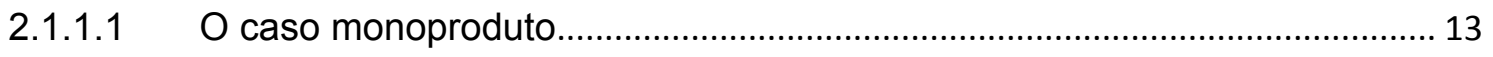

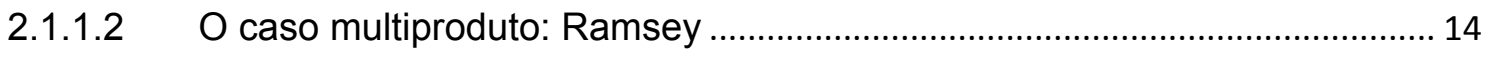

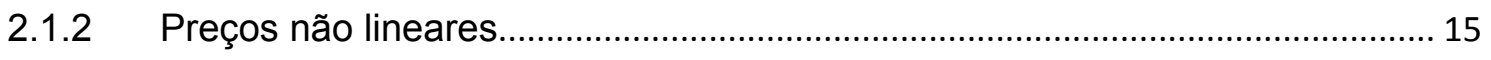

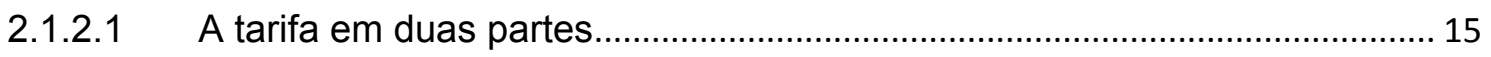

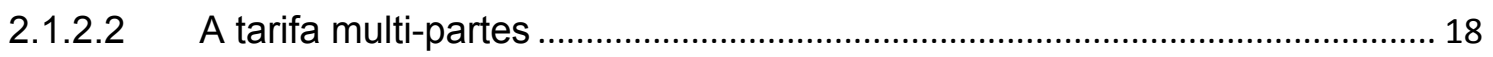

2.1.2.3 Precificação não linear aplicada aos sistemas de potência ............................ 24

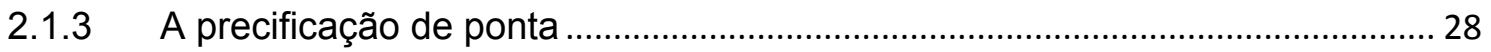

2.1.3.1 O preço de ponta para o "firm peak case" .......................................................... 29

2.1.3.2 O preço de ponta para o "shifting peak case" .................................................. 31

2.1.4 A questão dos custos na produção conjunta ..................................................... 34

2.1.4.1 Critérios para a divisão dos custos totais por nível de tensão ........................ 37

2.1.5 A discriminação de preços aos consumidores................................................... 41

3. Custos da Distribuição no Curto e no Longo Prazos ................................................. 43

3.1 A teoria: custos de curto e longo prazos .......................................................... 44

4. A Metodologia de Estrutura Tarifária Atualmente Praticada no Brasil ...................... 52

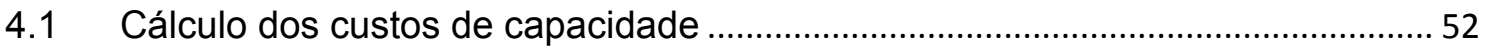




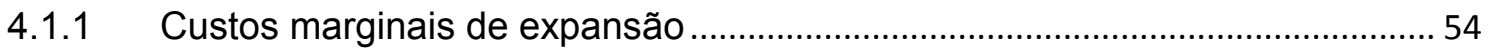

4.1.2 O coeficiente técnico de atendimento - CTA

4.1.3 As probabilidades de associação …………..................................................... 59

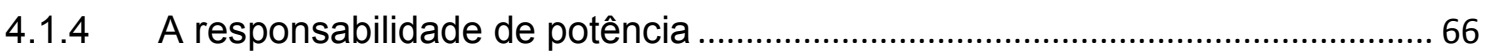

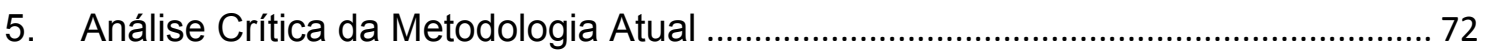

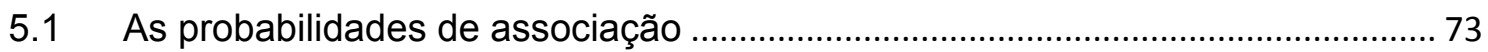

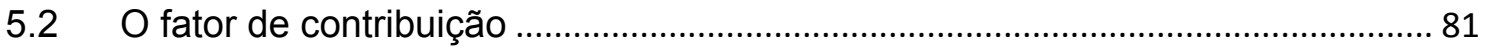

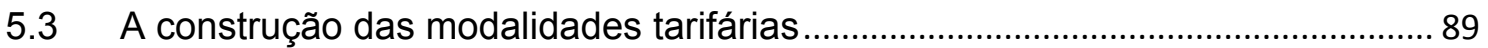

$5.4 \quad$ Hipóteses implicitamente consideradas no modelo .............................................. 93

5.4.1 Simplificação do sistema de distribuição ............................................................. 93

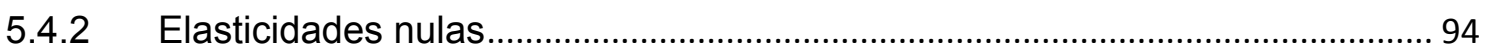

5.5 Principais problemas observados na atual metodologia ....................................... 94

5.5.1 O conceito do custo marginal do cliente ............................................................. 95

5.5.2 Postos tarifários e sinais entre ponta e fora de ponta ....................................... 96

6. Uma Proposta Simplificadora para a Estrutura Tarifária de Uso das Redes de

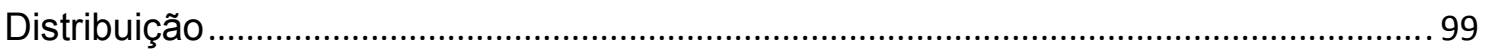

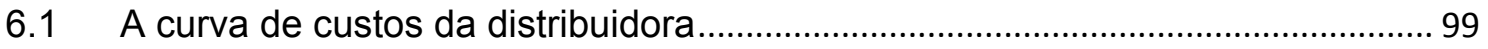

6.2 A questão dos custos marginais em um mesmo nível de tensão......................... 107

6.3 Premissas metodológicas para o desenvolvimento da proposta......................... 109

6.3.1 O diagrama simplificado de fluxo de energia .................................................... 110

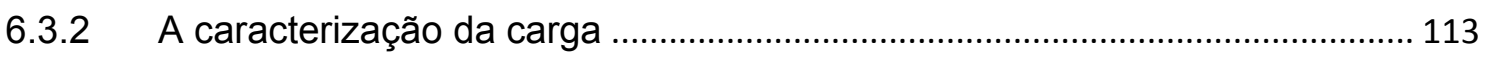

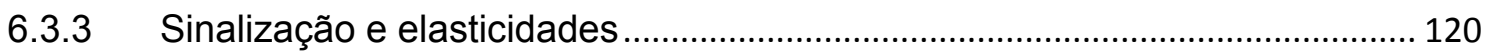

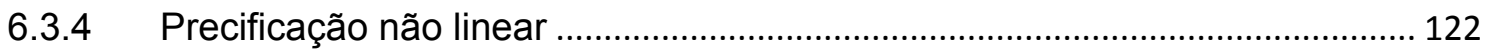

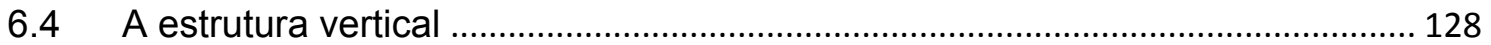

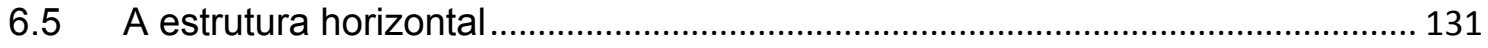

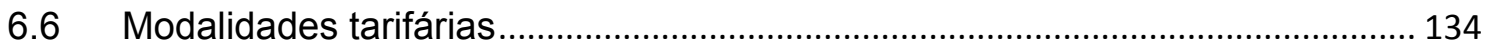

6.7 Alguns resultados para a estrutura vertical ....................................................... 140 


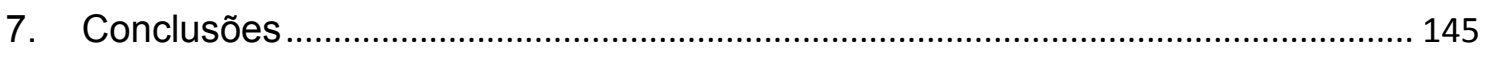

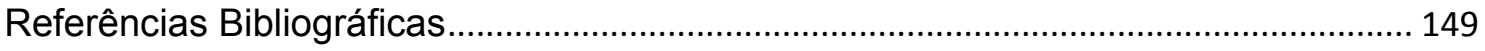

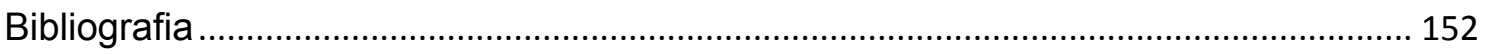

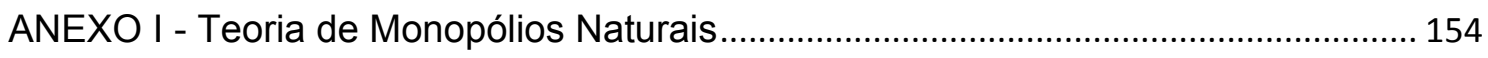

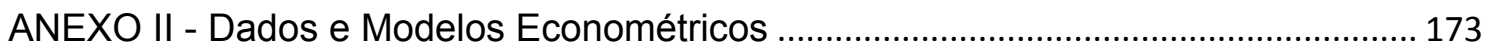

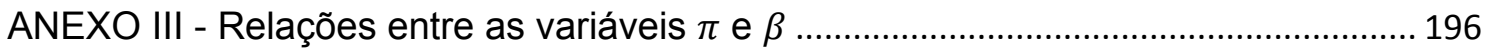

ANEXO IV - Determinação das Probabilidades de Associação ....................................... 199

ANEXO V - Inferência Estatística de uma Curva de Carga .............................................. 204 


\section{Introdução}

\subsection{Objetivos do trabalho}

A presente tese se organiza em torno da pesquisa para o estabelecimento de uma nova metodologia de cálculo para a estrutura tarifária de uso das redes de distribuição de energia elétrica no Brasil.

Primeiramente, define-se estrutura tarifária como 0 mecanismo de diferenciação de preços cobrados pelo uso das redes de distribuição aos diferentes tipos de consumidores ou mercados existentes em uma área de concessão deste serviço, independentemente da receita requerida da empresa distribuidora.

A abordagem histórica do problema da diferenciação de preços neste setor torna clara a necessidade atual de rediscussão das teorias, modelos e metodologias aplicadas ao sistema de distribuição de energia brasileiro.

A partir da chamada pública 008/2008 (ANEEL-E, 2008), fica evidente, do ponto de vista do órgão regulador nacional, a Agência Nacional de Energia Elétrica ANEEL, a necessidade de rediscussão da estrutura tarifária para o sistema de distribuição de energia vigente no país.

Nesta chamada publica, observa-se uma explícita intenção reformista, partindo da consideração de que "[...] a ANEEL vem adotando a mesma base metodológica dos anos 80, consolidada em um estudo publicado pelo Departamento Nacional de Águas e Energia Elétrica DNAEE, intitulado Nova Tarifa de Energia Elétrica - metodologia e aplicação, de 1985, e comumente conhecido como 'Livro Verde'.".

Ainda, segundo a agência, "[...] a estrutura está desatualizada[...]", o que indica a existência de "[...] incentivos que estão levando consumidores a um comportamento que não parece minimizar custos e otimizar a utilização do sistema[...]", observando o fato de que também "existe um 'descolamento' entre as tarifas no mercado de atacado (preço spot da $C C E E^{1}$ ) e no mercado de varejo[...]", e considerando que "as recentes tentativas por parte da ANEEL de revisar os níveis tarifários têm esbarrado em dificuldade na coleta de dados consistentes[...]".

\footnotetext{
${ }^{1}$ Câmara de Comercialização de Energia Elétrica
} 
Com base ainda nesta chamada, a ANEEL, assim como os agentes do setor, espera que pesquisas sejam direcionadas à questão da estrutura tarifária, oferecendo, entre outros resultados, a prospecção, análise e formalização do "[...] estado da arte dos modelos e técnicas mundialmente utilizados para tarifação de serviços públicos de distribuição de energia elétrica[...]".

Também como resultados da pesquisa, são esperados pelo órgão regulador as análises correspondentes à "[...] estrutura tarifária atualmente praticada no Brasil[...]", bem como à "[...] composição da cadeia de custos que é refletida na tarifa de fornecimento no Brasil (geração, transmissão e distribuição), e o comportamento da carga face ao sinal econômico da tarifa[...]".

Neste contexto, a presente pesquisa orienta-se no sentido de apresentar não somente ao órgão regulador, mas também aos agentes do setor de distribuição e à sociedade brasileira, insumos, teoria e proposições necessárias à confecção de uma nova metodologia, sem descartar possíveis adaptações à metodologia atual, no sentido de tornar mais transparente o processo de divisão de custos entre os diversos tipos de consumidores conectados ao sistema de distribuição.

De forma bastante resumida, pode-se dizer que o modelo regulatório para os serviços públicos de distribuição de energia atualmente utilizado pela ANEEL apresenta características mistas observadas em modelos teóricos de regulação econômica de monopólios naturais. Algumas características presentes no atual modelo remontam aos esquemas de tarifação pelo custo do serviço, tarifação pelo custo marginal e ao modelo de preço teto (price-cap) (PIRES \& PICCININI, 1998).

Adicionalmente, a ANEEL utiliza mecanismos complementares com o objetivo de mitigar os problemas de assimetria informacional e também de estabelecer padrões de eficiência, como é caso do modelo da empresa de referência e dos modelos de cálculo de perdas técnicas e não técnicas (Yardstick competition).

Nos ciclos de revisão tarifária, a ANEEL tem atuado na determinação da receita requerida (nível tarifário), essencialmente com base em características presentes em dois modelos teóricos: para a parcela $A$, que se refere aos custos não gerenciáveis, a ANEEL tem utilizado o princípio da neutralidade de custos ${ }^{2}$, o que está de certa forma relacionado ao modelo de tarifação pelo custo do serviço. Já para a

\footnotetext{
${ }^{2}$ No modelo de regulação brasileiro, algumas parcelas dos custos não gerenciáveis não são neutras, o que pode acarretar riscos às distribuidoras.
} 
parcela $B$, que se refere aos custos gerenciáveis, o modelo baseia-se na regulação por preço teto (price-cap).

Uma vez definida a Receita Requerida da distribuidora, composta pelos valores das parcelas $A$ e $B$, a ANEEL tem utilizado um mecanismo bastante complexo para a definição da estrutura tarifária (divisão da receita pelos mercados de cada subgrupo tarifário), cujos sinais são divididos por nível de tensão e por posto horário (ponta e fora-ponta).

Conforme descrito em (ANEEL-E, 2008), o atual modelo de estrutura tarifária, documentado em (DNAEE, 1985), foi concebido a partir de estudos realizados em um acordo de cooperação técnica entre o antigo Departamento Nacional de Águas e Energia Elétrica - DNAEE, a Eletrobrás, as principais empresas de distribuição de energia e a Eletricité de France - EDF.

Utilizando princípios da tarifação pelo custo marginal, o atual modelo objetiva calcular o custo de cada cliente típico através da determinação de suas responsabilidades, e também da relação de uso dos sistemas à montante do ponto de conexão destes clientes.

Embora engenhosa, a atual metodologia de definição da estrutura tarifária precisa ser rediscutida, seja para sua adequação ou substituição, tendo em vista os atuais questionamentos referentes à sua formulação, documentação e aplicação.

Outra questão emergente está relacionada ao fato de que, embora o conceito dos custos marginais de longo prazo detenha um papel central nas teorias e práticas de precificação regulatória, a determinação destes custos para cada empresa carece de especificações e abordagens teóricas mais sólidas, a serem consideradas em um contexto de assimetria informacional entre regulador e concessionária.

Dado este panorama nacional, e considerando que a tese tem por principal objetivo o desenvolvimento de estudo detalhado que possa oferecer sustentação teórica para a formulação de uma adequada metodologia de construção de tarifas, alguns preceitos econômicos e sociais devem nortear os resultados. São eles:

- Eficiência pelo lado da demanda: os consumidores devem ser taxados o mais próximo possível dos custos de serviço para atendê-los.

- Eficiência pelo lado da oferta: a distribuidora deve obter cobertura suficiente de custos para oferecer os serviços requeridos pelos consumidores. 
- Sólida fundamentação teórica: qualquer conceito ou metodologia empregada deve ser baseada em uma sólida fundamentação teórica.

- Objetividade e Justiça: a metodologia de preços empregada deve ser baseada em critérios objetivos e que resultem em preços justos.

- Estabilidade: a aplicação da metodologia deve resultar, na medida do possível, em estabilidade de preços para os consumidores.

- Transparência e confiabilidade: o regime de preços deve ser confiável e transparente para os consumidores, e defensável pelo órgão regulador.

- Praticidade e aplicabilidade: o modelo de preços deve ser aplicável e de prática implementação.

Desta forma, objetiva-se apresentar um consistente arcabouço teórico, principalmente sob a ótica da teoria econômica, direcionado aos modelos de precificação de monopólios naturais, dentre os quais os especialmente aplicados aos sistemas de distribuição de energia.

\subsection{Organização da tese}

A tese está estruturada em 6 capítulos principais, organizados com o propósito de oferecer ao leitor uma compreensão progressiva das questões relevantes ao trabalho. O capítulo 1, Introdução, almeja delinear os objetivos da tese, além de analisar os aspectos gerais que contextualizam o setor elétrico e a atual metodologia de cálculo da estrutura tarifária de uso das redes de distribuição de energia.

No capítulo 2, Fundamentação Econômica, é apresentada uma versão do estado da arte da precificação em monopólios naturais. A partir da abordagem da restrição do equilíbrio econômico dos monopólios, são apresentados, sob o foco da eficiência econômica, os mecanismos clássicos de precificação linear e não linear.

Neste mesmo capítulo, é discutida a teoria de precificação de ponta, bastante aplicada aos sistemas elétricos de potência através das chamadas tarifas por tempo de uso, como as tarifas horo-sazonais no Brasil.

O capítulo 3, Custos da Distribuição no Curto e no Longo Prazos, discute os modelos de custos aplicados a sistemas produtivos de capacidade rígida, como é o 
caso dos segmentos de geração, transmissão e distribuição de energia. De forma a assentar os fundamentos discutidos no capítulo 2, são apresentados os estudos clássicos desenvolvidos no início dos anos 1950, principalmente por economistas franceses e americanos.

No capítulo 4, já considerando absorvidos os conceitos existentes na teoria econômica clássica, condensada nos capítulos 2 e 3, é descrita em detalhes a atual metodologia nacional de cálculo da estrutura tarifária de uso das redes de distribuição de energia. No capítulo 5, por sua vez, faz-se uma análise crítica dos principais conceitos e variáveis presentes na atual metodologia, sendo identificadas as premissas metodológicas implícitas, a genealogia dos processos de diferenciação de preços e os principais problemas observados.

No capítulo 6, é apresentada a proposta metodológica para a substituição da atual metodologia, sendo valorizados sua sólida fundamentação teórica e a simplicidade operacional necessária a um bom entendimento dos agentes do sistema. Por fim, o capítulo 7 organiza as principais conclusões do trabalho.

Existem também 5 anexos contento o aprofundamento de algumas questões relacionadas ao problema central analisado no trabalho. Para tornar mais eficiente o tratamento destas questões, buscou-se referenciar, no corpo do texto, a condensação das discussões detalhadas nos referidos anexos.

\subsection{Contribuições explícitas do trabalho}

De forma bastante objetiva, o trabalho pretende contribuir para o tema da estrutura tarifária de uso das redes de distribuição de energia elétrica em três frentes principais. São elas:

i. Oferecer uma compreensão mais clara e melhor estruturada da atual metodologia de cálculo da estrutura de preços de uso dos sistemas de distribuição de energia no Brasil. Em especial, procurar-se-á avaliar as hipóteses implicitamente consideradas no modelo vigente, redefinir algumas de suas variáveis e processos segundo uma interpretação própria do autor, além de analisar a genealogia dos principais 
mecanismos de diferenciação de preços entre níveis de tensão e períodos de faturamento.

ii. Apresentar uma análise crítica da atual metodologia, identificando questões relativas à sua fundamentação econômica, à sua validade mediante investigações numéricas empíricas e, por fim, à sua complexidade operacional frente à qualidade de seus resultados.

iii. Propor uma nova metodologia simplificadora alternativa para o cálculo das estruturas de preços entre níveis de tensão e entre períodos tarifários de ponta e fora-ponta. Embora simplificadora, a proposta contará com uma base teórica mais sólida e consubstanciada, permitindo aliar estes dois objetivos principais e concorrentes entre si.

\subsection{Análise do contexto setorial}

Desde a invenção do transformador por Nicola Tesla no início do século XX até o final dos anos 1980, os processos de produção, transporte e comercialização de energia elétrica tem sido historicamente concebidos como uma cadeia produtiva integrada, operada de forma verticalizada por uma única empresa.

Neste sentido, inúmeros economistas, principalmente franceses e americanos, trabalharam a questão da precificação da eletricidade de forma integrada, avaliando o preço final ao consumidor em função dos custos totais de produção e transporte da energia.

Em outras palavras, não havia separação entre as atividades econômicas de produção de energia e do uso dos sistemas de transporte, mais especificamente os sistemas de transmissão e distribuição.

Foi somente após os processos de reforma institucional dos setores de energia elétrica ocorridos em diversos países, e também no Brasil, principalmente na década de 1990, que a cadeia produtiva da energia foi reinterpretada sob a ótica do novo paradigma organizacional dos governos, no qual o estado tem um caráter mais regulador e menos empreendedor. 
As reformas culminaram na desverticalização dos processos de geração, transmissão e distribuição da energia, não havendo mais dúvidas quanto à natureza essencial da atividade econômica legada aos sistemas de transmissão e distribuição de energia: o transporte.

Como a quantidade de energia consumida passou a ser definida como uma commodity, tornou-se um consenso a construção de tarifas finais aos consumidores compostas por duas parcelas: uma destinada à compra da quantidade consumida (energia) e outra à cobertura dos custos de transporte desde o local de produção até o consumidor final.

A reforma do Setor Elétrico Brasileiro se iniciou em 1993 com a Lei n 8.631, a qual extinguiu a equalização de tarifas aos consumidores finais até então existente, criando novos contratos de suprimento entre geradores e distribuidores. A reforma foi acentuada pela promulgação da Lei $n^{\circ} 9.074$ de 1995, que criou os conceitos do Produtor Independente de Energia e do Consumidor Livre.

Logo em seguida, em 1996, foi implantado pelo governo Fernando Henrique Cardoso o Projeto de Reestruturação do Setor Elétrico Brasileiro (Projeto RE-SEB), coordenado pelo Ministério de Minas e Energia.

A conclusão do projeto RE-SEB foi a necessidade de desverticalizar as empresas de energia elétrica, dividindo-as nos segmentos de geração, transmissão e distribuição. O objetivo era incentivar a competição nos segmentos de geração e comercialização, e manter sob regulação os setores de distribuição e transmissão de energia elétrica, caracterizados por monopólios naturais.

Neste ano, também foram criadas a Agência Nacional de Energia Elétrica ANEEL, o Operador Nacional do Sistema Elétrico - ONS e o já extinto Mercado Atacadista de Energia Elétrica - MAE (hoje substituído pela Câmara de Comercialização de Energia Elétrica), sendo este último um ambiente para a realização das transações de compra e venda de energia elétrica. Concluído em agosto de 1998, o Projeto RE-SEB instituiu as bases conceituais e institucionais do novo Setor Elétrico Brasileiro.

No entanto, motivado, dentre outros fatores, pelo severo racionamento de energia ocorrido em 2001, o novo governo, empossado em 2003, reavaliou algumas características e mecanismos até então existentes, implementando mudanças a partir 
de 2004, principalmente no que se refere aos ambientes de contratação de energia para os consumidores cativos das distribuidoras de energia.

Apesar das mudanças propostas pelo governo Luiz Inácio Lula da Silva em 2004, as bases estruturais da desverticalização entre os processos de Geração, Transporte e Comercialização da energia permaneceram, assim como a separação entre as componentes Energia e Uso dos seus sistemas de transporte.

\subsection{Histórico e visão geral sobre a estrutura tarifária brasileira}

De acordo com (ANEEL-A, 2009), "[...] no período compreendido entre 1977 e 1979 foi realizado o primeiro estudo, pelo Departamento Nacional de Águas e Energia Elétrica - DNAEE e a Centrais Elétricas Brasileira S.A. - ELETROBRÁS, em parceria com a Électricité de France - EDF, publicado com o título 'Estrutura do Sistema Tarifário Brasileiro de Energia Elétrica com Base nos Custos Marginais'. Esse estudo teve como objetivo examinar a viabilidade de se determinar os custos de fornecimento de energia elétrica no Brasil com base na teoria marginalista, sendo implementado nos anos seguintes. [...]'.

Lê-se ainda que, de "[...] 1980 a 1981, foi realizado um estudo mais completo, que resultou no livro "Estrutura Tarifária de Referência para Energia Elétrica". Esse trabalho teve como objetivo adequar a primeira publicação, por meio do uso de dados mais elaborados, divulgação das metodologias desenvolvidas, de modo a subsidiar a decisão política de aplicação de tarifas diferenciadas para os consumidores conectados em Alta Tensão. [...]".

Observando-se a mesma Nota Técnica, lê-se que no "[...] período entre a publicação das primeiras tarifas horo-sazonais, em 1982, e a publicação das primeiras TUSD, em 1999, quase nenhuma mudança foi realizada na Estrutura Tarifária, uma vez que a ANEEL vem adotando a mesma base metodológica aplicada nos anos 80 , consolidada em um estudo publicado pelo Departamento Nacional de Águas e Energia Elétrica - DNAEE, intitulado Nova Tarifa de Energia Elétrica - metodologia e aplicação, de 1985, e comumente conhecido como 'Livro Verde' [...]".

Em 1994, foram apresentados pelo antigo DNAEE diversos relatórios técnicos com diagnósticos e análises de todo o processo de construção da estrutura tarifária. 
Estes relatórios foram desenvolvidos no âmbito do PRT - Programa de Revisão Tarifária. Em especial, os relatórios 5 e 6 do projeto 3 - Tarifas de referência (DNAEE, 1994), são documentos que também descrevem a metodologia empregada na estrutura tarifária brasileira.

Desta forma, o "Livro Verde" (DNAEE, 1985), bem como os relatórios técnicos do PRT-DNAEE (DNAEE, 1994), são os documentos de referência metodológica para a construção da atual estrutura tarifária vigente no Brasil. Neste sentido, este trabalho considerará estes documentos como referências principais para a descrição da metodologia, embora apresente, consubstancialmente, interpretação analítica própria sobre seus equacionamentos e formulações.

Neste sentido, alguns conceitos presentes nestas referências foram reinterpretados ou reformulados de tal forma que houvesse maior consistência matemática e teórica. Tais reinterpretações, contudo, foram cuidadosamente avaliadas, de maneira que o resultado final, contido nos chamados custos de capacidade e nas tarifas de referência, fosse absolutamente o mesmo obtido pela ferramenta computacional que implementa a metodologia desenvolvida (Tardist, desenvolvido pelo CEPEL ${ }^{3}$ e utilizado pela ANEEL)

Pode-se dizer que o processo de cálculo das denominadas tarifas de referência, que definem as diferenças de preços entre os níveis de tensão e também entre os postos tarifários de ponta e fora-ponta, baseia-se em dados do sistema de distribuição e dos consumidores a ele conectados.

É importante lembrar, conforme (ANEEL-F, 2001), que os postos tarifários de ponta e fora-ponta, no Brasil, vinham sendo definidos a priori pela concessionária, sendo o horário de ponta, até o momento, caracterizado por três horas consecutivas em dias úteis, enquanto o horário de fora-ponta é formado pelas horas consecutivas e complementares ao período do horário de ponta.

Em uma visão holística, a metodologia pode ser desdobrada em dois processos fundamentais. O primeiro deles envolve o cálculo dos chamados custos de capacidade, em $\mathrm{R} \$ / \mathrm{kW}$.ano, enquanto o segundo se destina ao cálculo das chamadas tarifas de referência, também em $\mathrm{R} \$ / \mathrm{kW}$.ano. A Figura 1 ilustra os dados necessários ao cálculo dos custos de capacidade.

\footnotetext{
${ }^{3}$ Centro de Pesquisas de Energia Elétrica
} 
Neste primeiro processo, objetiva-se determinar os "custos marginais dos clientes", os quais, segundo (DNAEE, 1985), são, para um determinado cliente, "[...] o resultado de sua responsabilidade nos custos de desenvolvimento de capacidade dos diversos elementos que compõe o sistema elétrico situados a montante do seu ponto de conexão [...]".

Desta forma, denomina-se, segundo a metodologia, o custo de capacidade de um cliente como sendo o seu custo marginal na expansão de todos os elementos à montante do seu ponto de conexão.

Dentre os dados de entrada utilizados no cálculo dos custos de capacidade, destacam-se os custos marginais por nível de tensão. Estes custos marginais refletem os custos de expansão das redes existentes em determinado nível de tensão, e são efetivamente os dados mais importantes na construção da estrutura tarifária.

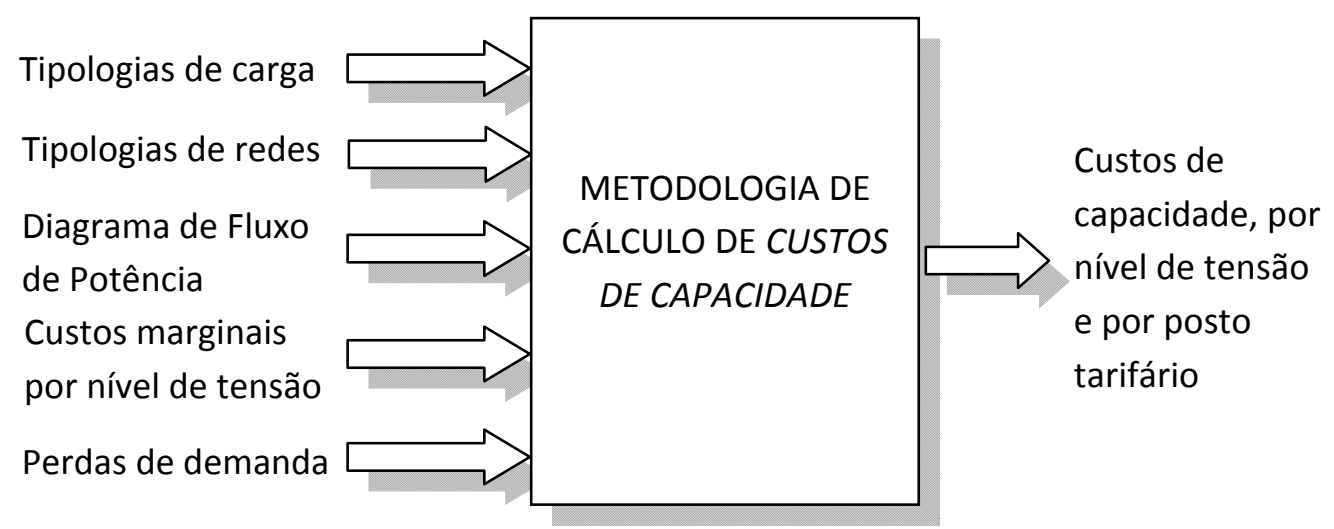

Figura 1 - Fluxograma de informações para o cálculo dos custos de capacidade

O processo subseqüente, após a determinação dos custos de capacidade, objetiva o cálculo das tarifas de referência, também divididas por nível de tensão e posto tarifário. As tarifas de referência são efetivamente as tarifas utilizadas na proporcionalização da parcela B (a parcela gerenciável pelas distribuidoras) da receita requerida.

A Figura 2 ilustra os dados necessários à segunda parte do processo de cálculo da estrutura tarifária. Como pode ser notado, são necessários, além dos custos de capacidade obtidos no processo inicial, dados reais da receita requerida, bem como dados de mercado de demanda e sinalizações pré-estabelecidas, como as diferenças de preços entre os postos da ponta e fora-ponta. 


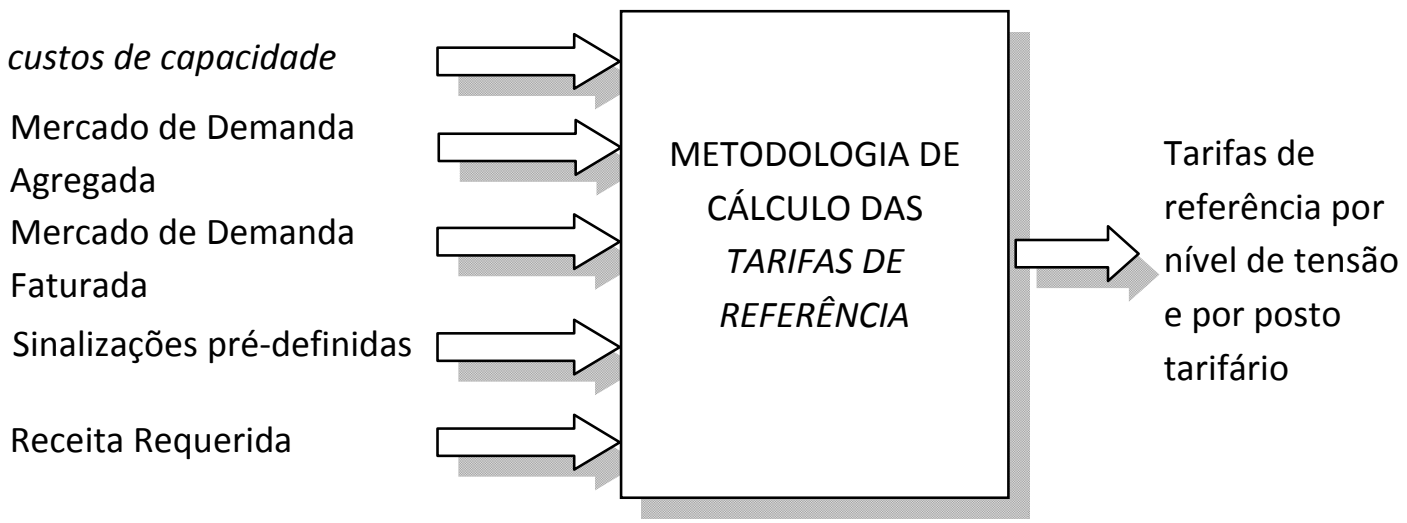

Figura 2 - Fluxograma de informações para o cálculo das tarifas de referência

Fundamentalmente, a primeira parte da metodologia, destinada ao cálculo dos custos de capacidade, não objetiva a reconciliação da receita requerida, enquanto que a segunda parte, destinada ao cálculo das tarifas de referência, além desta reconciliação, observa a relação entre as demandas agregadas e as efetivamente faturadas no mercado.

Essencialmente, a diferenciação de preços entre os níveis de tensão, entre postos tarifários e entre as classes de consumo está quase que totalmente relacionada à primeira parte do processo no escopo da metodologia existente, ou seja, ao cálculo dos custos de capacidade. O detalhamento da metodologia é apresentado no capítulo 4. 


\section{Fundamentação Econômica}

Neste capítulo, procurar-se-á abordar todas as questões da teoria econômica frequentemente aplicadas à problemática da estrutura tarifária, aqui caracterizada pelo conjunto de mecanismos e processos de diferenciação de preços aos consumidores atendidos por um monopólio natural multiproduto, como é o caso da distribuição de energia.

Para tanto, serão apresentados os modelos clássicos de precificação aplicados aos sistema de distribuição de energia encontrados na teoria econômica, cuja documentação descritiva resulta de uma vasta pesquisa bibliográfica.

O objetivo aqui é oferecer ao leitor o estado da arte dos processos de tarifação em sistemas de distribuição de energia, passo fundamental para a correta avaliação crítica e fundamentada da atual metodologia de construção da estrutura tarifária, bem como para a proposição de alternativas.

\subsection{Modelos de precificação em monopólios naturais}

Do ponto de vista da eficiência econômica, como pode ser deduzido das considerações apresentadas no ANEXO I, o melhor candidato para a construção de preços em um monopólio natural é o custo marginal de produção. Contudo, como também discutido neste anexo, a precificação ao custo marginal não proporciona o equilíbrio econômico-financeiro da firma quando da existência de economias de escala, uma vez que o custo marginal, para esta situação, situa-se abaixo do custo médio.

Existem alguns mecanismos de precificação que buscam resolver o problema do equilíbrio econômico do monopólio sob regulação, levando em consideração a eficiência econômica relacionada à quantificação do bem-estar social ${ }^{4}$.

Basicamente, os modelos de precificação dividem-se em mecanismos de cobrança lineares e não lineares, sendo subsequentemente divididos para os casos mono e multiproduto, como será descrito a seguir.

\footnotetext{
${ }^{4}$ Para maiores detalhes, consultar o ANEXO I
} 


\subsubsection{Preços lineares}

\subsubsection{O caso monoproduto}

Em uma firma monopolista monoproduto, a precificação linear que garante o equilíbrio econômico-financeiro do produtor, lembrando que o pressuposto de lucro econômico zero ${ }^{5}$ deve ser atendido, é a precificação a custos médios. Este tipo de precificação impõe ao sistema produtor-consumidor uma perda de bem-estar (peso morto) que não pode ser eliminada (ver Figura 3).

Neste caso, a única forma de minorar a perda de bem-estar, partindo-se do princípio que o mercado é regulado, é a adoção de mecanismos de incentivo à redução de custos (no contexto do nível tarifário), como ocorre nos modelos Price Cap, ou Yardistick Competition (PIRES \& PICCININI, 1998).

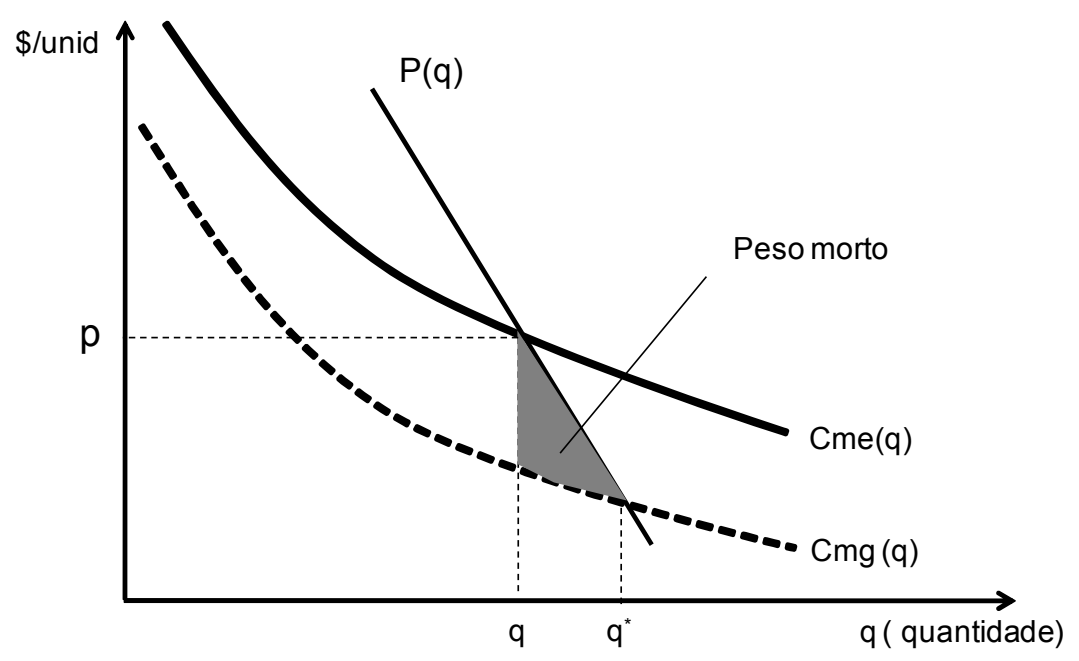

Figura 3 - Precificação a custos médios em um mercado monoproduto

\footnotetext{
${ }^{5}$ Lucro econômico zero implica em remuneração do capital igual ao custo de oportunidade do produtor
} 


\subsubsection{O caso multiproduto: Ramsey}

Para o caso multiproduto, em que o mercado total da firma é segmentado, (RAMSEY, 1927) propôs um mecanismo de diferenciação de preços com base nos custos marginais de cada produto e em suas elasticidades-preço da demanda.

A Regra de Ramsey está intimamente ligada ao conceito do segundo ótimo (second best) em mercados de retornos crescentes de escala. Como não é possível cobrar dos consumidores os custos marginais de cada produto (caso contrário não haveria equilíbrio econômico-financeiro), o seguinte problema de maximização do bem-estar social pode ser formulado (BROWN \& SIBLEY, 1986).

$\max [E C+E P]$

$\left\{P_{1}, P_{2}, \ldots P_{m}\right\}$

sujeito a:

$E P=C f$

Onde:

EC: Excedente do Consumidor.

EP: $\quad$ Excedente do Produtor.

$P_{i}: \quad$ Preço do produto $i$ ( $m$ produtos).

$C f$ : Custos fixos do produtor.

A partir da teoria apresentada no $\mathrm{ANEXO} \mathrm{I,} \mathrm{nota-se} \mathrm{que} \mathrm{a} \mathrm{restrição} \mathrm{EP}=\mathrm{Cf}$ é justamente a condição de equilíbrio para lucro econômico zero. O resultado deste problema de maximização, desconsiderando-se as elasticidades cruzadas entre os produtos (caso bem mais complexo), é dado pela Equação (2). 
$\operatorname{Markup}_{i}=\frac{P_{i}-C m g_{i}}{P_{i}}=\frac{\lambda}{\epsilon_{i}}$

Onde:

$P_{i}: \quad$ Preço do produto $i$.

$\mathrm{Cmg}_{i}: \quad$ Custo marginal do produto $i$.

$\epsilon_{i}: \quad$ Elasticidade-preço da demanda pelo produto $i$.

$\lambda: \quad$ Constante de Lagrange, igual para todos os mercados.

O resultado encontrado por Ramsey consiste em aplicar preços aos $m$ produtos produzidos por um monopolista de forma inversamente proporcional às elasticidades-preço da demanda por estes produtos. Ou seja, preços maiores devem ser aplicados a produtos de baixa elasticidade-preço.

Este resultado não deixa de ser intuitivo, dado que dever-se-ia buscar as menores retrações de consumo em todos os sub-mercados, e esta condição se dá exatamente através da aplicação de preços menores a consumidores mais elásticos e preços maiores a consumidores menos elásticos.

\subsubsection{Preços não lineares}

\subsubsection{A tarifa em duas partes}

Em meados do século XX, (COASE, 1946) sugeriu um tipo especial de tarifação não linear, conhecido como tarifa em duas partes. Neste mecanismo de tarifação, a tarifa ao consumidor é composta por uma parte fixa, denominada tarifa de acesso, e por uma parte variável, cujo valor por unidade é preferencialmente igual ao custo marginal de produção.

Como discutido no ANEXO I, é fato que em um mercado caracterizado por custos médios decrescentes a precificação ao custo marginal não é suficiente para a 
cobertura dos custos totais da firma. Neste contexto, a parcela de acesso da tarifa em duas partes seria destinada à reconciliação de receita, trazendo equilíbrio econômico ao negócio.

Além disso, a tarifa em duas partes é economicamente eficiente, uma vez que a decisão de consumo dos consumidores, assumindo-se que tenham pago a tarifa de acesso, não é afetada por qualquer markup sobre os custos marginais.

A Equação (3) descreve a fatura em duas partes para um determinado mercado consumidor. Nesta equação, supõe-se que o custo marginal é constante.

$P(q)=A+C m g \cdot q$

Onde:

$P(q): \quad$ Preço em função da quantidade.

A: $\quad$ Tarifa de acesso, independente da quantidade.

Cmg: $\quad$ Custo marginal.

Adicionalmente, supondo-se que o custo de produção em um mercado qualquer, com estrutura bastante simples, é dada pela Equação (4).

$C T(q)=C f+C m g \cdot q$

Onde:

$C T(q): \quad$ Custo total para produzir $q$ unidades.

$C f: \quad$ Custo fixo para atender este mercado.

Caso existam $N$ consumidores neste mercado, se a parcela fixa for desenhada como $A=C f / N$, o custo fixo passa a ser totalmente coberto pela tarifa de acesso. 
Dessa forma, (BROWN \& SIBLEY, 1986) demonstram que, para o caso de todos os $N$ consumidores aceitarem pagar a tarifa de acesso $A$, a eficiência econômica será máxima.

A Figura 4 ilustra uma interpretação gráfica do mecanismo de precificação em duas partes, sendo representada no eixo das ordenadas a fatura total para o consumidor em função da quantidade consumida. A constatação de que este tipo de precificação é não linear advém da observação da tarifa média aos consumidores deste mercado, que é dada pela Equação (5).

$\operatorname{Pme}(q)=\frac{A}{q}+C m g$

Onde:

Pme (q): $\quad$ Preço médio em função da quantidade.

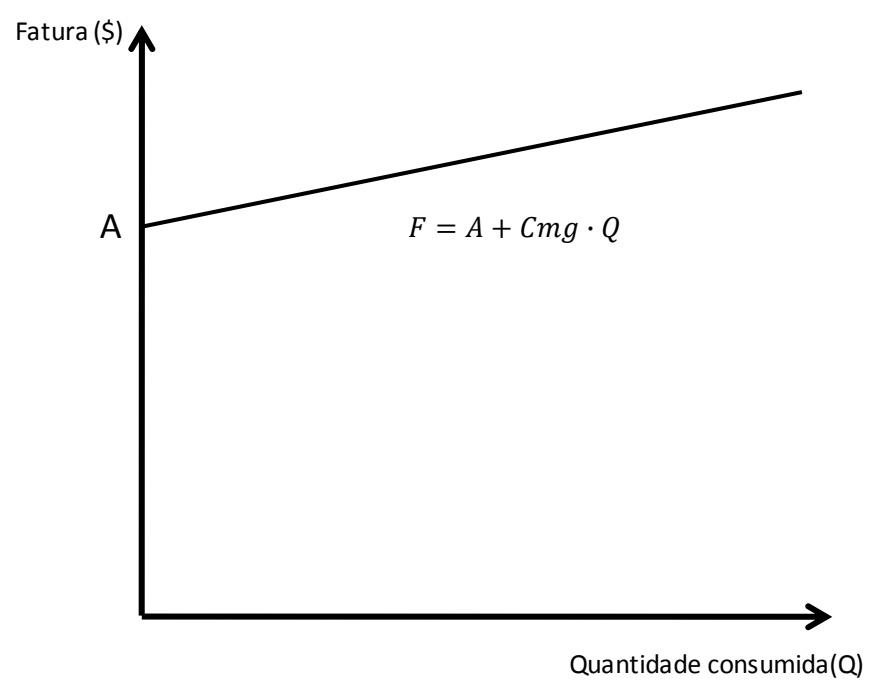

Figura 4 - Representação da tarifa em duas partes

Contudo, o problema observado neste mecanismo de tarifação é justamente a tarifa de acesso. Como, na prática, o mercado é composto por consumidores de diversos níveis de renda, a tarifa de acesso pode, dependendo de suas curvas de 
demanda (BROWN \& SIBLEY, 1986), inibir a entrada de consumidores de menor renda.

Este resultado seria bastante indesejado do ponto de vista social e político, além de ineficiente sob o aspecto econômico. Para contornar esse problema, existem mecanismos de ajuste tanto dos preços de acesso quanto dos preços unitários em função do nível de consumo dos consumidores. A este mecanismo, dá-se o nome de tarifas em múltiplas partes, ou precificação não linear, a ser tratado em detalhes no item 2.1.2.2.

\subsubsection{A tarifa multi-partes}

A questão central da precificação não linear, conforme aponta (WILSON, 1993), está ligada à melhoria da eficiência econômica a partir de um adequado tratamento da heterogeneidade de grupos de consumidores. Esse tratamento, como será abordado em maiores detalhes neste item, se resume basicamente à construção de um "menu" de opções tarifárias envolvendo o desenho de preços fixos e variáveis auto-selecionáveis pelos consumidores.

Conforme abordado de forma bastante detalhada por (BROWN \& SIBLEY, 1986), a observação do comportamento do consumidor é absolutamente necessária para a melhor compreensão do processo de formação das tarifas multi-partes, ou também como são conhecidas no Brasil, modalidades tarifárias.

Portanto, sabe-se que o mercado consumidor é bastante heterogêneo no que se refere à preferência de consumo de determinado produto. De forma geral, considerando-se como produto a eletricidade, pode-se dizer que a função demanda por este insumo tenha o formato: $Q_{e}=q(P, R, O)$, onde $P$ é o preço da eletricidade, $R$ é a renda do consumidor e $O$ representa outras variáveis geralmente utilizadas, tais como o preço de eletro-eletrônicos, ou o preço de outros energéticos, como por exemplo os derivados de petróleo. Para maiores detalhes, consultar (TAYLOR, 1975), (MODIANO, 1984), (ANDRADE \& LOBÃO, 1997) e (SCHMIDT \& LIMA, 2004).

Com o intuito da simplificação, suponhamos que a função demanda seja do tipo $Q_{e}=q(P, R)$, para a qual as demais variáveis são desprezadas. Suponhamos ainda que esta função seja fortemente monotônica em $R$, o que equivale a dizer que 
as demandas por eletricidade serão sempre maiores para consumidores com rendas maiores.

Para a melhor compreensão da questão da forte monotonicidade em $R$, observe-se a Figura 5. Nela é considerada a existência de apenas dois tipos de consumidores, o consumidor tipo grande e o tipo pequeno. Como, nesta consideração, a renda do consumidor grande é maior, sua demanda por eletricidade será sempre maior em qualquer nível de preços.

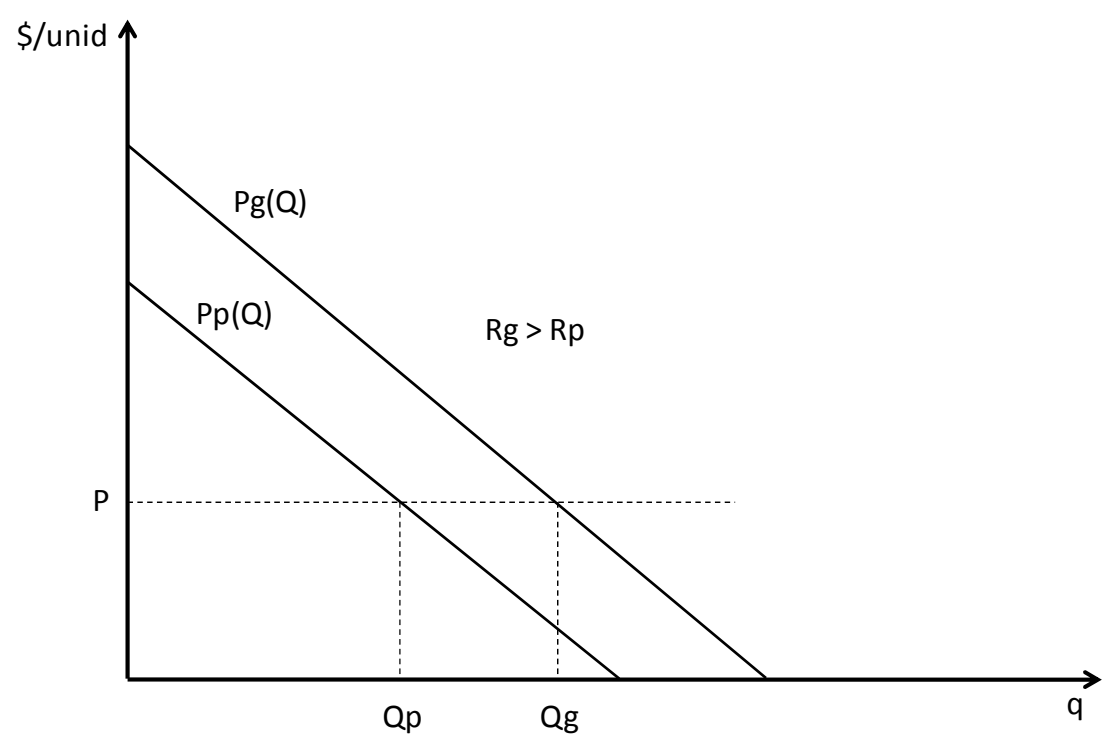

Figura 5 - Situação de forte monotonicidade em R da função demanda. A preços iguais, a demanda do consumidor grande será sempre maior que a demanda do consumidor pequeno.

Considerando-se que estes consumidores estejam inseridos em um mercado monopolista, e também que seja adotado um esquema de precificação linear a custos médios, suficientes para garantir o equilíbrio econômico da firma, serão observadas perdas de bem-estar social em ambos os sub-mercados, conforme pode ser observado na Figura 6. 


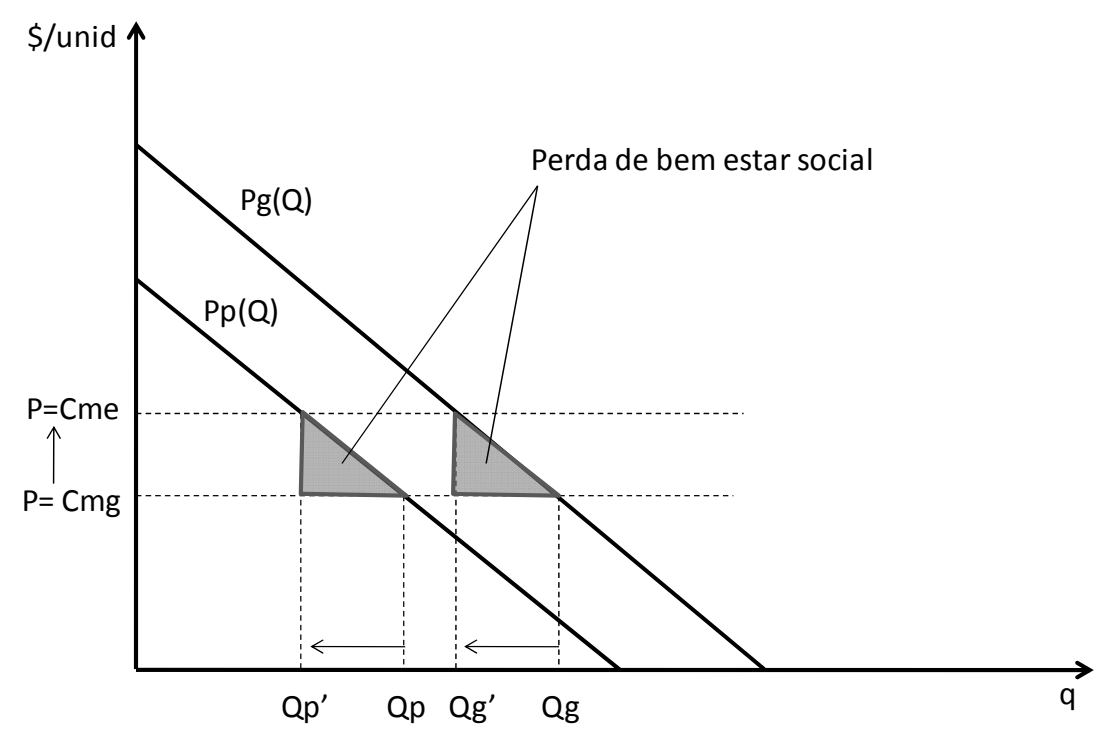

Figura 6 - Perda de bem-estar social em ambos os sub-mercados devido à precificação à custos médios.

Suponhamos agora que, ao invés da precificação a custos médios, seja criado um esquema de precificação em duas partes, para a qual o preço marginal é igual ao custo marginal de produção. Neste esquema, os excedentes dos consumidores podem ser observados através da Figura 7. Para este mecanismo de preços, não há perda de bem-estar social.

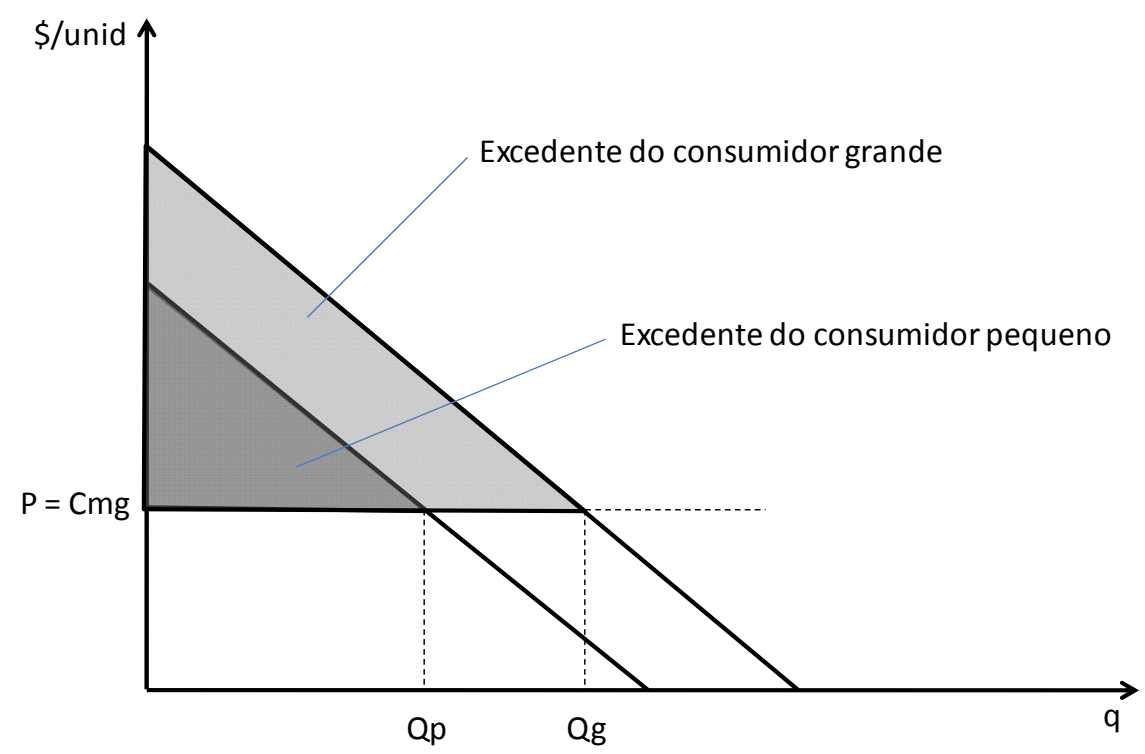

Figura 7 - Excedente dos consumidores tipo grande e tipo pequeno para precificação ao custo marginal. 
O problema da tarifação em duas partes surge devido a esta diferença quantitativa nos excedentes dos consumidores. Como o excedente do consumidor do tipo grande é maior que o excedente do consumidor pequeno, a cobrança de uma tarifa de acesso igual para ambos poderia parecer injusta para o consumidor pequeno.

Ainda, se a tarifa de acesso for superior ao excedente do consumidor pequeno, este não mais aceitará permanecer no mercado, causando perda ao produtor e aos consumidores remanescentes, uma vez que a quantidade $Q p$ deixará de existir, elevando consideravelmente o custo médio de produção.

Para evitar a saída do consumidor pequeno do mercado, se poderia utilizar algum mecanismo discriminatório para reduzir a tarifa de acesso do consumidor pequeno, e consequentemente, aumentar a tarifa de acesso do consumidor grande. $O$ problema desta linha de ação recairia sobre a impraticabilidade ou mesmo ilegalidade da discriminação de preços entre os consumidores.

Uma alternativa bastante inteligente para solucionar este problema dá-se a partir da construção de modalidades tarifárias opcionais, auto-selecionáveis pelos consumidores. Neste mecanismo, denominado tarifação multi-parte, objetiva-se limitar a exclusão de consumidores pequenos simultaneamente à limitação de perda de bemestar devido à redução do consumo eficiente ${ }^{6}$.

Para compreender este mecanismo, considere-se a Figura 8. Nela, são apresentadas duas modalidades tarifárias, sendo a primeira, $F 1$, a interpretação gráfica da fatura ao consumidor com preço marginal igual ao custo médio. A segunda, $F 2$, por sua vez, representa a fatura ao consumidor composta por uma parcela fixa, $E \leq A$, e uma parcela marginal, $P^{*}$, sendo que $C m e \geq P^{*} \geq C m g$.

No mesmo gráfico, é apresentada a tarifação em duas partes convencional, representada pela fatura $F=A+C m g \cdot Q, \operatorname{com} A=\frac{C f}{N}$.

\footnotetext{
${ }^{6} \mathrm{O}$ consumo eficiente é aquele causado pela precificação a custos marginais.
} 


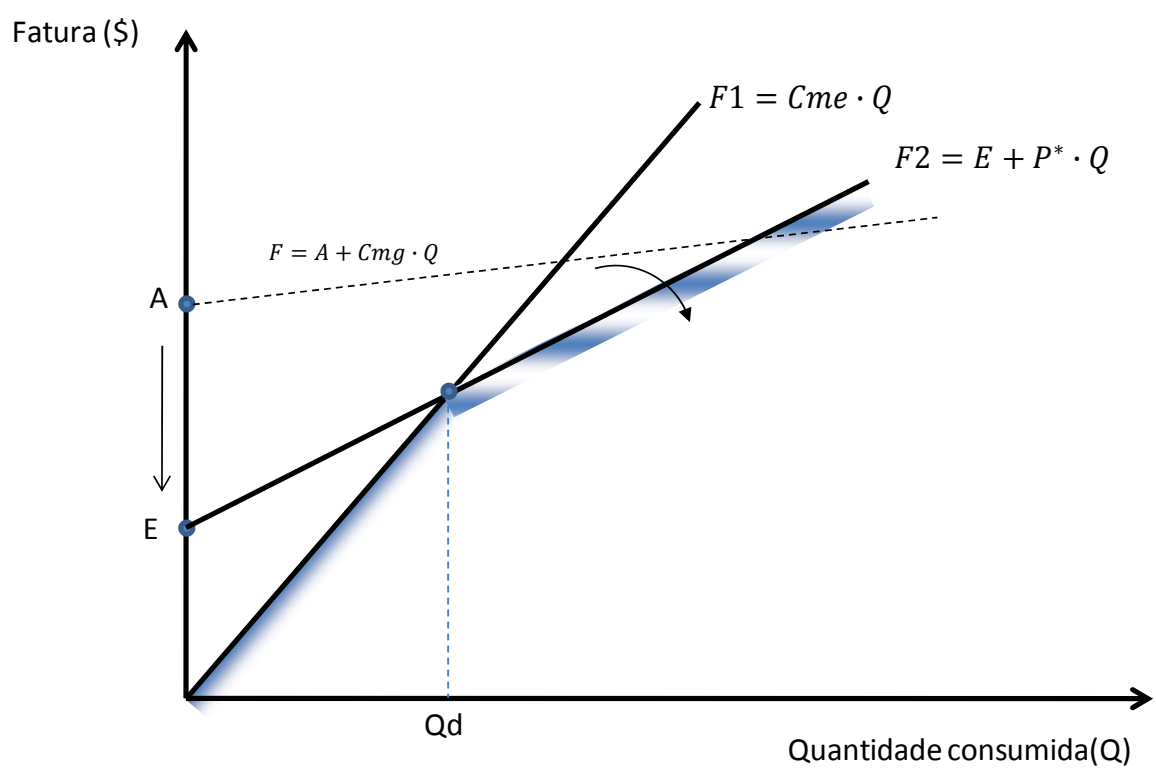

Figura 8 - Princípio econômico da tarifação em multi-partes: "Trade-off" entre exclusão de consumidores pequenos e a perda de bem-estar devido a preços marginais elevados.

Como estas duas modalidades tarifárias são opcionais, nota-se que, dependendo da quantidade consumida, os consumidores escolherão a opção que lhes proporcione a fatura mais barata. Ou seja, para $Q<Q d$ a opção $F 1$ é a mais barata, enquanto $F 2$ torna-se a mais atrativa para $Q>Q d$.

É possível demonstrar que a aplicação deste mecanismo de preços permite que todos os consumidores estejam em situação melhor ou igual em relação aos modelos de precificação a custos médios ou duas partes, além de aumentar o lucro do produtor. Para uma demonstração detalhada, consultar (BROWN \& SIBLEY, 1986), capítulo 4.

Existem inúmeras possibilidades de composição das modalidades apresentadas na Figura 8 a partir da escolha de valores para a tarifa de acesso $E$ e para a tarifa marginal $P^{*}$, definindo diferentes valores da quantidade de decisão $Q d$. No entanto, existe um par de valores que resulta na máxima eficiência economia, e este par $E_{\text {ótimo }}, P_{\text {ótimo }}^{*}$ depende da elasticidade-preço da demanda e também da elasticidade de participação em função da tarifa de acesso (BROWN \& SIBLEY, 1986).

A determinação das modalidade ótimas pode ser bastante complexa e impraticável, justamente devido aos problemas de estimação destas elasticidades. Uma alternativa bastante razoável para determinar conjuntos de modalidades tarifárias mais eficientes que a simples aplicação dos preços médios, ou mesmo da tradicional 
tarifa em duas partes, é a aplicação de modalidades chamadas Pareto dominantes e compatíveis com incentivos, ou em inglês, Pareto dominating and incetive compatible $-P D I C$.

Em (BROWN \& SIBLEY, 1986), demonstra-se que um esquema de tarifação com $n+1$ modalidades tarifárias é, em termos de eficiência econômica, Pareto dominante sobre um esquema com $n$ modalidades tarifárias. Intuitivamente isso é percebido, pois como há mais opções tarifárias, os consumidores podem selecionar a melhor alternativa para o seu perfil de consumo.

Já um esquema de modalidades compatível com incentivos garante que as opções com tarifas fixas maiores e tarifas marginais menores sejam preferiveis pelos consumidores de maior demanda, impedindo que consumidores considerados grandes optem por tarifas desenhadas para consumidores menores. Graficamente, pode-se garantir que o esquema de modalidades sela compatível com incentivos quando há cruzamento entre modalidades seqüenciais a preços menores e demandas maiores. $\mathrm{A}$ Figura 9 ilustra um mecanismo de tarifas compatíveis com incentivos.

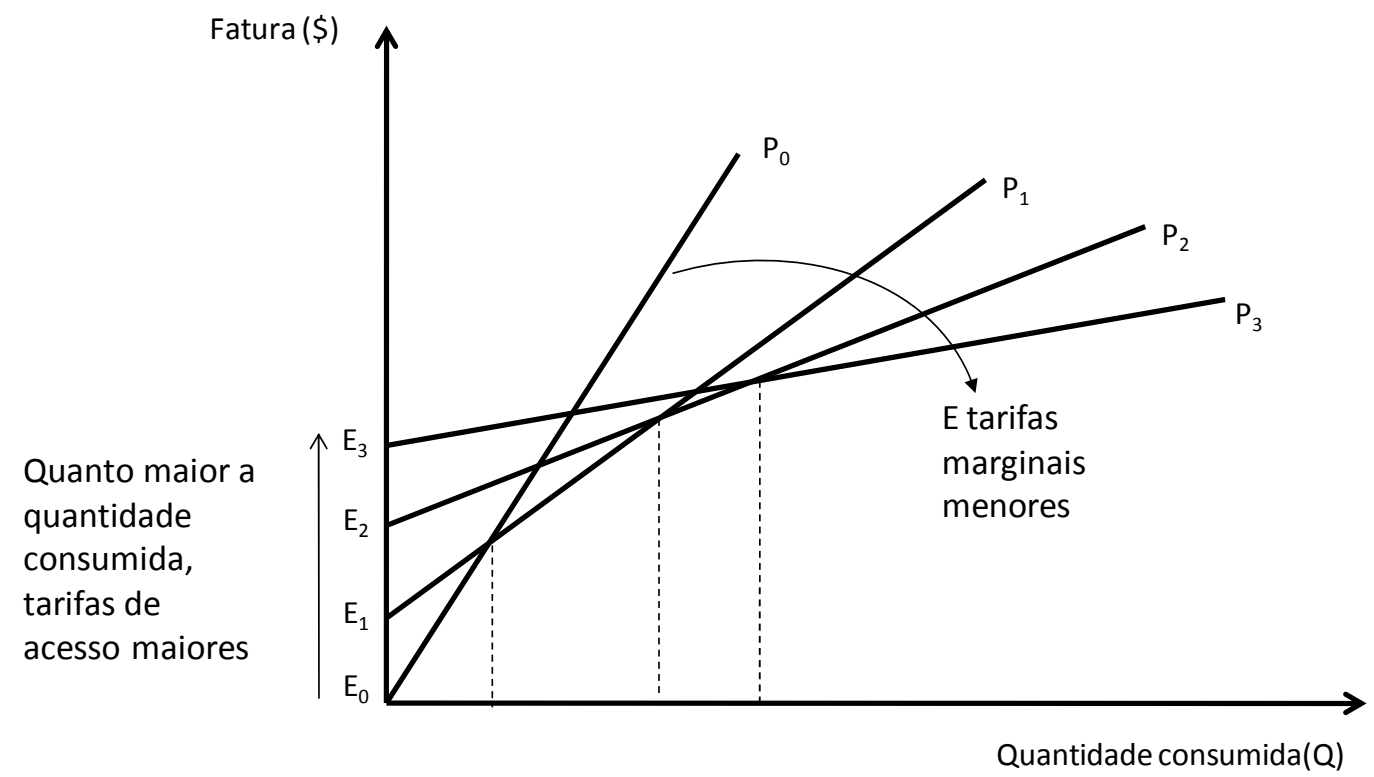

Figura 9 - Esquema de tarifação multi-parte compatível com incentivos

Uma outra interpretação bastante usual para justificar a importância dos mecanismos de tarifação em múltiplas partes, além do já citado aumento da eficiência econômica, é a consideração de que blocos decrescentes de preços para maiores quantidades é absolutamente aderente ao mercado monopolista. 
Como estes mercados apresentam economias de escala, ao menos no curto prazo, quando maior a quantidade demandada, menores os custos médios de produção, justificando assim a adoção de mecanismos de desconto no preço marginal para quantidades maiores.

\subsubsection{Precificação não linear aplicada aos sistemas de potência}

Antes de iniciar a discussão sobre a precificação não linear aplicada às tarifas de distribuição de energia, é importante e necessário avaliar a questão da valoração da energia e da potência elétricas, variáveis básicas para a tarifação de consumidores e geradores conectados a um sistema de distribuição.

Energia é definida como a integral da potência elétrica no domínio do tempo, sendo interpretada como o consumo acumulado de potência elétrica durante um determinado intervalo de tempo. Em sistemas elétricos de potência, a energia é medida em $M W h$ ou sub-múltiplos, como o $k W h$ ou $W h$.

Neste contexto, a quantidade de energia consumida é valorada, considerandose como unidade monetária o real brasileiro, em $R \$ / M W h$. Desta forma, analogamente à valoração de volume para energéticos estocáveis, como o petróleo e seus derivados, a valoração da energia independe da forma como ocorre o seu consumo ou a sua geração.

Por sua vez, a potência elétrica, definida como a derivada temporal da energia, é interpretada como o fluxo de consumo da energia por unidade de tempo. A unidade usual para quantificar a potência elétrica é o $k W$, com seus múltiplos e sub-múltiplos, como o $M W$ ou $W$.

Exatamente por se tratar de um fluxo, a valoração da potência elétrica deve ser dimensionada em $(R \$ / h) / k W$, e não simplesmente em $R \$ / k W$ (STOFT, 2002). Usualmente, a unidade utilizada para a valoração da potência elétrica é $R \$ / k W \cdot$ ano, que pode ser facilmente convertida em $R \$ / M W h$, dado que $1 R \$ / k W \cdot$ ano $\cong$ $0,114 R \$ / M W h$.

Ou seja, tanto a valoração da energia como a da potência tem dimensões conversíveis, em última análise, para $R \$ / k W h$, podendo ser somadas ou subtraídas, diferindo-se apenas por um fator escalar. 
Uma forma clássica de comparar financeiramente duas tecnologias de geração, por exemplo, se dá por meio das chamadas curvas de triagem (STOFT, 2002). Para compreender o mecanismo utilizado nas curvas de triagem, considere que o custo total anual para gerar energia através de uma planta geradora, por exemplo uma termo-elétrica, seja dado pela Equação (6).

$C T_{\text {anual }}=C C_{\text {anual }}+C O \cdot E_{\text {anual }}$

Onde:

$C T_{\text {anual }}: \quad$ Custo anual total, em $R \$ /$ ano

$C C_{\text {anual }}: \quad$ Custo de capital (ou de capacidade) anual, em $R \$ / a n o$

CO: $\quad$ Custo operacional da geração, em $R \$ / M W h$

$E_{\text {anual }}: \quad$ Energia anual gerada, em $M W h / a n o$

Dividindo-se a Equação (6) pela capacidade máxima da planta, em $k W$, é possível demonstrar facilmente que o custo total anual, por $k W$, será dado pela Equação (7).

$C T_{\text {anual }} / k W=C C_{\text {anual }} / k W+C O \cdot H_{u} /$ ano

Onde:

$H_{u}$ : Número de horas de utilização equivalentes, sendo $H_{u}=f_{c} \cdot 8760 h$, e $f_{c}$ o fator de carga da planta geradora.

Nota-se, a partir da Equação (7), a relação linear entre o custo total anual por $k W$ da usina e o número de horas equivalentes de geração, sendo as horas equivalentes função do fator de carga da planta geradora, definido como a demanda 
média sobre a capacidade máxima da usina. A Figura 10 ilustra a interpretação gráfica da Equação (7).

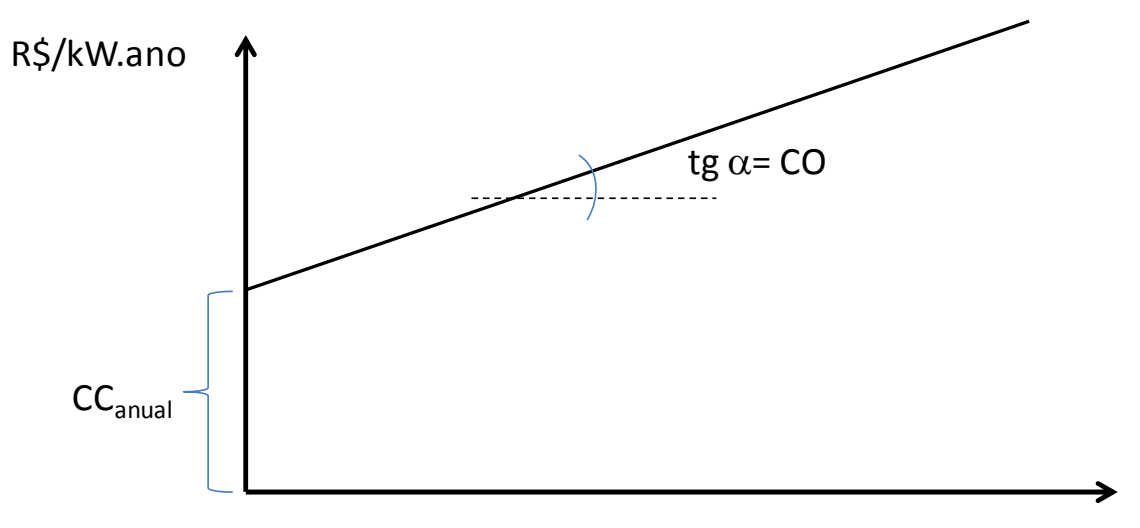

$\mathrm{Hu} / \mathrm{ano}$

Figura 10 - Curva de triagem dada pela Equação (7)

Como já mencionado, as curvas de triagem são bastante usadas para comparar financeiramente opções tecnológicas de geração, como por exemplo as opções hidrelétrica, nuclear, térmica a gás, térmica a óleo, etc. A Figura 11 ilustra uma comparação fictícia entre três opções de geração usualmente utilizadas na Europa e nos Estados Unidos.

Nota-se que, para altas horas equivalentes de utilização, as melhores opções costumam ser as de maior custo de capital e menor custo operacional, como as usinas hidrelétricas e nucleares.

Contudo, as grandes usinas(capital intensivas) constituem a chamada geração de base, cujo despacho deve ocorrer a um fator de carga bastante próximo a um, enquanto as outras opções energéticas não devem ser despachadas com a mesma freqüência ou duração, constituindo-se em alternativa para atender às demandas de ponta do sistema. 


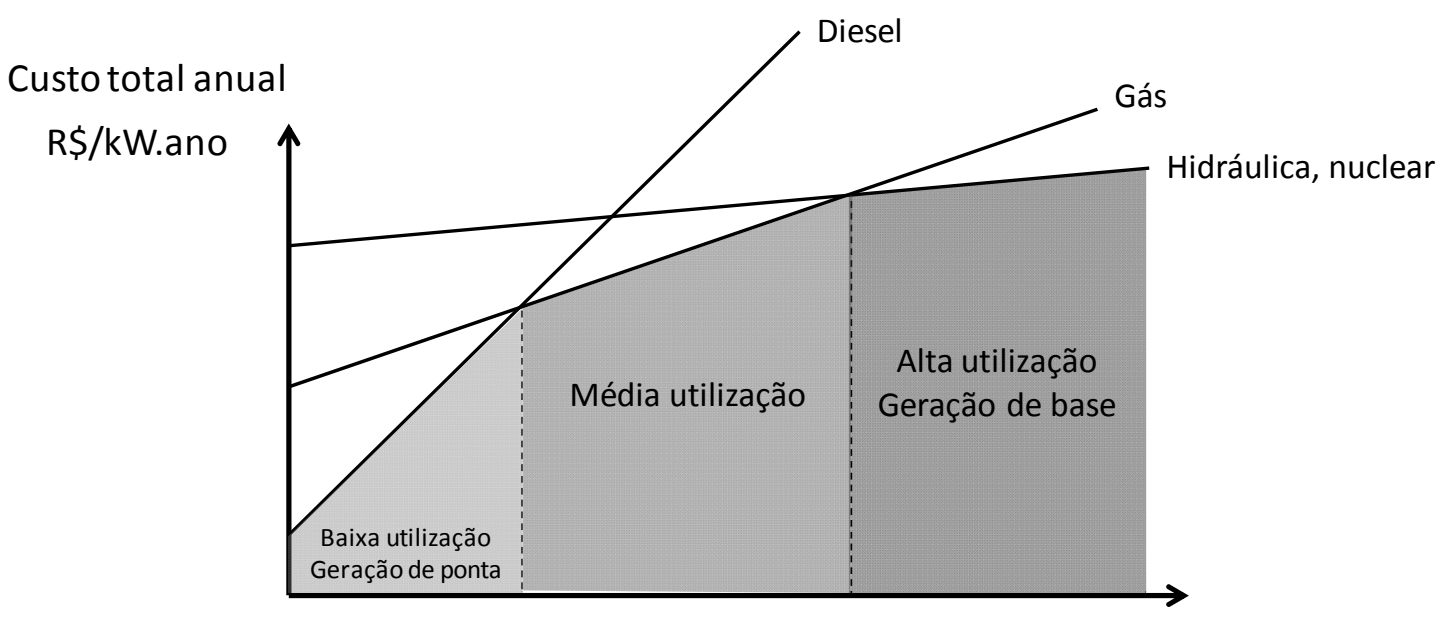

$\mathrm{Hu} / \mathrm{ano}$

Figura 11 - Comparação de alternativas tecnológicas de geração através das curvas de triagem. Nota-se a dominância da região de menor custo a partir da intersecção das curvas.

Em sistemas hidrotérmicos convencionais, como os europeus, é usual utilizar as curvas de triagem para adequar o despacho das usinas em ordem decrescente de prioridade (WILSON, 1993). Inicialmente, seriam despachadas as usinas da chamada geração de base, mais econômicas desde que bastante utilizadas (altas horas de utilização). Em seguida, seriam acionadas, dentro da mesma ordem de prioridade, usinas de menor custo de capital e de maior custo operacional, refletindo a necessidade do agregado dos consumidores que, ciclicamente, apresentam picos de demanda por períodos curtos de tempo (baixas horas de utilização).

Analogamente, geralmente as tarifas de distribuição são compostas por ao menos duas variáveis de faturamento, a energia ativa mensal consumida e a potência ativa máxima mensal registrada. Esse mecanismo de cobrança está intimamente relacionado com a questão dos custos da geração.

Como é usual valorar a capacidade em $R \$ / k W \cdot$ ano e a energia consumida em $R \$ / M W h$, é também usual a proposição de uma tarifa ao consumidor que seja composta por duas partes, uma fixa, geralmente mensal, por $k W$ contratado, e uma parte variável, por $M W h$ consumido, também em uma base mensal.

Em um sistema verticalizado, no qual a concessionária é a controladora dos processos de geração, transmissão, distribuição e comercialização da energia de 
forma integrada, é bastante clara e usual a separação dos custos totais em custos de capacidade, relacionados aos ativos elétricos do sistema, e custos operacionais, dentre os quais a geração de energia representa a maior parcela.

Já em um ambiente desverticalizado, a atividade de distribuição, assim como ocorre com a transmissão, é caracterizada pela atividade econômica do transporte da energia. Neste contexto, os custos operacionais da distribuidora passam a não contar com os custos de geração, que seriam a maior parcela dos custos operacionais em um sistema verticalizado.

\subsubsection{A precificação de ponta}

A teoria econômica utilizada na diferenciação de preços por horários do dia, meses do ano ou estações climáticas é originária dos estudos de (BOITEUX, 1960), engenheiro francês que presidiu a $\operatorname{EDF}^{7}$ a partir de 1967, e (STEINER, 1957), professor americano de economia e direito nas universidades da Califórnia e Wisconsin.

Dentre outros autores que abordaram o tema da precificação de ponta, estão (DRĖZE, 1964), (NELSON, 1964), (WILLIAMSON, 1966), (TURVEY, 1968), (DE SALVIA, 1969), (KAHN, 1970), (WENDERS, 1976), (PANZAR, 1976), (CARLTON, 1977), (CREW \& KLEINDFORFER, 1986), (JOSKOW, 2005), entre muitos outros.

A base teórica para a estruturação de preços por períodos de tempo prédeterminados reside na avaliação inicial dos custos de curto e longo prazos em mercados atendidos por plantas de capacidade rígida, como é o caso dos sistemas de geração, transmissão e distribuição de energia.

Ocorrendo demanda cíclica por eletricidade para um caso simples em que os consumidores são inelásticos, (BOITEUX, 1960) sugere que, aos consumidores que demandam potência no período em que o sistema é mais solicitado (ponta), deve-se aplicar preços iguais aos custos marginais de longo prazo, compostos por custos marginais de expansão e custos marginais de operação do sistema.

\footnotetext{
${ }^{7}$ Eletricité de France
} 
Conseqüentemente, aos consumidores que demandam potência no período em que o sistema é menos solicitado (fora-ponta), deve-se aplicar preços proporcionais aos custos marginais de curto prazo, compostos apenas por custos de operação do sistema no curto prazo.

Neste contexto, define-se $\beta$ como o custo marginal de expansão de uma planta qualquer de capacidade rígida, igual à derivada dos custos de capital em relação à capacidade do sistema. É importante lembrar que esta derivada somente se caracteriza no longo prazo, já que os custos de capital (fixos no curto prazo) somente variam em horizontes de longo prazo.

Define-se também $b^{\prime}$ como o custo marginal de operação por período ${ }^{8}$ de uma planta de capacidade rígida, ou $b^{\prime}=b / n$, sendo $b$ a derivada dos custos operacionais de curto prazo (essencialmente custos de energia) totais em relação à demanda e $n$ o número de períodos de faturamento. $b$ é definido no curto prazo, e pela consideração simplificada feita por (BOITEUX, 1960) e (DRÈZE, 1964), a ser discutida no capítulo 3 , $b$ é considerado praticamente constante em qualquer escala de produção.

Definidos os custos marginais de expansão e operação de uma supridora verticalizada de capacidade rígida, define-se o custo marginal de longo prazo como o custo marginal total para expandir e operar esta planta, ou seja, $c m l p=\beta+b$. Da mesma forma, o custo marginal de curto prazo é somente o custo marginal de operação no curto prazo, ou $c m c p=b$.

A teoria de precificação de ponta é, então, aplicada a duas situações, classificadas segundo a resposta dos consumidores aos sinais de preços de ponta e fora-ponta. São eles, o "firm peak case", ou caso de ponta firme, e o "shifting peak case", ou caso em que a ponta se desloca entre os períodos considerados. Ambos os casos são apresentados a seguir.

\subsubsection{O preço de ponta para o "firm peak case"}

Considere que a demanda de um sistema é periódica em um ciclo diário de dois períodos de igual duração, 1 e 2 , sendo a demanda do período 1 igual a $q_{1}$ e a do

\footnotetext{
${ }^{8}$ No caso clássico documentado por (BOITEUX, 1960), os períodos tem igual duração de tempo, e são caracterizados por demandas constantes dentro de cada período.
} 
período 2 igual a $q_{2}$. Considere ainda que $q_{1}>q_{2}$ para quaisquer preços aplicados às duas demandas, e que $q_{1}=q_{0}$, sendo $q_{0}$ a capacidade do sistema.

A Figura 12 ilustra as curvas de demanda para os períodos 1 e 2 em função dos preços e em função do tempo. É importante ressaltar que, a preços iguais, uma demanda maior no domínio do tempo é representada por um deslocamento da curva correspondente para a direita no sistema de coordenadas preços-quantidades.

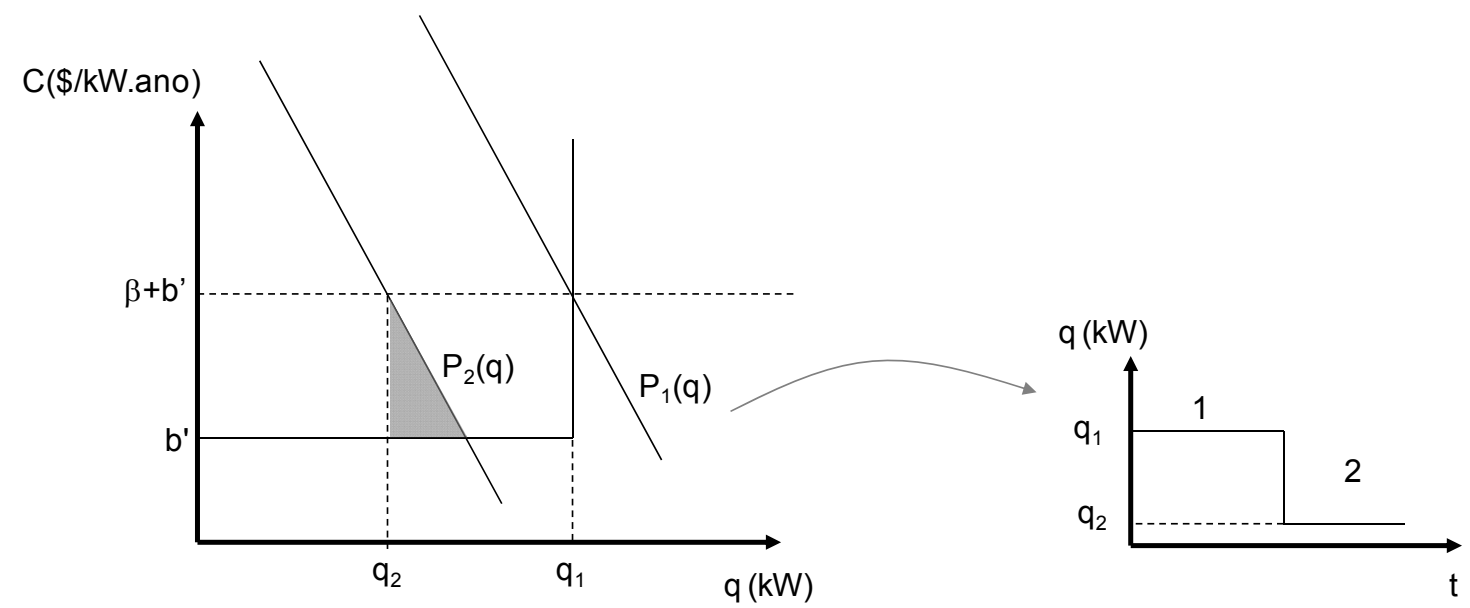

Figura 12 - Demandas $q_{1}$ e $q_{2}$ a preços iguais

Aplicando-se o mesmo preço a ambos os períodos igual ao custo marginal de longo prazo $\left(b^{\prime}+\beta\right)$, observa-se a ocorrência de perda de bem-estar social, ilustrada pela área hachurada abaixo da curva de demanda $P_{2}$ na Figura 12.

Diante deste fato, e considerando que as demandas nos períodos 1 e 2 sempre ocorrem sequencialmente, para o período 2 o preço aplicado deveria ser suficiente apenas para a cobertura dos custos marginais de operação no curto prazo no período, ou seja, $b^{\prime}$.

A Figura 13 ilustra a aplicação de preços diferenciados às demandas nos períodos 1 e 2, sem perda de bem-estar social. Este caso é conhecido como "firm peak case" devido ao fato de que, cobrando-se um único preço para ambos os períodos ou cobrando preços diferenciados, a demanda máxima continua sendo no período $1\left(q_{1}>q_{2}\right)$. 


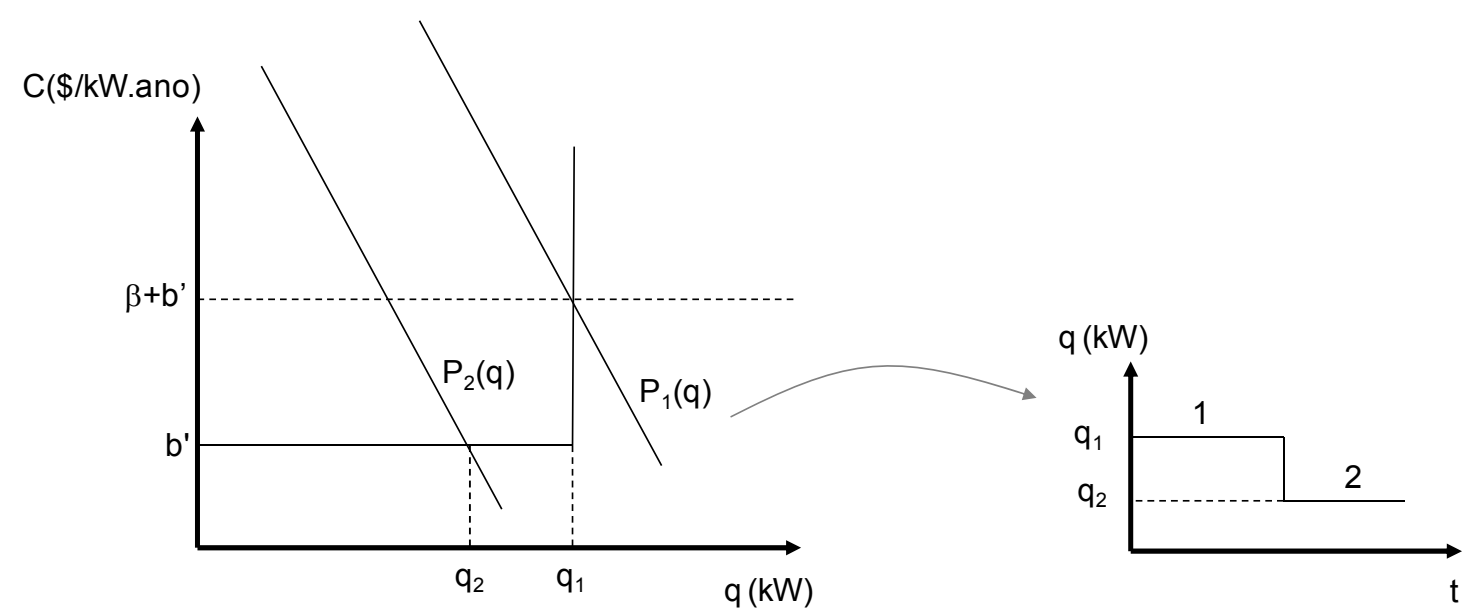

Figura 13 - "Firm peak case": A preços diferentes, a demanda máxima continua sendo $q_{1}$.

\subsubsection{O preço de ponta para o "shifting peak case"}

Dependendo das características das funções de demanda dos períodos 1 e 2 apresentadas no item 2.1.3.1, poderá ocorrer uma situação bastante indesejada após a aplicação de preços diferenciados às demandas $q_{1}$ e $q_{2}$. Esta situação se refere ao caso da inversão da ponta, ou, como denominado por (STEINER, 1957), "shifting peak case".

Caso as funções inversas da demanda, $P_{1}$ e $P_{2}$, sejam mais elásticas e mais próximas entre si, a aplicação de $\beta+b^{\prime}$ à demanda de ponta, e a conseqüente aplicação de $b^{\prime}$ à demanda de fora-ponta pode ocasionar uma forte retração do consumo $q_{1}$ e uma forte expansão do consumo $q_{2}$. Este efeito poderá ser de tal forma que, no equilíbrio, $q_{2}$ seja menor que $q_{1}$. A Figura 14 ilustra a ocorrência da inversão da ponta para um caso fictício. 

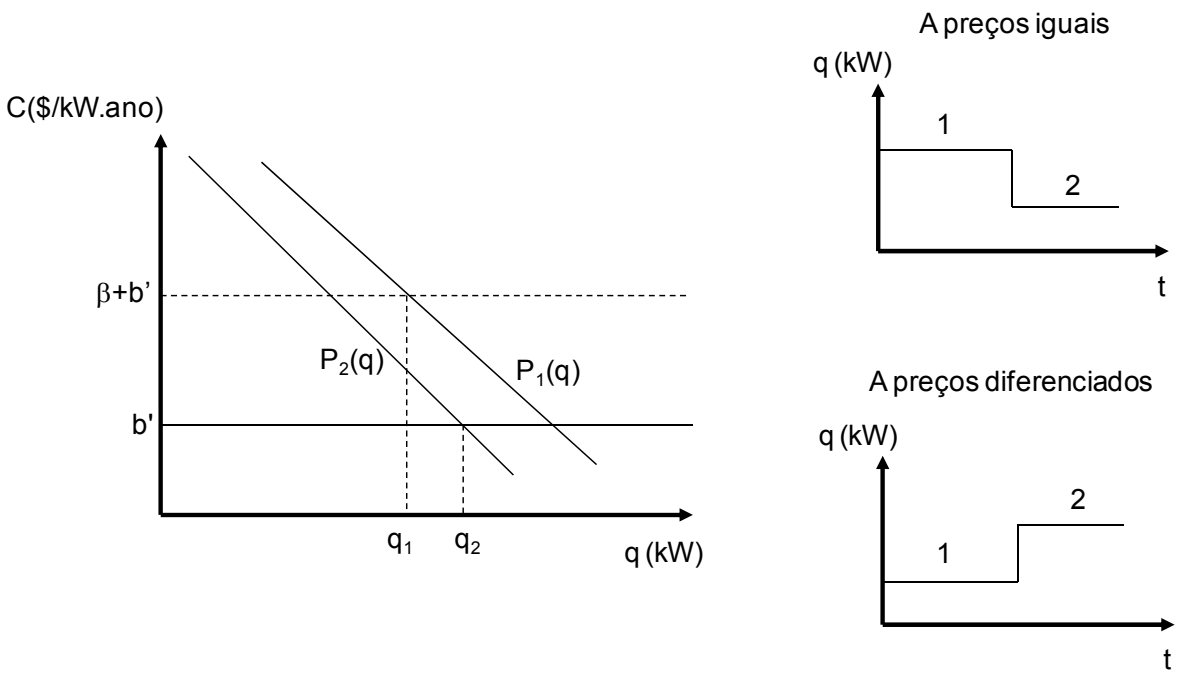

Figura 14 - "Shifting peak case": A preços diferenciados, a demanda menor se torna a máxima

A inversão da ponta, além de ser inapropriada tecnicamente, não é nem um pouco eficiente do ponto de vista econômico, pois cobra-se a expansão e operação da menor demanda e apenas a operação da maior demanda, gerando assim perda de bem-estar social.

(ECKEL, 1987), (STEINER, 1957) e (JOSKOW, 2005) demonstram de maneiras diferentes que a solução ótima para o caso de inversão da ponta é a aplicação de preços diferenciados para os períodos 1 e 2 de tal forma que as demandas $q_{1}$ e $q_{2}$ se igualem após a aplicação destes preços.
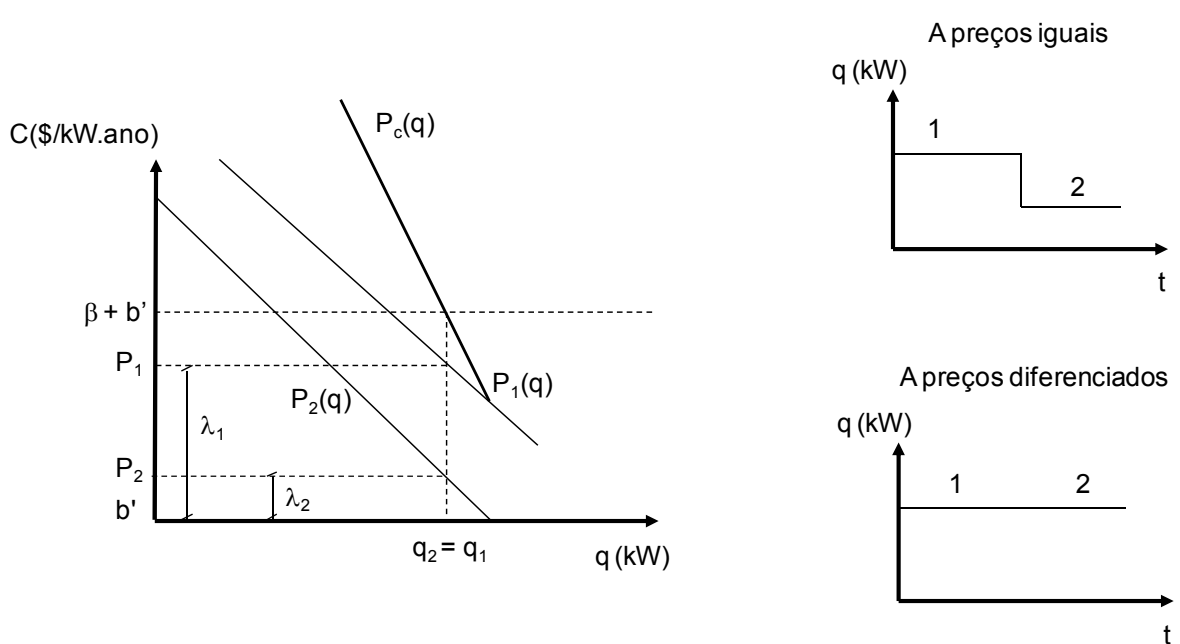

Figura 15 - Solução ótima para o problema de inversão da ponta documentada por (STEINER, 1957) 
A solução encontrada por (STEINER, 1957) se baseia em um método gráfico que se utiliza de uma curva de capacidade fictícia, $P_{c}(q)$, construída através da soma das curvas $P_{1}(q)$ e $P_{2}(q)$ no eixo dos preços. A Figura 15 ilustra a solução encontrada, na qual as quantidades $q_{1}$ e $q_{2}$ são iguais exatamente quando a curva $P_{c}(q)$ cruza a curva do custo marginal de longo prazo. Para tornar o gráfico menos poluído, a origem do eixo das ordenadas está em $b^{\prime}$.

Como pode ser observado, os preços a serem aplicados às demandas nos períodos 1 e 2 seriam $\mathrm{b}^{\prime}+\lambda_{1}$ e $\mathrm{b}^{\prime}+\lambda_{2}$, respectivamente, onde $\lambda_{1}$ e $\lambda_{2}$ seriam markups sobre o custo marginal de operação por período. Demonstra-se graficamente que $\lambda_{1}+\lambda_{2}=\beta$, e assim que ambos os períodos dividem entre si os custos marginais de expansão em uma proporção tal que não haja a inversão da ponta.

Em (JOSKOW, 2005), o mesmo problema da inversão de ponta é solucionado através da maximização do bem-estar social. Neste trabalho, são definidas as funções demanda, $q_{1}\left(p_{1}\right)$ e $q_{2}\left(p_{2}\right)$, sendo $q_{1}(p)>q_{2}(p)$ para qualquer preço $p$. Para o sistema da Figura 15 , o bem-estar social máximo, $L^{*}$, será dado por (8).

$L^{*}=S\left(q_{1}\right)+S\left(q_{2}\right)-(\beta) \cdot q_{0}-b^{\prime} \cdot\left(q_{1}+q_{2}\right)+\lambda_{1}\left(q_{0}-q_{1}\right)+\lambda_{2}\left(q_{0}-q_{2}\right)$

Onde:

$S\left(q_{1}\right): \quad$ Excedente dos consumidores que consomem no período 1.

$S\left(q_{2}\right)$ : $\quad$ Excedente dos consumidores que consomem no período 2 .

$\lambda_{1}: \quad \quad$ Preço sombra da demanda no período 1.

$\lambda_{2}$ : $\quad$ Preço sombra da demanda no período 2.

As condições de primeira ordem (primeiras derivadas parciais), lembrando que $\frac{\partial S_{i}}{\partial q_{i}}=p_{i}$, são dadas por (9)

$$
\begin{aligned}
& p_{1}-b^{\prime}-\lambda_{1}=0 \\
& p_{2}-b^{\prime}-\lambda_{2}=0 \\
& \lambda_{1}+\lambda_{2}-(\beta)=0
\end{aligned}
$$


Com condições complementares das inequações $q_{1} \leq q_{0}$ e $q_{2} \leq q_{0}$ dadas por (10).

$$
\begin{aligned}
& \lambda_{1} \cdot\left(q_{0}-q_{1}\right)=0 \\
& \lambda_{2} \cdot\left(q_{0}-q_{2}\right)=0
\end{aligned}
$$

O resultado, descrito pelo conjunto de equações em (11), é exatamente o mesmo encontrado por (STEINER, 1957) para o caso de inversão de pico (shifting peak case).

$$
\begin{aligned}
& p_{1}=b^{\prime}+\lambda_{1} \\
& p_{2}=b^{\prime}+\lambda_{2} \\
& \lambda_{1}+\lambda_{2}=\beta \\
& q_{1}=q_{2}
\end{aligned}
$$

\subsubsection{A questão dos custos na produção conjunta}

Como muitos mercados caracterizados por monopólios naturais, a distribuição de energia é um sistema produtivo de múltiplos produtos (energia em alta, média e baixa tensão) a diferentes mercados (residencial, industrial e outros). Uma das questões fundamentais, principalmente objetivando a questão tarifária, é diferenciar os custos por produtos, sejam médios, marginais ou totais.

É notável a discussão de que o setor de distribuição de energia, assim como outras utilities, apresenta custos não totalmente separáveis por nível de tensão. Por exemplo, os custos das subestações de distribuição, que são parcialmente utilizadas por consumidores de média e baixa tensão, não podem ser totalmente separados.

De forma bastante genérica, para uma firma que oferece dois produtos ao seu mercado, em quantidades $Q_{1}$ e $Q_{2}$, produzidas de forma conjunta, por exemplo pela mesma planta, pode-se considerar que seu custo total é função destas duas quantidades, ou $C T=f\left(Q_{1}, Q_{2}\right)$.

Como a função custo total é formada por custos comuns aos dois produtos, fixos e variáveis, e por custos atribuíveis exclusivamente a cada um dos produtos, de forma bastante genérica, poder-se-ia ter uma equação como a apresentada em (12). 
$C T\left(Q_{1}, Q_{2}\right)=C F+C C\left(Q_{1}, Q_{2}\right)+C A_{1}\left(Q_{1}\right)+C A_{2}\left(Q_{2}\right)$

Onde:

CF: $\quad$ Custos fixos comuns.

CC: $\quad$ Custos variáveis comuns aos dois produtos.

$C A_{1}$ : $\quad$ Custo variável atribuível ao produto 1.

$C A_{2}: \quad$ Custo variável atribuível ao produto 2.

Para calcular o custo médio do produto 1 ou do produto 2, seria necessário separar as parcelas de custos comuns aos dois produtos. No exemplo da Equação (12), estas parcelas seriam $C F$ e $C C$.

Muitas vezes isso não é possível, a não ser através de um método arbitrário baseado em alguma medida de proporção consumida (VISCUSI, HARRINGTON JR, \& VERMON, 2005) dos dois produtos. Um exemplo bastante ilustrativo para o setor de distribuição de energia seria a venda de energia para consumidores residenciais em baixa tensão, e para consumidores industriais em média tensão.

Os custos fixos de atendimento a estes consumidores, por exemplo, referentes aos ativos da subestação e alimentadores primários, não podem ser naturalmente divididos entre estes dois produtos, a não ser por um critério, que geralmente está relacionado às quantidades consumidas.

Da mesma forma, os custos variáveis comuns, como por exemplo as perdas de energia, são função das duas quantidades em conjunto, não sendo algebricamente separáveis $^{9}$. Desta maneira, o cálculo dos custos médios fica bastante dependente de um critério a ser adotado para esta separação de custos.

\footnotetext{
${ }^{9}$ Para ilustrar essa afirmação, propõe-se o seguinte exemplo: As perdas técnicas para o atendimento a duas cargas localizadas no final de um alimentador qualquer são proporcionais ao quadrado da soma das potências destas duas cargas, $\left(P_{1}+P_{2}\right)^{2}$. Sendo assim, não é possível atribuir o termo $2 \cdot P_{1} \cdot P_{2}$ a uma das cargas, senão ao conjunto delas.
} 
O custo marginal de cada um dos produtos, definido como a derivada parcial do custo total em relação a um destes produtos, é mais facilmente obtido, uma vez que a separabilidade do custo fixo é indiferente à avaliação marginal, pois a derivada de uma constante é nula.

Contudo, ainda faz-se necessário avaliar com precisão as funções $C C\left(Q_{1}, Q_{2}\right)$, $C A_{1}\left(Q_{1}\right)$ e $C A_{2}\left(Q_{2}\right)$ para calcular os custos marginais de cada um dos produtos. No exemplo da distribuição de energia, é bastante razoável supor que os custos marginais de atendimento em um mesmo nível de tensão sejam iguais para as várias classes de consumo existentes.

Resumidamente, pode-se dizer que existem custos de capital e de operação e manutenção que não podem ser totalmente separados entre os produtos, a não ser por um critério arbitrário que busque justiça, mas não necessariamente a eficiência econômica. A separação de custos para casos de produção conjunta é considerada, necessariamente, um critério arbitrário por (LAFFONT \& TIROLE, 1990), (BROWN \& SIBLEY, 1986), (JOSKOW, 2005), (VISCUSI, HARRINGTON JR, \& VERMON, 2005) e outros.

Custos totalmente distribuídos, ou em inglês, Fully Distributed Costs (FDC) é o nome de um mecanismo de precificação bastante utilizado em modelos de regulação de monopólios. (BROWN \& SIBLEY, 1986) descrevem diversas abordagens para separar custos comuns entre os produtos que compõem o mercado de fornecimento. Entre estas abordagens, destaca-se uma regra bastante simples, chamada Relative Output Method (ROM).

Esta regra pode ser compreendida através da Equação (13), considerando-se que uma empresa ofereça $N$ produtos.

$F D C_{i}=C A_{i}+f_{i} \cdot C C$

Onde:

$F D C_{i}: \quad$ Custos totais de produção do produto $i$.

$C A_{i}: \quad$ Custos atribuíveis ao produto $i$ 
CC: $\quad$ Custos comuns de produção.

$f_{i}: \quad$ Fração do produto $i$, sendo $f_{i}=\frac{q_{i}}{\sum_{j=1}^{N} q_{j}}$

É importante notar que a regra acima descrita é completamente arbitrária, definindo que os custos totais de produção de um determinado produto $i$ sejam iguais aos seus custos diretamente atribuíveis, somados a uma parcela dos custos comuns. Esta parcela, para este caso, é a proporção da quantidade de $i$ sobre a quantidade total fornecida pela empresa.

Como esta, existem outras inúmeras regras para a divisão dos custos comuns, inclusive relacionadas ao comportamento e às oportunidades dos consumidores. Esta discriminação de custos com objetivos tarifários deve, contudo, basear-se em critérios razoáveis e coesos, mesmo que estes sejam determinados segundo a ótica do regulador.

\subsubsection{Critérios para a divisão dos custos totais por nível de tensão}

Existem, basicamente, 3 critérios usualmente empregados para a divisão de custos totais entre produtos diferentes em um processo caracterizado pela produção conjunta, como o sistema de distribuição de energia. São eles:

\section{i. Critérios baseados na razoabilidade da atribuição de custos}

Estes são critérios absolutamente subjetivos, mas que tem por objetivo a razoabilidade na determinação da origem do custo, sempre por um critério não econômico e melhor relacionado com o senso de justiça.

Por exemplo, na Nota Técnica ANEEL-271/2009 (ANEEL-A, 2009), o órgão regulador brasileiro usa de critérios aderentes à razoabilidade da atribuição de custos quanto propõe alocar todos os custos operacionais comerciais ao nível da baixa tensão, através de argumentação lógica e análise de dados. 
Desta forma, todos os custos poderiam ser atribuídos a algum nível de tensão, integralmente ou proporcionalmente a alguma medida da utilização dos sistemas elétricos, como subestações, alimentadores, transformadores, etc.

\section{ii. Critérios contábeis e financeiros}

Estes critérios, de certa forma relacionados à razoabilidade na atribuição de custos, são baseados em regras contábeis e financeiras para a divisão de custos totais entre os diversos tipos de produtos, neste caso caracterizados por níveis de tensão.

\section{iii. Critérios relacionados à proporção dos custos marginais}

Os critérios para a divisão de custos totais relacionados à proporção dos custos marginais são os mais aderentes à ótica econômica, e estão intrinsecamente relacionados aos modelos de precificação em monopólios naturais.

Como pode ser observado no ANEXO I, em um monopólio natural os custos marginais de curto prazo não são suficientes para cobrir os custos totais devido às economias de escala provocadas pelos altos custos fixos existentes. Desta forma, aplicando-se preços iguais aos custos marginais de curto prazo para cada produto, a receita obtida será necessariamente menor que a receita requerida para a cobertura dos custos totais, exigindo um ajuste para a reconstituição de receita.

Existem três processos teóricos bastante utilizados, além de inúmeros outros derivados, para a reconstituição de receita. Quais sejam, tarifa e duas partes, preços de Ramsey e reconstituição multiplicativa, proporcional aos custos marginais de cada produto.

No entanto, calcular os custos marginais de longo prazo, constituídos pelos custos marginais de expansão e operação para cada produto, ou para cada nível de tensão, constitui-se de uma tarefa árdua e, de certa forma, dependente de critérios subjetivos. De acordo com (ANTUNES, 2004), no "[...] segmento de distribuição de 
energia elétrica, as metodologias concebidas para determinação do custo marginal de expansão se fundamentaram em dois conceitos:

- A avaliação do desenvolvimento das obras num período préespecificado;

- A previsão dos investimentos requeridos para fazer frente ao crescimento esperado da demanda.[...]".

Ainda, de acordo com Antunes, "[...] Como as metodologias baseadas na previsão de investimentos utilizam planos de expansão dos sistemas de distribuição, também são contempladas referências específicas direcionadas ao planejamento de longo prazo das redes de média e baixa tensão. [...]"

De forma resumida, utilizam-se no Brasil duas metodologias para o cálculo dos custos marginais de longo prazo para cada nível de tensão, são elas, a Lei de Quantidade de Obras - LQO, a qual utiliza-se de dados passados de investimentos e quantidades de obras realizadas, e a metodologia do Custo Incremental Médio de Longo Prazo - CIMLP, que, ao contrário da LQO, utiliza-se de previsões de investimentos e de acréscimos de demanda.

A LQO pode ser interpretada como uma metodologia "backward looking", considerando que o futuro se comporta como o passado recente, enquanto o CIMLP, por trabalhar com previsões, é interpretada como uma metodologia "forward looking". Para maiores detalhes, consultar (ANTUNES, 2004).

Finalmente, pode-se afirmar que o conhecimento dos custos marginais para cada nível de tensão é essencial e suficiente para a construção de uma estrutura de preços entre níveis de tensão, tornando-se uma solução econômica para a divisão de custos em um sistema de produção conjunta. Vale ressaltar que este critério é o atualmente empregado pela ANEEL para o cálculo da estrutura de preços entre níveis de tensão.

\section{a. O Custo incremental médio de longo prazo - CIMLP}

De acordo com (ANTUNES, 2004), o Custo Incremental Médio de Longo Prazo - CIMLP é definido pela Equação (14). 
$\operatorname{CIMLP}=\frac{\sum_{k=1}^{n} I_{k}(1+i)^{-k}}{\sum_{k=1}^{n} \Delta D_{k}(1+i)^{-k}}$

Onde:

$I_{k}: \quad$ Investimentos agregados realizados durante o período $k$

$\Delta D_{k}: \quad$ Variação de demanda máxima durante o período $k$

$i: \quad$ Taxa de atualização do capital

Ainda, segundo (ANTUNES, 2004), “[...] Os dados necessários para a aplicação da metodologia do CIMLP são:

- $\quad$ Previsão plurianual de mercado;

- $\quad$ Plano plurianual de investimentos.

A partir da rede existente e do acréscimo de carga a ser solicitado ao sistema, é definido um programa de obras necessárias ao atendimento da carga prevista, dentro de critérios pré-estabelecidos de confiabilidade e qualidade de serviço, como por exemplo, o plano decenal de obras do setor elétrico.

Dispondo-se do banco de informações sobre os sistemas planejados para os horizontes de curto, médio e longo prazos, "Plano Decenal", calcula-se o "Custo Marginal Médio" utilizando-se a metodologia do CIMLP para cada nível de tensão conforme [...]" a Equação (14).

Ainda, (ANTUNES, 2004) afirma que, "[...] A partir do Custo Marginal Médio, passa-se à etapa final do procedimento que consiste no cálculo do custo marginal de expansão em base anual. Isto pode ser feito por meio de duas formas básicas:

- Multiplicando-se cada investimento (li) por uma taxa de anualização através do Método "Sinking Fund" que consiste na aplicação de um Fator de Recuperação do Capital - FRC aos investimentos; 
- $\quad$ A partir da amortização linear, que consiste em multiplicar cada investimento (Ii) por uma taxa de anualização dada pela somatória da taxa de remuneração anual dos investimentos, da taxa de depreciação do primeiro ano e da taxa de operação das instalações.[...]".

Deste modo, obtém-se o custo marginal de expansão em base anual a partir da Equação (15).

$C m g=C I M L P \cdot T x_{\text {anualização }}$

Onde:

$T x_{\text {anualização: }}$ Soma das taxas de remuneração do capital, depreciação e operação e manutenção.

\subsubsection{A discriminação de preços aos consumidores}

Existem diversos mecanismos de diferenciação de preços aos consumidores de um monopólio natural. Como já discutido no item 2.1, em um mercado multiproduto, a diferenciação de preços entre os produtos deve ter como base a diferença entre seus custos marginais. Sob uma visão mais generalista, pode-se dizer que existem basicamente três formas clássicas de diferenciação de preços aos consumidores. São elas:

1) Discriminação de preços de $1^{\circ}$ grau:

Supondo que o produtor conheça a disponibilidade a pagar de cada consumidor individualmente (seu preço de reserva), seria possível a aplicação de preços diferentes a consumidores diferentes, considerando um mesmo produto, com o propósito de extrair totalmente o excedente de cada consumidor. Este mecanismo de discriminação de preços é conhecido como discriminação de $1^{\circ}$ grau (LANDSBURG, 2008), sendo absolutamente teórico. 
2) Discriminação de preços de $2^{\circ}$ grau:

O mecanismo de discriminação de preços que depende da quantidade consumida pelos consumidores é um mecanismo de $2^{\circ}$ grau (STOFT, 2002). A precificação não linear é o mais conhecido instrumento de discriminação de preços por quantidades consumidores, o que, em última instância, está relacionado ao nível de renda dos consumidores (BROWN \& SIBLEY, 1986).

3) Discriminação de preços de $3^{\circ}$ grau:

Quando a diferenciação de preços aos consumidores ocorre pela atribuição de variáveis descritoras dos consumidores, como elasticidade, classe, perfil de carga ou localização geográfica/topológica, esta é dita de $3^{\circ}$ grau. Geralmente, o termo "Custo do Cliente" está relacionado a um mecanismo de discriminação de $3^{\circ} \mathrm{grau}$, como é o caso, por exemplo, da tarifa locacional, ou também chamada de tarifa nodal. 


\section{Custos da Distribuição no Curto e no Longo Prazos}

Neste capítulo, será discutida a teoria econômica aplicada à análise das curvas de custos totais, em horizontes de curto e longo prazos, de classes de empresas com capacidade de produção rígida. Nesta classe de empresas, encontram-se as distribuidoras de energia elétrica.

No contexto destas empresas, os custos fixos são bastante elevados, resultando em grandes regiões de produção com fortes economias de escala no curto prazo. Como as empresas de distribuição também são caracterizadas por economias de escopo, apresentam-se as condições necessárias para definição de um monopólio natural, como discutido no ANEXO I.

As discussões sobre as características da função custo total de longo e curto prazos de empresas de energia elétrica, seja nos segmentos de geração, transmissão ou distribuição, é originária dos estudos aplicados à solução do problema de tarifação de pico, apresentado sob o título de Teoria da Precificação de Pico (Peak-load pricing theory).

Como já mencionado no item 2.1.3, a teoria econômica utilizada na diferenciação de preços por horários do dia, discriminados como horários de ponta e fora-ponta no Brasil, é originária dos estudos de (BOITEUX, 1960) e (STEINER, 1957).

A discussão do problema da precificação de demanda de ponta, e consequentemente dos custos de curto e longo prazos, se origina no fato de que a eletricidade não pode ser armazenada de forma economicamente viável. Assim, exigese a necessidade de capacidade física disponível dos sistemas de geração, transmissão e distribuição de energia para o atendimento à demanda de ponta, seja ela constante ou impulsiva, por exemplo, com duração de apenas alguns minutos por ano em determinados pontos destes sistemas.

(JOSKOW, 2005) lembra que os sistemas de distribuição de energia, assim como ocorre em outras utilities, são consideravelmente capital-intensivos, e que os custos do capital (depreciação e remuneração) constituem uma parcela significativa dos custos totais de uma distribuidora.

Ocorre ainda que a demanda por eletricidade varia ao longo de períodos cíclicos sazonais, seja diariamente, semanalmente, mensalmente e até anualmente. 
Isso torna a análise das curvas de carga diárias dos consumidores, e também das redes, uma atividade essencial para o desenho tarifário, e para o próprio projeto dos sistemas de distribuição de energia.

\subsection{A teoria: custos de curto e longo prazos}

A partir da teoria inicialmente descrita por (BOITEUX, 1960), aborda-se aqui a análise dos custos totais de uma pequena supridora de energia verticalizada. Esta rede, por simplicidade, será composta por apenas uma subestação de distribuição cuja curva de custos totais, no curto prazo, assemelha-se à observada na Figura 16.

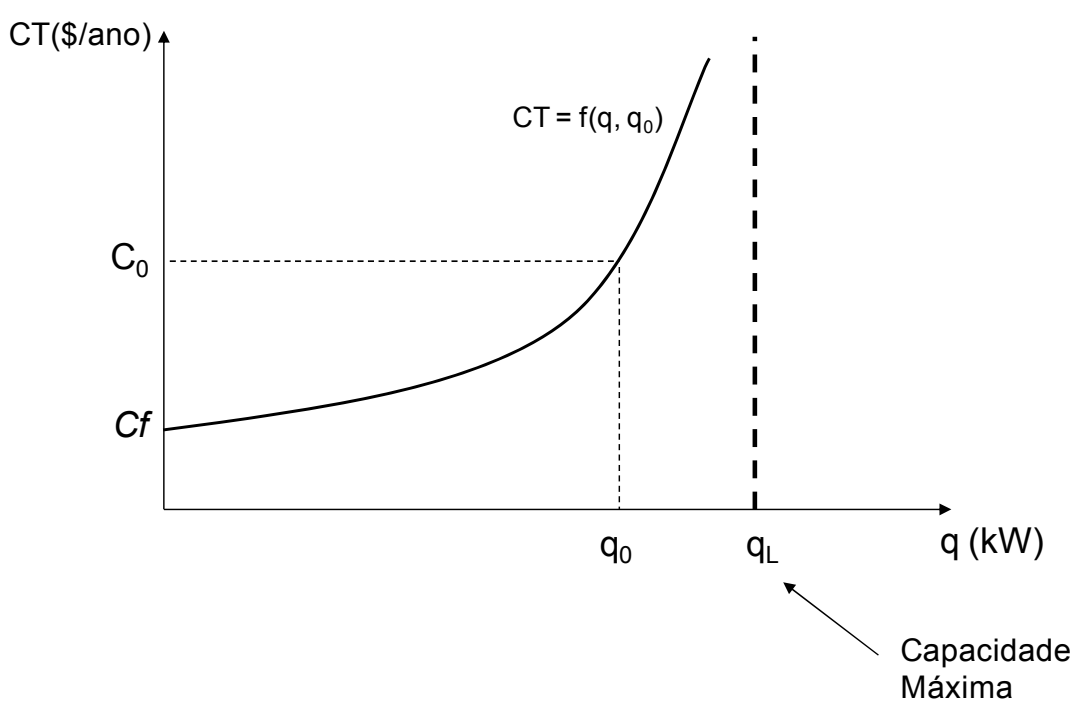

Figura 16 - Curva de custos totais de uma rede composta por apenas uma SE

A curva de custos totais desta rede simples é função da quantidade efetivamente demandada $q$, e da capacidade para a qual a rede foi projetada, $q_{0}$. Inicialmente, considera-se $q_{0}$ constante e não cíclica no curto prazo.

Observa-se, através da Figura 16, que existe um custo fixo $C f$ independente da demanda atendida, além de um custo variável levemente crescente para demandas inferiores a $q_{0}$, e fortemente crescente para demandas superiores a $q_{0}$.

Nesta curva teórica, os custos totais tornam-se muito altos quando a demanda se aproxima da capacidade máxima da rede não somente devido ao aumento dos 
custos operacionais, mas também à iminência de descontinuidade do atendimento, o que afetaria todos os consumidores (custo do déficit).

No entanto, para quantidades inferiores a $q_{0}$, supõe-se que os custos variáveis sejam basicamente relacionados à compra de energia. Ou seja, quanto maior a demanda máxima atendida pela subestação, maiores o consumo de energia, as perdas técnicas, e algumas parcelas dos custos operacionais.

Considere-se agora que a demanda máxima no longo prazo é sempre crescente, e que não é possível atender continuamente a acréscimo de demanda devido ao limite de capacidade da subestação existente. Sendo assim, será economicamente mais interessante, e também necessário, expandir a rede, aumentando-se a sua capacidade instalada. A Figura 17 ilustra o processo de expansão deste sistema de suprimento.

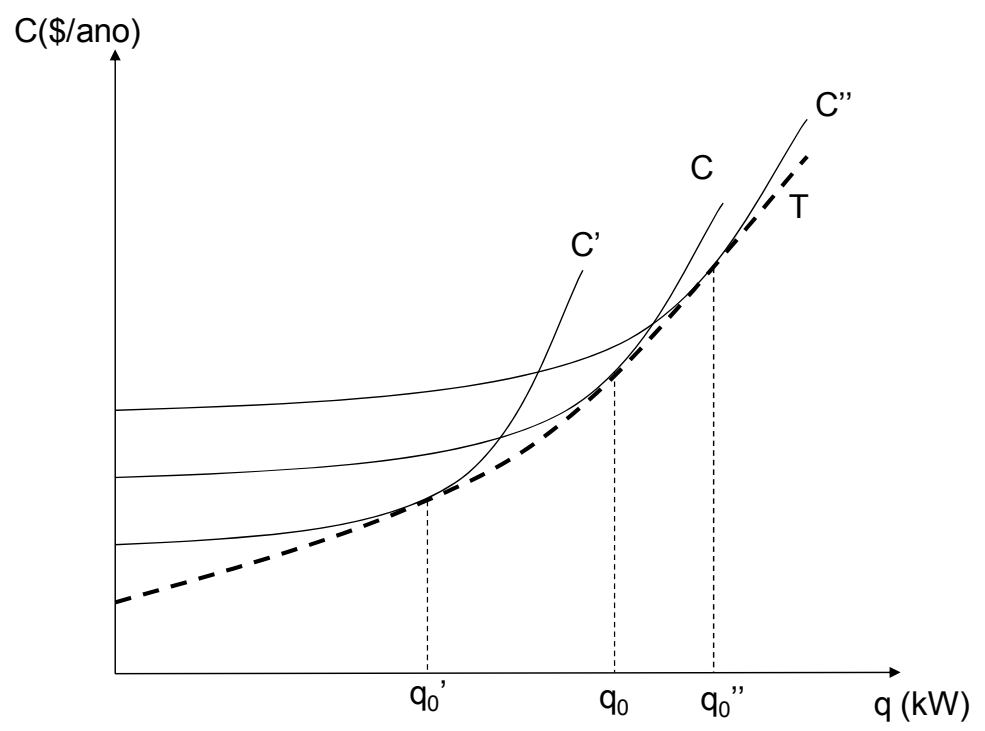

Figura 17 - Curvas de curto prazo para consecutivas expansões de capacidade

São consideradas no exemplo da Figura 17 três curvas de custos de redes de curto prazo, $C^{\prime}, C$ e $C^{\prime \prime}$, construídas para atender às demandas $q_{0}^{\prime}, q_{0}, q_{0}{ }^{\prime \prime}$ respectivamente. Observando-se as curvas de curto prazo, pode-se construir uma curva imaginária $T$ que tangencie pontos em todas as curvas de curto prazo de tal forma que esta curva $T$ ofereça um custo total sempre menor ou igual aos custos das curvas de curto prazo. A esta curva tangente, dá-se o nome de curva de custos de longo prazo, em função das demandas para as quais as redes foram construídas $\left(q_{0}^{\prime}, q_{0}, q_{0}{ }^{\prime \prime}\right)$. 
Imaginando-se que as demandas de operação são contínuas no eixo das abscissas, é possível concluir que os pontos ótimos de operação serão exatamente os pontos em que as curvas de curto e longo prazo se tangenciam, pois para demandas maiores ou menores que este valor, os custos de curto prazo seriam maiores.

Analisando-se apenas a condição da rede existente, cuja função custo é apresentada pela curva $C$, teríamos a condição de operação ajustada para atender à demanda $q_{0}$. O gráfico da Figura 18 ilustra as curvas de custos totais e de suas derivadas, que constituem as curvas de custos marginais de longo e curto prazos. É interessante observar que as curvas de custo marginal se cruzam no ponto para o qual a rede foi construída, ou seja, $q_{0}$.

Como a demanda $q_{0}$, neste exemplo considerada constante e não cíclica no curto prazo, é a demanda que define a curva ótima de custos de curto prazo para o seu atendimento, conclui-se que, no ótimo, a rede deve trabalhar em uma região onde os custos marginais de longo e curto prazo sejam iguais.
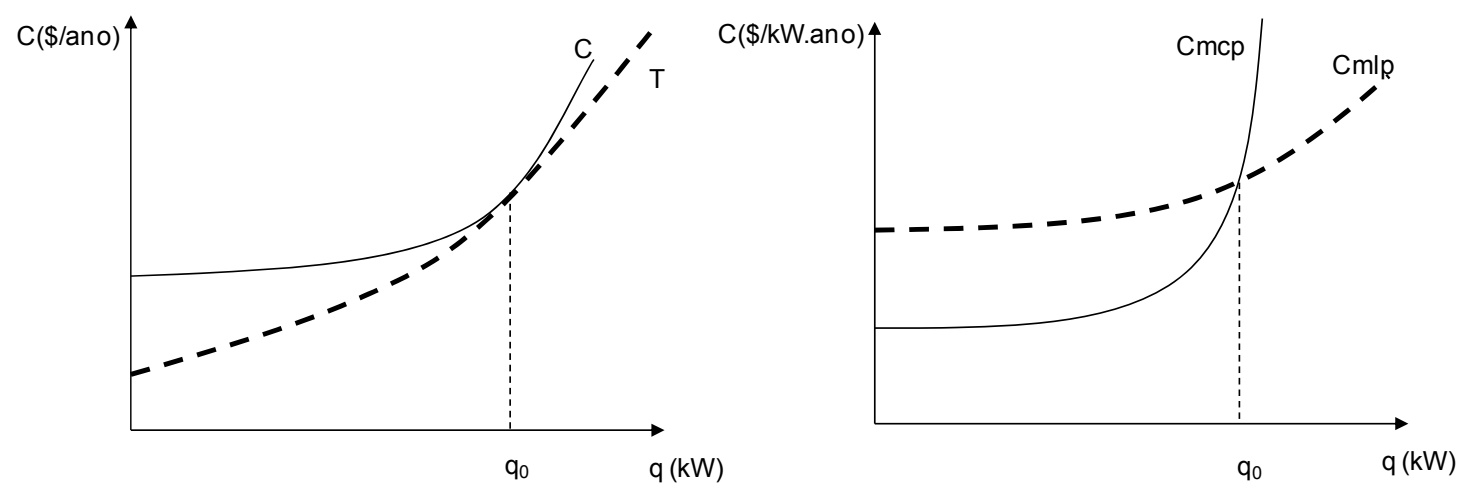

Figura 18 - Curvas de custos totais e marginais de curto e longo prazos.

De acordo com as considerações propostas por (BOITEUX, 1960) e (DRÈZE, 1964), alterando-se um pouco o formato das curvas de custos totais de curto prazo no sentido de torná-las mais rígidas em relação aos custos de atendimento para demandas superiores à capacidade, chega-se aos formatos observados na Figura 19.

De acordo com esta consideração, e assumindo-se que a demanda máxima é suficientemente estável no curto prazo, é de se esperar que a capacidade seja definida o mais próximo possível da demanda, tornando a curva de custos de curto prazo mais rígida. 
Embora para uma única supridora esta situação seja um tanto inapropriada devido aos critérios de contingência, para um grande sistema composto por várias subestações, esta consideração se torna mais aderente à realidade, como será discutido adiante.

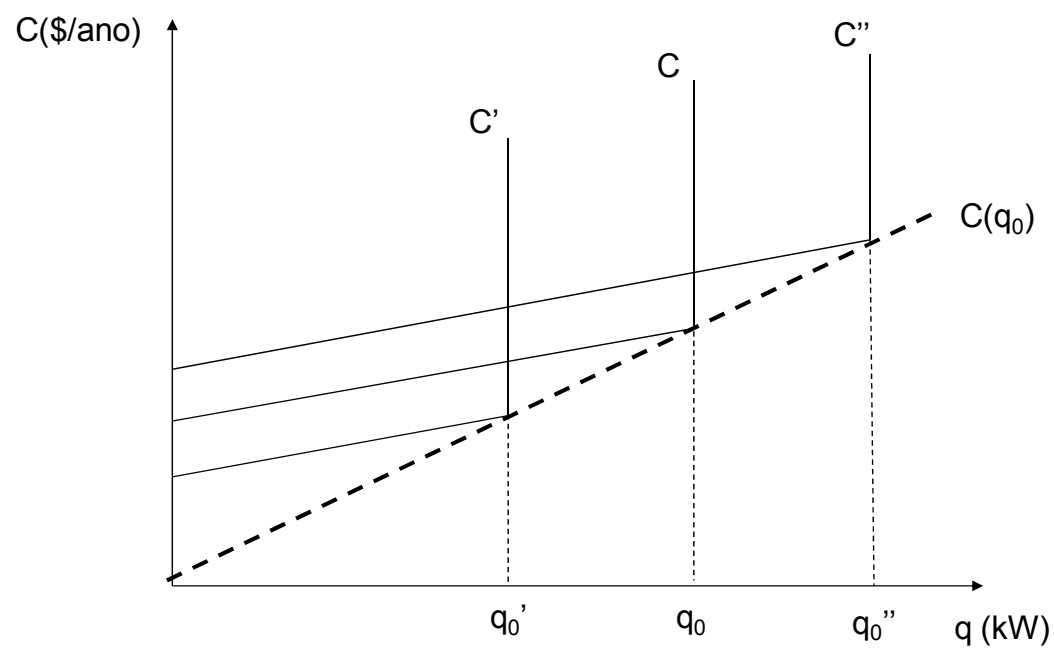

Figura 19 - Curvas de custos de curto prazo mais rígidas.

Assim, derivando-se a curva de custo de curto prazo $C$, e a curva de custo de longo prazo $C\left(q_{0}\right)$, observadas na Figura 19 , são obtidas as curvas de custos marginais para redes com capacidades rígidas, ilustradas na Figura 20. Observa-se que, sem o rigor matemático necessário, as curvas de custos marginais de curto e longo prazos continuam se interceptando no ponto de demanda $q_{0}$.
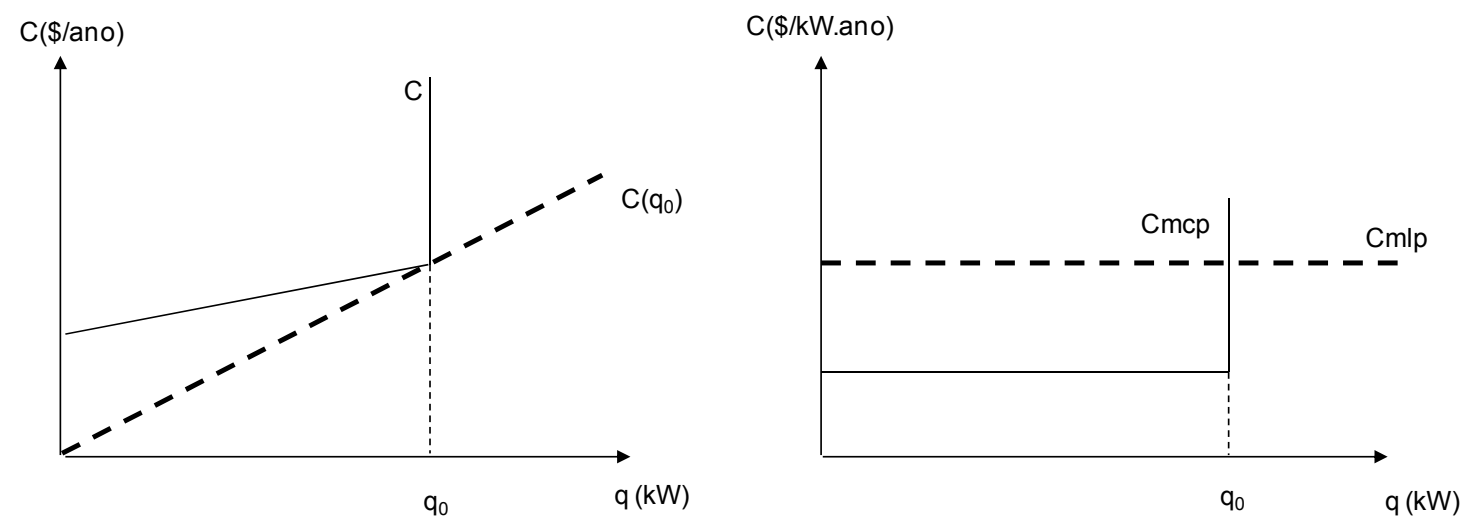

Figura 20 - Curvas de custos totais e marginais de curto e longo prazos. 
Analisando-se mais detalhadamente a curva rígida de custos totais de curto prazo desta rede simplificada, pode-se escrever, por hipótese, uma equação linear para $\mathrm{q}<\mathrm{q}_{0}$, dada pela Equação (16), e representada pela Figura 21.

$\mathrm{C}(\mathrm{q})=\mathrm{Cf}+\mathrm{b} \cdot \mathrm{q} \quad \forall \mathrm{q}<\mathrm{q}_{0}$

Onde:

Cf: $\quad$ Custos fixos.

b: $\quad$ Custo marginal de curto prazo (operação).

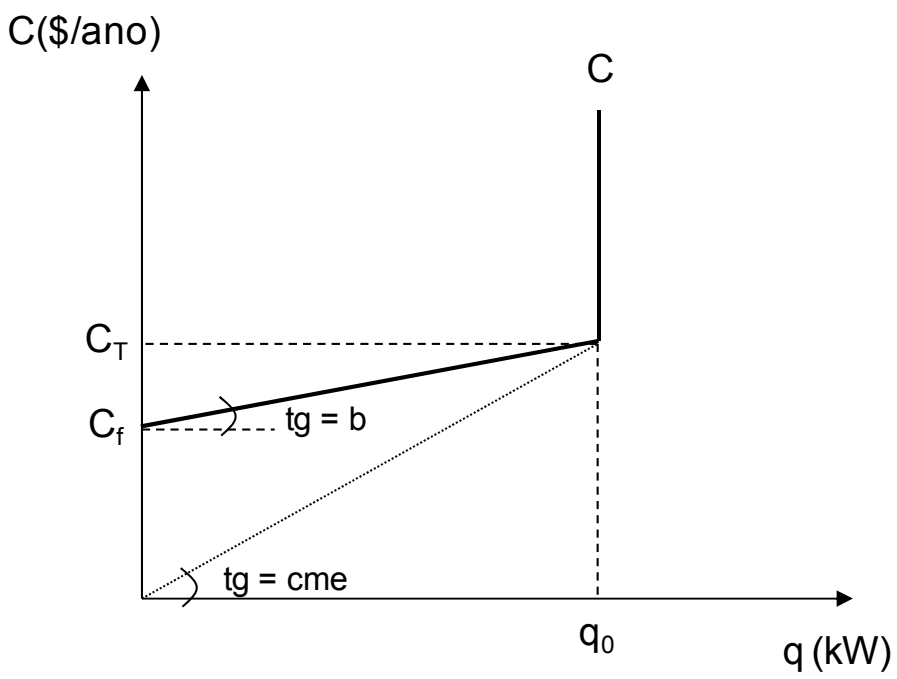

Figura 21 - Curva de custos totais de curto prazo de uma rede simplificada

Define-se como $b$ o custo marginal de operação no curto prazo, sendo $\frac{d c(q)}{d q}=b=c m c p$. Ainda, através da Figura 21, observa-se que o custo médio, cme, para o ponto de atendimento $q_{0}$, é dado pela tangente da reta que liga a origem do sistema de coordenadas ao ponto da curva $C\left(q_{0}\right)$. Graficamente, é possível notar que cme é maior que $b$ para todos os pontos inferiores a $q_{0}$, o que caracteriza um mercado em economia de escala no curto prazo.

Analisando-se novamente a Figura 19, que ilustra o processo fictício de expansão de uma supridora no longo prazo, nota-se, pela consideração levantada por (BOITEUX, 1960), que os custos marginais de curto prazo são praticamente 
constantes em função das demandas para as quais as redes são construídas, $\left(q_{0}{ }^{\prime}, q_{0}\right.$ e $\left.q_{0}{ }^{\prime \prime}\right)$.

Esta consideração pode ser observada graficamente pela inclinação semelhante das três curvas de curto prazo para valores inferiores às demandas de operação. Matematicamente, pode-se escrever que $b\left(q_{0}\right) \cong$ constante. Ou seja, para sistemas com capacidades de atendimento distintas, os custos marginais de operação para o fornecimento de $1 \mathrm{~kW}$ adicional de demanda, por construção, não se diferenciam muito.

Considerando-se que estes custos operacionais envolvem energia, perdas elétricas e uma parcela dos custos operacionais, é razoável imaginar que suas derivadas não dependam sobremaneira da capacidade do sistema.

Ainda observando-se a Figura 19, nota-se que existe uma relação entre o aumento da capacidade operacional $q_{0}$, e o aumento dos custos fixos, representados pelos ativos diretamente relacionados à estrutura do sistema elétrico. Estes custos fixos são observados a partir dos coeficientes lineares das funções de custo de curto prazo. Desta forma, supondo que exista a derivada dos custos fixos em relação à capacidade operacional $q_{0}$, a Equação (17) representaria o custo marginal de expansão do sistema, aqui designado pela letra $\beta$.

$$
\frac{d C f\left(q_{0}\right)}{d q_{0}}=\beta
$$

Onde:
$C f\left(q_{0}\right): \quad$ Custos fixos, em função da capacidade operacional $q_{0}$.
$\beta: \quad$ Custo marginal de expansão.

Imaginando-se que a função de longo prazo $C\left(q_{0}\right)$ possa ser representada pela Equação (18), o termo $b\left(q_{0}\right)$ pode ser substituído por $b$, já que é considerado constante por construção. 
Onde:

$b\left(q_{0}\right): \quad$ Custo marginal de operação, em função de $q_{0}$.

Derivando-se a função apresentada em (18) em relação à $q_{0}$, obtêm-se a Equação (19), na qual o custo marginal de longo prazo é a soma dos custos marginais de operação e de expansão do sistema.

$$
\begin{aligned}
& \frac{d C\left(q_{0}\right)}{d q_{0}}=\frac{d C f\left(q_{0}\right)}{d q_{0}}+\frac{d b\left(q_{0}\right)}{d q_{0}} \\
& \frac{d C\left(q_{0}\right)}{d q_{0}}=\beta+b
\end{aligned}
$$

A Figura 22 representa o custo marginal de longo prazo, que é composto pelos custos de expansão e operação $(\beta+b)$, o custo marginal de curto prazo, que é composto apenas pelo custo marginal de operação no curto prazo, $b$, e uma função demanda $P(q)$ qualquer, neste exemplo representada por uma função linear.

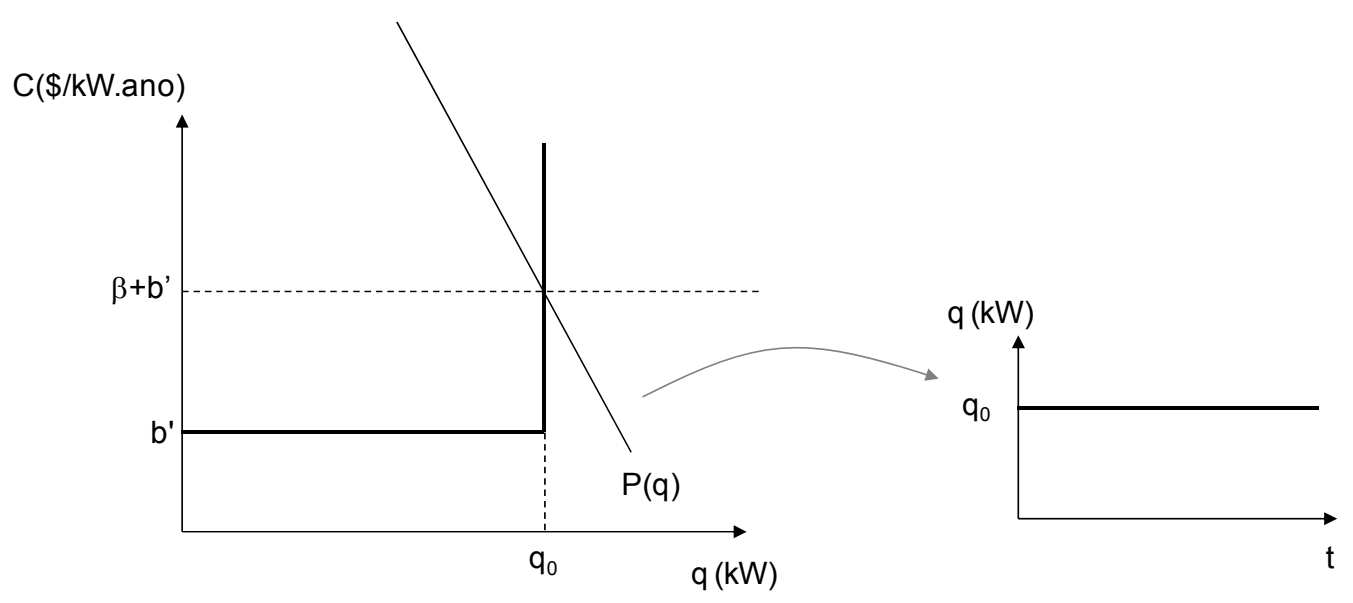

Figura 22 - Função demanda e os custos marginais de curto e longo prazos. 
Nota-se também, através da Figura 22, que a função demanda é representada à esquerda no domínio dos preços, e à direita no domínio do tempo, indicando seu caráter não cíclico e constante no curto prazo.

Segundo (BOITEUX, 1960), e como também discutido no item 2.1.3, a precificação eficiente para o atendimento à demanda $q_{0}$, para a qual o sistema foi projetado, é a precificação ao custo marginal de longo prazo, neste caso representado por $\beta+b$. Considerando-se a existência de retornos constantes de escala no longo prazo, o custo marginal de longo prazo seria suficiente para operar e expandir o sistema, garantindo o equilíbrio econômico do produtor.

Para atender ao princípio do lucro econômico nulo, o custo marginal de longo prazo deve ser igual ao custo médio em $q_{0}$. Para que isso ocorra, a curva de custo total, $C\left(q_{0}\right)$, representada na Figura 19 e considerada linear neste exemplo, deve necessariamente passar pela origem do sistema de coordenadas, corroborando com a discussão apresentada em (LOOTTY \& SZAPIRO, 2002), na qual os custos fixos são considerados variáveis no longo prazo, sendo por definição, $C\left(q_{0}=0\right)=0$.

Dado o contexto da variabilidade sazonal da demanda, principalmente para o período diário, foi discutida no item 2.1.3 a teoria da precificação de ponta. Como pôde ser observado, desde que não haja o problema da inversão de ponta (shifting peak), (BOITEUX, 1960) e (STEINER, 1957) demonstram que a precificação eficiente ocorre a partir da aplicação do custo marginal de expansão somado ao custo marginal de operação no curto prazo, por período, à demanda de ponta. Da mesma forma, demonstram que à demanda de fora ponta deve ser aplicado apenas o custo marginal de operação no curto prazo, também por período. 


\section{A Metodologia de Estrutura Tarifária Atualmente Praticada no Brasil}

O principal objetivo deste capítulo é analisar a metodologia empregada na construção da atual estrutura tarifária de precificação do uso da distribuição de energia. Esta análise, por sua vez, não terá por principal diretriz a descrição normativa dos processos, mas $\operatorname{sim}$ a observação dos fundamentos utilizados para a diferenciação da tarifa de uso aos consumidores referente à parcela $\mathrm{B}$.

O chamado "Livro Verde" (DNAEE, 1985), bem como os relatórios técnicos do PRT-DNAEE (DNAEE, 1994), são os documentos de referência metodológica para a construção da atual estrutura tarifária vigente no Brasil. Neste sentido, serão considerados estes documentos como referências principais para a descrição da metodologia. Contudo, o que se apresentará aqui é uma interpretação analítica própria do autor sobre os equacionamentos e formulações.

Assim, alguns conceitos encontrados nestas referências foram reinterpretados ou reformulados de maneira que houvesse maior consistência teórica e matemática. Estas reinterpretações, contudo, foram cuidadosamente avaliadas, de maneira que o resultado final fosse rigorosamente o mesmo obtido pela ferramenta computacional que implementa a metodologia desenvolvida (Tardist).

Conforme descrito no item 1.5, a principal variável responsável pela diferenciação de preços aos consumidores na atual metodologia de estrutura tarifária é o chamado custo de capacidade. A partir de seu cálculo, são obtidas a denominada receita de referência, e as conseqüentes tarifas de referência, que constituem a estrutura tarifária por nível de tensão e por posto horário.

\subsection{Cálculo dos custos de capacidade}

Para o cálculo dos chamados custos de capacidade, considera-se inicialmente que o sistema elétrico de distribuição pode ser representado por um diagrama simplificado, composto por transformações típicas entre níveis de tensão, 
denominadas redes-tipo, e por consumidores típicos conectados aos respectivos níveis de tensão, denominados consumidores-tipo.

As informações relacionadas às redes e consumidores típicos referem-se aos perfis horários, em base diária, de cada um destes elementos. Por exemplo, o sistema elétrico pode ser composto por dezenas de tipos de consumidores e dezenas de tipos de transformações, ou redes, entre níveis de tensão.

O processo de determinação destes perfis típicos de uso da energia, em base diária, consiste na chamada "Caracterização da Carga" (DNAEE, 1985). Neste processo, amostras de consumidores e transformadores são medidas, em vários níveis de tensão, durante algumas semanas. A partir das curvas de carga individuais de cada consumidor e de cada transformador, ou rede, utilizam-se métodos de classificação para o agrupamento de perfis semelhantes.

Consideraremos aqui que cada consumidor-tipo e cada rede-tipo, existentes no diagrama simplificado, representam, com significância estatística aceitável, os perfis de carga encontrados na população de consumidores e redes existentes no sistema. Não fará parte da presente análise o detalhamento do processo de "Caracterização da Carga" (DNAEE, 1985).

Considere-se, então, a representação de um sistema de distribuição a partir de um diagrama simplificado de três níveis de tensão (Figura 23), por exemplo os níveis AT (alta tensão), MT (média tensão) e BT (baixa tensão). Nesta representação, os elementos B1, B2, B3 e B4 representam perfis típicos de consumo no nível de baixa tensão, assim como os elementos M1, M2, M3 são perfis típicos para a média tensão e os elementos A1 e A2 para a alta tensão. Supõe-se aqui que os perfis agregados em cada nível representem a curva agregada de consumo do nível de tensão.

Os elementos 11 e 12 representam as injeções nos níveis de alta e média tensão, respectivamente. Os elementos T1, T2, T3, T4 e T5 representam os perfis típicos de subestações de transformação entre níveis. Da mesma forma que para os consumidores, supõe-se que os perfis agregados de transformação representem a curva agregada de transformação entre níveis.

Cada elemento, seja consumidor típico, transformação típica ou injeção de energia (fronteira do sistema com outras redes) tem associado a si um formato típico, suposto representativo, de uso diário de energia, ou seja, uma curva de carga típica de 24 pontos. 


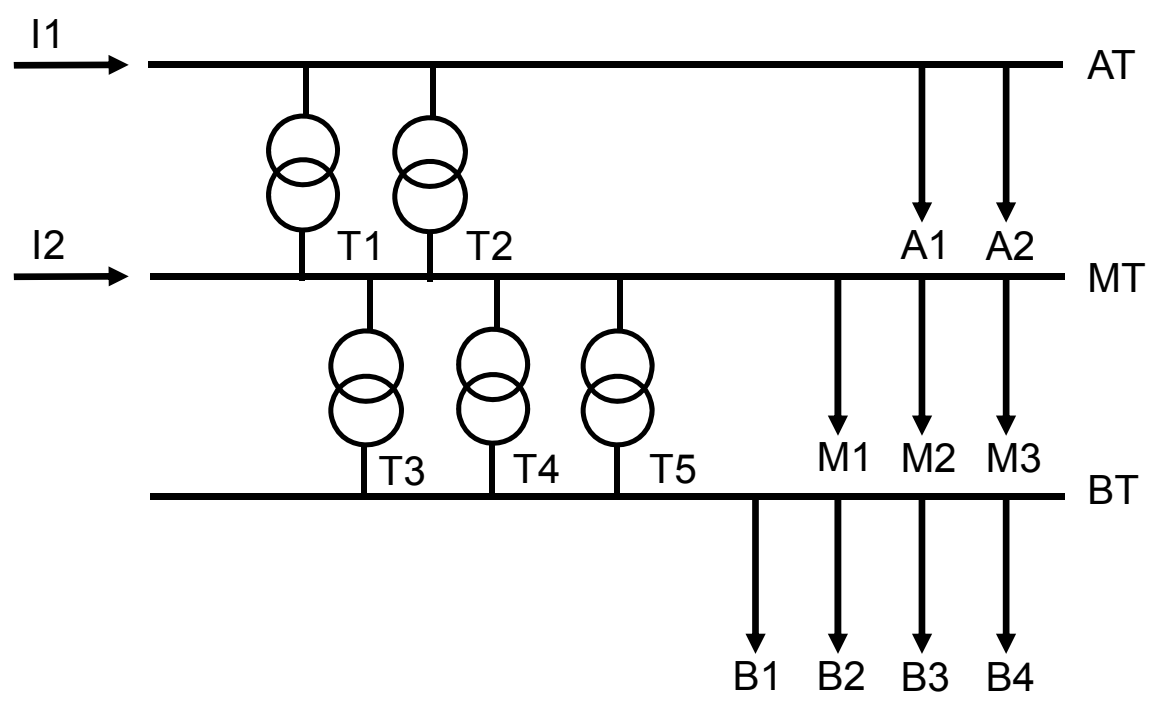

Figura 23 - Representação simplificada de um sistema de distribuição com três níveis de tensão

A problemática a ser solucionada envolve o seguinte raciocínio: o sistema de distribuição é dimensionado para atender à demanda máxima agregada em seus elementos, tais como redes e transformadores. Sendo assim, a demanda máxima observada em um destes elementos é de interesse fundamental, pois é esta demanda máxima que promove a necessidade de expansão.

A pergunta que a metodologia atual se propõe a responder é a seguinte: dado que a forma de consumo da energia dos consumidores afeta diretamente a curva de carga dos elementos do sistema, como responsabilizar estes consumidores típicos pela formação das pontas observadas no sistema?

A questão será respondida através da formulação do problema, qual seja, a identificação das responsabilidades dos consumidores na formação das pontas observadas nas curvas de carga dos elementos do sistema, representados pelas tipologias de redes (no exemplo, T1, T2, T3, T4 e T5).

\subsubsection{Custos marginais de expansão}

Os custos marginais de expansão são essenciais na determinação da estrutura tarifária brasileira, uma vez que, como será demonstrado, são eles os principais 
responsáveis pela chamada "Estrutura Vertical", que é a relação de preços entre os níveis de tensão.

Conforme definido no item 3.1, os custos marginais de expansão representam a variação dos custos de capital associados ao aumento de capacidade para uma variação de $1 \mathrm{~kW}$ na demanda máxima (ponta) do sistema elétrico em questão.

Em (ANTUNES, 2004), são discutidas metodologias de cálculo do custo marginal de expansão, segundo diversos enfoques. Pode-se dizer que existem, basicamente, duas metodologias empregadas na estimação dos custos marginais de expansão do sistema, quais sejam, a Lei de Quantidade de Obras (LQO) e o Custo Incremental Médio de Longo Prazo (CIMLP), ambas descritas em (DNAEE, 1985).

De forma bastante resumida, mesmo porque o objetivo deste texto não é aprofundar a questão, a Lei de Quantidade de Obras busca relações entre dados de uma série histórica de quantidades de equipamentos instalados frente à demanda máxima atendida pela distribuidora. Através de uma regressão por mínimos quadrados, é estimada uma equação do tipo observado em (20).

$Q(t)=k \cdot D_{\max }(t)^{\alpha}$

Onde:

$Q(t): \quad$ Quantidade de equipamentos de um determinado tipo, em $t$.

$D_{\max }(t): \quad$ Demanda máxima atendida pela distribuidora, em $\mathrm{t}$.

$\mathrm{Na}$ expressão (20), $\alpha$ e $k$ são variáveis determinadas ao solucionar-se o problema de minimização de erros quadráticos das estimativas, conhecidas como variáveis de ajuste da função de quantidade de obras.

A partir do conhecimento de um custo unitário destas quantidades estimadas, tem-se uma estimativa do custo total de determinado tipo de ativo em função da demanda máxima atendida pela distribuidora. Sabe-se que a derivada desta função custo total em relação à demanda máxima resultará no custo marginal de expansão 
para cada tipo de ativo. Por fim, a soma dos custos marginais de todos os ativos considerados resultará no custo marginal da expansão.

Por sua vez, e também de forma bastante resumida, a metodologia do Custo Incremental Médio de Longo Prazo (CIMLP) trabalha com previsões de investimentos futuros frente a previsões de variações de demandas máximas futuras por um período pré-estabelecido. Todos os investimentos considerados devem ser exclusivamente relacionados à expansão de ativos elétricos.

A Figura 24 ilustra o conceito do fluxo de investimentos e acréscimos de demanda projetados para um horizonte $n$ qualquer.

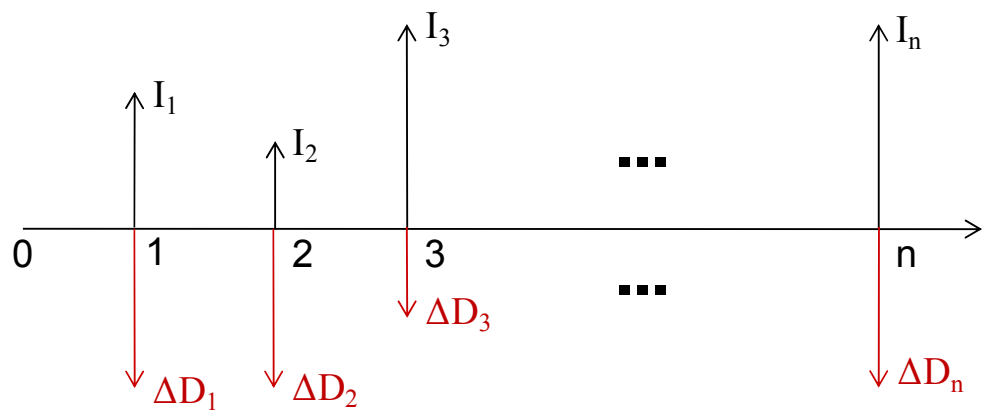

Figura 24 - Previsão de investimentos em expansão $\left(I_{i}\right)$ e de variações de demandas máximas $\left(\Delta D_{i}\right)$

Como o quociente entre os investimentos e as variações de demanda projetados é diferente para cada ano considerado, faz-se necessário definir um Custo Médio Incremental, de tal forma que a sua aplicação às variações de demanda em cada período resulte em um fluxo de investimentos, a valor presente, equivalente ao fluxo real de investimentos, também a valor presente.

Desta forma, retomando a definição do CIMLP dado pela Equação (14), na qual $i$ representa a taxa de atualização do capital.

$\operatorname{CIMLP}=\frac{\sum_{k=1}^{n} I_{k}(1+i)^{-k}}{\sum_{k=1}^{n} \Delta D_{k}(1+i)^{-k}}$ 
O custo incremental procura ser um substituto (proxy) para o custo marginal de expansão, uma vez que as variações no custo da capacidade de um sistema de distribuição, anualmente, são bastante discretas.

Uma questão bastante relevante em ambas as metodologias aqui descritas, é que os custos marginais ou incrementais de expansão são calculados por nível de tensão. Deste modo, é possível, de imediato, estabelecer uma estrutura vertical de custos marginais (por nível de tensão), independentemente de qualquer outra informação.

De todo modo, considera-se aqui que os custos marginais de expansão, relacionados à variação do custo de capacidade em relação a um acréscimo de $1 \mathrm{~kW}$ de demanda de potência no sistema, são obtidos por alguma destas metodologias atualmente utilizadas, ou mesmo por outra, desde que o conceito esteja relacionado ao custo da expansão das redes.

\subsubsection{O coeficiente técnico de atendimento - CTA}

O Coeficiente Técnico de Atendimento - CTA é uma variável bastante simples, mas não menos importante no processo de cálculo da atual metodologia de estrutura tarifária. O uso do CTA se faz necessário quando existem injeções de energia em níveis de tensão mais baixos que os níveis de tensão da fronteira da distribuidora, ou ainda, quando um determinado nível de tensão está relacionado com dois ou mais níveis à montante, através de transformadores de potência.

Especificamente, para casos em que há injeção de energia em níveis de tensões inferiores, o objetivo do CTA é impedir que todo o custo marginal dos níveis à montante do nível de atendimento de determinado consumidor lhe seja passado, no caso da existência de uma parcela de potência que o alimenta em seu próprio nível de tensão. Para ilustrar o conceito do CTA, considere o exemplo da Figura 25. 


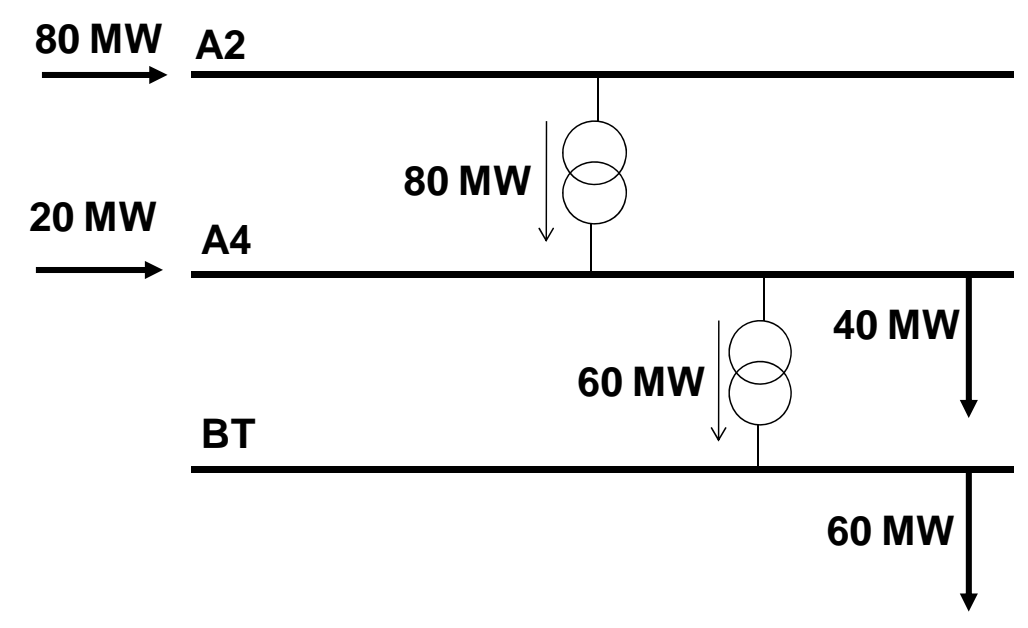

Figura 25 - Exemplo de diagrama de fluxo simplificado para a determinação do CTA

O diagrama exemplificado na Figura 25, teoricamente, deve representar as potências instantâneas para o horário de máxima solicitação do sistema elétrico em questão, no qual a carga agregada do sistema é máxima. Neste diagrama, todas as perdas referentes às transformações e redes são somadas às cargas do nível de tensão imediatamente à jusante, de tal modo a obter um diagrama de fluxo de potência líquido (demandas injetadas iguais às demandas consumidas).

Considere o nível BT do diagrama. Como os $60 \mathrm{MW}$ consumidos por este nível são integralmente provenientes do nível A4, o CTA de atendimento do nível BT pelo nível A4 é de $100 \%$. Já o CTA de atendimento do nível A4 pelo nível A2 é de $80 \%$, pois dos $100 \mathrm{MW}$ consumidos no nível A4, apenas $80 \mathrm{MW}$ são provenientes do nível A2.

Da mesma forma, o CTA de atendimento do nível BT pelo nível A2 é obtido através de duas parcelas, já que existe um nível de tensão intermediário (A4). A primeira parcela se refere ao atendimento direto do nível BT pelo nível $A 2$, no exemplo da Figura 25, igual a zero. A segunda parcela é composta pela multiplicação do CTA do nível $B T$ pelo nível $A 4$ e do CTA do nível $A 4$ pelo nível $A 2$, o que resulta em um CTA de atendimento do nível BT pelo nível A2 de $80 \%$.

Formalmente, a Equação (21) define o CTA de um consumidor $j$, conectado em seu nível de tensão, por um nível de tensão $\varepsilon$ qualquer à montante do nível de conexão do consumidor, lembrando que podem existir níveis intermediários entre $\varepsilon$ e $j$. 
$C T A_{j}^{\varepsilon}=\frac{P_{j}^{\varepsilon}}{P_{j}}+\sum_{\begin{array}{c}i \in \text { Níveis } \\ \text { intermediários }\end{array}} C T A_{j}^{i} \cdot C T A_{i}^{\varepsilon}$

Onde:

$P_{j}^{\varepsilon}$ : $\quad$ Potência ativa direta, transferida entre um nível de tensão $\varepsilon$ e o nível de tensão ao qual se conecta o consumidor $j$.

$P_{j}$ : $\quad$ Potência ativa total que atende o nível de tensão ao qual se conecta o consumidor $j$.

CTA $A_{j}^{i}$ : CTA de atendimento do nível ao qual se conecta $j$ pelo nível intermediário $i$.

$\quad C T A_{i}^{\varepsilon}: \quad \quad \quad \quad$ CTA de atendimento do nível intermediário $i$ pelo nível $\varepsilon$.

É importante lembrar que o CTA de atendimento de um consumidor $j$ pelo seu próprio nível de tensão é, por definição, 1. Ou seja, para um consumidor conectado, por exemplo, em baixa tensão, o CTA de atendimento deste consumidor pela baixa tensão é 1 .

\subsubsection{As probabilidades de associação}

Partindo-se da constatação de que as tipologias de clientes e redes, conforme representação simplificada do sistema, foram obtidas de forma dissociada, ou seja, sem que se saiba quais redes alimentam quais consumidores, faz-se necessário solucionar o problema das associações entre redes e clientes como uma primeira abordagem ao problema das responsabilidades.

Para tal, considere-se o diagrama apresentado na Figura 26. Neste diagrama são apresentadas as variáveis $\alpha$ (redes) e $\gamma$ (consumidores). Esta variáveis são definidas como as proporções de mercado, em energia, associadas a cada tipologia, ou também como as probabilidades de existência destas tipologias no sistema. 
Por exemplo, considere-se, na Figura 26, que $\alpha_{1}$ e $\alpha_{2}$ sejam, respectivamente, $30 \%$ e $70 \%$. Poder-se-ia afirmar, então, que a tipologia $T 1$ representa $30 \%$ de toda a energia que trafega entre os níveis $N 2$ e $N 1$. Da mesma forma, poder-se-ia afirmar que, dada uma quantidade de energia, a probabilidade de encontrá-la sob a forma da tipologia $T 1$ no sistema é de $30 \%$.

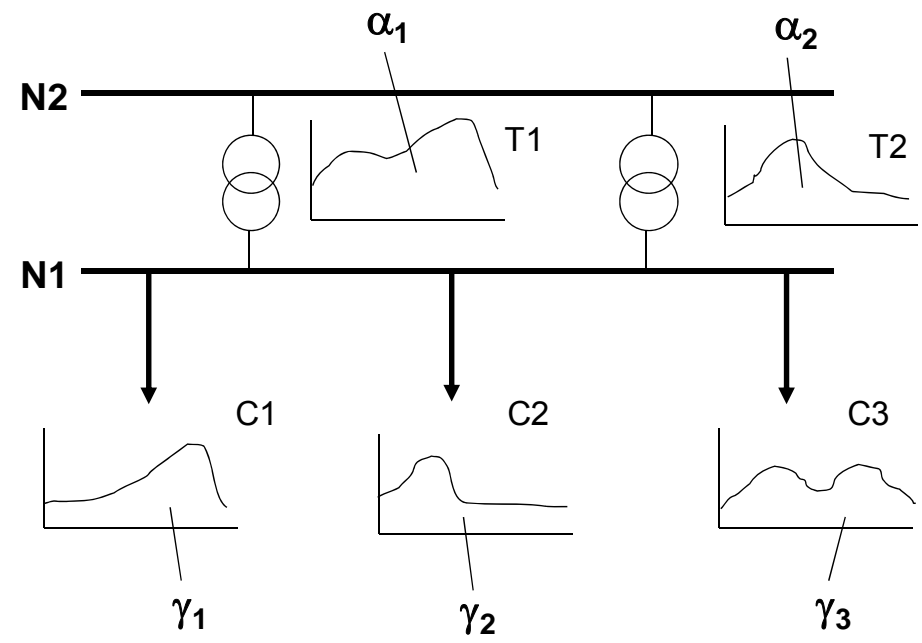

Figura 26 - Diagrama contendo as curvas de consumidores-tipo e redes-tipo

Resumidamente, pode-se escrever $\alpha_{i}=P\left(T_{i}\right)$, e $\gamma_{j}=P\left(C_{j}\right)$. Desta forma, a somatória das probabilidades de existência das redes-tipo e dos consumidores-tipo deve ser igual a 1 , ou, respectivamente, $\sum_{i} P\left(T_{i}\right)=1$ e $\sum_{j} P\left(C_{j}\right)=1$.

Define-se também a probabilidade de associação de um consumidor-tipo de índice $j$ com uma rede-tipo de índice $i$. Esta probabilidade é denominada $\pi_{j i}$, e representa a probabilidade condicionada de uma rede-tipo $i$ existir, dado que o consumidor-tipo $j$ existe. A Figura 27 ilustra a interpretação desta variável. 


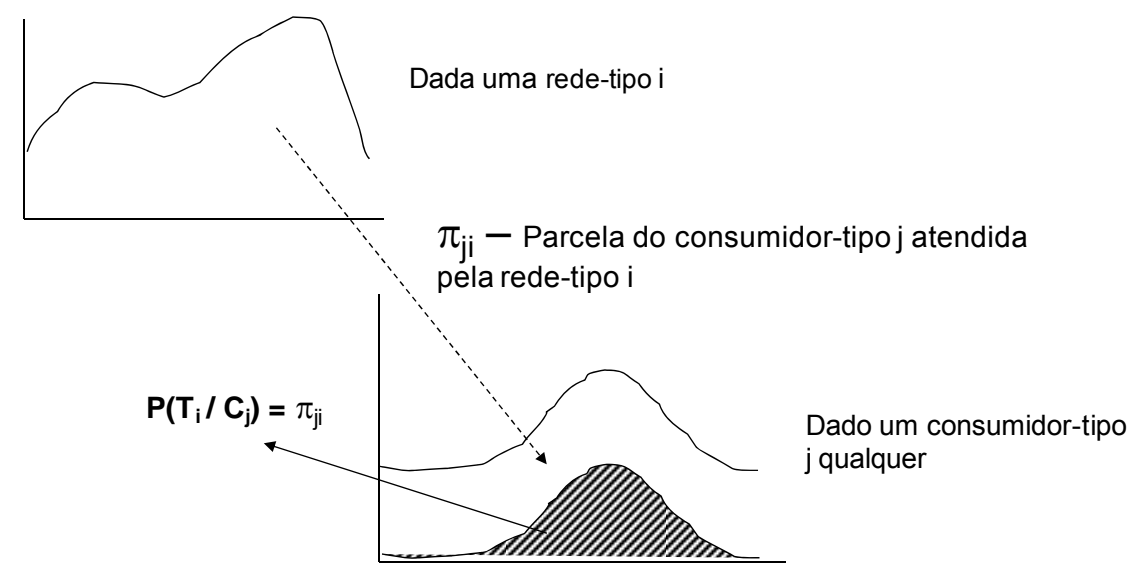

Figura 27 - Probabilidade de associação $\pi_{j i}$

Esta probabilidade condicionada, $P\left(T_{i} / C_{j}\right)=\pi_{j i}$, pode ser interpretada, observando-se a Figura 27, como a parcela do consumidor-tipo $j$ que é atendida pela rede-tipo $i$. É interessante notar que a parcela do consumidor $j$ apresenta perfil idêntico ao da curva deste consumidor-tipo, o que torna-se aqui uma hipótese.

Da mesma forma, define-se como $P\left(C_{j} / T_{i}\right)=\beta_{i j}$ a probabilidade condicionada do consumidor-tipo $j$ existir, dado que a rede-tipo $i$ existe. Esta probabilidade condicionada também pode ser interpretada como a parcela da rede-tipo $i$ que atende ao consumidor-tipo $j$, conforme ilustra a Figura 28.

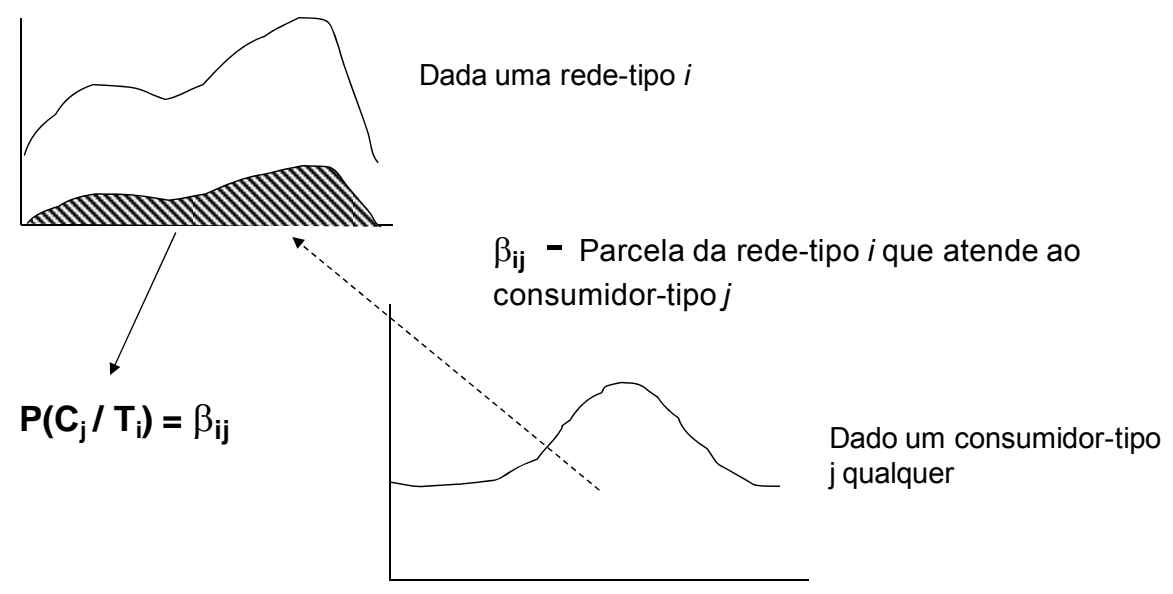

Figura 28 - Probabilidades de associação $\beta_{i j}$

Para a compreensão das relações entre as variáveis $\pi_{j i}, \beta_{i j}, \alpha_{i}$ e $\gamma_{j}$, consulte o ANEXO III. 
A formulação do problema matemático para a determinação das variáveis $\pi_{j i} \mathrm{e}$ $\beta_{i j}$ será necessariamente numérica, a partir da minimização de erros quadráticos entre estimativas e valores observados das curvas de carga típicas das redes-tipo.

Para compreender esse processo, lança-se mão da determinação das variáveis $\pi_{j i}$ pelo chamado "Método Direto" (DNAEE, 1994). Para tanto, considere-se um caso exemplo com a existência de três consumidores-tipo atendidos por uma rede-tipo, conforme Figura 29.

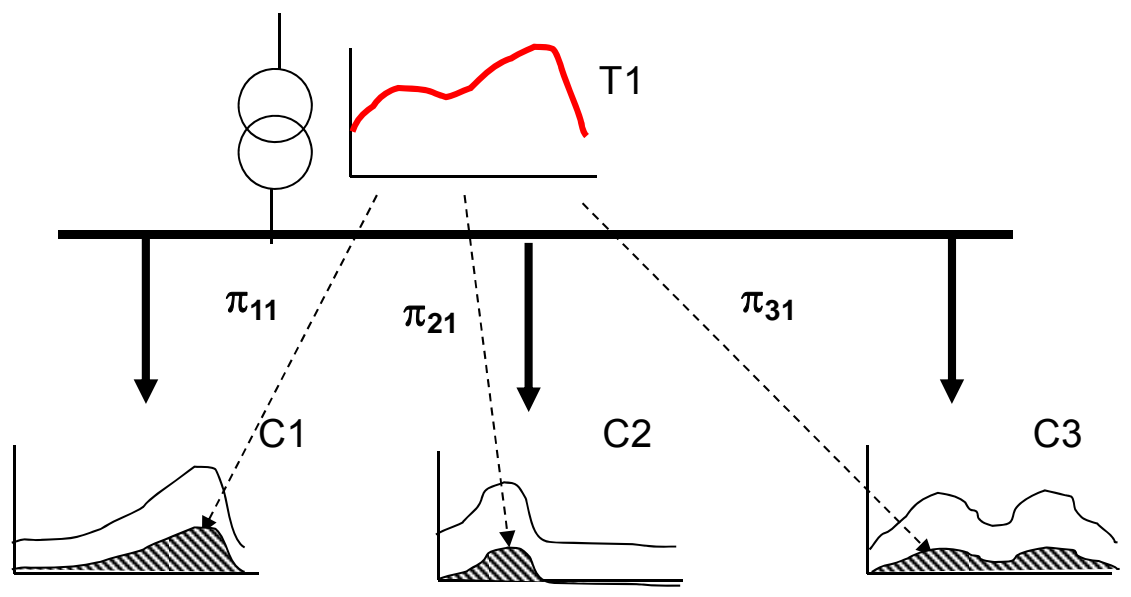

Figura 29 - Caso exemplo, com três consumidores-tipo atendidos por uma rede-tipo

Como cada elemento $\pi_{j i}$ representa a parcela de um consumidor-tipo $j$ qualquer atendido por uma rede-tipo $i$ qualquer, pode-se concluir que a rede-tipo $i$ é formada por todas as parcelas de consumidores-tipo presentes no sistema. Como as tipologias contém, em geral, 24 pontos (intervalos de 1h), pode-se escrever a Equação (22) para cada ponto $t$ em um determinado nível de tensão.

$T_{1}(t)=\pi_{11} \cdot C_{1}(t)+\pi_{21} \cdot C_{2}(t)+\pi_{31} \cdot C_{3}(t)+\varepsilon_{1}(t)$

Desta forma, a Equação (22) descreve a tipologia de rede-tipo $T_{i}(t)$, em kW, como sendo uma combinação linear de parcelas de consumidores-tipo atendidos por esta rede. Como a combinação linear dos consumidores-tipo é uma estimativa, faz-se necessária a consideração de uma parcela de erro $\varepsilon_{1}(\mathrm{t})$ para cada instante $t$ considerado. A Figura 30 ilustra a representação gráfica de $\varepsilon_{1}(\mathrm{t})$. 


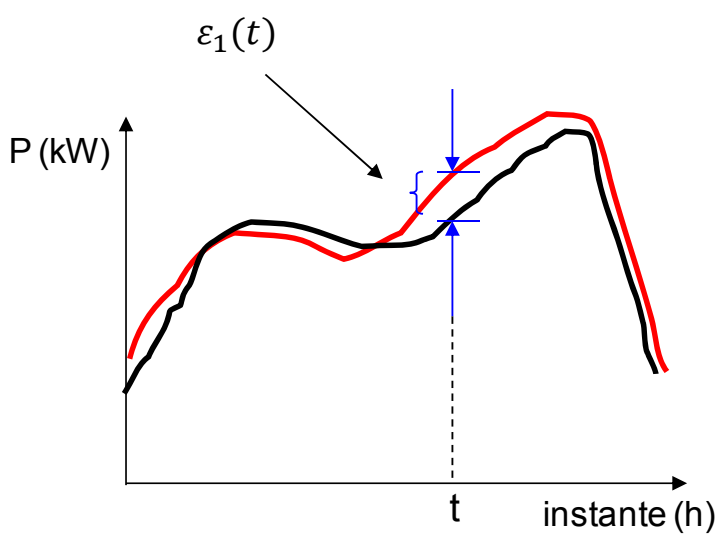

Figura 30 - Representação gráfica do erro $\varepsilon_{1}(t)$

Genericamente, para qualquer número de consumidores-tipo, pode-se escrever:

$T_{i}(t)=\sum_{j} \pi_{j i} \cdot C_{j}(t)+\varepsilon_{i}(t)$

Conseqüentemente, a determinação das variáveis $\pi_{j i}$ será realizada através de um problema de minimização de erros quadráticos, considerando a soma dos erros $\varepsilon_{i}(t)$ em todos os instantes considerados (no caso, 24) e para todas as redes-tipo. Em (24) observa-se a formulação deste problema de otimização.

$\min \left\{\sum_{i} \sum_{t} \varepsilon_{i}(t)^{2}\right\}=\min \left\{\sum_{i} \sum_{t}\left[T_{i}(t)-\sum_{j} \pi_{j i} \cdot C_{j}(t)\right]^{2}\right\}$

Sujeito a:

$\sum_{i} \pi_{j i}=1 \forall j$

$\pi_{j i} \geq 0 \quad \forall j \forall i$ 
Nesta formulação, observa-se a restrição $\sum_{i} \pi_{j i}=1$ como uma condição necessária, uma vez que a somatória das parcelas de cada consumidor-tipo $j$ alimentadas por todas as redes-tipo $i$ deve ser igual a 1, por definição.

Como já mencionado, a solução do problema pelo "Método Direto" considera que a unidade dos vetores $C_{j}(t)$ e $T_{i}(t)$ é o $\mathrm{kW}$. Desta forma, por princípio, deve haver equilíbrio energético entre a energia total das redes-tipo e a energia total dos consumidores-tipo.

Matematicamente, considera-se como condição primária para a solução do problema formulado em (24), em um determinado nível de tensão, a igualdade (25).

$$
\sum_{t} \sum_{j} C_{j}(t)=\sum_{t} \sum_{i} T_{i}(t)
$$

Esta igualdade garante o balanço energético entre redes e consumidores em um dado nível de tensão. Para que este balanço seja possível, as perdas totais, técnicas e não técnicas, devem estar consideradas nos vetores $C_{j}(t)$, distribuídas entre os consumidores-tipo de forma proporcional à variável $\gamma_{j}$ de cada consumidor.

Um forma alternativa para a determinação das variáveis $\pi_{j i}$ é a chamada solução pelo "Método Indireto" (DNAEE, 1994). Nesta solução, não há necessidade de garantir a igualdade em (25), pois todas as tipologias, tanto de consumidores como de redes, são convertidas em tipologias por unidade da demanda média (p.u. da demanda média).

As equações (26) e (27) demonstram as transformações algébricas para a obtenção das tipologias em p.u. da demanda média.

$$
\begin{aligned}
& t_{i}(t)=\frac{T_{i}(t)}{\left[\sum_{1}^{24} T_{i}(t)\right] / 24} \\
& c_{j}(t)=\frac{C_{j}(t)}{\left[\sum_{1}^{24} C_{j}(t)\right] / 24}
\end{aligned}
$$


Desta forma, retomando-se as Equações (23), (26) e (27), e utilizando-se da transformação algébrica apresentada na Equação (28), é possível determinar a igualdade em (29).

$\frac{T_{i}(t)}{\left[\sum_{1}^{24} T_{i}(t)\right] / 24}=\frac{\sum_{j} \pi_{j i} \cdot C_{j}(t)}{\left[\sum_{1}^{24} T_{i}(t)\right] / 24} \cdot \frac{\left[\sum_{1}^{24} \pi_{j i} \cdot C_{j}(t)\right] / 24}{\left[\sum_{1}^{24} \pi_{j i} \cdot C_{j}(t)\right] / 24}+\varepsilon_{i}(t)$

$t_{i}(t)=\sum_{j} \beta_{i j} \cdot c_{j}(t)+\varepsilon_{i}(t)$

É importante observar que o termo $\beta_{i j}$ surge na Equação (29) pela sua própria definição, ou seja, $\beta_{i j}$ é a parcela da rede-tipo $i$ que atende ao consumidor-tipo $j$. Esta parcela é dada pela expressão em (30), conforme foi apresentado na Figura 28.

$\beta_{i j}=\frac{\left[\sum_{1}^{24} \pi_{j i} \cdot C_{j}(t)\right]}{\left[\sum_{1}^{24} T_{i}(t)\right]}$

Finalmente, o enunciado do problema pelo chamado "Método Indireto" se dará segundo a formulação em (31). Apresentada a determinação das variáveis $\beta_{i j}$, é possível determinar indiretamente as variáveis $\pi_{j i}$ a partir das relações apresentadas no ANEXO III.

$\min \left\{\sum_{i} \sum_{t} \varepsilon_{i}(t)^{2}\right\}=\min \left\{\sum_{i} \sum_{t}\left[t_{i}(t)-\sum_{i} \beta_{i j} \cdot c_{j}(t)\right]^{2}\right.$

sujeito a

$\sum_{j} \beta_{i j}=1 \forall i$

$\beta_{i j} \geq 0 \forall j$ 
No ANEXO IV é demonstrado que o problema proposto em (31) pode ser expresso na forma de um equacionamento de programação quadrática com otimização convexa, o qual apresenta apenas um mínimo global.

\subsubsection{A responsabilidade de potência}

Como já mencionado, a solução do problema das probabilidades de associação, conforme descrito no item 4.1.3, é o primeiro passo para a determinação das chamadas responsabilidades de potência.

Outro conceito fundamental intimamente ligado à definição de responsabilidade de potência é o fator de contribuição de um consumidor-tipo em relação à curva de uma rede-tipo. Dada uma curva de carga qualquer de um consumidor-tipo, alimentado por uma rede-tipo, define-se o fator de contribuição deste consumidor de acordo com a Equação (32).

$$
F c_{j i}=\frac{D_{j}(T M)}{D_{j M A X}}
$$

Onde:

$D_{j}(T M)$ : Demanda do consumidor $j$ no horário de demanda máxima $(T M)$ da rede $i$ que o alimenta.

$D_{j M A X}: \quad$ Demanda máxima do consumidor $j$.

Complementarmente, a Figura 31 ilustra as demandas $\mathrm{D}_{\mathrm{j}}(\mathrm{TM})$ e $\mathrm{D}_{\mathrm{JMAX}}$ dadas as curvas de carga de um consumidor-tipo j e de uma rede-tipo i quaisquer. 


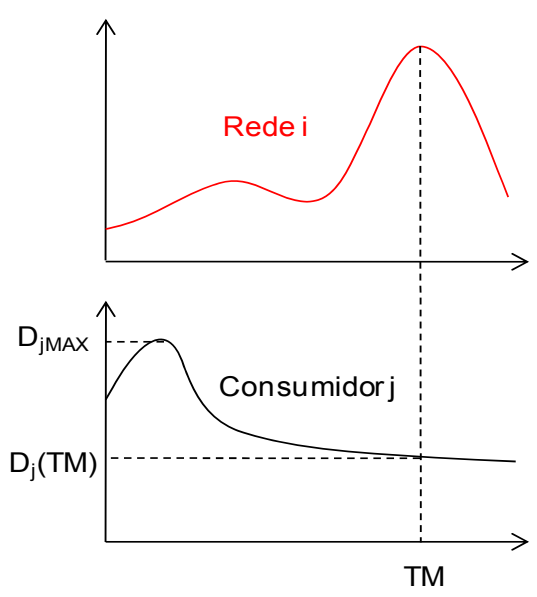

Figura 31 - Variáveis $D_{j}(T M)$ e $D_{J M A X}$ utilizadas no cálculo do fator de contribuição

Ocorre que, na metodologia atual, o número de pontas observado nas redestipo pode ser maior que um, definindo assim um conjunto de pontos $T M$. Na metodologia, o critério adotado para a definição de uma ponta é o seguinte: Qualquer demanda horária superior $90 \%$ da demanda máxima de uma curva de rede-tipo é considerada uma ponta. Deste modo, uma curva com demanda constante (fator de carga igual a 1) terá 24 pontas.

Assim, é calculado um vetor de fatores de contribuição por consumidor-tipo e por posto tarifário (ponta e fora-ponta), referente a cada rede-tipo a qual ele se associa. Em (33), é apresentada a formulação deste vetor de fatores de contribuição.

$F c_{j i}^{u}(h)=\frac{D_{j}(h)}{D_{j M A X}^{u}} \forall h \in N p_{i}$

Onde:

$F c_{j i}^{u}(h)$ : $\quad$ Fator de contribuição do consumidor $j$ na rede $i$, para o posto tarifário $u$ no instante de ponta $h$.

$D_{j}(h)$ : $\quad$ Demanda do consumidor $j$ no instante de ponta $h$.

$D_{J M A X}^{u}: \quad$ Demanda máxima do consumidor $j$ no posto tarifário $u$.

$h: \quad$ Instante em que ocorre ponta na rede $i$. 
$N p_{i}: \quad \quad \quad \quad \quad$ Número de pontas observadas na curva de carga da rede $i$.

Para melhor interpretar a Equação (33), considere o seguinte exemplo numérico, para o qual será considerado horário de ponta o intervalo entre 19 e 21 horas ( $\mathrm{Na}$ Tabela 1, em destaque). Suponha que exista uma rede-tipo $i$ com os valores horários de demanda, conforme a Tabela 1.

Tabela 1 - Dados de demanda ativa, em base horária, de uma rede-tipo $i$ qualquer

\begin{tabular}{|l|r|r|r|r|r|r|r|r|r|r|r|r|r|r|r|r|r|r|r|r|r|r|r|r|}
\hline $\mathbf{t}$ & $\mathbf{1}$ & $\mathbf{2}$ & $\mathbf{3}$ & $\mathbf{4}$ & $\mathbf{5}$ & $\mathbf{6}$ & $\mathbf{7}$ & $\mathbf{8}$ & $\mathbf{9}$ & $\mathbf{1 0}$ & $\mathbf{1 1}$ & $\mathbf{1 2}$ & $\mathbf{1 3}$ & $\mathbf{1 4}$ & $\mathbf{1 5}$ & $\mathbf{1 6}$ & $\mathbf{1 7}$ & $\mathbf{1 8}$ & $\mathbf{1 9}$ & $\mathbf{2 0}$ & $\mathbf{2 1}$ & $\mathbf{2 2}$ & $\mathbf{2 3}$ & $\mathbf{2 4}$ \\
\hline $\mathrm{D}(\mathrm{kW})$ & 10 & 12 & 15 & 20 & 22 & 25 & 27 & 26 & 20 & 15 & 12 & 10 & 10 & 12 & 13 & 15 & 24 & 26 & 27 & 23 & 15 & 10 & 10 & 10 \\
\hline
\end{tabular}

Utilizando-se do critério de definição dos instantes de ponta, conforme a metodologia atualmente empregada pela ANEEL, para a qual são consideradas pontas as demandas horárias superiores a $90 \%$ da demanda máxima da curva, obtémse a Tabela 2. Note que, através deste critério, o número de pontas $N p_{i}$ é igual a 5 , e conjunto de instantes de ponta é dado por $h=\{6,7,8,18,19\}$.

Tabela 2 - Identificação dos instantes de ponta $h$ da rede-tipo $i$

\begin{tabular}{|l|r|r|r|r|r|r|r|r|r|r|r|r|r|r|r|r|r|r|r|r|r|r|r|r|}
\hline $\mathbf{t}$ & $\mathbf{1}$ & $\mathbf{2}$ & $\mathbf{3}$ & $\mathbf{4}$ & $\mathbf{5}$ & $\mathbf{6}$ & $\mathbf{7}$ & $\mathbf{8}$ & $\mathbf{9}$ & $\mathbf{1 0}$ & $\mathbf{1 1}$ & $\mathbf{1 2}$ & $\mathbf{1 3}$ & $\mathbf{1 4}$ & $\mathbf{1 5}$ & $\mathbf{1 6}$ & $\mathbf{1 7}$ & $\mathbf{1 8}$ & 19 & 20 & 21 & $\mathbf{2 2}$ & $\mathbf{2 3}$ & $\mathbf{2 4}$ \\
\hline $\mathrm{h}$ & & & & & & 1 & 1 & 1 & & & & & & & & & & 1 & 1 & & & & & \\
\hline
\end{tabular}

Considere agora a existência de uma curva de carga de um consumidor-tipo $j$ qualquer (Tabela 3), alimentado em alguma proporção pela rede-tipo $i$, considerada na Tabela 1.

Tabela 3 - Dados de demanda ativa, em base horária, de um consumidor-tipo $j$ alimentado pela rede-tipo $i$

\begin{tabular}{|l|r|r|r|r|r|r|r|r|r|r|r|r|r|r|r|r|r|r|r|r|r|r|r|r|}
\hline $\mathbf{t}$ & $\mathbf{1}$ & $\mathbf{2}$ & $\mathbf{3}$ & $\mathbf{4}$ & $\mathbf{5}$ & $\mathbf{6}$ & $\mathbf{7}$ & $\mathbf{8}$ & $\mathbf{9}$ & $\mathbf{1 0}$ & $\mathbf{1 1}$ & $\mathbf{1 2}$ & $\mathbf{1 3}$ & $\mathbf{1 4}$ & $\mathbf{1 5}$ & $\mathbf{1 6}$ & $\mathbf{1 7}$ & $\mathbf{1 8}$ & $\mathbf{1 9}$ & $\mathbf{2 0}$ & $\mathbf{2 1}$ & $\mathbf{2 2}$ & $\mathbf{2 3}$ & $\mathbf{2 4}$ \\
\hline $\mathrm{D}(\mathrm{kW})$ & 5 & 5 & 3 & 3 & 2 & 1 & 1 & 3 & 5 & 8 & 5 & 4 & 4 & 3 & 4 & 3 & 5 & 7 & 9 & 10 & 11 & 8 & 7 & 7 \\
\hline
\end{tabular}

Finalmente, o vetor de Fatores de Contribuição, $F c_{j i}^{u}(h)$, conforme definido na Equação (33), será dado pela Tabela 4. 
Tabela 4 - Vetor de Fatores de Contribuição do consumidor-tipo $j$

\begin{tabular}{|l|r|r|r|r|r|r|r|r|r|r|r|r|r|r|r|r|r|r|r|r|r|r|r|r|}
\hline $\mathbf{t}$ & $\mathbf{1}$ & $\mathbf{2}$ & $\mathbf{3}$ & $\mathbf{4}$ & $\mathbf{5}$ & $\mathbf{6}$ & $\mathbf{7}$ & $\mathbf{8}$ & $\mathbf{9}$ & $\mathbf{1 0}$ & $\mathbf{1 1}$ & $\mathbf{1 2}$ & $\mathbf{1 3}$ & $\mathbf{1 4}$ & $\mathbf{1 5}$ & $\mathbf{1 6}$ & $\mathbf{1 7}$ & $\mathbf{1 8}$ & $\mathbf{1 9}$ & $\mathbf{2 0}$ & $\mathbf{2 1}$ & $\mathbf{2 2}$ & $\mathbf{2 3}$ & $\mathbf{2 4}$ \\
\hline $\mathrm{D}(\mathrm{kW})$ & & & & & & 0,1 & 0,1 & 0,4 & & & & & & & & & & 0,9 & 0,8 & & & & & \\
\hline
\end{tabular}

Definidos os dois principais conceitos relacionados à responsabilidade de potência, quais sejam, as probabilidades de associação $\pi_{j i}$ e os vetores de Fatores de Contribuição $F c_{j i}^{u}(h)$, sua definição, dado um consumidor $j$ em um nível de tensão $\varepsilon$, no posto tarifário $u$, é dada a partir da Equação (34).

$R_{j}^{\varepsilon, u}=\left(1+\tau^{\varepsilon}\right) \cdot \sum_{i}\left[\pi_{j i} \cdot \frac{\sum_{h \in N p_{i}^{u}} F c_{j i}^{u}(h)}{N p_{i}}\right]$

Na Equação (34), segundo observado em (DNAEE, 1985), $\tau^{\varepsilon}$ representa a "[...] taxa média de perda de potência [...] acumulada desde o ponto de conexão do cliente até a origem do nível $\varepsilon$ em consideração". Embora seja intuitiva a necessidade de consideração de uma taxa de perdas acumulada desde a origem do nível $\varepsilon$ até o ponto de conexão dos consumidores, é de difícil compreensão a definição de uma "taxa média de perdas de potência".

No capítulo 6 será rediscutida e reavaliada a questão de um índice de perdas acumuladas a ser considerado na estrutura tarifária entre níveis de tensão. Por hora, objetiva-se a compreensão fundamental da diferenciação de preços aos consumidores na atual metodologia, obtida pela responsabilidade de potência, e relacionada aos outros termos da Equação (34), ou seja, $\pi_{j i}$ e $F c_{j i}^{u}(h)$.

A partir das "Responsabilidades de Potência", definem-se os chamados custos de capacidade a partir da Equação (35).

$\operatorname{Ccap}_{j}^{\varepsilon, u}=R_{j}^{\varepsilon, u} \cdot C m g_{\text {exp }}^{\varepsilon} \cdot C T A_{j}^{\varepsilon}$ 
Onde:

$\operatorname{Ccap}_{j}^{\varepsilon, u}: \quad$ Custo de capacidade de um consumidor $j$ no nível de tensão $\varepsilon$, no posto tarifário $u$.

$C m g_{\text {exp }}^{\varepsilon}: \quad$ Custo marginal de expansão do nível de tensão $\varepsilon$, em $R \$ / k W$.ano.

$C T A_{j}^{\varepsilon}$ : $\quad$ Coeficiente técnico de atendimento do consumidor $j$ a partir do nível de tensão $\varepsilon$.

O custo de capacidade de um consumidor-tipo $j$ em todo o sistema, no posto tarifário $u$, será a soma dos seus custos de capacidade em todos os níveis de tensão à montante do seu ponto de conexão. A Equação (36) define o custo de capacidade total de um consumidor $j$ no posto tarifário $u$.

$\operatorname{Ccap}_{j}^{u}=\sum_{\varepsilon} \operatorname{Ccap}_{j}^{\varepsilon, u} \forall \varepsilon$ a montante de $j$

Como as tarifas não são aplicadas a cada consumidor-tipo, mas sim a todo um conjunto de consumidores, utiliza-se de um mecanismo para calcular um custo médio equivalente por nível de tensão, também denominado custo de capacidade por nível de tensão. A Equação (37) descreve a construção deste custo de capacidade médio.

$\operatorname{Ccap}_{\varepsilon}^{u}=\frac{\sum_{\forall j \in \varepsilon} \operatorname{Ccap}_{j}^{u} \cdot D_{j}^{u}}{D_{\text {agregada }}^{\varepsilon, u} \forall j}$

Onde:

$D_{j}^{u}: \quad$ Demanda máxima do consumidor $j$ no ponto tarifário $u$.

$D_{\text {agregada }}^{\varepsilon, u}$ Demanda máxima agregada de todos os consumidores conectados ao nível $\varepsilon$, no posto tarifário $u$. 
Em (37) determina-se, para cada nível de tensão, e para cada posto tarifário (ponta e fora-ponta), um custo de capacidade médio. Esta matriz de custos, contendo dois valores por nível de tensão, é a responsável pela chamada "estrutura vertical" da tarifa, que é a relação de preços entre níveis de tensão. Basicamente, a estrutura tarifária da tarifa de uso do sistemas de distribuição brasileiros é resultado direto do cálculo destes custos de capacidade médios. 


\section{Análise Crítica da Metodologia Atual}

A metodologia de estrutura tarifária descrita no capítulo 4, responsável pela diferenciação de preços entre níveis de tensão, entre tipos de consumidores em um mesmo nível, e até mesmo entre postos tarifários, é baseada fundamentalmente em duas variáveis. São elas: a probabilidade de associação de um consumidor-tipo com uma rede-tipo e os fatores de contribuição deste consumidor nos horários em que há pontas nas rede-tipo.

A partir da Equação (36), verifica-se que os custos de capacidade de um consumidor são cumulativos desde o nível em que ele se conecta ao sistema até os níveis de tensão mais elevados. Isto é consistente com o sistema de transporte da energia, já que uma variação marginal de demanda deste consumidor causará uma variação marginal de demanda em todos os níveis à montante de seu ponto de conexão.

Entretanto, o custo de capacidade de um consumidor em um mesmo nível de tensão é resultado direto de sua responsabilidade de potência, como pode ser observado na Equação (35). É esse mecanismo de diferenciação de preços que será abortado com maior detalhes neste item.

Para analisar a essência desta diferenciação de preços, serão consideradas, separadamente, análises concernentes aos conceitos isolados das probabilidades de associação e do fator de contribuição, desprezando-se neste momento as taxas de perdas de potência.

Nos dois primeiros ciclos de revisão tarifária das empresas de distribuição nacionais, sabe-se que o órgão regulador não aplicou diretamente as diferenciações de preços obtidas através da metodologia às classes do nível de baixa tensão. Calculou-se, na verdade, uma tarifa média para a baixa tensão, conforme descrito na Equação (37), a qual foi atribuída à classe residencial (B1). As diferenciações de preços entre as classe B1 e as classes B2 (rural), B3 (comercial e industrial) e B4 (iluminação pública) foram obtidas através das relações existentes nas tarifas homologadas no anexo II do contrato de concessão das distribuidoras.

No entanto, pressupõe-se que a diferenciação de preços entre estas classes, existente no contrato de concessão, originou-se no mecanismo da presente metodologia, conforme o exemplo descrito neste item. 


\subsection{As probabilidades de associação}

Como discutido no item 4.1.3, de forma bastante resumida, o problema das associações entre consumidores e redes pode ser observado através da Figura 32. Neste exemplo, três consumidores-tipo são alimentados por duas redes-tipo, constituindo-se seis variáveis de associação entre redes e consumidores.

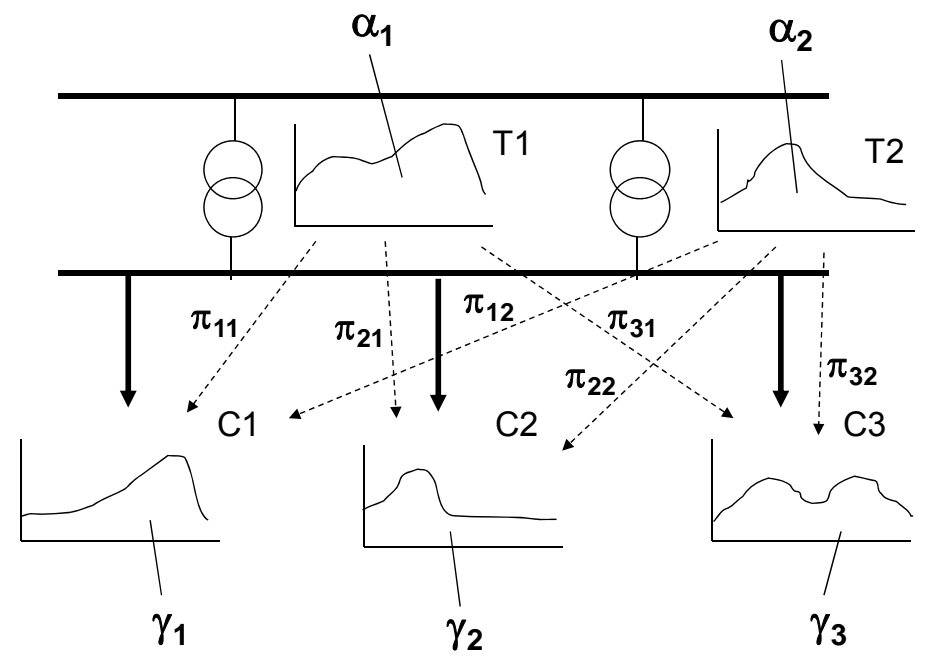

Figura 32 - Representação gráfica do problema de associações entre consumidores e redes

A determinação das probabilidades de associação é obtida através da solução de um problema de minimização de erros quadráticos, definidos pelas diferenças horárias entre os valores estimados e reais das curvas das rede-tipo. O sistema de equações (38) elucida a formulação do problema de otimização pelo chamado "Método Direto".

$\operatorname{Min}_{e m \forall \pi_{j i}}\left(\sum_{1}^{24}\left(\varepsilon_{1 t}\right)^{2}+\left(\varepsilon_{2 t}\right)^{2}\right)$

Sendo

$T_{1 t}=\pi_{11} \cdot C_{1 t}+\pi_{21} \cdot C_{2 t}+\pi_{31} \cdot C_{3 t}+\varepsilon_{1 t}$

$T_{2 t}=\pi_{12} \cdot C_{1 t}+\pi_{22} \cdot C_{2 t}+\pi_{32} \cdot C_{3 t}+\varepsilon_{2 t}$

Sujeito a

$\pi_{11}+\pi_{12}=1$

$\pi_{21}+\pi_{22}=1$

$\pi_{31}+\pi_{32}=1$ 
As probabilidades de associação podem também ser interpretadas como as derivadas parciais dos incrementos de potência das redes, dados os incrementos de potência nas cargas, uma vez que as curvas das redes são especificadas por combinações lineares das cargas. Por exemplo, quando $\pi_{11}$ for igual a 0,5 , pode-se entender que um aumento incremental de potência de $1 \mathrm{~kW}$ por parte do consumidor $C_{1}$ resultará em um aumento incremental de $0,5 \mathrm{~kW}$ na rede $T_{1}$.

Uma questão bastante relevante a ser discutida está diretamente relacionada à validade da formulação ou especificação do modelo. Como pode ser observado em (38), as curvas estimadas das redes $T_{1}$ e $T_{2}$ são combinações lineares, a taxas constantes, das curvas dos consumidores $C_{1}, C_{2}$ e $C_{3}$.

Ou seja, a formulação do problema admite a hipótese de que todas as curvas de redes-tipo são formadas por combinações lineares das curvas de consumidorestipo. Tal hipótese carece de validação, que dependerá de características observáveis nos erros obtidos e também nos formatos estimados para as curvas das redes.

Um exemplo que pode ilustrar um problema de especificação na formulação apresentada em (38) pode ser observado na Figura 33. Este sistema de distribuição é formado por um alimentador, duas fontes energéticas - sendo um gerador, $G$, e uma transformação proveniente de um nível de tensão a montante, $F$ - e duas cargas, $C_{1} \mathrm{e}$ $C_{2}$.

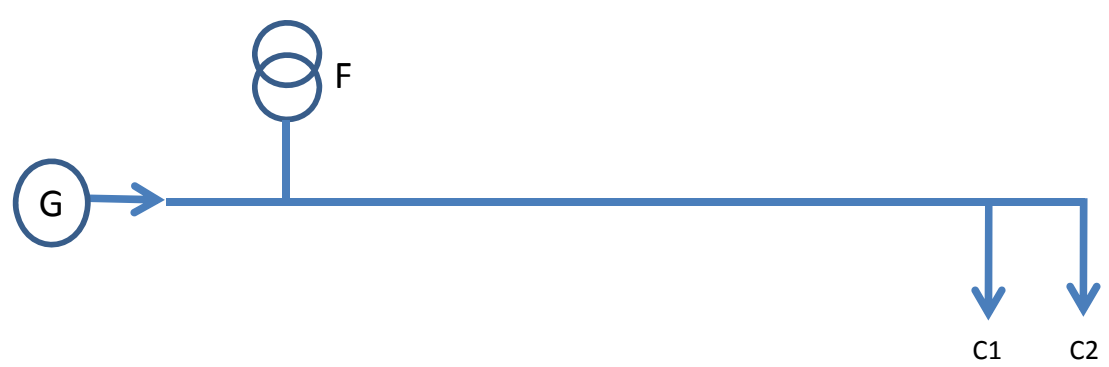

Figura 33 - Exemplo de um alimentador que atende a dois consumidores e tem duas fontes energéticas, um gerador e uma transformação de um nível a montante.

As cargas $C_{1}$ e $C_{2}$ têm associadas a si curvas de carga horárias com 24 valores de potência ativa. A geração $G$ também tem associada a si uma curva de carga de injeção de potência ativa, compatível com o modelamento matemático de um sistema de potência, no qual o ponto de geração é do tipo $P-V$, sendo os dados de entrada a tensão $V$ e a potência ativa fornecida $P$. 
Com exceção das perdas elétricas, que neste exemplo são desprezadas, a fonte $F$ é equivalente a uma barra swing, cujo modelamento em um sistema de potência é dado por uma barra do tipo $V,-\theta$, sendo dados de entrada a tensão $V$ e seu ângulo $\theta$. Para maiores detalhes sobre a modelagem matemática de sistemas de potência, consultar (KAGAN, OLIVEIRA, \& ROBBA, 2005).

De forma bastante aproximada, a curva de carga da fonte $F$ pode ser obtida, desprezando-se as perdas e a impedância do alimentador, a partir do balanço energético descrito pela simples equação $F_{t}=C_{1 t}+C_{2 t}-G_{t}$, na qual $t$ representa 0 instante da curva de carga. Os valores de potência ativa da fonte $F$ são, então, obtidos a partir das cargas e da geração $G$.

A Figura 34 apresenta as curvas de carga das fontes e cargas considerados no exemplo da Figura 33. Como as perdas e as impedâncias são desprezadas, a soma ponto-a-ponto das fontes deve ser igual à soma das cargas, indicando balanço líquido de energia igual a zero. A coincidência entre a curva da soma das cargas e a da soma das fontes é observada na Figura 35.

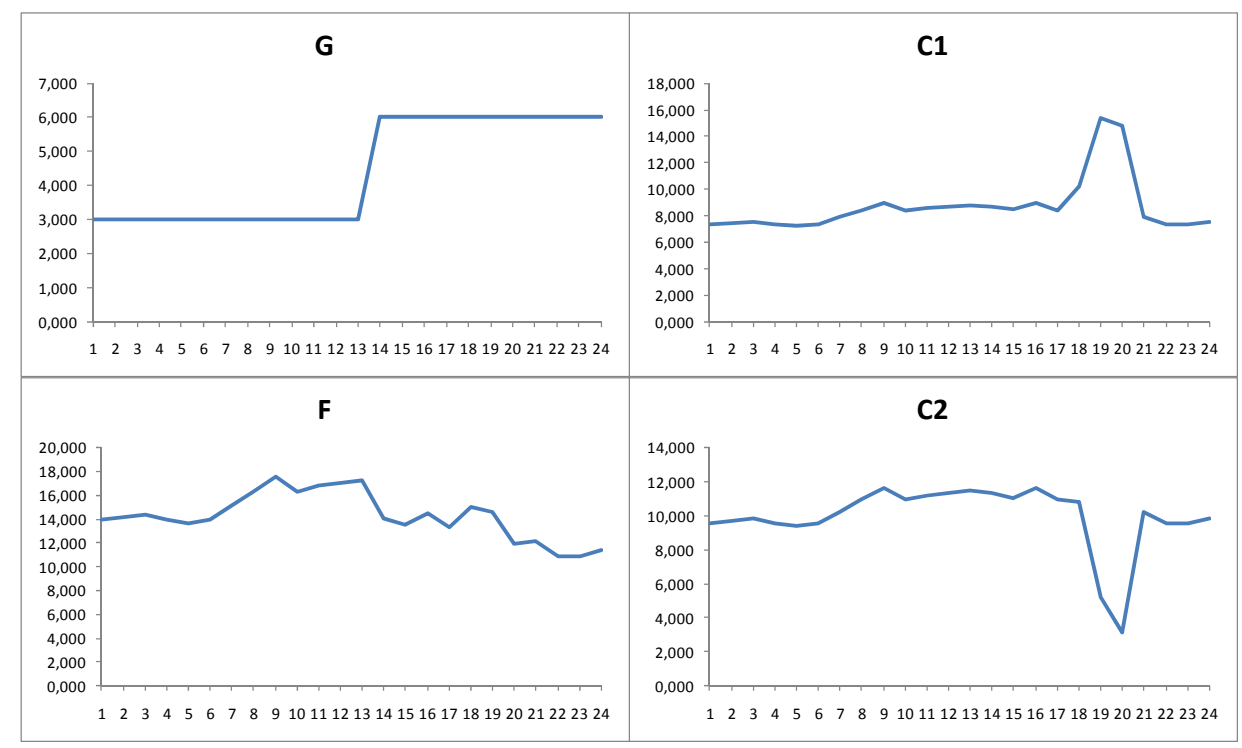

Figura 34 - Curvas de carga utilizadas no exemplo da Figura 33. 


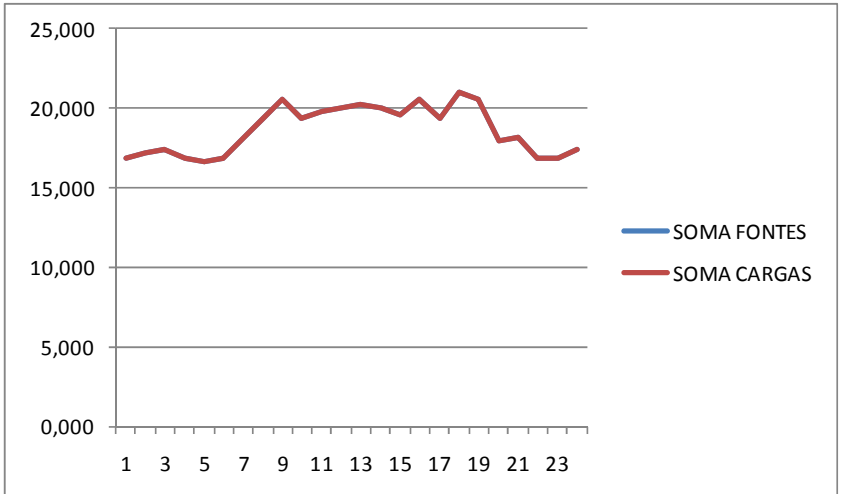

Figura 35 - Curvas de carga da soma das cargas e fontes.

Vale mencionar que, considerando-se as áreas das curvas de potência ativa, pode-se calcular as proporções de energia fornecida pelas duas fontes às cargas. Estas proporções são, respectivamente, para as fontes $F$ e $G, 76,54 \%$ e $23,46 \%$.

Finalmente, para o exemplo em questão, foi utilizada a formulação apresentada em (38) para o cálculo das probabilidades de associação, observando-se que a estimação das curvas $G$ e $F$ deve ser, por especificação, resultante de combinações lineares das curvas $C_{1}$ e $C_{2}$. A formulação para a determinação das probabilidades de associação do exemplo da Figura 33 é apresentada em (39).

$\operatorname{Min}_{e m \forall \pi_{j i}}\left(\sum_{1}^{24}\left(\varepsilon_{F t}\right)^{2}+\left(\varepsilon_{G t}\right)^{2}\right)$

Sendo

$F_{t}=\pi_{1 F} \cdot C_{1 t}+\pi_{2 F} \cdot C_{2 t}+\varepsilon_{F t}$

$G_{t}=\pi_{1 G} \cdot C_{1 t}+\pi_{2 G} \cdot C_{2 t}+\varepsilon_{G t}$

Sujeito a

$\pi_{1 F}+\pi_{1 G}=1$

$\pi_{2 F}+\pi_{2 G}=1$

O resultado da estimação, calculado a partir da otimização do sistema (39) através de programação matemática em ambiente Matlab ${ }^{10}$, pode ser observado na Tabela 5, na qual são apresentadas as estimativas dos valores $\pi_{1 F}, \pi_{1 G}, \pi_{2 F}$ e $\pi_{2 G}$, as suas respectivas estatísticas de teste de hipótese nula e os coeficientes de ajuste $R^{2}$

${ }^{10}$ Software de cálculo numérico, desenvolvido pela MathWorks 
para ambas as equações do sistema. A Figura 36 também ilustra as curvas estimadas das fontes $G$ e $F$ a partir das probabilidades de associação calculadas.

Tabela 5 - Resultado das probabilidades de associação obtidas a partir da otimização do sistema apresentado em (39). As estatísticas de teste de hipótese nula (T-Statistic) foram calculadas ao nível de $95 \%$ de confiabilidade. R2 é coeficiente de correlação dos ajustamentos.

\begin{tabular}{|c|c|c|}
\hline Variável & Estimativa & T-Statistic \\
\hline$\pi_{1 \mathrm{G}}$ & 0,37 & 4,12 \\
\hline$\pi_{1 \mathrm{~F}}$ & 0,63 & 1,39 \\
\hline$\pi_{2 \mathrm{G}}$ & 0,11 & 0,95 \\
\hline$\pi_{2 \mathrm{~F}}$ & 0,89 & 1,53 \\
\hline
\end{tabular}

\begin{tabular}{|l|c|}
\cline { 2 - 2 } \multicolumn{1}{c|}{} & R2 \\
\hline Equação 1 (F) & 0,47 \\
\hline Equação 2 (G) & 0,14 \\
\hline
\end{tabular}

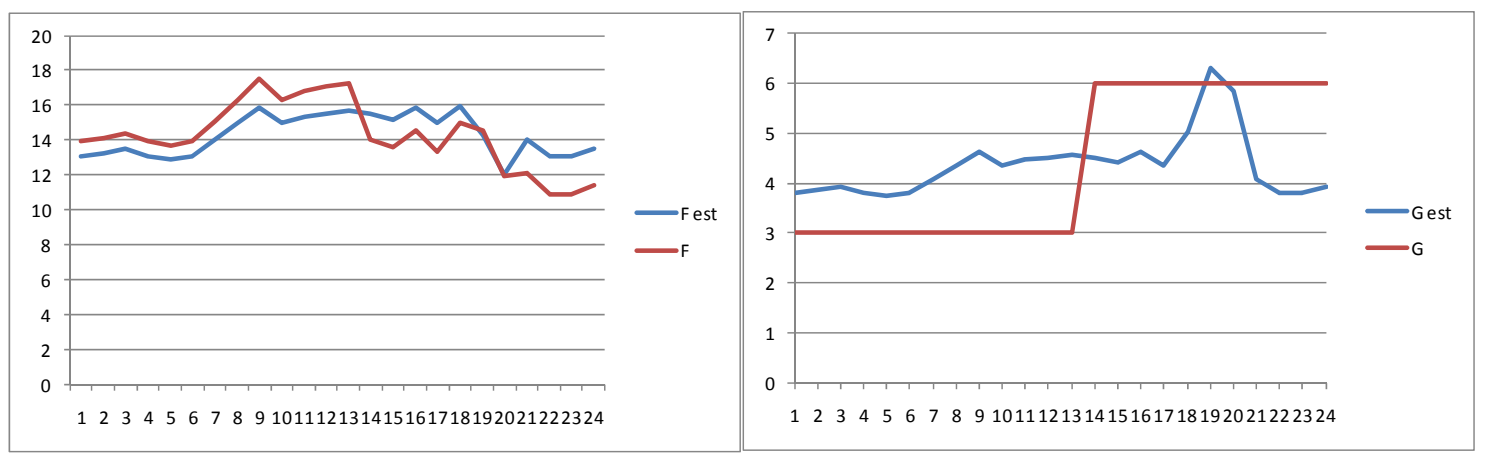

Figura 36 - Curvas estimadas e reais das fontes $G$ e $F$.

Os resultados obtidos no exemplo da Figura 33 são bastante elucidativos e suscitam a reflexão sobre a formulação do problema das probabilidades de associação apresentado em (38). Há, basicamente, duas formas de avaliar criticamente este formulação, uma sob o prisma da engenharia e outra sob o prisma econômico.

Sob o prisma da engenharia, nota-se claramente que há um erro de especificação no equacionamento apresentado em (38), já que as curvas $F_{t}$ e $G_{t}$ não são combinações lineares das cargas $C_{1}$ e $C_{2}$. A curva $F_{t}$, no entanto, é obtida através de uma combinação das curvas $C_{1 t}, C_{2 t}$ e $G_{t}$, já que a curva de potência ativa $G_{t}$ é dada, analogamente à variável potência ativa em uma barra do tipo $P-V$ para um modelamento do cálculo de fluxo de potência. 
A inconsistência dos resultados é também observada nos formatos das curvas estimadas das fontes $F$ e $G$. Através da Figura 36, é possível averiguar que os erros de estimação são bastante grandes, indicando que há erro de especificação no modelo.

Outro aspecto que chama a atenção nos resultados, ainda sob a ótica da engenharia, é que, enquanto as proporções de energia provenientes de $F$ e $G$ são, respectivamente, $76,54 \%$ e $23,46 \%$, as probabilidades de associação apresentadas na Tabela 5 não tem nenhuma semelhança com estas proporções.

Considerando que a formulação em (38) é válida, os resultados da Tabela 5 indicariam que, se o consumidor $C_{1}$ demanda $1 \mathrm{~kW}$ médio adicional do sistema, este $\mathrm{kW}$ seria composto por $0,37 \mathrm{~kW}$ provenientes de $G$ e $0,63 \mathrm{~kW}$ provenientes de $F$. Pelo mesmo raciocínio, quando houvesse uma demanda de $1 \mathrm{~kW}$ adicional por parte de $C_{2}$, $F$ contribuiria com $0,89 \mathrm{~kW}$ e $G$ com $0,11 \mathrm{~kW}$, o que não deixa de ser uma situação improvável.

Seria mais razoável considerar, por exemplo, dada a falta de informações sobre o sistema elétrico, que os consumidores, ao demandarem marginalmente $1 \mathrm{~kW}$ médio adicional do sistema, absorvessem das fontes $F$ e $G, 0,7654 \mathrm{~kW}$ e 0,2346 kW respectivamente, uma vez que são estas as proporções de energia fornecidas pelas fontes.

Sob o prisma econômico, os resultados seriam também bastante inadequados, pois as probabilidades de associação resultariam em "responsabilidades de potência" diferentes, o que indicaria "custos marginais dos clientes" diferentes. Como o sistema de distribuição é caracterizado pela produção conjunta, os custos marginais em um mesmo nível de tensão deveriam ser iguais para todos os tipos de clientes, independentemente de suas curvas de carga.

A não significância estatística de três das quatro variáveis do problema, ao nível de $95 \%$ de confiabilidade, bem como os baixos valores dos coeficientes de correlação $R^{2}$ (observados na Tabela 5 ), demonstram que há um provável erro de especificação no modelo apresentado em (39). Esse erro de especificação indica também a ausência de causalidade entre as variáveis exógenas $\left(C_{1}\right.$ e $\left.C_{2}\right)$ e as variáveis endógenas $(F e G)$, o que torna o modelo inadequado para determinar as responsabilidades dos consumidores. 
A partir da avaliação de um caso real, é possível confirmar a ocorrência do mesmo problema de especificação encontrado no equacionamento apresentado em (38), tornando bastante inapropriado o uso de tal mecanismo de diferenciação de preços aos consumidores do sistema de distribuição.

A Figura 37 ilustra o modelamento do problema das probabilidades de associação para a concessionária DME-PC ${ }^{11}$, a partir de dados das tipologias de carga obtidas no $2^{\circ}$ ciclo de revisão tarifária da companhia. Para simplificar a análise, as tipologias de redes-tipo entre os níveis $A 4-B T$ foram reduzidas a apenas três através de um processo hierárquico de classificação.

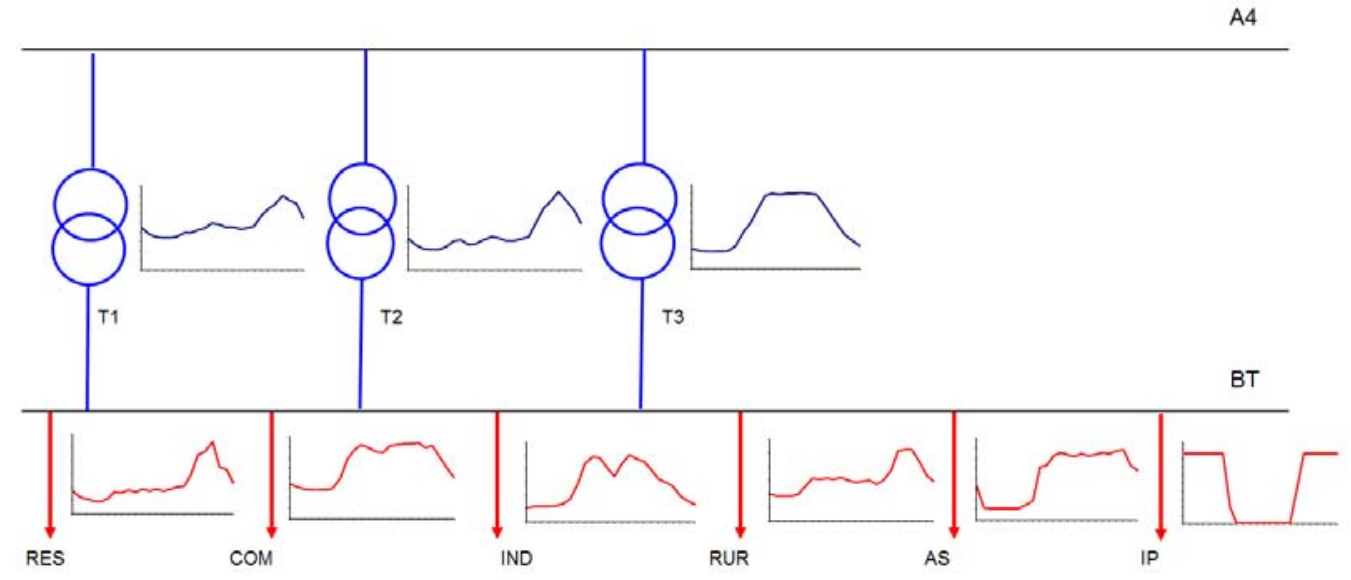

Figura 37 - Modelamento do problema das probabilidades de associação para o nível de baixa tensão (BT) da DME-PC. Foram consideradas curvas agregadas dos consumidores das classes residencial (RES), comercial (COM), industrial (IND), rural (RUR), subterrâneo (AS) e iluminação pública (IP). Fonte: Aneel-Tardist.

Como existem 3 tipologias de redes-tipo e 6 tipologias agregadas de consumidores-tipo, a formulação do problema para a determinação das probabilidades de associação contará com 3 equações e 18 incógnitas. Solucionando-se o problema a partir da mesma ferramenta utilizada no exemplo anterior, chegou-se a 17 estatísticas de teste de hipótese nula não significativas ao nível de 95\%, corroborando à tese de erro de especificação e não causalidade entre consumidores e redes. $O$ resultado da simulação do algoritmo de mínimos quadrados pode ser observado na Tabela 6 e Tabela 7.

\footnotetext{
${ }^{11}$ Departamento Municipal de Energia de Poços de Caldas - MG
} 
Tabela 6 - Resultados da estimativa das probabilidades de associação para o caso da Figura 37. São apresentadas as estimativas das variáveis $\left(\pi_{j i}\right)$, seus desvios $\left(\sigma_{j i}\right)$, as estatísticas dos testes de hipótese nula (t-stat) e suas correspondentes probabilidades (Prob).

\begin{tabular}{rcccc}
\hline & $\pi_{j i}$ & $\sigma_{j i}$ & t-stat & Prob \\
\hline Res -T1 & 0.4615 & 0.2501 & 1.8452 & 0.1145 \\
Com -T1 & 0.4143 & 1.6245 & 0.2551 & 0.8072 \\
Ind - T1 & 0.0000 & 9.4527 & 0.0000 & 1.0000 \\
Rur - T1 & 1.0000 & 7.1187 & 0.1405 & 0.8929 \\
As - T1 & 0.0000 & 65.7934 & 0.0000 & 1.0000 \\
IP - T1 & 0.6635 & 0.5535 & 1.1988 & 0.2758 \\
Res -T2 & 0.4263 & 0.1233 & 3.4566 & 0.0135 \\
Com -T2 & 0.0000 & 0.8010 & -0.0000 & 1.0000 \\
Ind - T2 & 0.0000 & 4.6611 & -0.0000 & 1.0000 \\
Rur - T2 & 0.0000 & 3.5102 & 0.0000 & 1.0000 \\
As - T2 & 0.0000 & 32.4426 & 0.0000 & 1.0000 \\
IP - T2 & 0.3365 & 0.2729 & 1.2330 & 0.2637 \\
Res -T3 & 0.1121 & 0.2320 & 0.4834 & 0.6459 \\
Com -T3 & 0.5857 & 1.5066 & 0.3887 & 0.7109 \\
Ind - T3 & 1.0000 & 8.7667 & 0.1141 & 0.9129 \\
Rur - T3 & 0.0000 & 6.6021 & 0.0000 & 1.0000 \\
As - T3 & 1.0000 & 61.0187 & 0.0164 & 0.9875 \\
IP - T3 & 0.0000 & 0.5133 & 0.0000 & 1.0000 \\
\hline
\end{tabular}

Tabela 7 - Resultados dos coeficientes de correlação não ajustados da estimativa ${ }^{12}$.

\begin{tabular}{c|c}
\hline Equação & $\begin{array}{c}\text { R2 (não } \\
\text { ajustado) }\end{array}$ \\
\hline T1 & 0.5967 \\
T2 & 0.8843 \\
T3 & 0.6347 \\
\hline
\end{tabular}

É importante mencionar que a estimativa das variáveis $\pi$ é sempre caracterizada por uma amostra de 24 pontos (dadas as curvas com intervalos de $1 \mathrm{~h}$ ). $\mathrm{Na}$ maioria dos casos observados no segundo ciclo de revisões tarifárias, havia mais de 24 variáveis $\pi$ a serem estimadas. Ocorre que estimativas econométricas realizadas por modelos com mais variáveis que amostras são, por definição, não especificadas, e apresentam graus de liberdade negativos (GUJARATI, 2006).

Ou seja, ao solucionar-se um problema de estimação de variáveis com graus de liberdade negativos, o que se obtém é uma solução matemática sem causalidade ou representatividade estatística.

\footnotetext{
${ }^{12}$ Não foi possível estimar os coeficientes de correlação ajustados. Este sistema de equações foi otimizado em ambiente MatLab, uma vez que a ferramenta apropriada utilizada (Eviews) não permite a construção de sistemas de equações com restrições de igualdade.
} 


\subsection{0 fator de contribuição}

Para avaliar o mecanismo de diferenciação de preços inserido na variável fator de contribuição, imaginemos um exemplo hipotético e simplificado, para o qual não exista a problemática da determinação das probabilidades de associação, nem tão pouco a consideração de qualquer índice de perdas. A Figura 38 ilustra este exemplo.

Observa-se no exemplo, para o nível de tensão BT, a existência de apenas uma fonte de alimentação ( $T 1$ : Rede) para três consumidores (C1: Residencial, C2: Comercial e C3: Industrial). Esta consideração faz com que as probabilidades de associação, $\pi_{11}, \pi_{21}, \pi_{31}$, sejam iguais a um, podendo ser desconsideradas na composição da responsabilidade de potência de cada consumidor. Ou seja, cada consumidor será $100 \%$ atendido por T1.

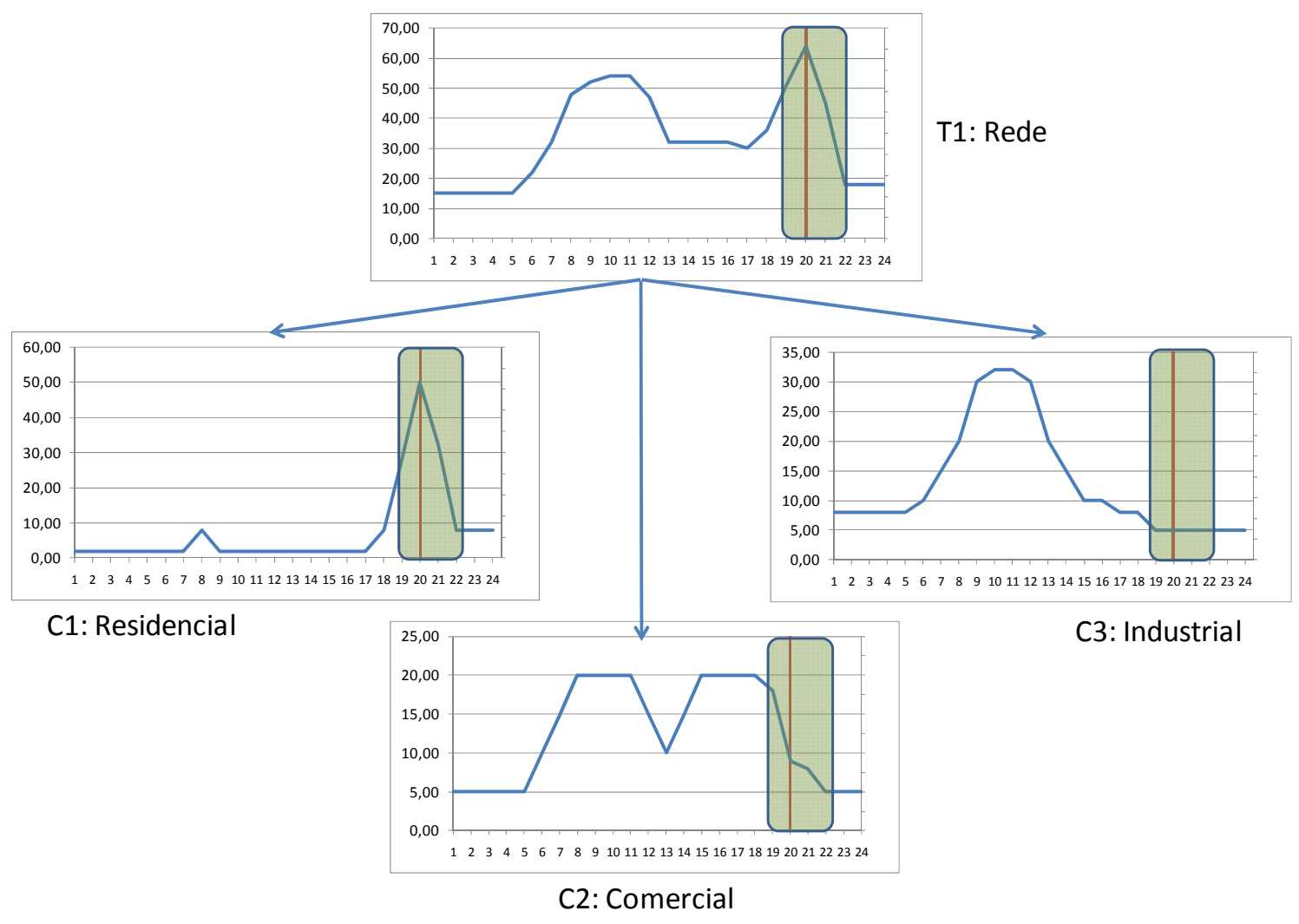

Figura 38 - Exemplo de um sistema determinístico, com uma única fonte de alimentação

Na Figura 38, observa-se a existência de apenas uma ponta na curva de carga de $\mathrm{T} 1$, às $20 \mathrm{~h}$, representada por uma linha. Esta ponta foi determinada pelo critério 
dos $90 \%$, explicitado no item 4.1.4, e ocorre dentro do pré-estabelecido horário de ponta. Neste exemplo, o horário de ponta ocorre entre as $19 \mathrm{~h}$ e as $21 \mathrm{~h}$.

Existindo apenas uma única ponta no horário da ponta, e sabendo que o problema é determinístico, ou seja, que as probabilidades de associação são unitárias, as responsabilidades de potência, na ponta, para cada um dos consumidores seriam dadas pelas Equações (40), (41) e (42). É importante notar que a inexistência de pontas no posto de fora-ponta faz com que as responsabilidades neste posto sejam nulas.

$$
\begin{aligned}
& R_{C 1}^{B T, \text { ponta }}=\frac{F c_{C 1, \text { Rede }}^{\text {ponta }}(20 h)}{N p_{\text {Rede }}}=\frac{1}{1}=1 \\
& R_{C 2}^{B T, \text { ponta }}=\frac{F c_{C 2, \text { Rede }}^{\text {ponta }}(20 h)}{N p_{\text {Rede }}}=\frac{0,5}{1}=0,5 \\
& R_{C 3}^{B T, \text { ponta }}=\frac{F C_{C 3, \text { Rede }}^{\text {ponta }}(20 h)}{N p_{\text {Rede }}}=\frac{1}{1}=1
\end{aligned}
$$

Os custos de capacidade, por sua vez, definidos na Equação (35), são calculados e representados nas Equações (43), (44) e (45). Neste exemplo hipotético, foi suposto que o custo marginal de expansão do nível BT é igual a $100 R \$ / k W$.ano.

$$
\begin{aligned}
& \operatorname{Ccap}_{C 1}^{B T, \text { ponta }}=100 \cdot 1=100 \mathrm{R} \$ / \mathrm{kW} . \text { ano } \\
& \operatorname{Ccap}_{C 2}^{B T, \text { ponta }}=100 \cdot 0,5=50 \mathrm{R} \$ / \mathrm{kW} . \text { ano } \\
& \operatorname{Ccap}_{C 3}^{B T, \text { ponta }}=100 \cdot 1=100 \mathrm{R} \$ / \mathrm{kW} . \text { ano }
\end{aligned}
$$

Em primeira análise, nota-se que o custo marginal atribuído ao consumidor $\mathrm{C} 2$ seria metade do custo marginal atribuído aos consumidores C1 e C3. Observando-se as curvas de carga dos três consumidores, e também as Equações (40), (41), (42), nota-se que a essência desta diferenciação tem origem na não coincidência da demanda máxima do consumidor com o horário de ponta da rede $\mathrm{T} 1$, dentro do posto tarifário de ponta (mensurada pelo próprio fator de contribuição). 
Como discutido no item 2.1.4, devido à problemática da produção conjunta, há motivos bastante fortes, dado o contexto do diagrama simplificado do fluxo de potência, para considerar que os custos marginais de expansão em um mesmo nível de tensão sejam iguais para qualquer tipo de consumidor.

Como explicar, então, a diferença de custos de capacidade observada entre o consumidor C2 e os consumidores C1 e C3? Embora não esteja documentado em nenhuma das referências utilizadas para avaliar a atual metodologia, considera-se que esta diferenciação está relacionada a uma consideração implícita relacionada à tecnologia de medição supostamente utilizada, proporcionando um mecanismo de diferenciação de preços de terceiro grau.

Como o consumidor C2 é supostamente faturado pela sua demanda máxima não coincidente, faz-se necessário um ajuste no custo de capacidade deste consumidor de tal forma que a receita gerada pelo seu faturamento seja equivalente à receita gerada pela aplicação do custo marginal do nível à demanda coincidente com a ponta da rede que o alimenta.

No nosso exemplo, a demanda coincidente do consumidor C2, às $20 \mathrm{~h}$, é $9 \mathrm{~kW}$. Contudo, como a sua máxima demanda no posto tarifário da ponta é $18 \mathrm{~kW}$, e supostamente é esta a demanda faturada, a "Tarifa" aplicada a este consumidor deveria ser multiplicada por um fator igual a 0,5 , de tal forma que a receita produzida pelo seu faturamento resulte em $\mathrm{R} \$ 900,00 /$ ano, que nada mais é do que a demanda coincidente $(9 \mathrm{~kW})$ vezes o custo marginal integral do nível de tensão BT (100 $\mathrm{R} \$ / \mathrm{kW}$.ano).

Esta interpretação da metodologia reforça a visão econômica discutida no item 2.1.4, ou seja, de que, para um mesmo nível de tensão, os custos marginais de expansão são iguais independentemente do tipo de consumidor atendido. A diferença de valores resultante da metodologia, desta forma, não está relacionada ao cálculo de um custo marginal para cada cliente, mas sim ao ajuste de faturamento deste consumidor em função da coincidência de sua ponta com a ponta do sistema.

De forma complementar, considere a Figura 39. Analisando-se a estrutura de receitas arrecadadas pela aplicação do custo marginal integral do nível BT às demandas máximas coincidentes de cada consumidor no horário das $20 \mathrm{~h}$, referente à ponta do sistema (T1), é obtida a proporção observada na Tabela 8. 


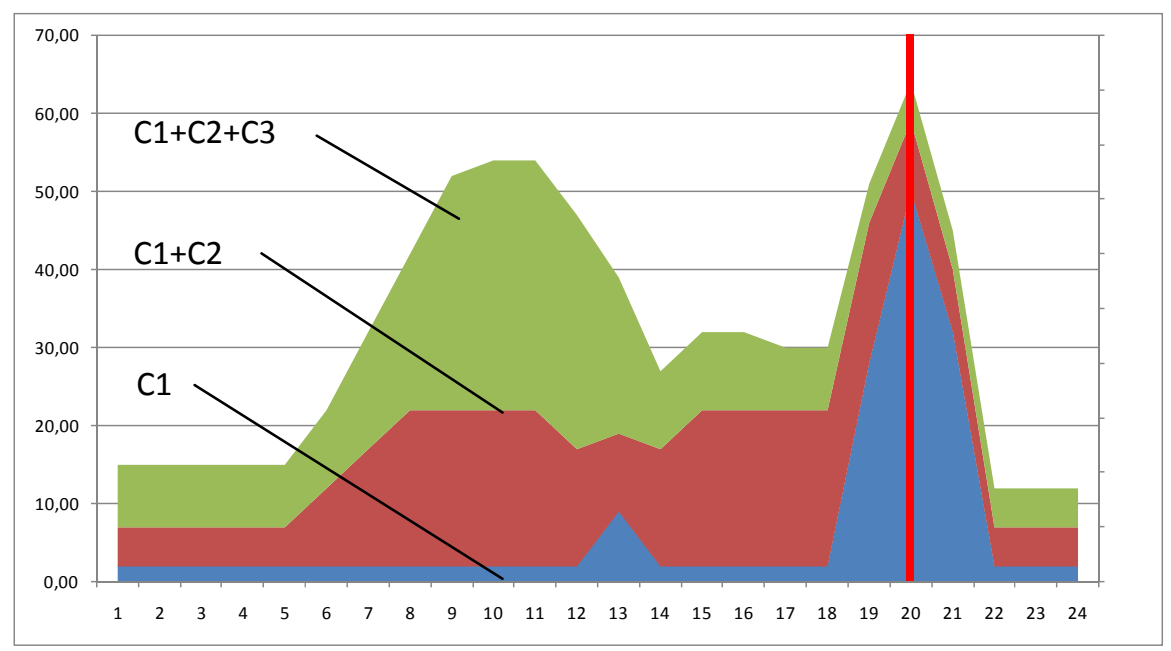

Figura 39 - Consumidores C1, C2 e C3 agregados

Esta proporção oferece uma interpretação de arrecadação por responsabilidade de uso das instalações elétricas. Neste caso, a receita total é obtida aplicando-se uma "Tarifa" de $\mathrm{R} \$ 100 / \mathrm{kW}$.ano a todos os consumidores, somente às suas demandas coincidentes verificadas às $20 \mathrm{~h}$.

É fato que a aplicação de uma tarifa igual ao custo marginal de expansão do nível $\mathrm{BT}$, conforme descrito no capítulo 3 , não recupera a receita total requerida para garantir o equilíbrio econômico-financeiro da concessionária, fazendo-se necessário um ajuste multiplicativo (no caso brasileiro) para reconciliar a receita total.

Como o ajuste multiplicativo não distorce a proporção de receitas observadas na Tabela 8, conclui-se que os preços devam ser iguais para todos os consumidores, desde que aplicados às suas demandas coincidentes.

Tabela 8 - Proporção de Receitas Faturadas aplicando-se Cmg do nível às demandas coincidentes dos consumidores

\begin{tabular}{|c|c|c|r|r|}
\hline Consumidor & D (kW às 20h) & $\begin{array}{c}\text { Cmg do Nível } \\
\text { (R\$/kW.ano) }\end{array}$ & Receita (R\$) & \multicolumn{1}{c|}{ Proporção } \\
\hline C1 & 50,0 & 100,0 & $5.000,00$ & $78,13 \%$ \\
\hline C2 & 9,0 & 100,0 & 900,00 & $14,06 \%$ \\
\hline C3 & 5,0 & 100,0 & 500,00 & $7,81 \%$ \\
\hline
\end{tabular}

Calculando-se a proporção de receitas provenientes dos consumidores através da aplicação dos custos de capacidade obtidos nas Equações (43), (44) e (45) às demandas máximas no posto tarifário de ponta, que representam as demandas faturadas considerando-se a tecnologia de medição, obtém-se a Tabela 9. 
Tabela 9 - Proporção de Receitas Faturadas aplicando-se o Custo de Capacidade dos consumidores às respectivas demandas máximas do posto da ponta

\begin{tabular}{|c|c|c|r|r|}
\hline Consumidor & $\begin{array}{c}\text { D Max (posto de } \\
\text { ponta) }\end{array}$ & C Cap (R\$/kW.ano) & Receita (R\$) & \multicolumn{1}{c|}{ Proporção } \\
\hline C1 & 50,0 & 100,0 & $5.000,00$ & $78,13 \%$ \\
\hline C2 & 18,0 & 50,0 & 900,00 & $14,06 \%$ \\
\hline C3 & 5,0 & 100,0 & 500,00 & $7,81 \%$ \\
\hline
\end{tabular}

Observando-se os dados de proporção de receitas em ambas as tabelas, notase que a metodologia, através dos custos de capacidade, proporciona a mesma estrutura de receitas quando comparada à aplicação do custo marginal integral do nível de tensão às demandas coincidentes de cada um dos consumidores.

Avaliando-se outro exemplo hipotético, obtido a partir da alteração da curva residencial (C1) no exemplo ilustrado na Figura 38, pode-se avaliar a aderência do mecanismo de diferenciação de preços quando existem mais de uma ponta na redetipo T1. Neste novo exemplo, ilustrado na Figura 40, existem 3 pontas, sendo uma no posto tarifário de ponta e duas no posto tarifário de fora-ponta.

A única alteração em relação ao exemplo da Figura 38 é a demanda máxima do cliente residencial (C1) no horário das 20h, que passou de $50 \mathrm{~kW}$ para $45 \mathrm{~kW}$. Todas os outros dados permaneceram inalterados.

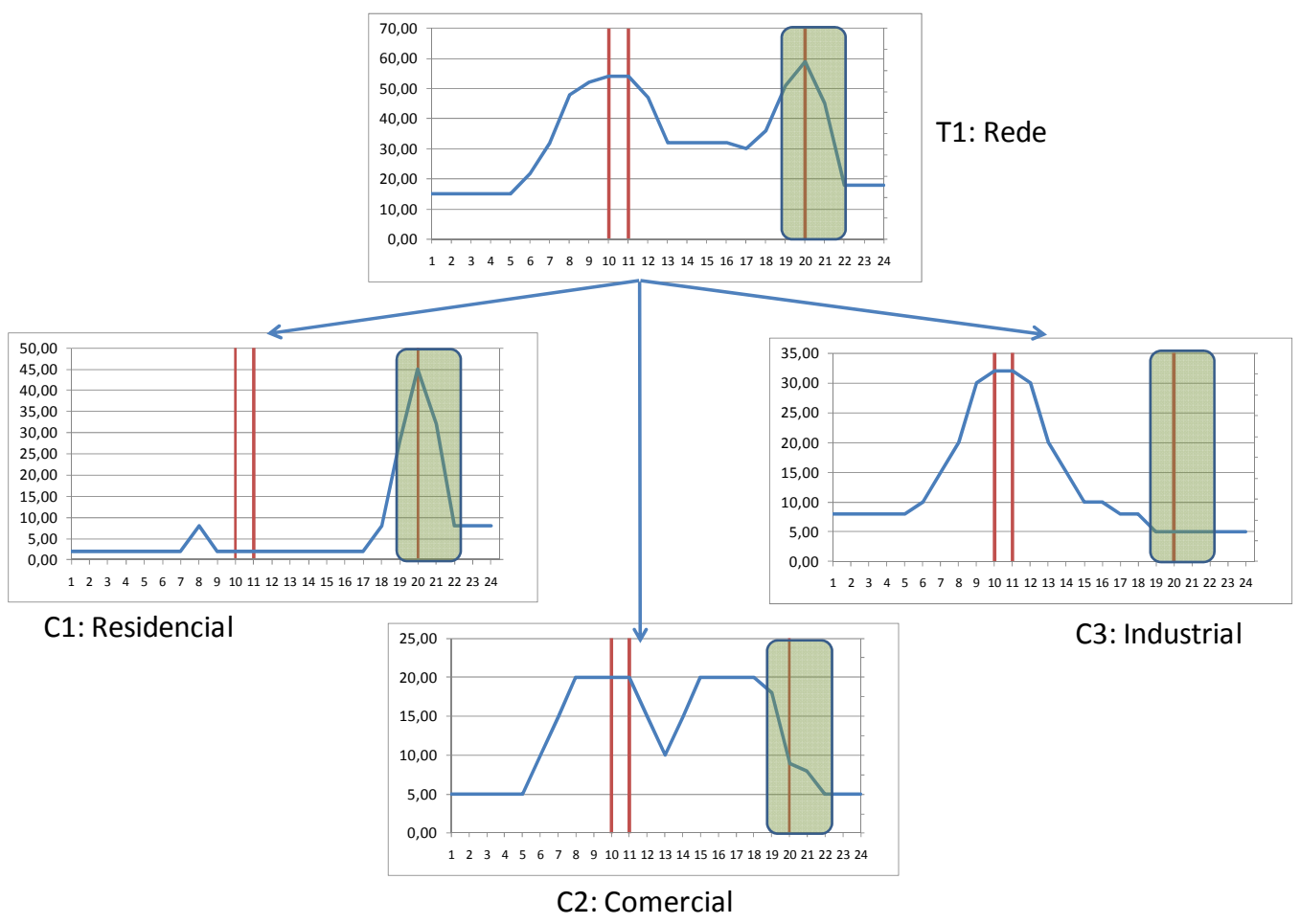

Figura 40 - Exemplo de um sistema determinístico, com uma única fonte de alimentação, e três pontas observáveis na rede T1 
Como agora existem 3 pontas, e duas delas ocorrem fora do posto de ponta, o cálculo das responsabilidades de potência será dado pelas Equações (46), (47) e (48) para o posto da ponta, e pelas Equações (49), (50) e (51) para o posto de fora-ponta.

$$
\begin{aligned}
& R_{C 1}^{\text {BT,ponta }}=\frac{F c_{C 1, \text { Rede }}^{\text {ponta }}(20 h)}{N p_{\text {Rede }}}=\frac{1}{3}=0,333 \\
& R_{C 2}^{\text {BT,ponta }}=\frac{F c_{C 2, \text { Rede }}^{\text {ponta }}(20 h)}{N p_{\text {Rede }}}=\frac{0,5}{3}=0,167 \\
& R_{C 3}^{\text {BT,ponta }}=\frac{F c_{C 3, \text { Rede }}^{\text {ponta }}(20 h)}{N p_{\text {Rede }}}=\frac{1}{3}=0,333
\end{aligned}
$$

$R_{C 1}^{B T, \text { fora-ponta }}=\frac{F c_{C 1, \text { Rede }}^{\text {fora-ponta }}(10 h)+F c_{C 1, \text { Rede }}^{\text {fora-ponta }}(11 h)}{N p_{\text {Rede }}}=\frac{0,22+0,22}{3}=0,147$

$R_{C 2}^{B T, \text { fora-ponta }}=\frac{F c_{C 2, \text { Rede }}^{\text {fora-ponta }}(10 h)+F c_{C 2, \text { Rede }}^{\text {fora-ponta }}(11 h)}{N p_{\text {Rede }}}=\frac{1+1}{3}=0,667$

$R_{C 3}^{B T, \text { fora-ponta }}=\frac{F c_{C 3, \text { Rede }}^{\text {fora-ponta }}(10 h)+F c_{C 3, \text { Rede }}^{\text {fora-ponta }}(11 h)}{N p_{\text {Rede }}}=\frac{1+1}{3}=0,667$

Multiplicando-se as responsabilidades obtidas pelo custo marginal do nível BT, igual a $100 \mathrm{R} \$ / \mathrm{kW}$.ano, obtém-se a Tabela 10 , onde também são apresentadas as demandas máximas de cada consumidor-tipo, para cada posto tarifário.

Tabela 10 - Custos de capacidade calculados, em R\$/kW.ano

\begin{tabular}{|c|c|c|}
\hline Consumidor & $\begin{array}{c}\text { Custo de capacidade } \\
\text { PONTA }\end{array}$ & $\begin{array}{c}\text { Custos de capacidade } \\
\text { FORA-PONTA }\end{array}$ \\
\hline C1 & 33,3 & 14,8 \\
\hline C2 & 16,7 & 66,7 \\
\hline C3 & 33,3 & 66,7 \\
\hline Consumidor & Demanda PONTA & Demanda FORA-PONTA \\
\hline C1 & 45,0 & 9,0 \\
\hline C2 & 18,0 & 20,0 \\
\hline C3 & 5,0 & 32,0 \\
\hline
\end{tabular}


Calculando-se as proporções de receitas, agora obtidas não somente para o posto de ponta mas também para o posto de fora-ponta, obtém-se os resultados apresentados na Tabela 11.

Tabela 11 - Receitas obtidas através da aplicação dos custos de capacidade às demandas máximas dos consumidores-tipo, em ambos os postos tarifários

\begin{tabular}{|c|c|c|c|c|}
\hline Consumidor & Receita PONTA & $\begin{array}{c}\text { Receita FORA- } \\
\text { PONTA }\end{array}$ & Receita (R\$) & Proporção \\
\hline C1 & 1500,00 & 133,33 & 1633,33 & $29,34 \%$ \\
\hline C2 & 300,00 & 1333,33 & 1633,33 & $29,34 \%$ \\
\hline C3 & 166,67 & 2133,33 & 2300,00 & $41,32 \%$ \\
\hline
\end{tabular}

Observando-se agora a proporção de uso da rede T1 em cada um dos três instantes de ponta, conforme pode ser observado na Figura 41, é possível avaliar qual seria a receita arrecadada de cada consumidor caso o custo marginal de $\mathrm{R} \$ 100 / \mathrm{kW}$.ano fosse aplicado integralmente a todos os consumidores, faturado pelas demandas coincidentes em cada instante de pico.

Como agora existem três pontas, e o custo marginal de expansão é sempre atribuído à ponta, é razoável que este custo marginal seja igualmente dividido pelas três pontas existentes. Neste caso, ao atribuir R $\$ 33,33 / \mathrm{kW}$.ano a cada uma das pontas, uma expansão uniforme de $1 \mathrm{~kW}$ em cada um dos instantes de ponta arrecadaria os $100 \mathrm{R} \$ / \mathrm{kW}$.ano necessários para a expansão desta rede. Esta consideração é bastante razoável, uma vez que seria demasiado complexo avaliar a expansão de forma diferente para cada um dos instantes de ponta.

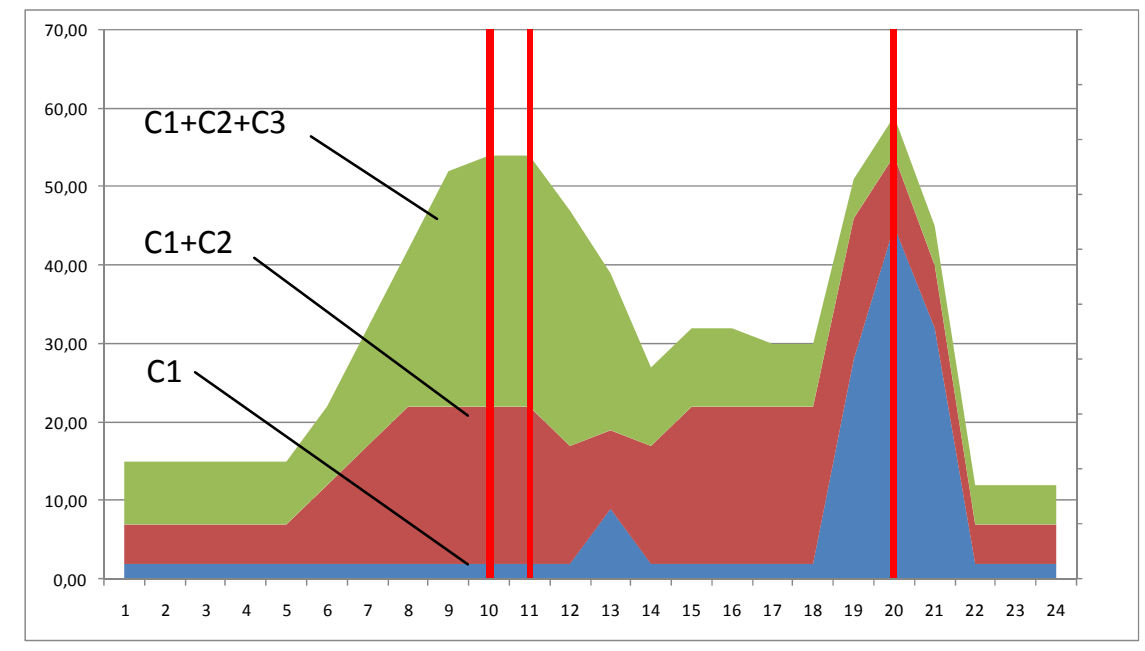

Figura 41 - Proporção de uso da rede T1 em cada um dos instantes de ponta 
$\mathrm{Na}$ Tabela 12 são observadas as demandas coincidentes dos consumidores em cada um dos horários de ponta da rede T1. Aplicando-se o custo marginal de R\$ 100/kW.ano ao conjunto de pontas do sistema ( $R \$ 33,33 \mathrm{R} \$ / \mathrm{kW}$.ano/ponta), e calculando receitas supostamente faturadas em cada um dos instantes de pico, obtém-se a proporção de receita total arrecadada (Tabela 13).

Tabela 12 - Demandas coincidentes dos consumidores nos horários de ponta

\begin{tabular}{|c|c|c|c|c|}
\hline Consumidor & $\mathbf{D}$ (kW às 10h) & $\mathbf{D}$ (kW às 11h) & $\mathbf{D}$ (kW às 20h) & $\begin{array}{c}\text { Cmg do Nível } \\
\text { (R\$/kW.ano)/ponta }\end{array}$ \\
\hline C1 & 2,00 & 2,00 & 45,00 & 33,33 \\
\hline C2 & 20,00 & 20,00 & 9,00 & 33,33 \\
\hline C3 & 32,00 & 32,00 & 5,00 & 33,33 \\
\hline
\end{tabular}

Tabela 13 - Receitas supostamente faturadas por demandas coincidentes nos horários de ponta

\begin{tabular}{|c|c|c|c|c|c|}
\hline Consumidor & Receita (10h) & Receita (11h) & Receita (20h) & Receita Total & Proporção \\
\hline C1 & 66,67 & 66,67 & 1500,00 & 1633,33 & $29,34 \%$ \\
\hline C2 & 666,67 & 666,67 & 300,00 & 1633,33 & $29,34 \%$ \\
\hline C3 & 1066,67 & 1066,67 & 166,67 & 2300,00 & $41,32 \%$ \\
\hline
\end{tabular}

Avaliando-se os resultados, nota-se claramente que a metodologia atual é aderente à consideração de que os custos marginais de expansão são iguais para todos os tipos de consumidores em um mesmo nível de tensão. Como as demandas registradas para faturamento são as demandas máximas dentro de um posto tarifário, há que se ajustar o custo marginal do consumidor de modo a produzir a mesma receita obtida com as demandas coincidentes no instante de ponta.

Esse fato reforça a interpretação econômica de que a conexão de consumidores de classes diferentes a um mesmo nível de tensão não caracteriza diferentes produtos, mas sim diferentes mercados.

Embora haja forte consistência no mecanismo de diferenciação de preços observado na metodologia atual de estrutura tarifária, há que se discutir as hipóteses implicitamente consideradas neste modelo, a partir das quais a metodologia foi concebida e aplicada. 


\subsection{A construção das modalidades tarifárias}

As modalidades tarifárias do sistema de distribuição brasileiro foram inicialmente construídas, na década de 1980, a partir de um contexto verticalizado, no qual os custos de capital e operação da geração e da transmissão eram levados em consideração no cálculo da tarifa final da distribuição.

A partir do que está documentado em (DNAEE, 1985), a construção de modalidades tarifárias deve ter por objetivo refletir o melhor possível os custos causados pelos consumidores ao sistema, de tal forma que a determinação dos preços fixos e variáveis de uma reta tarifária dependa da solução de um problema de regressão linear, considerando que sejam mensuráveis os custos de cada consumidor-tipo.

Por exemplo, na Figura 42 são representados os custos de cada consumidortipo, calculados no contexto de um sistema verticalizado através da soma dos custos de capacidade da geração, transmissão e distribuição da energia. Considerando-se que os pontos representem corretamente os custos de cada consumidor-tipo, o problema consiste em encontrar um conjunto de modalidades, com seus parâmetros, de tal forma a minimizar o desvio de todos os pontos em relação à modalidade mais próxima.

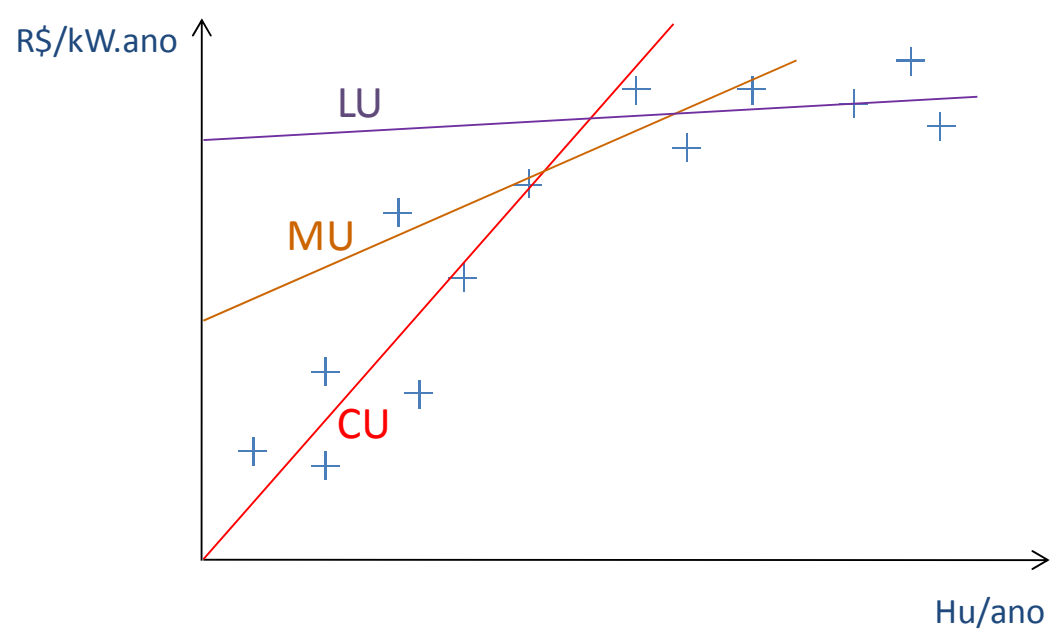

Figura 42 - Exemplo de determinação das retas de curta (CU), média (MU) e longa (LU) utilização a partir de regressões lineares dos custos de cada cliente-tipo 
No entanto, existem alguns problemas envolvendo esta linha de desenvolvimento. O principal deles se refere ao conceito de "custo do cliente", relacionado ao consumidor-tipo. Como é demonstrado no item 5.1, o modelo matemático utilizado para o cálculo das chamadas "responsabilidades de potência" apresenta problemas de especificação, indicando ineficiência dos estimadores que são diretamente utilizados no cálculo do "custo do cliente".

De outro ponto de vista, como o modelo de cálculo das responsabilidades baseia-se em um diagrama simplificado de fluxo de potência, no qual não existem informações topológicas ou elétricas para sustentar o cálculo de custos diferenciados aos consumidores-tipo, comprometem-se as bases teóricas atualmente utilizadas para a construção das modalidades tarifárias brasileiras.

O problema se acentua quando a atual metodologia é observada sob a luz do contexto desverticalizado do sistema elétrico nacional. Sendo o segmento da distribuição caracterizado pela atividade econômica de transporte da energia, estudos apresentados no ANEXO II demonstraram que os custos operacionais estão melhor relacionados à capacidade instalada do sistema do que propriamente à energia consumida.

Desta forma, descaracterizam-se os maiores custos associados às maiores utilizações do sistema (horas de utilização), como ocorre na geração. Para avaliar o problema conceitual da atual metodologia de construção de modalidades tarifárias, considere a Figura 43.

Neste gráfico, cada ponto representa o custo de capacidade de cada consumidor-tipo, e a distância em relação ao custo marginal do nível de tensão, que é independente da utilização, é função do modelo de cálculo das responsabilidades de potência, calculadas a partir da probabilidade de associação $(\pi)$ e dos fatores de contribuição.

Assim, não é possível afirmar que quanto maior a utilização (horas de utilização) de cada consumidor-tipo, maiores serão seus custos totais. $\mathrm{Na}$ verdade, cada ponto no gráfico da Figura 43 é posicionado segundo o resultado de um algoritmo de otimização que obtém resultados estatisticamente não significativos, como demonstrado no item 5.1, e que não apresentam relação com o fator de carga. 


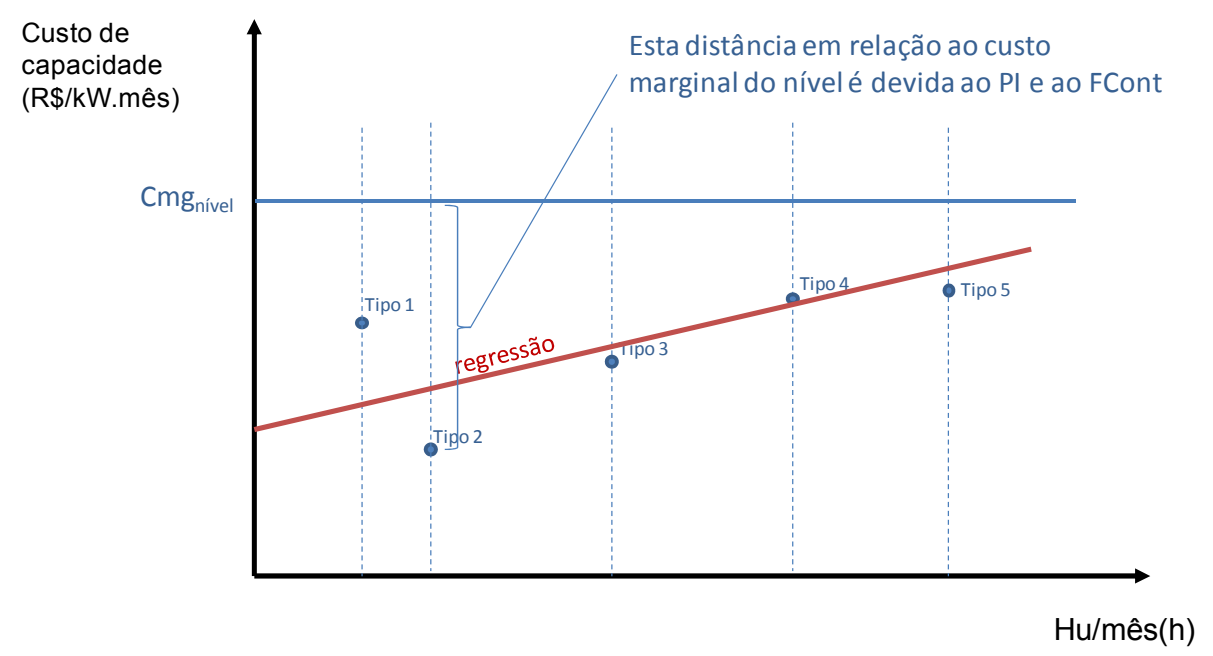

Figura 43 - Interpretação gráfica dos custos de capacidade no contexto da atual metodologia

Para averiguar estas afirmações, considere-se três casos reais. A Figura 44 apresenta uma análise de dispersão entre o custo de capacidade calculado pelo sistema Tardist e o fator de carga, ambos no horário da ponta para a ESCELSA (utilizando dados da campanha de 2009). Da mesma forma, a Figura 45 e a Figura 46 apresentam dados da RGE e ELEKTRO.

Como é possível averiguar, os resultados das análises de dispersão mostram correlação inexpressiva entre os custos de capacidade e o fator de carga. Não é possível, sob o ponto de vista teórico, que consumidores com alta utilização apresentem baixíssimos custos totais de capacidade, como ocorrem nos três casos.

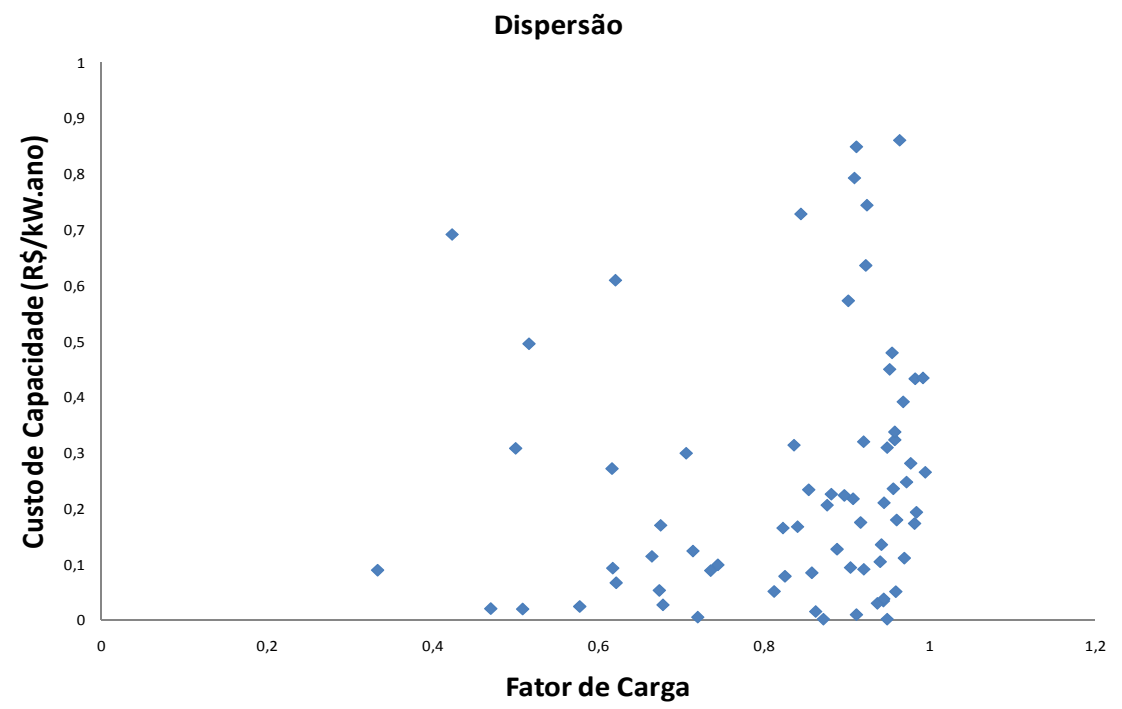

Figura 44 - Análise de dispersão entre o custo de capacidade e o fator de carga para o horário de ponta, com correlação estatística de 13,32\%. Dados da campanha de medidas da ESCELSA 2009. Fonte: ANEEL 


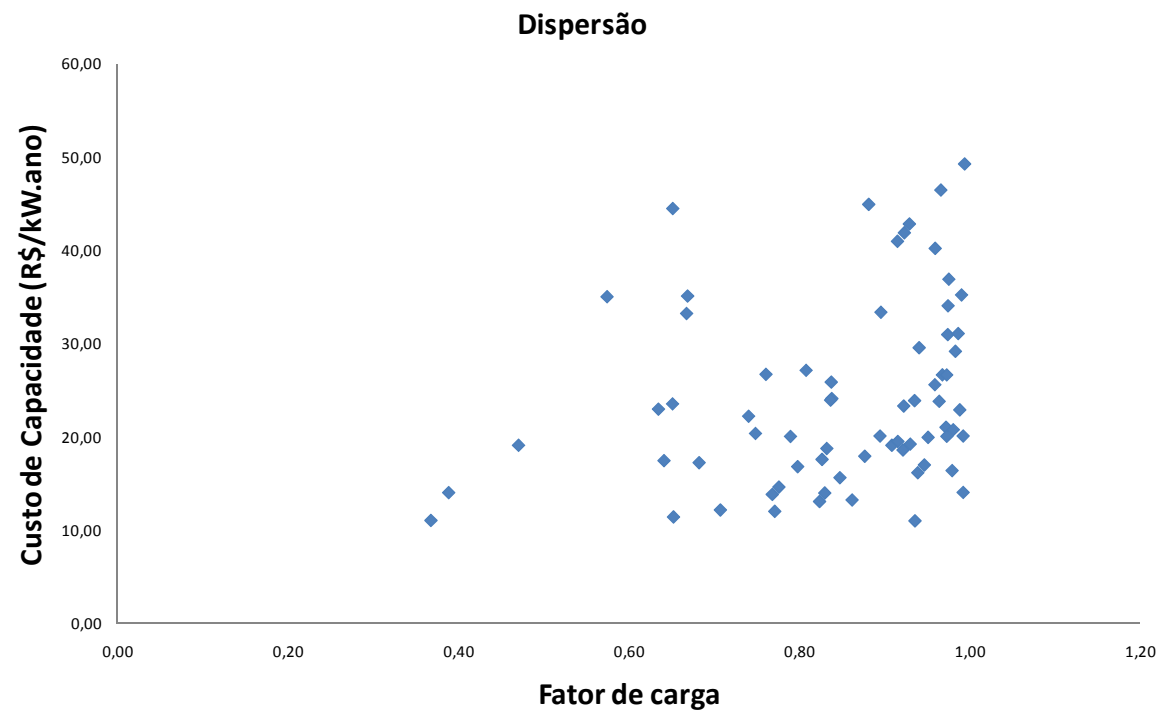

Figura 45 - Análise de dispersão entre o custo de capacidade e o fator de carga para o horário de ponta, com correlação estatística de $25,75 \%$. Dados da campanha de medidas da RGE 2008. Fonte: ANEEL

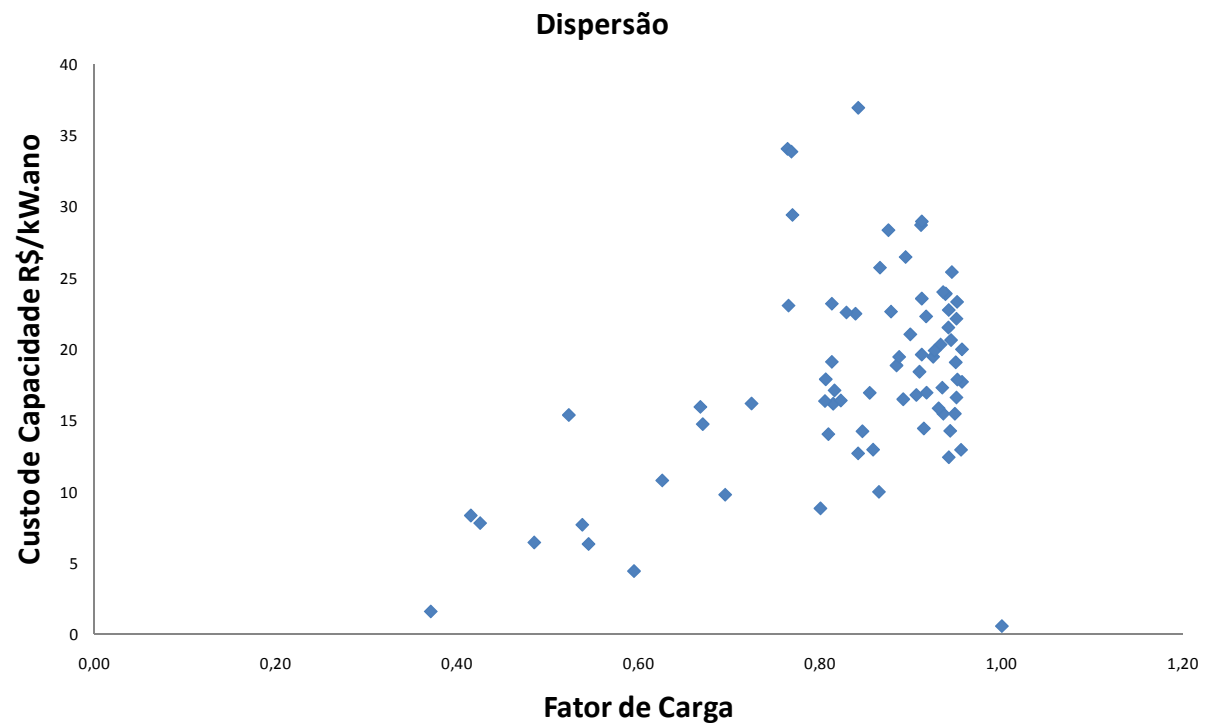

Figura 46 - Análise de regressão entre o custo de capacidade e o fator de carga para o horário de ponta, com correlação estatística de $45,93 \%$. Dados da campanha de medidas da ELEKTRO 2002. Fonte: ANEEL 


\subsection{Hipóteses implicitamente consideradas no modelo}

Algumas hipóteses são implicitamente consideradas no desenho da metodologia atual de estrutura tarifária. A interpretação destas hipóteses, principalmente sob o ponto de vista da teoria econômica, é de fundamental importância para uma correta análise crítica pretendida nesta tese. São elas:

\subsubsection{Simplificação do sistema de distribuição}

Toda a concepção da metodologia é baseada em um diagrama unifilar simplificado de fluxo de potência, composto por níveis de tensão, transformações, consumidores e pontos de injeção de energia. Neste diagrama, não são representados outros equipamentos do sistema, nem tão pouco especificidades topológicas reais das redes de distribuição.

Uma alternativa natural ao uso de um diagrama simplificado seria o uso da topologia real das redes de distribuição em um enfoque locacional, como ocorre no cálculo da tarifa nodal de uso dos sistemas de transmissão.

Embora seja possível uma abordagem locacional para construção de tarifas de uso da distribuição de energia, dada a extensa utilização de bancos de dados topológicos geo-referenciados por parte das concessionárias, ela seria bastante trabalhosa e dependente de critérios pré-definidos.

O volume de dados para a representação topológica detalhada dos níveis de baixa e média tensão seria imenso, além da problemática relacionada ao dinamismo de um sistema de distribuição, dadas as constantes manobras no sistema de média tensão e a alta variabilidade da carga.

Neste sentido, a abordagem simplificada, embora naturalmente superficial e generalista, é bastante apropriada ao cálculo das tarifas médias de uso do sistema de distribuição. Dentre os requisitos necessários a uma boa estrutura tarifária, destacamse a simplicidade, a boa fundamentação e a justa atribuição das responsabilidades dos consumidores. Considera-se que estes requisitos são abarcados por esta abordagem simplificada. 


\subsubsection{Elasticidades nulas}

O processo de cálculo da estrutura tarifária é realizado a cada ciclo tarifário. Neste processo, a determinação da estrutura é obtida considerando-se as curvas de carga de consumidores obtidas ex ante, ou seja, antes da aplicação das tarifas aos consumidores.

Desta forma, considera-se implicitamente que os perfis de carga dos consumidores não serão afetados pela aplicação das tarifas, o que equivale dizer que as elasticidades-preço da demanda destes consumidores, e também as elasticidades cruzadas entre as demandas em diferentes períodos tarifários, são nulas.

É certo que a elasticidade-preço da demanda por energia elétrica é consideravelmente baixa para a média dos consumidores brasileiros, como apontam os estudos de (MODIANO, 1984), (ANDRADE \& LOBÃO, 1997) e (SCHMIDT \& LIMA, 2004). No entanto, existem na literatura apenas estudos destinados à estimação agregada das elasticidades de longo prazo através de séries históricas longevas de consumo, preços, renda e outras variáveis exógenas.

Dito isto, fica clara a dificuldade da consideração quantitativa da elasticidadepreço da demanda por energia em um processo de desenho da estrutura de tarifas, para o qual avulta-se o horizonte de curto prazo e a divisão do mercado consumidor em diversos segmentos, reflexo da própria estrutura tarifária.

\subsection{Principais problemas observados na atual metodologia}

A atual metodologia de construção das tarifas de uso dos sistema de distribuição é caracterizada por um mecanismo de diferenciação de preços de terceiro grau, uma vez que a discriminação entre tipos de consumidores está relacionada a atributos a eles conferidos, como é o caso do perfil de carga.

Como pôde ser observado no item 5.1, o principal mecanismo de diferenciação de preços relacionado ao conceito de responsabilidade de potência apresenta problemas conceituais tanto sob a ótica econômica, como da engenharia elétrica. Os principais problemas observados são: 


\subsubsection{O conceito do custo marginal do cliente}

Conforme já discutido no item 4.1, a metodologia em vigor considera que consumidores representados por tipologias típicas de carga têm custos marginais de fornecimento diferentes, e esta diferença baseia-se na responsabilidade de potência de cada tipologia.

Existem algumas restrições de ordem conceitual em relação ao processo de cálculo dos custos marginais dos clientes. São elas:

\section{i. Representatividade dos consumidores-tipo e redes-tipo}

Conforme descrito no item 4.1 , as curvas de carga dos consumidores-tipo e redes-tipo são obtidas através de um processo amostral baseado na determinação de um perfil médio de consumo, dados o erro amostral admissível e o intervalo de confiança da amostragem.

Embora o tratamento estatístico especificado nos Procedimentos da Distribuição (ANEEL-C, 2008) seja inadequado à estimação de uma variável ndimensional, como é o caso de uma curva de carga, esta análise não fará parte deste trabalho. Será considerado, para os propósitos pretendidos no trabalho, que cada estrato amostral é representado com erros amostrais e intervalo de confiança adequados.

Como as tipologias são obtidas pela fragmentação destes estratos amostrais a partir de processos de grupamento de perfis de consumo por semelhança, a representatividade estatística de cada tipologia não pode ser assegurada, uma vez que o cálculo amostral é exclusivamente destinado à representatividade da curva média.

Desta forma, fica bastante prejudicada a concepção de uma metodologia que relaciona probabilisticamente consumidores-tipo e redes-tipo, dado que as curvas de carga que os representam não tem confiabilidade estatística. 


\section{ii. As probabilidades de associação}

Conforme descrito em detalhes no item 5.1, a formulação do problema de otimização para o cálculo das probabilidades de associação apresenta indícios bastante fortes de erro de especificação.

Como os coeficientes de correlação ajustados são baixos para casos exemplificados e reais, e como também as estatísticas de testes de hipótese nula indicam não significância para as variáveis do problema, há indícios de não haver causalidade linear entre consumidores-tipo e redes-tipo.

Este problema de especificação torna frágil a fundamentação teórica na qual a atual metodologia se alicerça, fazendo com que o processo de cálculo das tarifas seja incerto do ponto de vista estatístico.

\section{iii. A construção das modalidades tarifárias}

Como detalhado no item 5.3, no contexto da atual metodologia, os custos de capacidade de determinada tipologia de carga são supostamente correlacionados ao seu fator de carga. Como foi possível observar neste item, esta hipótese não pode ser sustentada teoricamente ou empiricamente, dadas as simulações econométricas apresentadas.

Deste modo, o princípio de construção de modalidades tarifárias não poderia consubstanciar-se na relação custos de capacidade $x$ fator de carga, mas sim à teoria econômica da precificação não linear, apresentada no item 2.1.2.

\subsubsection{Postos tarifários e sinais entre ponta e fora de ponta}

A metodologia atual considera que os postos tarifários de ponta e fora-ponta são definidos a priori. Desta forma, pontas que ocorram em redes-tipo em instantes fora do horário de ponta terão, associadas a si, custos marginais de expansão. 
A aplicação pura e simples da metodologia, muitas vezes, resulta em custos de capacidade fora de ponta maiores que os custos de capacidade de ponta, o que parece bastante inconsistente do ponto de vista econômico. Custos marginais de expansão e operação (longo prazo), como observado no item 2.1.3, deveriam ser alocados ao horário de ponta, deixando ao horário fora-ponta apenas os custos marginais de operação (curto prazo).

É interessante lembrar que os horários de ponta e fora-ponta são sempre referenciados a uma determinada curva de carga do sistema. Geralmente, esta curva é a curva agregada de fronteira da distribuidora, representando todas as curvas agregadas de todos os consumidores em determinado dia (geralmente o dia de máxima solicitação).

Como a curva agregada do sistema representa a curva média de todos os consumidores, obviamente, se consideradas curvas agregadas de sub-sistemas, como por exemplo subestações de distribuição, ocorrerão pontas em instantes fora do horário de ponta, o que não inviabiliza a construção de uma tarifa que atenda a média dos consumidores e redes.

O problema do surgimento de custos de capacidade fora do horário de ponta decorre, principalmente, de duas considerações implícitas. A primeira, como já mencionado, refere-se à definição a priori dos horários de ponta e fora-ponta. Se há instantes de ponta observados na curva agregada do sistema fora do horário de ponta, seriam necessários mais postos de ponta para representar adequadamente o perfil de carga, ou ainda a consideração de mais de uma região por diversidade da tipologia da carga.

A segunda consideração está relacionada ao fato de os consumidores de média e alta tensão apresentarem perfis de carga já modulados, segundo a relação de preços vigente entre ponta e fora-ponta. Ou seja, como os consumidores tem perfis de carga já resultantes da aplicação de preços diferenciados, as pontas observadas fora do horário de ponta são resultado das modulações dos consumidores de média e alta tensão.

Atualmente, devido a esta inversão de sinais, a ANEEL não utiliza as relações de custos de capacidade de ponta e fora-ponta para sinalizar a diferenciação de preços entre postos tarifários, também chamada de estrutura horizontal. $\mathrm{O}$ órgão 
regulador utiliza relações exógenas entre estes preços, mantendo apenas os resultados referentes à estrutura vertical (entre níveis de tensão).

Avalia-se que os custos de capacidade (expansão) fora do horário ou dos horários de ponta deveriam ser nulos, restando para este posto tarifário apenas os custos de operação do sistema. Para que esta avaliação seja passível de aplicação nos moldes da metodologia atual, um ponto deve ser observado.

Este ponto está relacionado com a consideração dos perfis "naturais" de consumo dos clientes de média e alta tensão, submetidos a preços diferentes nos postos de ponta e fora-ponta. Para obter esses perfis "naturais", poder-se-ia proceder a uma simulação de "desmodulação" de consumo para a construção de curvas de carga destes consumidores a preços constantes.

Desta forma, a curva agregada do sistema refletiria as pontas "naturais" a preços constantes, indicando com maior precisão o horário efetivo da ponta. Infelizmente, esta "desmodulação" encontra barreiras de ordem prática, além de problemas de conduta do método, pois as elasticidades de curto prazo são desconhecidas. No capítulo 6 , será proposta uma metodologia de estrutura horizontal que subjuga esta questão circunstancial da relação entre custos de capacidade de ponta e fora-ponta. 


\section{Uma Proposta Simplificadora para a Estrutura Tarifária de Uso das Redes de Distribuição}

A partir da compilação de parte da teoria econômica clássica aplicada aos sistemas de potência, documentada nos capítulos 2 e 3 , e também a partir da avaliação crítica da atual metodologia praticada no país, discutida em detalhes nos capítulos 4 e 5, é possível avançar no delineamento de uma proposta simplificadora, porém economicamente fundamentada, para a estrutura tarifária de uso das redes de distribuição no Brasil.

Inicialmente, será rediscutido o modelo econômico da curva de custos de uma distribuidora de energia elétrica, que, na visão do autor, deve ser avaliada à luz do atual contexto setorial da desverticalização das atividades de geração, transporte e comercialização de energia.

Em seguida, serão discutidas as premissas metodológicas para a construção de variáveis que quantificarão as estruturas de preços entre níveis de tensão (estrutura vertical) e entre períodos diários (estrutura horizontal).

Contudo, a proposta não se esgota em si. Apesar de avançar na construção de bases mais sólidas para o desenvolvimento das variáveis e processos metodológicos, não são abordados os detalhes e as especificidades inerentes à sua aplicação plena aos sistemas de distribuição nacionais.

\subsection{A curva de custos da distribuidora}

Segundo (LOOTTY \& SZAPIRO, 2002), os estudos empíricos para a determinação da curva de custos de longo prazo são sub-divididos nos seguintes grupos: estudos baseados em custos de engenharia, estudos baseados em análise estatística e estudos baseados nas técnicas do "sobrevivente".

Nos estudos baseados em análise estatística, fundamentalmente avalia-se um modelo econométrico causal, a partir da determinação de variáveis que significativamente explicam o comportamento do custo. Neste sentido, deve-se avaliar não somente o número de variáveis, como também o melhor ajuste algébrico para a função custo. 
Nos estudos baseados na técnica do "sobrevivente", desenvolvida por George Stigler em 1958, avalia-se, por hipótese, que os tamanhos das empresas que "sobrevivem" em determinada indústria são tamanhos eficientes, desde que estas empresas tenham contribuído com a oferta da indústria de forma crescente ao longo do tempo.

Assim, a partir da teoria apresentada no item 3.1 e de uma análise mista entre o conjunto de estudos estatísticos e estudos baseados na técnica do "sobrevivente", propõe-se um modelo econométrico causal para estimar a curva de custos totais de empresas de distribuição brasileiras, a partir de dados em seção cruzada (cross section) de várias empresas a preços constantes de outubro de 2009.

Parte-se da hipótese simplificadora de que o modelo econômico da curva de custos de longo prazo é linear, como apresentado em (DRĖZE, 1964) e (DE SALVIA, 1969), sendo função apenas da demanda máxima agregada atendida pela distribuidora. Este modelo econômico será analisado e validado econometricamente, como será detalhado a seguir.

No atual contexto regulatório, a receita de uma distribuidora de energia brasileira é composta pelas parcelas A e B. A parcela A é a chamada parcela não gerenciável, e é formada por custos de aquisição da energia e encargos diversos. Esta parcela é, em essência ${ }^{13}$, repassada diretamente aos consumidores através de um mecanismo "pass through". A parcela B, por sua vez, é a parcela sobre a qual a distribuidora tem total gerência, sendo composta, em sua definição regulatória, pelos custos de capital (remuneração e depreciação), e pelos custos de operação e manutenção da distribuidora.

O equilíbrio econômico-financeiro da empresa é, então, proporcionado pela parcela B. O marco regulatório do setor elétrico brasileiro, originado no governo Fernando Henrique Cardoso, inseriu as distribuidoras em um regime de regulação price cap, com alguns mecanismo de regulação por referência (yardstick regulation) (PIRES \& PICCININI, 1998).

A composição da Parcela B pode ser vista na Tabela 14. É importante salientar que as distribuidoras recuperam esses custos a partir das tarifas cobradas sobre seus clientes, conforme previsto nos contratos de concessão.

\footnotetext{
${ }^{13}$ No modelo brasileiro, algumas parcelas dos custos não gerenciáveis não são totalmente neutras, atribuindo riscos às distribuidoras.
} 
Tabela 14 - Estrutura da Parcela B.

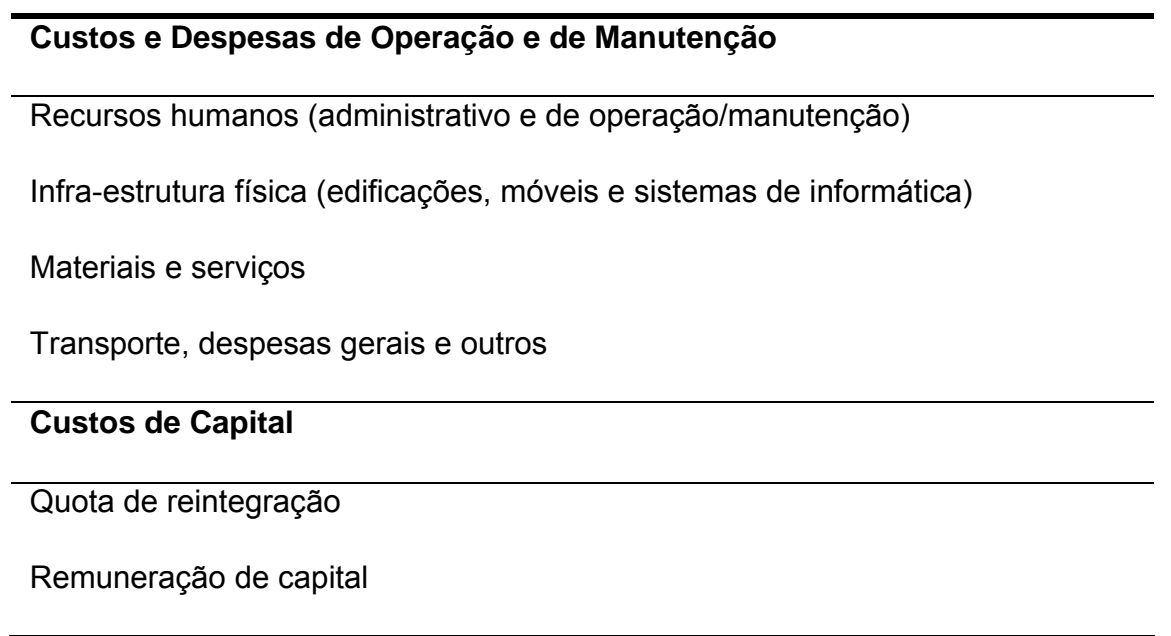

No atual regime regulatório brasileiro, todos os custos que compõem a parcela B são calculados pela agência reguladora do setor, a ANEEL, no momento das revisões tarifárias. Desta forma, através de uma série de metodologias e processos, calculam-se os custos de capital a partir da base de remuneração regulatória e os custos de operação e manutenção a partir da chamada empresa de referência. Maiores detalhes podem ser obtidos em (ANEEL-B, 2006).

Nos processos de revisão tarifária periódica, a Superintendência de Regulação Econômica - SRE publica a descrição da metodologia, assim como todos os dados referentes aos custos de capital e operação e manutenção da concessionária submetida à revisão. Nesse mesmo período, os valores de demandas máximas das redes de distribuição são publicados pela Superintendência de Regulação da Distribuição - SRD, através dos resultados do cálculo dos custos de capacidade.

Com base nos dados de custos operacionais regulatórios, dados da Base de Remuneração Regulatória (BRR) e da demanda máxima agregada das distribuidoras, estimativas de regressão sugerem um ajustamento linear para a curva de custos de longo prazo das distribuidoras.

Considerando dados de 56 empresas nacionais, referentes ao $2^{\circ}$ ciclo de revisões tarifárias periódicas, avalia-se que o custo marginal de longo prazo destas empresas é provavelmente constante. Os resultados econométricos destas estimativas podem ser observados no ANEXO II.

Retomando-se a teoria econômica apresentada nos capítulos 2 e 3, embora se encontre um arcabouço teórico bastante denso e fundamentado sobre a problemática 
da precificação de ponta nos trabalhos clássicos, nota-se a inexistência de discussões a respeito da aplicação destes preços a casos reais, principalmente àqueles inseridos em um ambiente institucionalmente desverticalizado, como é caso das distribuidoras de energia brasileiras.

Nos exemplos iniciais ilustrados por (BOITEUX, 1960) e (STEINER, 1957), as curvas de custos remontam a sistemas de potência verticalizados, para os quais a energia gerada constituía-se no principal insumo dos custos variáveis, também comumente chamados de custos de operação de curto prazo.

Em (DRĖZE, 1964), é proposto um modelo econômico simplificado que apresenta retornos constantes de escala no longo prazo. Assim como o sugerido por (BOITEUX, 1960), o modelo de Drèze considera custos marginais operacionais constantes e independentes da capacidade instalada da supridora. O modelo de Drèze pose ser observado na Figura 47.

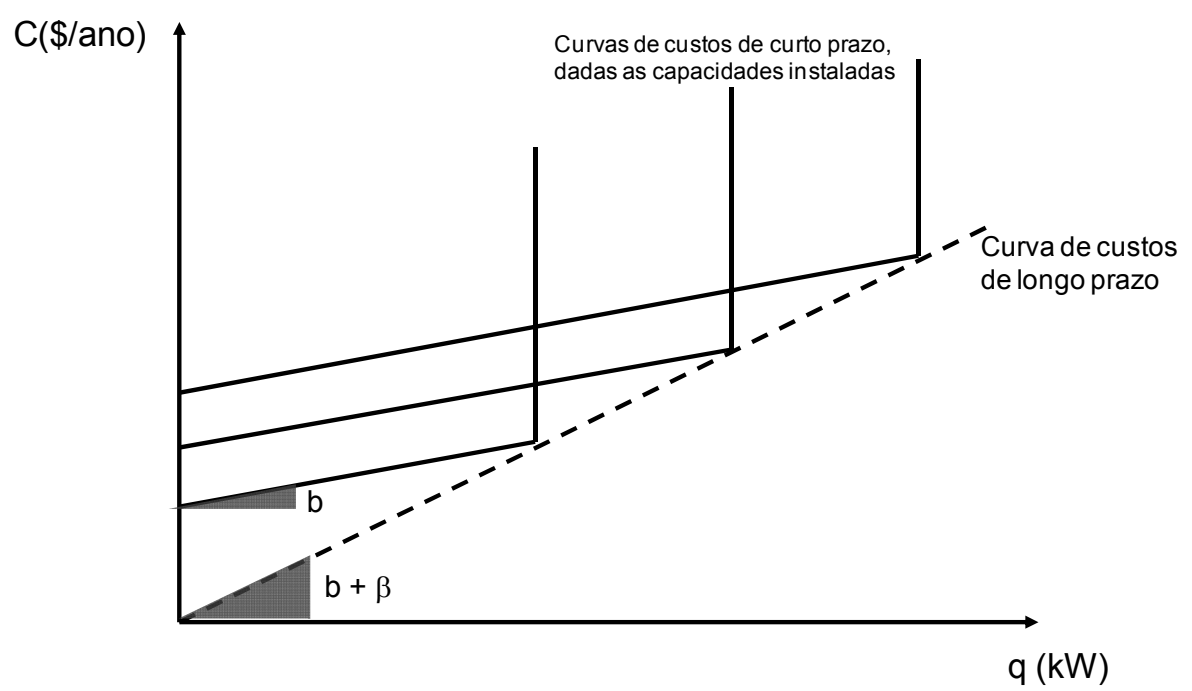

Figura 47 - Modelo econômico de (DRÈZE, 1964)

Neste trabalho, a demanda do mercado é apresentada como uma curva de carga diária próxima de uma curva real, discretizada em intervalos temporais de $1 h$, conforme ilustra a Figura 48. 


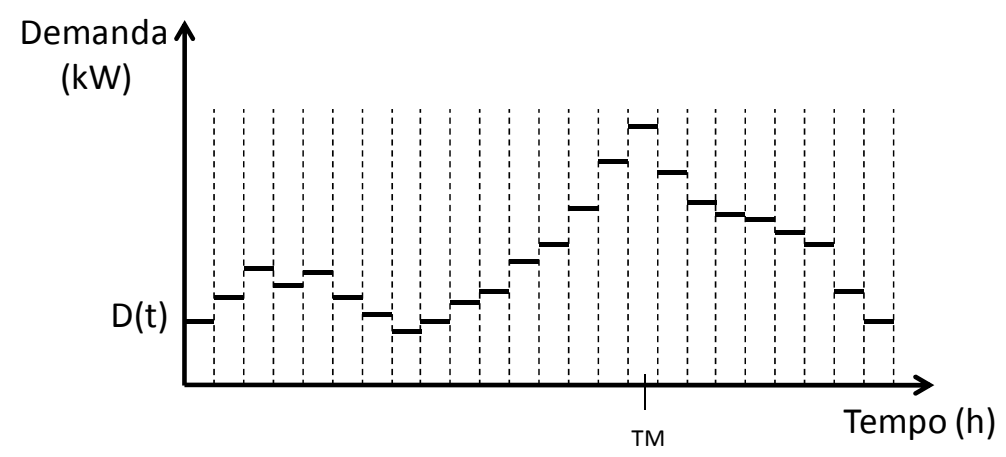

Figura 48 - Exemplo de carga periódica ilustrado por (DRÈZE, 1964).

Assumindo que os custos marginais de operação e expansão sejam constantes, os custos totais seriam calculados a partir de uma integralização de custos marginais horários, conforme a Equação (52)(66). Para que esta precificação seja possível, é necessário que haja o faturamento de 24 demandas diárias.

$C T=\left[\sum_{t=1}^{24} D(t) \cdot \frac{b}{24}\right]+D(T M) \cdot \beta$

Sendo

$D(t): \quad$ Demanda em $k W$ no instante $t$

TM: $\quad$ Instante em que ocorre a demanda máxima $D(T M)$.

Como já mencionado, observa-se na maioria dos trabalhos acadêmicos avaliados sobre o assunto da precificação de ponta, por serem antigos, um contexto econômico verticalizado, no qual os custos da geração são a maior parcela dos custos operacionais de curto prazo.

Em sistemas de potência desverticalizados, onde a atividade de transporte é separada das atividades de geração e comercialização da energia, os custos da geração de energia não são insumos para os custos operacionais de empresas distribuidoras. 
Neste sentido, surge uma questão bastante importante sobre o modelo econômico a ser considerado para o segmento da distribuição. Para ilustrá-la, considere a Figura 49. Neste exemplo, são apresentadas duas empresas hipotéticas, Empresa 1 e Empresa 2.

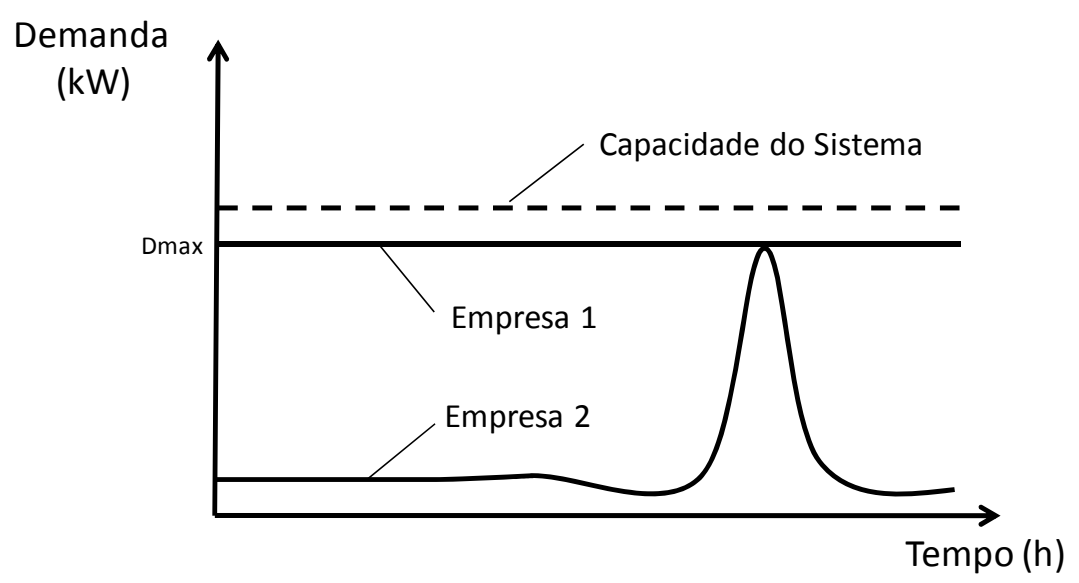

Figura 49 - Exemplo de curvas de carga agregadas para duas empresas hipotéticas, Empresa 1 e Empresa 2.

A Empresa 1 possui um mercado cuja demanda agregada é constante, com fator de carga $f c_{1}$ unitário, enquanto a Empresa 2 atende a um mercado cuja curva agregada possui um fator de carga $f c_{2}$ muito menor. Como pode ser observado, ambas atendem à mesma potência máxima, neste exemplo menor que a capacidade do sistema.

Supondo-se que o custo marginal de operação de curto prazo, $b$, seja o mesmo para ambas as empresas, e também que existam 24 períodos diários de faturamento, como no exemplo apresentado em (DRĖZE, 1964), os custos totais de curto prazo (sem necessidade de expansão) para cada uma das empresas seriam dados pelas Equações (53) e (54).

$$
C T_{1}=\sum_{t=1}^{24} D_{1}(t) \cdot \frac{b}{24}=24 \cdot \text { Dmed }_{1} \cdot \frac{b}{24}=D \max \cdot b
$$


$C T_{2}=\sum_{t=1}^{24} D_{2}(t) \cdot \frac{b}{24}=24 \cdot$ Dmed $_{2} \cdot \frac{b}{24}=f c_{2} \cdot \operatorname{Dmax} \cdot b$

Como é possível notar, a formulação da composição horária dos custos leva à conclusão de que os custos de curto prazo são função direta do fator de carga da curva agregada do mercado. Esta relação é verdadeira somente quando são considerados os custos da geração nos custos operacionais de curto prazo, como ocorre em sistemas verticalizados.

Para uma distribuidora de energia desverticalizada, cuja atividade econômica é o transporte da energia, os custos operacionais não são diretamente proporcionais ao fator de carga, estando muito mais relacionados com a estrutura física das redes de distribuição (disponibilidade de potência).

Nos estudos econométricos apresentados no ANEXO II, nota-se claramente que os custos totais regulatórios, compostos pelas parcelas de capital e operação, para o caso brasileiro, tem uma correlação estatística quase unitária com a demanda máxima atendida pela distribuidora.

No exemplo da Figura 49, como ambas as empresas atendem à mesma demanda máxima, é correto supor que ambas tem a mesma estrutura física (ativos elétricos). Como no caso brasileiro os custos operacionais de uma distribuidora são bastante correlacionados com a demanda máxima atendida, poder-se-ia supor que os custos operacionais das empresas 1 e 2 são muito próximos.

É claro que a Empresa 2, por alimentar um mercado com baixo fator de carga, terá um custo operacional ligeiramente menor que a Empresa 1, principalmente se consideradas as perdas elétricas e outras variáveis de risco associadas à compra da energia. Todavia, os modelos econométricos apresentados no ANEXO II permitem inferir que os custos operacionais de ambas as empresas seriam estatisticamente iguais.

A reflexão sugere a construção de um modelo econômico diferente dos modelos clássicos para as distribuidoras de energia. Se os custos operacionais estão muito mais relacionados à estrutura de capital do negócio, seu vetor de crescimento surgiria apenas quando a demanda atendida fosse igual ou maior que a demanda máxima. 
O modelo econômico proposto, constituído de curvas de custos de longo e curto prazos, é ilustrado na Figura 50 e seu equacionamento apresentado nas Equações (55) e (56).

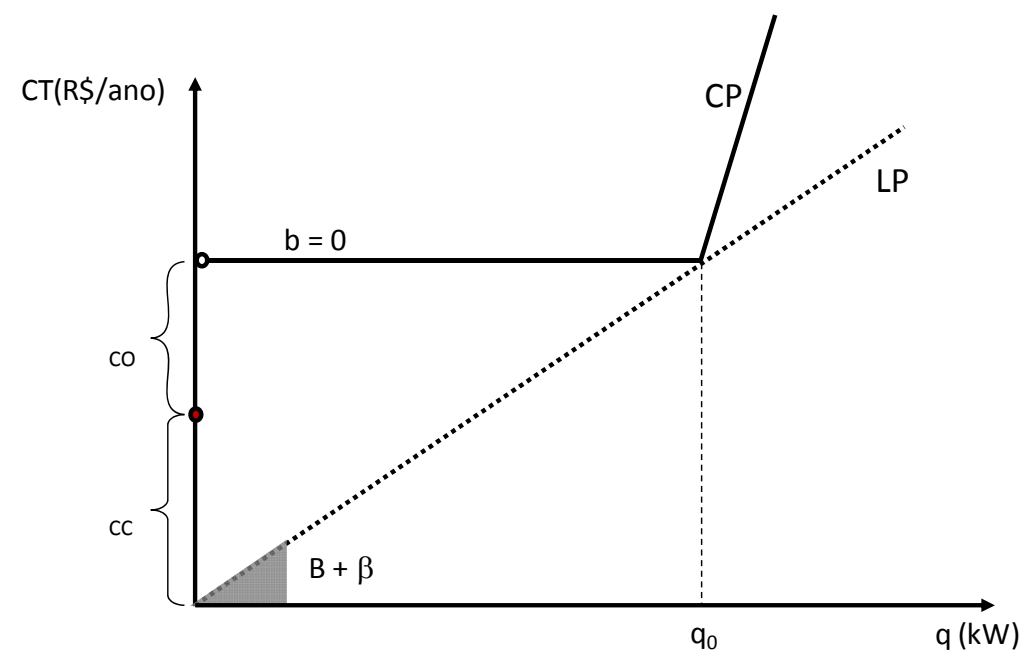

Figura 50 - Modelo econômico proposto para os custos totais de uma distribuidora.

$C T_{C P}\left(D_{\max }, q_{0}\right)\left\{\begin{array}{rll}=C C & \text { se } & D_{\max }=0 \\ =C C+C O & \text { se } & q_{o}>D_{\max }>0 \\ >(B+\beta) \cdot q_{0} & \text { se } & D_{\max } \geq q_{0}\end{array}\right\}$

$C T_{L P}\left(q_{0}\right)=(B+\beta) \cdot q_{o}$

Onde:

CC: Custos de capital, constantes para a capacidade $q_{0}$.

CO: Custos de operação, constantes para a capacidade $q_{0}$.

$b$ : $\quad$ Custo marginal de operação no curto prazo.

B: $\quad$ Custo marginal de operação no longo prazo.

$\beta$ : $\quad$ Custo marginal da expansão ${ }^{14}$, somente definido no longo prazo.

\footnotetext{
${ }^{14}$ A variável $\beta$ neste modelo não inclui os custos marginais de operação de longo prazo. Supõe-se que nos modelos clássicos verticalizados, $\beta$ conjugava o custo marginal da expansão dos ativos e o custo marginal para operá-los, que são distintos dos custos marginais de operação de curto prazo.
} 
No modelo de custos de curto prazo da Figura 50, há uma descontinuidade para demandas máximas próximas de zero. Isso ocorre porque os custos da operação somente se caracterizam quando há estrutura de capital, representada pelos custos de capacidade.

O custo operacional de curto prazo é nulo neste modelo. Como a distribuidora, por se tratar de uma empresa de transporte de energia, oferece disponibilidade de potência, não existem custos marginais significativos no curto prazo, como ocorria com as supridoras verticalizadas.

É também fundamental observar que, pelo modelo econômico proposto, o custo marginal de longo prazo será igual ao custo médio para qualquer demanda atendida, caracterizando a ausência de economias de escala no longo prazo, o que pode parecer contraditório para um caso de monopólio.

Ocorre que a curva de custos de longo prazo, conforme observa (LOOTTY \& SZAPIRO, 2002), é uma curva teórica de planejamento, servindo apenas de guia para os deslocamentos das curvas de curto prazos. Como constatado no modelo proposto, as curvas de custos de curto prazo sempre apresentam economias de escala, caracterizando o monopólio natural.

\subsection{A questão dos custos marginais em um mesmo nível de tensão}

Como será abordado em maiores detalhes na proposta, a metodologia de construção da estrutura tarifária de uso dos sistemas de distribuição, assim como a atual, será totalmente baseada em um diagrama simplificado de fluxo de energia, no qual não são consideradas especificidades topológicas ou elétricas do sistema de distribuição.

Neste contexto da uniformidade hipotética da rede, por definição, os custos marginais para o atendimento a acréscimos de demanda em um mesmo nível de tensão são iguais independentemente do tipo de consumidor ou da forma de sua curva de carga. Para compreender essa questão, considere-se o exemplo a seguir, ilustrado na Figura 51. 


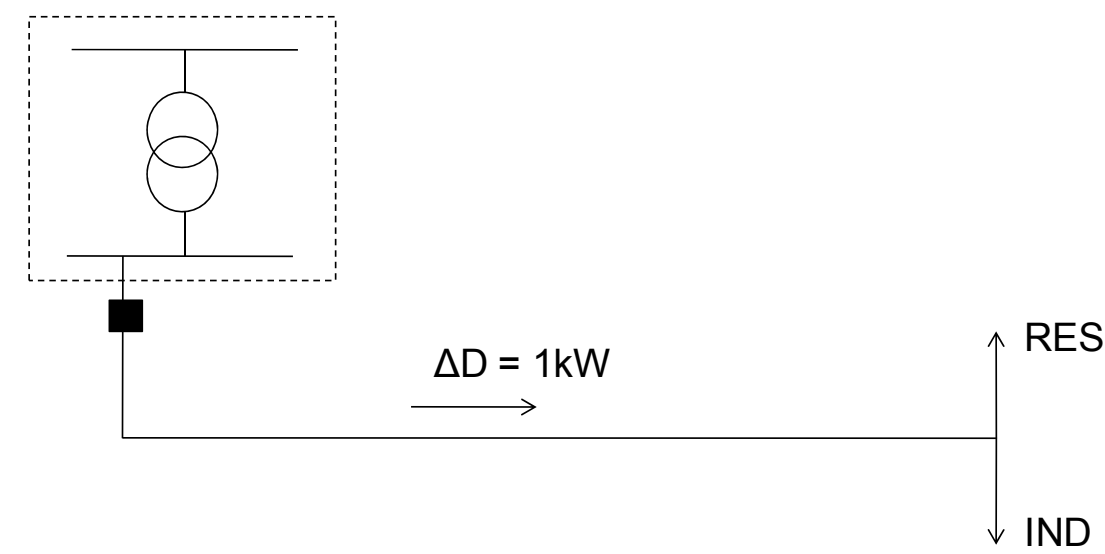

Figura 51: Sistema para atendimento a dois tipos de consumidores em um mesmo nível de tensão

Neste exemplo, um sistema de distribuição composto por um transformador e um circuito atende a dois tipos diferentes de consumidores, um residencial e outro industrial. Considere-se que, no horário de maior solicitação do sistema, ou no seu horário de pico, as demandas destes consumidores sejam, respectivamente, para o residencial e para o industrial, $D_{r}=100 \mathrm{~kW}$ e $D_{i}=0 \mathrm{~kW}$.

Como a demanda do consumidor industrial, coincidente com o pico do sistema, é nula, poder-se-ia imaginar que este consumidor não deveria pagar pela expansão do sistema. Ocorre que, marginalmente, um acréscimo de $1 \mathrm{~kW}$ deste consumidor, passando de 0 a $1 \mathrm{~kW}$, causaria uma variação de $1 \mathrm{~kW}$ no sistema, exatamente da mesma forma que uma variação da demanda do consumidor residencial de 100 para $101 \mathrm{~kW}$.

Ou seja, independente das quantidades absolutas demandas por estes consumidores, um acréscimo de demanda provocado por qualquer um deles implicaria em um aumento marginal de demanda no sistema, o qual, estando em seu ótimo operativo, como será discutido no capítulo 3, exigirá expansão de sua capacidade.

A Equação (57) mostra que os custos marginais totais são iguais para ambos os consumidores conectados a um mesmo nível de tensão, corroborando assim com a tese de que não há, do ponto de vista econômico, diferenças de custos marginais para consumidores que consomem o mesmo produto, definido neste caso como a conexão a certo nível de tensão. 
$C m g_{r}=\frac{\partial C T}{\partial D_{r}}=\frac{\partial C T}{\partial D_{i}}=C m g_{i}$

É extremamente importante constatar que, qualquer diferença de preços finais entre estes dois consumidores deverá basear-se em critérios não relacionados à diferença de custos para atendimento a estes consumidores.

\subsection{Premissas metodológicas para o desenvolvimento da proposta}

Dentre os principais preceitos econômicos e sociais que devem orientar uma adequada estrutura tarifária, conforme descrito no item 1.1, destacam-se a eficiência econômica, a fundamentação teórica, a objetividade e justiça, a transparência, a praticidade e, por fim, a aplicabilidade da metodologia.

Neste contexto, a proposta metodológica apresentada neste capítulo buscará encontrar um equilíbrio no sentido Paretiano para estes preceitos econômicos, tendo como principal eixo de atuação a simplificação operacional com fundamentação teórica.

Para estruturar a proposta, faz-se necessário delinear premissas metodológicas para o desenvolvimento das variáveis e processos. Este contexto, que funcionará como um alicerce, contemplará os seguintes tópicos: o diagrama simplificado de fluxo de energia, a caracterização da carga, a sinalização econômica (elasticidades) e a mecânica da precificação não linear.

Identificadas as bases que sustentarão a proposta metodológica, será possível o desenho de variáveis e processos que formarão as estruturas vertical (entre níveis) e horizontal (entre períodos) de preços de uso das redes de distribuição.

Serão descritos a seguir os quatro tópicos que formam o contexto em que se desenvolverão as variáveis e processos da proposta, conforme organização ilustrada na Figura 52. 


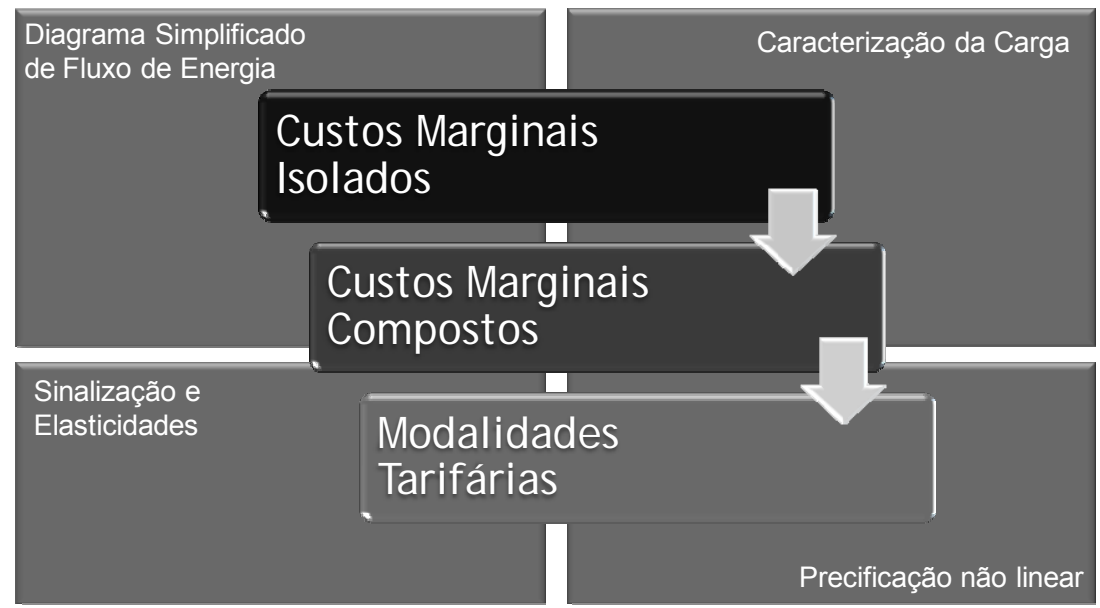

Figura 52 - Contexto metodológico no qual serão definidas as variáveis e processos da metodologia proposta

\subsubsection{O diagrama simplificado de fluxo de energia}

No contexto da separação estrutural entre energia (commodity) e transporte (uso da rede), a problemática do custeio da atividade de transporte pode ser abordada sob diversos aspectos. Frequentemente, é encontrada na literatura uma abordagem que leva em consideração a capacidade limitada das linhas e circuitos elétricos frente a seus níveis de carregamento, ou congestionamento.

O gerenciamento da congestão das linhas e circuitos elétricos deve usufruir da construção de uma política de preços que leve o sistema a uma operação e expansão racional e eficiente, induzindo os agentes a tomar decisões coincidentes com a otimização do sistema.

A tarifa nodal, considerada a precificação eficiente para o gerenciamento da congestão de linhas e circuitos elétricos (STOFT, 2002) é aplicada no Brasil na construção da tarifa de uso dos sistemas de transmissão - TUST.

A TUST é calculada individualmente para cada barramento do sistema de transmissão, que pode corresponder a um consumidor, um ponto de conexão com outra concessionária ou um ponto de geração.

A metodologia de cálculo da TUST leva em conta as informações elétricas detalhadas da topologia real e dos fluxos passantes nas redes de transmissão, contabilizando os custos marginais de expansão incorridos para acréscimos de $1 \mathrm{~kW}$ 
em todas as barras do sistema, analisadas uma a uma. Neste processo, os custos utilizados são os custos unitários de reposição por capacidade, e não os custos totais unitários, que incluem operação, manutenção, perdas e outros. Para maiores detalhes da metodologia nodal, consultar (ANEEL-D, 2005).

A aplicação de uma metodologia nodal ao sistema de distribuição mostra-se demasiado complexa e de certa forma inapropriada ${ }^{15}$. A complexidade de aplicação seria bastante grande, em primeiro lugar, devido ao imenso número de barramentos ("clientes") existentes, em alguns casos podendo chegar a milhões.

Além disso, seria também bastante difícil avaliar as condições de carregamento de cada elemento do sistema de distribuição devido ao constante dinamismo dos fluxos de carga à variabilidade da topologia da rede devido a manobras frequentes.

Por estes motivos, e também pela premissa desejável da praticidade e aplicabilidade da metodologia, propõe-se a representação do sistema de distribuição por um diagrama simplificado de fluxo de energia, de forma análoga ao diagrama de fluxo de potência utilizado na metodologia vigente.

Conforme discutido no item 6.2, em um diagrama simplificado de fluxo não há informações suficientes para diferenciar os custos marginais de suprimento aos consumidores conectados a um mesmo nível de tensão.

Cada nível de tensão será, por definição, formado por linhas e equipamentos do nível e por transformações para o nível de tensão, uma vez que as transformações entre níveis existem para alimentar os níveis a jusante.

A escolha de um diagrama de fluxo de energia ao invés de um diagrama de fluxo de potência se dá por alguns motivos. O principal deles consiste no fato de que o diagrama simplificado servirá para avaliar acréscimos marginais de potência média, e por hipótese simplificadora, estes acréscimos marginais serão supridos na mesma proporção da energia.

Para compreender a questão do acréscimo marginal de potência, considere a Figura 53. Nela são representados apenas três níveis de tensão. A hipótese simplificadora que se configura na escolha do fluxo de energia é a de que, dado um acréscimo marginal de potência de $1 \mathrm{~kW}$ médio em algum nível de tensão, os fluxos

\footnotetext{
${ }^{15}$ Para os níveis A2 e A3, dependendo da complexidade do sistema, é possível a aplicação da metodologia nodal.
} 
incrementais de suprimento e de transferência entre níveis ocorrerão na mesma proporção do fluxo da demanda média, que é igual à proporção do fluxo de energia.

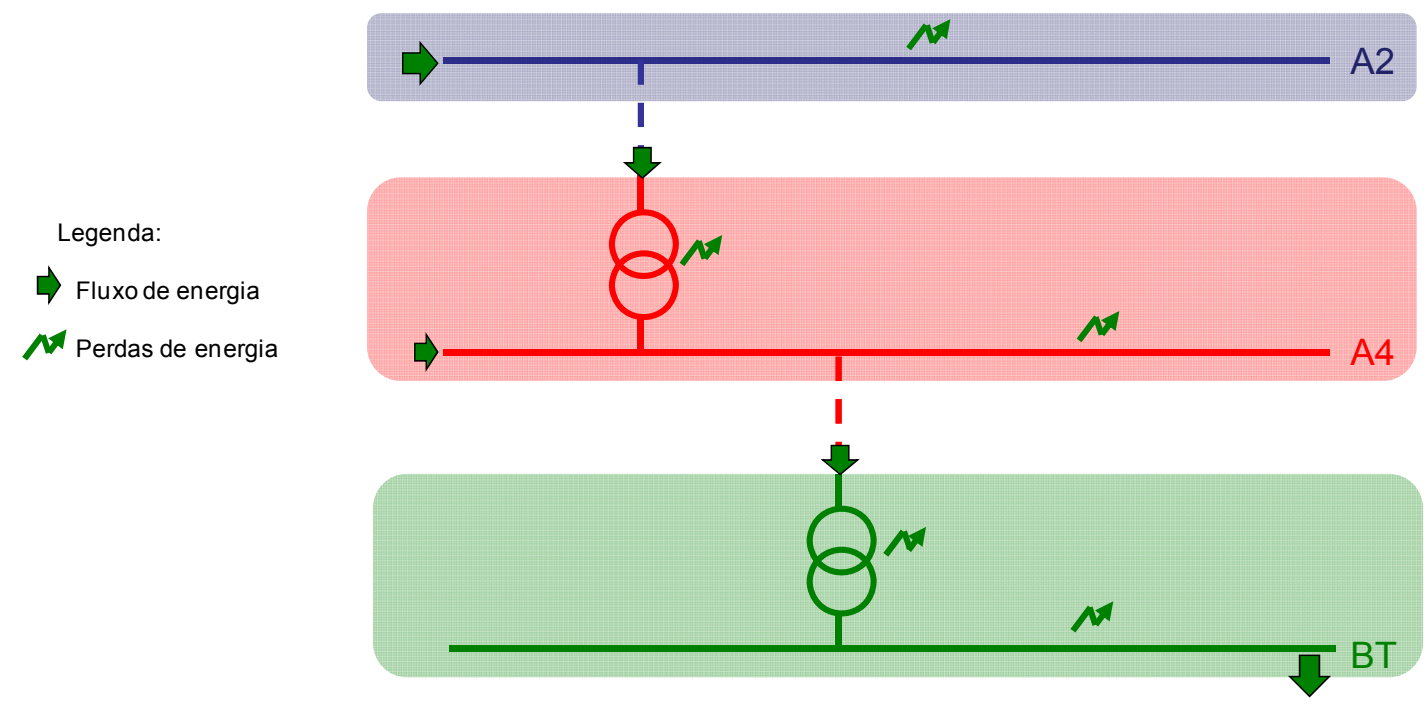

Figura 53 - Exemplo de diagrama simplificado de fluxo de energia com três níveis: A2, A4 e BT

No diagrama da Figura 53 também são representadas as perdas técnicas em percentual da energia fornecida pelo nível de tensão. Aqui, parte-se do pressuposto de que as perdas incrementais ocasionadas pelo incremento de potência no nível BT também ocorram na mesma percentagem em relação às perdas totais de energia.

Na metodologia atual, são consideradas as perdas de potência relacionadas à potência máxima. No entanto, a estimativa das perdas de potência é bastante complexa, pois deve levar em consideração as potências coincidentes em todos os níveis de tensão, além de dados topológicos detalhados.

A opção pela consideração das perdas de energia, embora de certa forma imprecisa, é bastante apropriada devido à disponibilidade dos dados de perdas técnicas de energia, acumuladas geralmente em um período de um ano.

Sob outro prisma, a escolha de um diagrama de energia alinha-se melhor com a característica da aplicação de um preço médio anual aos consumidores do sistema. Enquanto o diagrama de fluxo de potência reflete unicamente o estado de maior solicitação do sistema, equivalente a uma fotografia, o diagrama de energia reflete o que ocorre em média. 
Por fim, deve-se notar também que a expansão do sistema não ocorre pontualmente para atender ao instante de máximo carregamento agregado, mas sim para atender às demandas máximas de cada sub-sistema. Como o diagrama simplificado agrega todos os sub-sistemas em um sistema equivalente (médio), o fluxo de energia é uma opção consistente com a expansão média.

\subsubsection{A caracterização da carga}

No contexto da atual metodologia de cálculo da estrutura tarifária de uso dos sistemas de distribuição brasileiros, a etapa de Caracterização da Carga assume um papel de fundamental importância, pois visa determinar os perfis de consumo típicos de usuários e de redes do sistema, com objetivos diretamente relacionados ao cálculo dos preços de referência.

A Caracterização da Carga consiste em uma série de métodos e procedimentos que vão desde a determinação do número de amostras a serem medidas no sistema até a construção final das tipologias representativas de cada perfil de consumo.

Sintetizando-se os processos atuais de maneira objetiva, a Caracterização da Carga trata dos seguintes itens: a determinação do número de amostras a serem medidas, o sorteio de consumidores e equipamentos, a campanha de medidas, o tratamento das medições, a escolha das curvas de carga a serem efetivamente utilizadas e, por fim, a classificação de curvas em tipologias representativas de grupos de consumidores ou redes com perfis de uso semelhantes.

A ANEEL, em seus Procedimentos de Distribuição (ANEEL-C, 2008), trata apenas da questão da determinação das amostras a serem medidas, não havendo referências a qualquer dos outros itens mencionados acima. Cabe também ressaltar que a agência oferece um tratamento univariado à questão do cálculo específico do número de amostras, o que não é apropriado ao tratamento de um problema multidimensional.

Contudo, pode-se dizer que existem inúmeros fins para o estudo de perfis horários de consumo da energia elétrica, podendo-se destacar como principais os 
relacionados ao planejamento dos sistemas de distribuição, e aqueles relacionados à determinação da estrutura tarifária, objetivo principal desta tese.

É fato que a grande maioria dos consumidores de energia apresenta um perfil típico de consumo diário relacionado ao seu comportamento rotineiro, que, salvo exceções, tende a ser bastante cíclico. Este fato torna a previsão de demandas horárias mais precisa em segmentos agregadores de carga do sistema, tais como alimentadores ou subestações de distribuição.

Neste sentido, são necessários esforços para a correta interpretação e determinação destes perfis típicos de consumo, dado o contexto para o qual se pretende o estudo, e também dadas as inúmeras possibilidades de tratamento dos dados.

Cada consumidor conectado ao sistema de distribuição de energia consome potência instantaneamente, segundo seu perfil temporal diário, durante 24 horas por dia, 365 dias por ano. Dependendo da precisão do equipamento de medição a ele associado, poder-se-ia armazenar as potências médias em determinados intervalos de tempo, como por exemplo a cada 5, 10 ou 15 minutos.

Dadas as 365 curvas de carga armazenadas, seria possível calcular a curva de carga média do consumidor, que poderia ou não representar bem o seu perfil típico de consumo, dependendo dos desvios associados a cada ponto de medição armazenada.

Se fossem divididos os 365 dias entre duas categorias, dias úteis e finais de semana, ter-se-ia, por premissa, uma menor dispersão nos perfis típicos médios de cada um destes grupos se comparados à dispersão obtida considerando-se todas as 365 curvas do ano.

Como, de forma geral, as curvas de carga de dias úteis apresentam as maiores demandas máximas verificadas, seriam estes dias os melhores candidatos para a avaliação dos perfis típicos de consumo. No contexto da metodologia atual de estrutura tarifária, são selecionadas curvas de dias úteis para a construção das chamadas tipologias de carga.

Para exemplificar esse fato, considere a Figura 54, na qual são apresentadas curvas de carga de um consumidor real conectado em média tensão, medido por 32 dias ininterruptos. As curvas de carga diárias deste consumidor foram armazenadas 
com intervalo de precisão de 5 minutos, resultando em 288 pontos para cada dia medido.

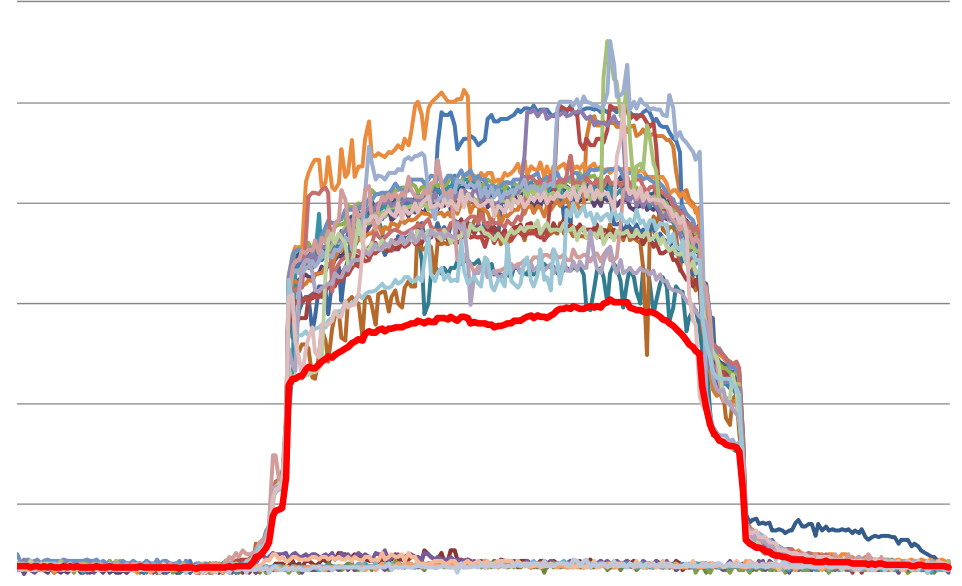

Figura 54: Curvas de carga de um consumidor de média tensão, representando 32 dias ininterruptos de medição

Nota-se nitidamente, através da Figura 54, dois grupos de medições bastante características. O primeiro grupo, que caracteriza-se por uma elevação considerável no consumo entre às $7 \mathrm{~h}$ e as $18 \mathrm{~h}$, aproximadamente, representa o grupo de medições em dias úteis. O outro grupo, com um perfil relativamente constante durante o dia, agrega as curvas de finais de semana.

$\mathrm{Na}$ Figura 55, é possível observar que a curva de desvios padrão indica variabilidade muito elevada exatamente entre às $7 \mathrm{~h}$ e às $18 \mathrm{~h}$, horário em que os dois grupos distinguem-se consideravelmente.

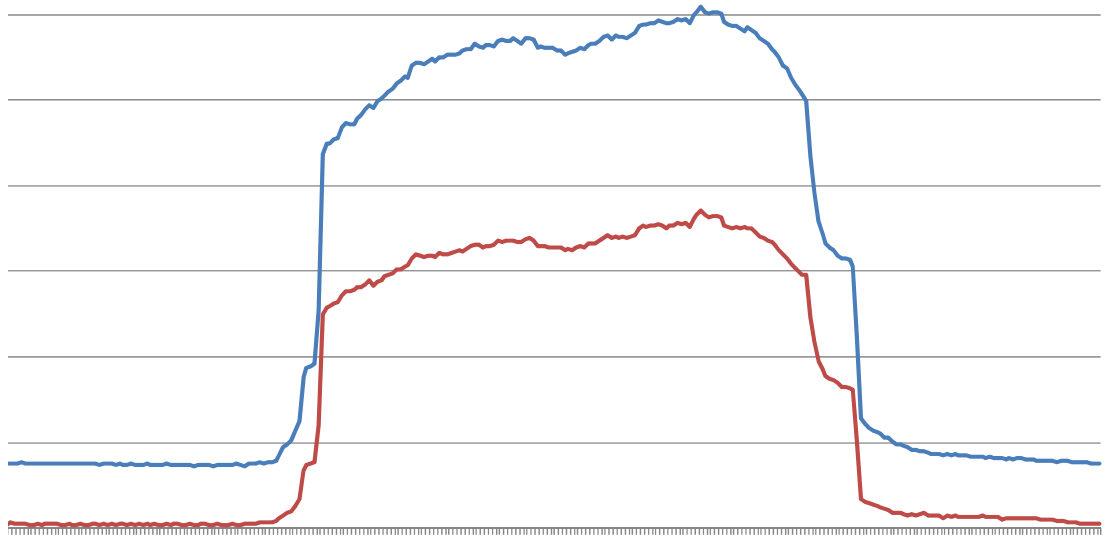

Figura 55: Média e desvio padrão dos 288 pontos armazenados durante os 32 dias de medição. Média em azul e desvio padrão em vermelho 
Nota-se que a curva média, obtida através da média aritmética de cada um dos 288 pontos, não representa bem nem um grupo nem o outro. Por outro lado, fazendose a classificação das medições nos dois grupos já mencionados, dias úteis e finais de semana, pode-se construir curvas médias bastante mais representativas, como ilustrado na Figura 56 e na Figura 57.

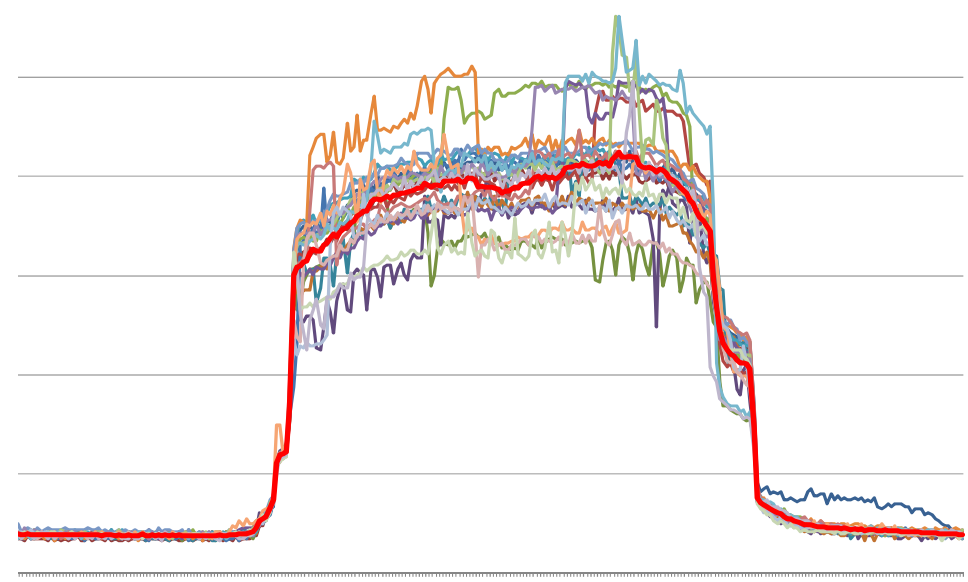

Figura 56: Grupo de curvas de dias úteis, contendo 22 dias de medição, além da curva média

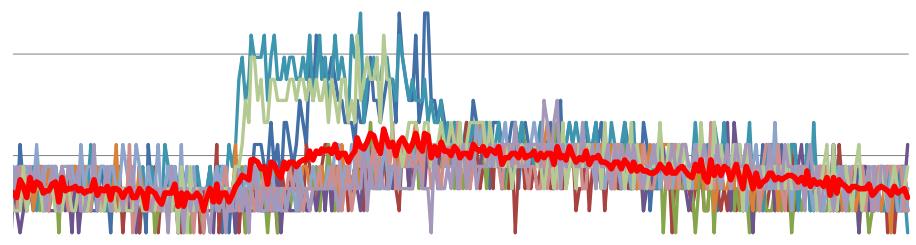

Figura 57: Grupo de curvas de finais de semana, contendo 10 dias de medição, além da média

Através da Figura 58 e da Figura 59, é possível notar que as curvas de desvios padrão para cada grupo são bem menores que a curva de desvios observada na Figura 55, indicando, para este exemplo, a natural separação dos perfis de carga observados em dias úteis e finais de semana. 


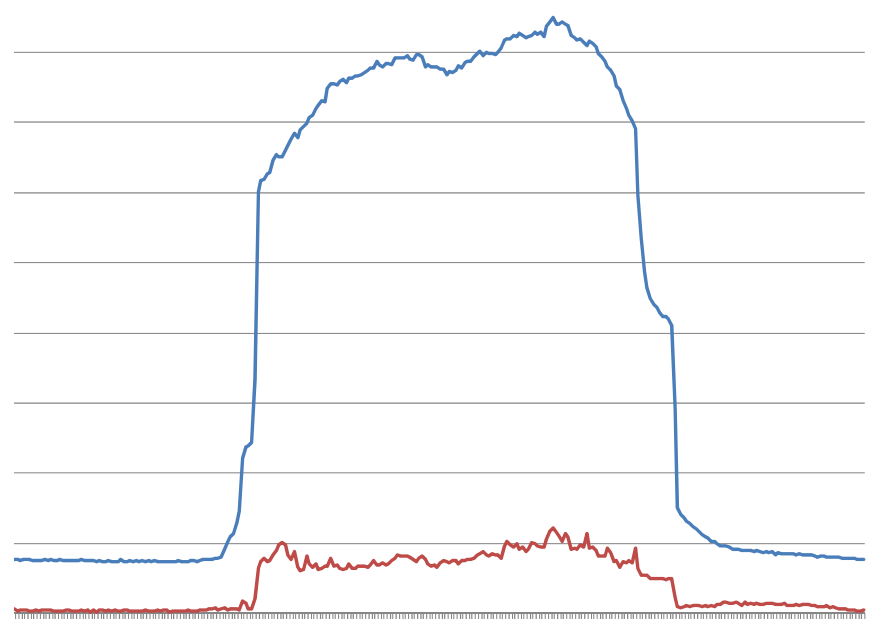

Figura 58: Curvas de médias e desvios de cada um dos 288 pontos para dias úteis. Média em azul e desvio padrão em vermelho

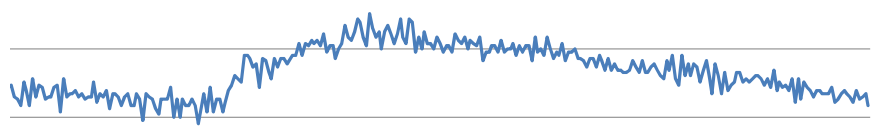

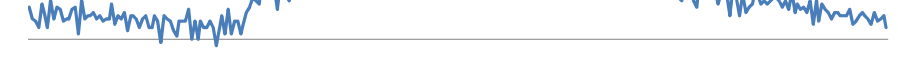

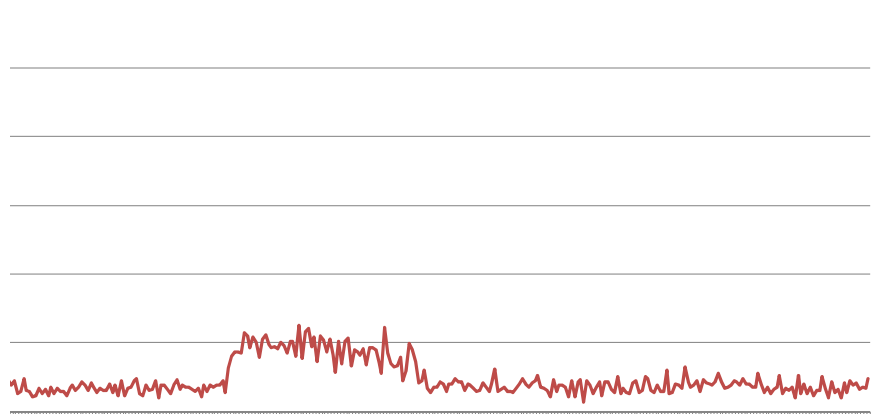

Figura 59: Curvas de médias e desvios de cada um dos 288 pontos para os finais de semana. Média em azul e desvio padrão em vermelho

Embora o exemplo citado obviamente não possa ser utilizado para inferir situação equivalente para a maioria ou para a média dos consumidores de energia elétrica, parte-se da premissa de que, em geral, o procedimento de classificação de curvas de carga em dias úteis e finais de semana é apropriado para a identificação perfis típicos.

Tal premissa decorre da correlação empírica do perfil de consumo com o ciclo social do trabalho, no qual o sábado e o domingo são, em geral, dias de baixa atividade. É claro que existem casos particulares que fogem ao geral, como shopping centers por exemplo, o que não invalida o tratamento aplicado à média ou à maioria dos consumidores. 
Qualquer procedimento para determinar o perfil típico de consumo dos consumidores ou equipamentos de um sistema de distribuição deverá contar com dados de curvas de carga medidas. Atualmente, para a maioria das empresas concessionárias de distribuição brasileiras, não existem dados armazenados de curvas de carga para consumidores de baixa tensão e para transformadores de distribuição.

De forma geral, em alguma medida, existem curvas de carga armazenadas em meio digital, 365 dias por ano, para subestações de distribuição e consumidores de alta tensão. Já para consumidores de média tensão, embora algumas empresas contem com medição eletrônica para todos os consumidores, a maioria delas possui dados de curvas de carga armazenados apenas para consumidores com tarifas horosazonais, dos tipos Verde e Azul.

Dado este contexto, para a aquisição de dados de curvas de carga de consumidores que geralmente não contam com medição eletrônica e armazenamento de dados em meio digital, é necessária a realização de campanhas de medidas temporárias, realizadas em amostras representativas de consumidores.

Geralmente, considerando-se o segundo ciclo de revisões tarifárias no Brasil, iniciado em abril de 2007 e com término em agosto de 2010, as campanhas de medidas geralmente são realizadas para consumidores de baixa tensão, consumidores de média tensão, e transformadores de distribuição.

Segundo o Módulo 2 dos Procedimentos da Distribuição (ANEEL-C, 2008), a concessionária deve "[...] realizar medições em todas as unidades consumidoras com instalações conectadas em tensão igual ou superior a $69 \mathrm{kV}$ e por amostragem nos demais níveis de tensão [...]".

No entanto, apesar de facultar às distribuidoras a realização de "[...] medição permanente para caracterização da carga de suas unidades consumidoras e o carregamento de suas redes e transformadores [...]", no âmbito da campanha para transformadores de distribuição, consumidores de baixa e média tensão, o órgão regulador nada versa sobre definições como:

Quantos dias cada consumidor ou transformador deve ser medido.

$>$ Dentre as curvas medidas de dias úteis, sábados e domingos, qual delas escolher, ou mesmo se dever-se-ia utilizar ou não a curva média dos dias medidos. 
$>$ Caso uma curva deva ser escolhida como representativa, qual o procedimento objetivo e reprodutível para fazê-lo.

$>$ Em qual período realizar a campanha de medidas.

$>$ As medições deveriam ou não referir-se ao mesmo período de tempo.

A indefinição de questões como estas deixa bastante subjetivo o processo de aquisição, escolha e tratamento das curvas de carga medidas para a construção de perfis típicos de consumo. Devido ao caráter bastante abrangente e normativo das questões que envolvem a representatividade da curva de carga típica dos consumidores, esta análise não fará parte desta proposta.

Desta forma, supondo que estes perfis típicos de cada consumidor estejam bem definidos e normatizados (embora ainda não estejam), a questão que naturalmente surge é a da representatividade da população de consumidores a qual é aplicada uma tarifa média.

O problema está intrinsecamente ligado ao processo de inferência estatística detalhado no ANEXO V. De forma geral, como a construção de um perfil de consumo representativo da população será a partir de uma amostra de consumidores, deve-se, antes de mais nada, definir qual a variável a ser inferida.

Neste caso, a "variável" é o próprio formato da curva. De acordo com (COSTA NETO, 2002), a estimação de um parâmetro pode ser realizada para a média de uma variável, para o seu desvio padrão ou variância, e para a proporção populacional.

No caso do perfil de consumo, que essencialmente é uma variável ndimensional, pretende-se inferir qual o perfil médio da população. Partindo-se do fato indiscutível de que a tarifa é também um preço médio a ser aplicado a todos os consumidores que se enquadram em uma dada modalidade, nada mais sugestionável que a consideração de um perfil médio de consumo da energia para representar o conjunto destes consumidores.

A Figura 60 ilustra o problema da inferência da curva média. Dada uma população de consumidores para a qual é aplicada uma tarifa média, como por exemplo a classe de consumidores residenciais, existe uma curva de carga média para o conjunto da população que é desconhecida. Pretende-se, pois, determinar uma amostra estatística que represente com certo grau de precisão esta curva média da 
população. Para maiores detalhes sobre a inferência estatística multivariada da curva de carga média, consultar o ANEXO V.

Resumidamente, o que está sendo proposto é a consideração de uma curva de carga média representativa de cada tipo de modalidade tarifária (por exemplo, as cargas do sistema nas modalidades B1, B2, B3, B4, A4-CONV, A4-VERDE, A4-AZUL, etc) e também de cada transformação ou injeção representados no diagrama simplificado de fluxo de energia.
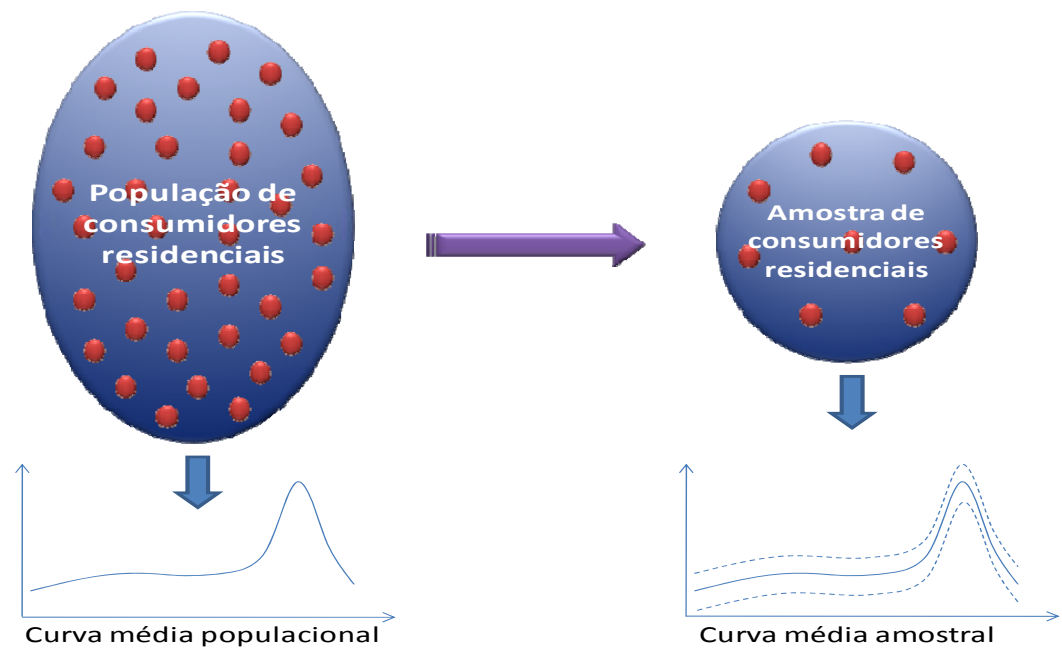

Figura 60: Inferência do formato da curva média da população de determinada modalidade. As linhas tracejadas representam o erro amostral

\subsubsection{Sinalização e elasticidades}

Conforme detalhado no item 2.1.3, a questão da sinalização de preços de ponta e fora-ponta em sistemas de distribuição de energia não está somente relacionada à diferença de custos marginais de curto e longo prazos, mas também ao comportamento dos consumidores na forma de suas elasticidades-preço da demanda por eletricidade.

A quantificação da resposta dos consumidores aos sinais de preços é fundamental para a correta avaliação da retração ou expansão dos mercados de energia e potência. Em um sistema regulatório de preço teto, como o brasileiro, esta 
avaliação é ainda mais importante, pois a receita da distribuidora está diretamente relacionada ao comportamento do mercado, que obviamente não é função apenas dos preços.

Assim, a avaliação da elasticidade-preço da demanda por eletricidade é, teoricamente, de grande importância para a avaliação da dinâmica do mercado total e também dos mercados contabilizados separadamente nos períodos de ponta e foraponta, principalmente porque existem elasticidades cruzadas entre estes dois períodos, fazendo com que o preço em um período afete o consumo no outro período.

Apesar da importância da consideração das elasticidades dos consumidores na avaliação do mercado, e consequentemente da estrutura tarifária, a quantificação destas elasticidades é bastante problemática para a aplicação em horizontes de curto prazo, como são os ciclos tarifários.

Geralmente, na literatura, são estimadas apenas as elasticidades de longo prazo através de modelos econométricos de séries temporais, como os usados em (MODIANO, 1984), (ANDRADE \& LOBÃO, 1997) e (SCHMIDT \& LIMA, 2004).

(SCHMIDT \& LIMA, 2004) estimaram as elasticidades das classes residencial, comercial e industrial no Brasil, utilizando dados históricos anuais de 1969 a 2000, também através de um modelo cointegrado do tipo VAR. Neste trabalho, as elasticidades-preço da demanda por energia elétrica para as classes residencial, comercial e industrial foram estimadas, respectivamente, em -0,085, -0,174 e -0,129.

Em (EL HAGE, 2009), é possível concluir que as elasticidades de curto prazo, importantes na avaliação do comportamento do mercado no horizonte de um ciclo tarifário, são menores que aquelas estimadas no longo prazo.

A partir de uma pesquisa bibliográfica sobre o tema, é possível afirmar que existem estudos quantitativos apenas para as elasticidades de longo prazo, relacionadas ao consumo da energia elétrica. Sabe-se, todavia, que a variável utilizada na construção da estrutura tarifária é a potência elétrica, e que o horizonte de interesse, devido ao período de um ciclo tarifário, é o de curto prazo.

Este contexto indicará que uma solução simplificadora, como tem sido a diretriz da proposta, seria desconsiderar as elasticidades-preços da demanda por potência e por energia elétrica, porém de forma controlada, como será descrito no item 6.5. 


\subsubsection{Precificação não linear}

Conforme a discussão teórica apresentada no item 2.1.2, constatou-se que o objetivo da precificação não linear está relacionado diretamente ao aumento da eficiência econômica.

Ficou claro que, dependendo do perfil médio de consumo de cada consumidor, avaliado pelo fator de carga, um esquema de precificação não linear deve induzir o consumidor a auto-selecionar a alternativa mais econômica para o seu perfil. Isto ocorrerá, obviamente, se o consumidor dispuser de informações claras sobre o mecanismo de precificação adotado.

No Brasil, existe um mecanismo de precificação não linear para consumidores de média tensão. As duas modalidades diretamente concorrentes deste esquema são as conhecidas modalidades Azul e Verde, sendo opcionais aos consumidores desde que atendidos em níveis de tensão A4 e A3a, e com potência contratada de até 300 kW. Para maiores detalhes, consultar (ANEEL-G, 2005).

Estas modalidades são exatamente iguais para o posto tarifário de fora-ponta, porém concorrentes para o posto da ponta. A ANEEL, para o segundo ciclo de revisões tarifárias iniciado em 2007, definiu o fator de carga de "corte" entre estas duas modalidades em $66 \%$. Não há documentos oficiais da agência descrevendo o método utilizado para a determinação deste valor.

A Figura 61 ilustra as curvas de triagem das modalidades Verde e Azul em base de faturamento mensal. Vale lembrar que a modalidade Verde não contém tarifa faturada em potência de ponta (fixa), e também que para a tarifa Azul toda a TUSD Tarifa de Uso da Distribuição é faturada em potência. 


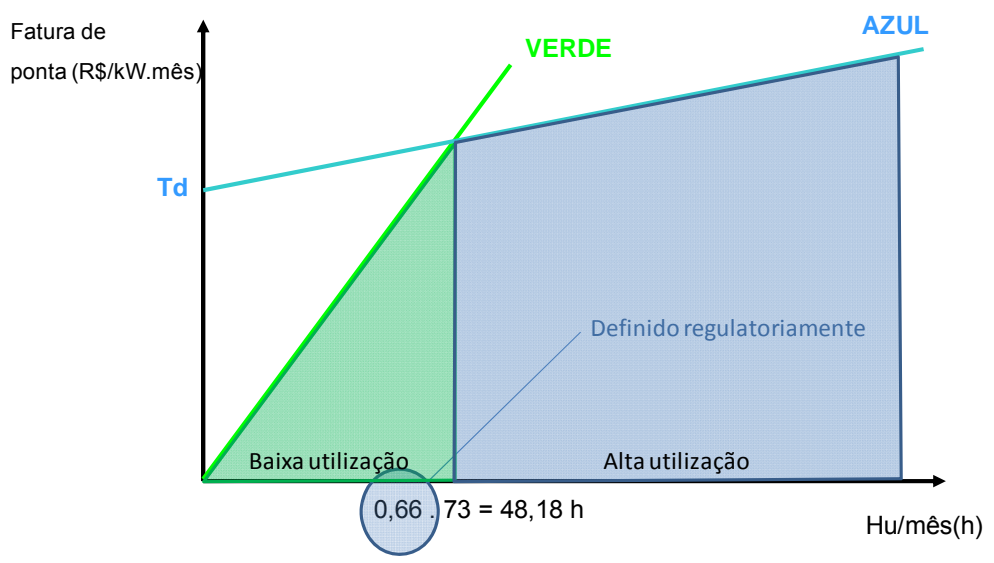

Figura 61 - Modalidades Azul e Verde atualmente empregadas nos sistemas de distribuição brasileiros

Atualmente, devido a uma conjuntura de altos preços de transporte e propriamente da energia, tem-se observado pelo país afora o crescimento de soluções de auto-produção para suprimento no horário da ponta. Dentre as tecnologias mais difundidas está a geração a diesel.

Para melhor compreender as possíveis razões que estão levando os consumidores a optarem por uma tecnologia operacionalmente custosa, e também poluidora, em detrimento da energia disponível através do sistema de distribuição, considere a Figura 62.

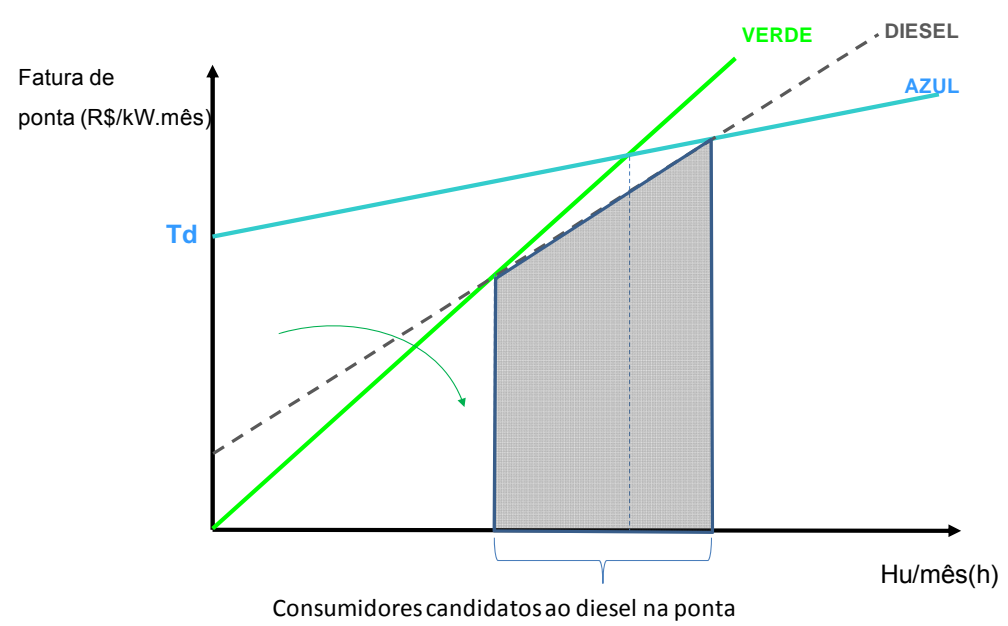

Figura 62 - Possível curva de custos da geração a diesel

É fato que atualmente, para a maior parte das empresas de distribuição nacionais, os custos de capacidade da auto-produção a diesel são menores que as 
tarifas fixas por potência contratada na modalidade Azul. Ainda, os custos operacionais relacionados ao custo do combustível são maiores que o valor da tarifa final de energia da modalidade Azul, incluídos encargos e impostos em ambos os casos.

Desta forma, para o panorama atual, conforme ilustrado na Figura 62, uma gama de consumidores teria como mais econômica a opção da auto-produção, tornando necessária a ação regulatória, já que essa alternativa, além de inibir a modicidade tarifária, parece ser inadequada frente a um sistema que distribui energia fundamentalmente hidráulica, em escala e ecologicamente superior.

Esta ação regulatória poderia caminhar em duas direções. A primeira, mais óbvia, seria a reavaliação do nível médio de preços, bastante relacionado aos encargos e impostos diversos existentes na tarifa de energia brasileira. A segunda direção regulatória a tomar, independente de ações no nível médio dos preços ${ }^{16}$, seria a construção de modalidades tarifárias intermediárias às existentes Azul e Verde.

A construção de uma modalidade tarifária sobreposta aos custos da curva da auto-produção a diesel, construída através de um estudo detalhado sobre os custos desta alternativa tecnológica, e também de outras, poderia inibir ou inviabilizar aos consumidores a opção pela auto-produção.

Não se deve esquecer, todavia, que a decisão do consumidor é realizada também com base em fatores exógenos ao preço da energia ou da potência. A cobrança monômia em energia, por exemplo, traz ao consumidor reduzidos custos de gerenciamento de seu perfil de consumo, uma vez que não há a necessidade de limitar a potência.

Em (WILSON, 1993), são descritas algumas aplicações bastante interessantes da teoria de precificação não linear. Dentre estas aplicações, destacam-se as modalidades tarifárias da EDF - Elecricitè de France, empresa estatal francesa.

A análise dos mecanismos de preços utilizados na EDF é bastante apropriada, uma vez que boa parte da metodologia de construção da estrutura tarifária brasileira foi originária de um convênio entre o governo brasileiro e a estatal francesa.

\footnotetext{
${ }^{16}$ Não cabe à ANEEL arbitrar sobre o nível de encargos existentes na tarifa, reduzindo seu poder de ação para a redução do nível médio de preços.
} 
Segundo (WILSON, 1993), as modalidades tarifárias francesas para o setor energético denominam-se modalidade Azul, para clientes residenciais e rurais, além de comerciais até 36 kVA de potência, modalidade Amarela, para todos os consumidores com potências entre 36 e 250 kVA, e modalidade Verde, segmentada em séries $(A, B$, etc.), dependendo da potência máxima dos consumidores.

A seguir, serão descritas as principais características observadas nas modalidades da EDF, atentando para o desenho dos sistemas de precificação não linear, sempre baseados em uma tarifa fixa, por potência, e uma tarifa variável, por consumo de energia mensal acumulado.

\section{i. A modalidade Azul}

A tarifa Azul francesa possui três retas tarifárias opcionais para os consumidores comerciais até $36 \mathrm{~kW}$. As opções são denominadas básica, horas de vazio e horas críticas. Para compreender o esquema não linear de precificação, considere as informações abaixo. Todos os preços estão relativizados e têm como base a opção Básica.

\section{Básica}

Tarifa fixa por potência: $100 \%$ (\$/kVA.mês)

Tarifa de energia: $100 \%$ (\$/kWh)

\section{Horas de Vazio}

Tarifa fixa por potência: 125\% (\$/kVA.mês)

Tarifa de energia fora ponta: $50 \%(\$ / k W h)$

Tarifa de energia ponta: $100 \%(\$ / k W h)$

\section{Horas Críticas}

Tarifa fixa por potência: 50\% (\$/kVA.mês)

Tarifa de energia: 64\% (\$/kWh)

Tarifa de energia: $900 \%$ após anúncio de escassez (\$/kWh) 
A Figura 63 ilustra a interpretação gráfica das três opções da modalidade Azul para o horário de ponta. Como pode ser observado, a opção Horas de Vazio, em relação à opção Básica, tem menores custos variáveis de energia porém maiores custos fixos por potência, refletindo os custos verticalizados da geração de base.

A opção de Horas Críticas talvez seja a mais interessante para uma possível implementação no Brasil, pois apresenta características que permitem um inteligente gerenciamento pelo lado da demanda. Sendo a opção mais barata em situação normal, tanto para o custo fixo como para o custo variável, esta opção seria a mais interessante para os auto-produtores.

Os consumidores optantes pela tarifa Azul de Horas Críticas devem se desconectar ao receber um aviso de escassez de energia, podendo sofrer uma sobretaxação de $800 \%$ no preço da energia caso continuem consumindo. Sendo assim, consumidores auto-produtores teriam interessantes incentivos por esta opção, uma vez que teriam flexibilidade na modulação do consumo proveniente da rede.

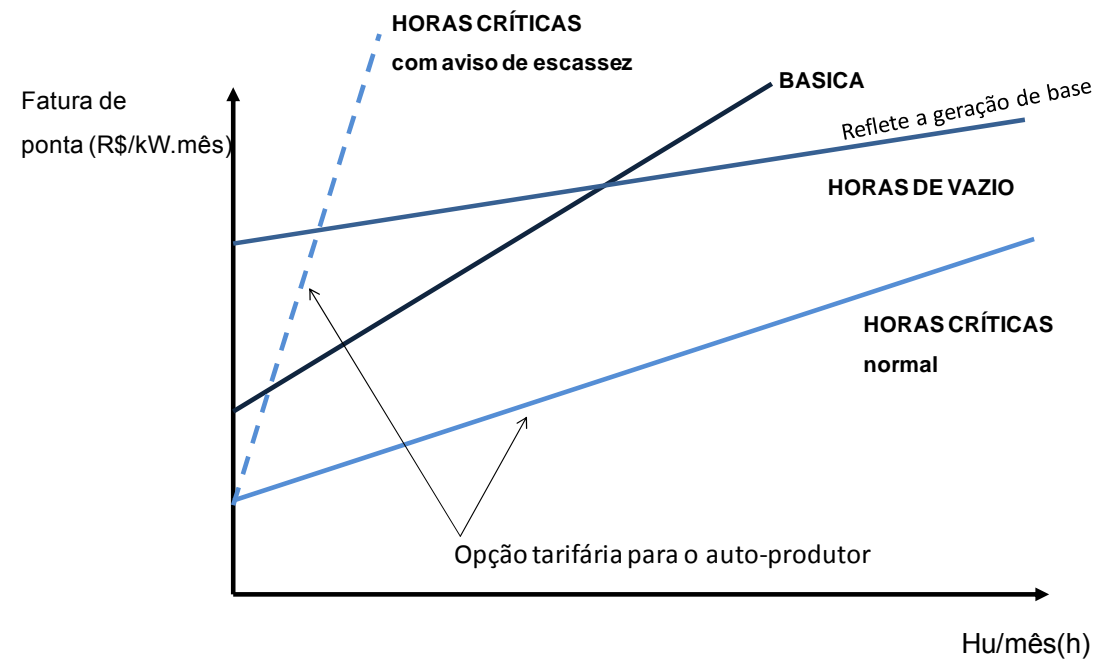

Figura 63 - Interpretação gráfica das opções da modalidade Azul da EDF

\section{ii. A modalidade Amarela}

A tarifa Amarela possui as mesmas três opções existentes na tarifa Azul, porém com algumas diferenças. A primeira delas se refere ao preço da energia, que passa a ser sazonal dependendo do período do ano em que é consumida. Outra 
diferença em relação à tarifa Azul, segundo (WILSON, 1993), encontra-se no processo de faturamento dos consumidores.

A partir de um medidor capaz de registrar o histórico de potências consumidas em intervalos de tempo amostrais pré-definidos (15 em 15 minutos), classificam-se os consumidores pelo uso, podendo ser de alta utilização ou de baixa utilização. Desta forma, os preços cobrados tendem a refletir o processo verticalizado de reflexão dos custos da produção de energia.

\section{iii. A modalidade Verde}

A tarifa Verde é a tarifa destinada aos grandes consumidores na França, independentemente de seu ramos de atividade. Para cada faixa de potências máximas registradas, por exemplo, até $10.000 \mathrm{~kW}, 10.000$ a $40.000 \mathrm{~kW}$ e assim por diante, existem várias modalidades ( $A 1, A 2$, etc.), objetivando a maior eficiência econômica.

A Figura 64 ilustra um esquema de tarifação Verde para uma faixa de potências qualquer. Como descrito no item 2.1.2.2, um esquema de tarifação com $n+1$ modalidades é mais eficiente que um outro $\operatorname{com} n$ modalidades. Neste sentido, a tarifa Verde da EDF é uma aplicação fiel da teoria econômica da precificação não linear.

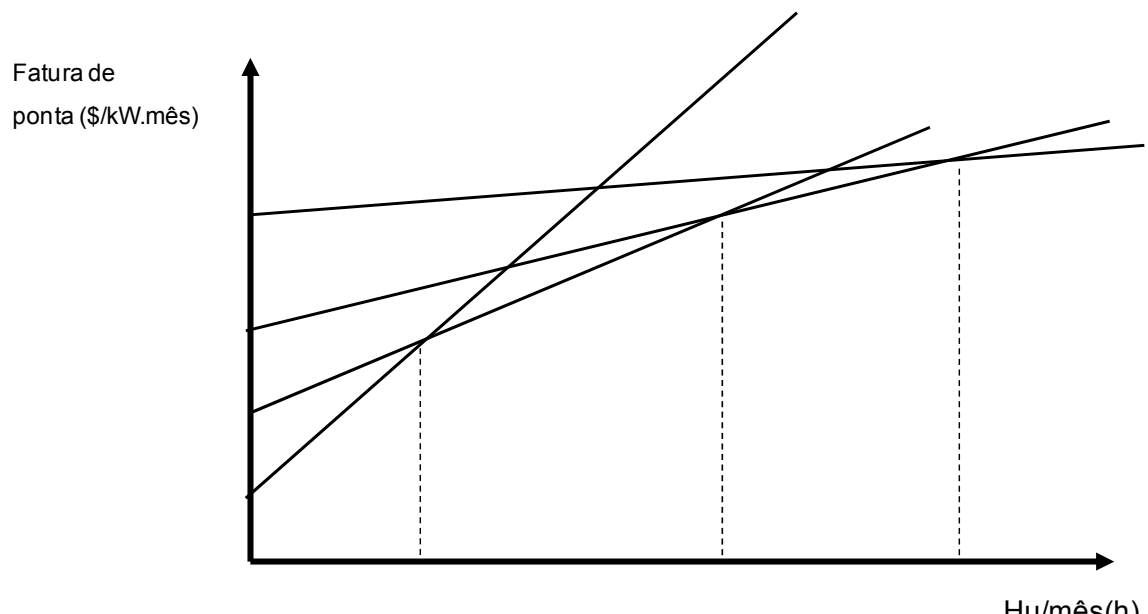

Figura 64 - Modalidades A1, A2, ..., An de uma das faixas da tarifa Verde francesa. 


\subsection{A estrutura vertical}

Para constituir a base da metodologia que determinará a estrutura vertical de preços de um sistema de distribuição, serão apresentadas as variáveis e índices algébricos que quantificarão a estrutura de preços entre os níveis de tensão.

A base para a construção dos preços de referência dos níveis de tensão são os custos marginais de longo prazo, aqui denominados Custos Marginais Isolados - CMI. Esta nomenclatura está relacionada ao fato destes valores referirem-se aos custos marginais de expansão e operação das redes de apenas determinado nível de tensão, isoladamente.

A questão da determinação dos Custos Marginais Isolados, que são os custos marginais de longo prazo de um determinado nível de tensão, foi tratada em maiores detalhes no item 2.1.4. Não fará parte desta proposta a especificação de um método para a determinação destes custos isolados, mas sim como utilizá-los para calcular o que se denomina aqui de Custos Marginais Compostos - CMC.

Os Custos Marginais Compostos são os custos marginais cumulativamente incorridos pelo uso de diversos níveis de tensão a montante do ponto de conexão da carga em análise. Estes custos compostos refletem os custos advindos de um sistema de transporte, para o qual maiores distâncias implicam em maiores custos.

Como representa-se o sistema de distribuição por um diagrama simplificado de fluxo de energia, serão obtidos Custos Marginais Compostos diferentes somente entre os níveis de tensão, o que convenciona-se denominar de estrutura vertical de preços.

Os Custos Marginais Compostos são equivalentes aos custos de capacidade obtidos na atual metodologia de estrutura tarifária, porém com uma diferença significativa: Os Custos Marginais Compostos não são calculados por período de faturamento, mas sim para um período diário médio.

Outra diferença considerável entre os Custos Marginais Compostos e os custos de capacidade reside na simplicidade de cálculo do primeiro em detrimento da alta complexidade operacional do segundo, como observado no item 4.1.

Para definir algebricamente os Custos Marginais Compostos, é necessário definir algumas variáveis intermediárias, como o Índice de Proporção de Fluxo - IPF e 
o Índice Técnico de Atendimento - ITA, apresentados a seguir pelas Equações (58) e (60).

$I P F_{f i}=\frac{F_{f i}}{\sum_{i=1}^{n} F_{f i}}$

Sendo

$\sum_{i=1}^{n} I P F_{f i}=1$

Onde:

$I P F_{f i}: \quad \quad$ Índice de proporção de fluxo que alimenta o nível $f$ a partir do nível $i$.

$F_{f i}: \quad \quad \quad \quad \quad \quad \quad \quad$ luxo de energia entre os níveis $f$ e $i$.

O IPF nada mais é do que a percentagem de energia que alimenta um nível de tensão a partir de transformações de outros níveis ou a partir de injeções de energia no próprio nível de tensão.

$I T A_{f i}=\left[\left(1+\tau_{f}\right) \cdot I P F_{f i}+\sum_{m=1}^{n} I T A_{f m} \cdot I P F_{m i}\right] \cdot\left(1+\tau_{i}\right)$

$\forall f \neq i$

$\forall m \in n$ níveis intermediários

$\operatorname{IT} A_{f f}=\left(1+\tau_{f}\right)$

Onde:

$\tau_{i}$ : $\quad$ Perdas Técnicas do nível $i$, tendo como base a energia fornecida pelo nível $i$.

O Índice Técnico de Atendimento de um nível de tensão final a partir de um nível de tensão inicial, $I T A_{f i}$, reflete a demanda média incremental que será solicitada 
do nível inicial para o suprimento de uma demanda média incremental de $1 \mathrm{~kW}$ consumida no nível final.

Finalmente, a partir das definições do Índice de Proporção de Fluxo, do Índice Técnico de Atendimento e dos Custos Marginais Isolados, é possível definir os Custos Marginais Compostos, apresentado na Equação (61).

$C M C_{e}=\sum_{n=e}^{m} I T A_{e n} \cdot C M I_{n} \cdot F C_{e n}$

$\forall n$ a montante de $e$

Onde:

$F c_{e n}$ : $\quad$ Fator de contribuição da curva média conectada ao nível $n$ em relação à curva média de suprimento do nível $e$.

Nota-se que o mecanismo de cumulatividade de custos incorridos nos níveis a montante pelos níveis a jusante é bastante semelhante ao observado no cálculo dos custos de capacidade, como detalhado no item 4.1, porém, matematicamente muito mais simples.

Para elucidar a comparação entre a metodologia proposta e a atual, pode-se dizer que os Custos Marginais Compostos substituem os custos de capacidade, que são calculados a partir do mecanismo associação probabilística entre redes e consumidores tipológicos.

Seria possível também considerar o cálculo de Custos Marginais Compostos para cada modalidade tarifária, desde que representada por uma curva de carga média. Neste sentido, a única variável que diferenciaria os Custos Marginais Compostos de modalidades conectadas ao mesmo nível de tensão seria o fator de contribuição $F c_{e n}$.

A Equação (62) poderia ser usada para o cálculo dos Custos Marginais Compostos para cada modalidade tarifária em um determinado nível de tensão. Vale lembrar que, embora por razões de simplificação, haja uma diferença de "custos" entre modalidades de um mesmo nível, a natureza desta diferenciação não reside nos 
custos, mas sim em um critério de justiça aos consumidores, como foi discutido no item 6.2.

$C M C_{e}^{\text {mod }}=\sum_{n=e}^{m} I T A_{e n} \cdot C M I_{n} \cdot F c_{e n}^{\text {mod }}$

$\forall n$ a montante de $e$

Onde:

$C M C_{e}^{\text {mod }} \quad \quad$ Custo Marginal Composto da modalidade conectada ao nível $e$.

$F c_{e n}$ : $\quad$ Fator de contribuição da curva média da modalidade conectada ao nível $n$ em relação à curva média de suprimento do nível $e$.

\subsection{A estrutura horizontal}

Como os custos marginais de operação no curto prazo são nulos no modelo econômico apresentado no item 6.1, a precificação de ponta e fora ponta para um caso hipotético de pico firme (firm peak), como discutido no item 2.1.3.1, seria a aplicação de um preço igual a zero para a demanda menor (fora-ponta) e igual a $(B+\beta)$ para a demanda máxima (ponta).

É evidente que a situação clássica de pico firme não existiria para este caso, dada a cobrança de um preço igual a zero para a demanda fora-ponta. A solução para este caso pode ser encontrada em (JOSKOW, 2005). Por se tratar de um trabalho mais atual, a formulação do problema de precificação de ponta é realizada separandose os custos marginais de energia e de potência (demanda), o que facilita bastante a aplicação para o caso em que não são considerados custos marginais de energia.

Em (JOSKOW, 2005), o problema da precificação eficiente de demandas periódicas em plantas de capacidade rígida é solucionado a partir da maximização do bem-estar social, como apresentado no item 2.1.3.2.

Considerando-se o modelo econômico apresentado no item 6.1 , no qual o custo marginal de operação de curto prazo (custo da energia) é nulo $(b=0)$, 
naturalmente invalida-se a situação de pico firme, restando apenas a situação de inversão de pico, conforme o conjunto de equações em (63).

O caso de inversão de pico (shifting peak case) com $b=0$ :

$$
\begin{aligned}
& p_{p}=\lambda_{p} \\
& p_{f p}=\lambda_{f p} \\
& \lambda_{p}+\lambda_{f p}=B+\beta \\
& q_{p}=q_{f p}
\end{aligned}
$$

Concluindo, a relação de ponta e fora-ponta é dada pelos preços-sombra $\lambda_{p} \mathrm{e}$ $\lambda_{f p}$, que dependem das funções de demanda por potência em ambos os períodos. De forma prática, mesmo desconhecendo as funções demanda, é possível concluir que a relação ótima ponta/fora-ponta deve ser tal que as demandas $q_{p}$ e $q_{f p}$ se igualem.

Esta condição pode ser observada com facilidade, uma vez que estas demandas são monitoradas continuamente. Todavia, para o modelo proposto, não haveria uma relação de "partida" entre os preços de ponta e fora-ponta, como ocorre nos casos em que $b>0$.

Ainda, dado o contexto apresentado no item 6.3.3, é possível concluir que as elasticidades-preço da demanda por energia elétrica são bastante baixas no longo prazo, e mais baixas ainda no curto prazo, o que se torna bastante importante na avaliação da consideração destes dados na metodologia da estrutura tarifária.

Como não existem dados disponíveis de estimativas de elasticidades-preço da demanda de potência elétrica no curto prazo, e sabendo que para a energia estas elasticidades são muito pequenas em ambos os horizontes (curto e longo prazos), por hipótese simplificadora, as elasticidades serão consideradas nulas nesta proposta metodológica.

Contudo, para o caso da sinalização horizontal (preços de ponta e fora-ponta), apesar da proposição de considerar elasticidades nulas em um momento ex ante (o cálculo da estrutura), é perfeitamente possível fazer ajustes nestas sinalizações em um momento ex post, através da análise do comportamento da curva de carga agregada do sistema. 
Este mecanismo de ajuste ex post dependeria de um acompanhamento por parte do órgão regulador, ou, se possível, da própria empresa. Através da análise do comportamento da curva de carga do mercado agregado, seria possível detectar situações de "shifting peak", e assim alterar sobre-sinalizações de preços em alguns sub-mercados, como por exemplo os de média e baixa tensão.

A Figura 65 ilustra o mecanismo de aplicação de preços de ponta e fora-ponta em função da dinâmica da curva de carga agregada do sistema objeto da otimização. Como pôde ser observado no item 2.1.3, as tarifas de ponta e fora ponta ( $T p$ e $T f p$ ) devem estar situadas entre os custos marginais de longo e curto prazos.

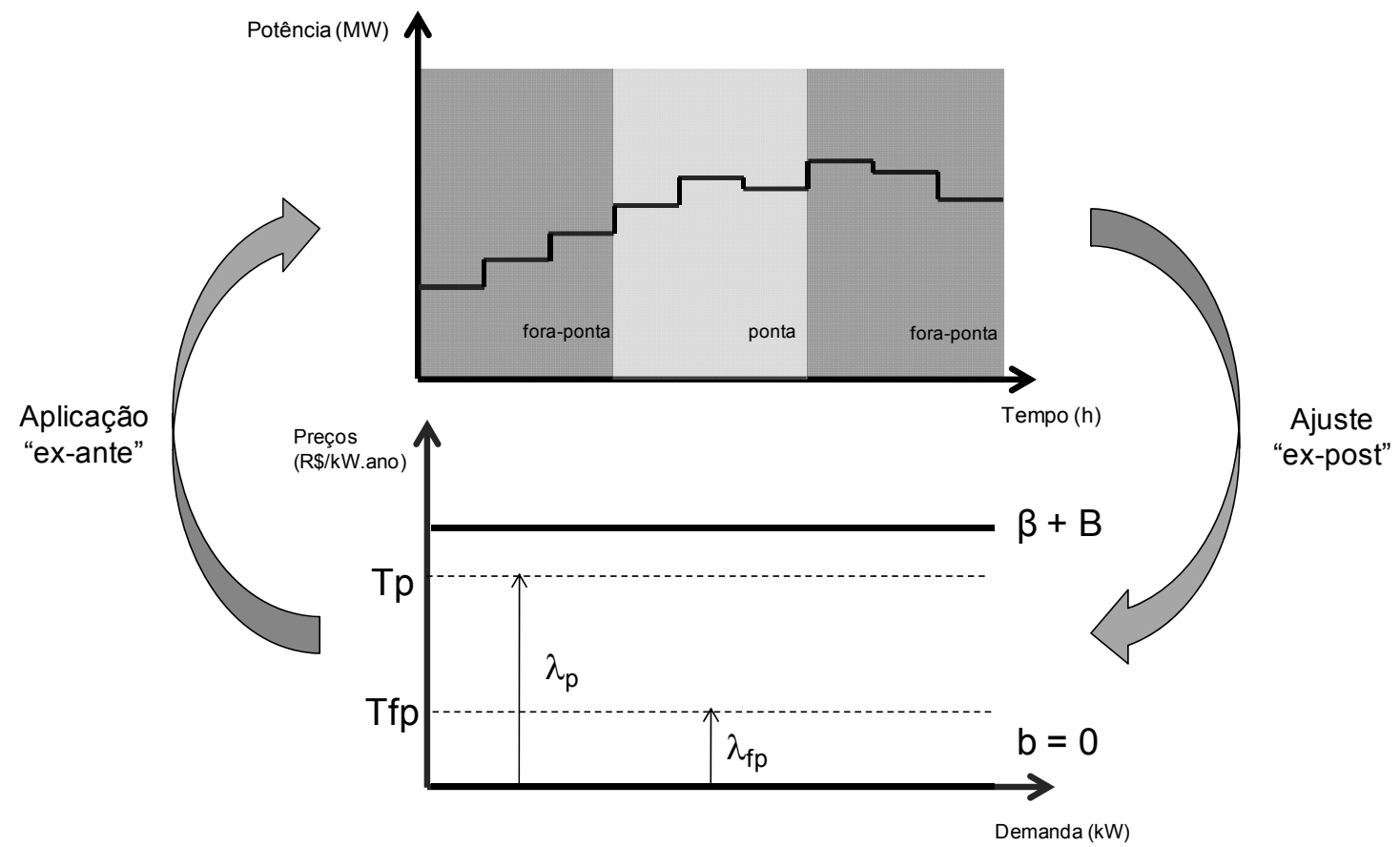

Figura 65 - Mecanismo proposto de ajuste regulatório das sinalizações entre ponta e fora-ponta com base nos custos marginais de curto e longo prazos, e na análise da dinâmica do mercado através da observação da curva agregada do sistema. 


\subsection{Modalidades tarifárias}

Como visto no item 2.1.2.3, as tarifas de eletricidade são geralmente compostas por duas variáveis de faturamento, a energia ativa mensal consumida e a potência ativa máxima mensal registrada. Como é usual valorar a capacidade em $R \$ / k W \cdot$ ano e a energia consumida em $R \$ / M W h$, é também usual a proposição de uma tarifa ao consumidor que seja composta por duas partes, uma fixa, geralmente mensal, por $k W$ contratado, e uma parte variável, por $M W h$ consumido, também em uma base mensal.

Em um sistema verticalizado, no qual a concessionária é a controladora dos processos de geração, transmissão, distribuição e comercialização da energia de forma integrada, é bastante clara e usual a separação dos custos totais em: custos de capacidade, relacionados aos ativos elétricos do sistema, e custos operacionais, dentre os quais a geração de energia representa a maior parcela.

Desta forma, a cobrança da capacidade poderia ser inteiramente alocada na tarifa fixa, por potência contratada, ao mesmo tempo em que os custos operacionais poderiam ser alocados na tarifa variável, por consumo integralizado de energia.

Todavia, nada impede que a cobrança dos custos de capacidade seja feita através do faturamento da energia, o que ocorre com bastante freqüência para os consumidores dos níveis de baixa tensão, ou mesmo que os custos operacionais sejam cobrados através do faturamento da potência ativa.

Como as variáveis de faturamento da tarifa binômia clássica são, como já discutido, a potência ativa máxima registrada em um período mensal, valorada em $R \$ / k W \cdot$ mês, e a energia mensal consumida, em $R \$ / M W h$, é possível alocar os custos de capacidade e operação de infinitas formas entre estas duas variáveis, uma vez que as unidades são múltiplas entre si por um fator de conversão escalar.

Para compreender melhor essa questão, considere que o custo total de produção, transmissão e distribuição de energia de uma determinada concessionária, no curto prazo, seja dado pela equação $C T(e)=100.000 /$ ano $+50 / M W h \cdot e$, onde $e$ representa a energia consumida por seus consumidores. Na estrutura de custo, $\$ 100.000$ é o custo fixo anual, enquanto $50 \$ / M W h$ é o custo operacional da produção e transporte da energia. 
Suponha agora que o mercado agregado da distribuidora, em um ano, seja constante e igual a $1.000 \mathrm{MWh}$, e que seu perfil de consumo agregado, também considerado constante, apresente um fator de carga de 0,7. Para este mercado atendido pela concessionária, considerando-se que exista um único produto (a energia) e um único tipo de consumidor, o desenho tarifário natural seria a concepção de uma tarifa em duas partes, conforme fatura $F 1$ apresentada na Equação (64). Nesta equação, $d$ representa a demanda máxima faturada em um ano.

Nesta exemplo, para facilitar a compreensão, supõe-se que o fator de coincidência do sistema seja unitário, ou que o mercado agregado seja igual ao mercado faturado.

$F 1=(613,2 / k W$. ano $) \cdot d+(50 / M W h) \cdot e$

É fácil perceber que a aplicação desta tarifa ao mercado consumidor, que possui potência máxima anual de $163,07 \mathrm{~kW}$ e energia anual consumida de $1.000 M W h$ cobrirá os custos totais de produção, no valor total de $\$ 150.000,00$.

Uma outra alternativa tarifária seria a construção de uma tarifa média monômia, a ser faturada apenas em energia. A Equação (65) mostra como seria esta alternativa, denominada $F 2$.

$F 2=(150 / M W h) \cdot e$

Da mesma forma que a tarifa $F 1$, a tarifa $F 2$ deveria recuperar o custo total, mas isso pode não ocorrer devido à retração do mercado consumidor frente a um preço maior que o custo marginal de produção, de $\$ 50 / \mathrm{MWh}$. Considerando-se que a elasticidade dos consumidores é muito baixa, poder-se-ia desprezar esta retração de mercado.

Neste caso, seria interessante uma discussão sobre o modelo de regulação aplicado a esta concessionária, que poderia ou não prever compensações à empresa em caso de uma retração efetiva do mercado. Se a tarifa é calculada ex ante, a não consideração de um mecanismo de compensação poderia desequilibrar 
economicamente a empresa. Contudo, esta discussão não é relevante ao escopo deste trabalho.

Por fim, uma terceira opção tarifária, bastante incomum mas possível, seria a alocação dos custos de capacidade no faturamento da energia e dos custos operacionais no faturamento da demanda, conforme Equação (66).

$F 3=(306,6 / k W$. ano $) \cdot d+(100 / M W h) \cdot e$

As três opções tarifárias podem ser visualizadas através da Figura 66. Para compará-las graficamente, é necessário dividir as equações pela demanda máxima $d$, obtendo assim as curvas de triagem equivalentes.

Note-se que as três opções tarifárias se cruzam no ponto $919,8 \$ / k W$. ano $; 6.132 \mathrm{~h} /$ ano. Isso ocorre justamente porque $919,8 \$ / k W$. ano $\times$ $163,07 \mathrm{~kW}=150.000,00 /$ ano, que é o custo total da concessionária, considerado na construção das modalidades $F 1, F 2$ e $F 3$.

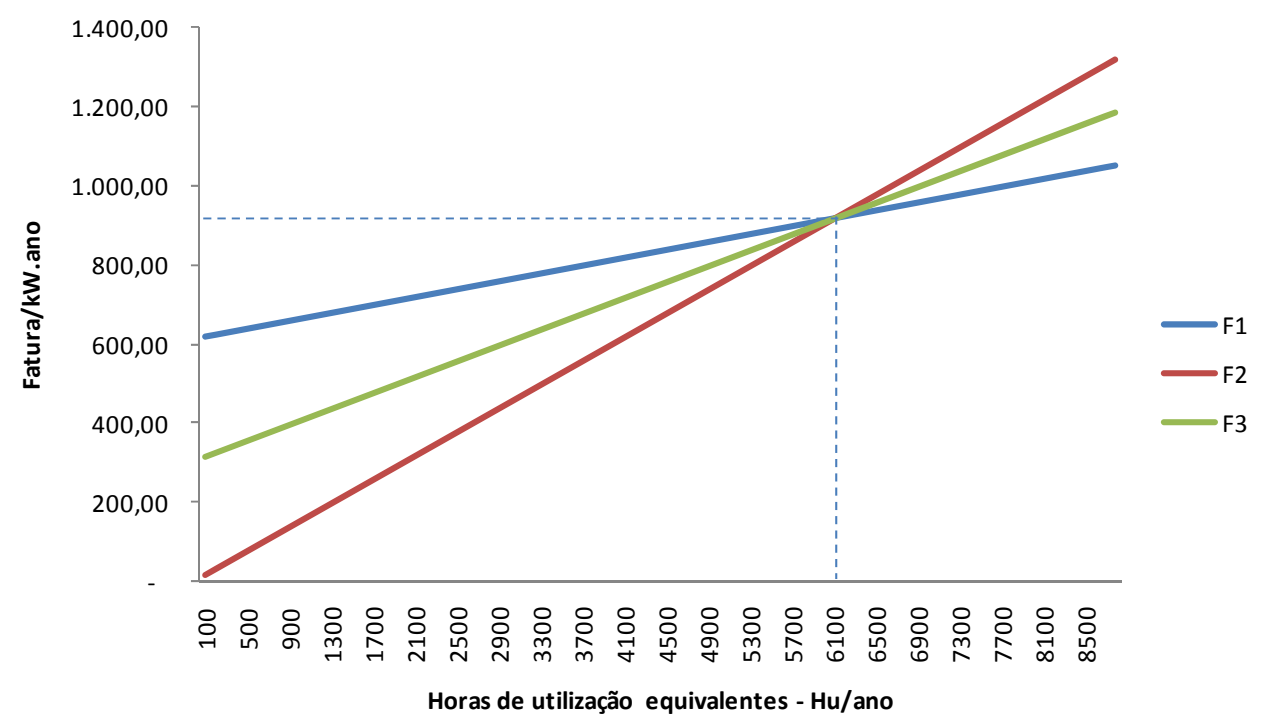

Figura 66 - Visualização gráfica das três modalidades tarifárias, F1, F2 e F3.

Do ponto de vista econômico, as opções tarifárias $F 2$ e $F 3$ são naturalmente ineficientes por apresentarem preços marginais superiores ao custo marginal de produção. É necessário, contudo, relembrar que a opção $F 1$ só terá máxima eficiência 
se todos os consumidores optarem por pagar a tarifa de acesso, o que pode não ocorrer.

Desta forma, somente após uma análise quantitativa da elasticidade de participação em função da tarifa de acesso e da elasticidade-preço da demanda por energia deste mercado, é que seria possível avaliar comparativamente as opções $F 1$, $F 2$ ou $F 3$ em termos de eficiência econômica.

Este exemplo mostra que é possível construir opções tarifárias binômias a partir de qualquer mecanismo de alocação de custos de capacidade e de operação nas variáveis de faturamento potência e energia. Como a opção natural $(F 1)$ de alocação dos custos de capacidade (fixos) na potência e dos custos operacionais (variáveis) na energia não garante a máxima eficiência econômica, outras opções tarifárias, como $F 2$ e $F 3$, não podem ser descartadas a priori.

Já em um ambiente desverticalizado, a atividade de distribuição é caracterizada pela atividade econômica do transporte da energia. Assim, os custos operacionais da distribuidora passam a não contar com os custos de geração.

Desta forma, como pôde ser observado no ANEXO II, os custos totais de uma distribuidora, compostos pelas parcelas de capital e operação, são estatisticamente ocasionados pela potência máxima agregada atendida pela distribuidora.

As simulações econométricas para a estimativa da curva de custos totais demonstrou que, mesmo os custos operacionais são ocasionados pela demanda máxima, que pode ser interpretada como uma proxy para a capacidade do sistema de distribuição (considerando operação otimizada).

Considerando que toda a tarifa de transporte da energia seja faturada na variável potência máxima registrada por período, conforme ilustrado na Figura 67, a tarifa de uso do sistema de distribuição refletiria a estrutura de custos do sistema, o que é apropriado. 


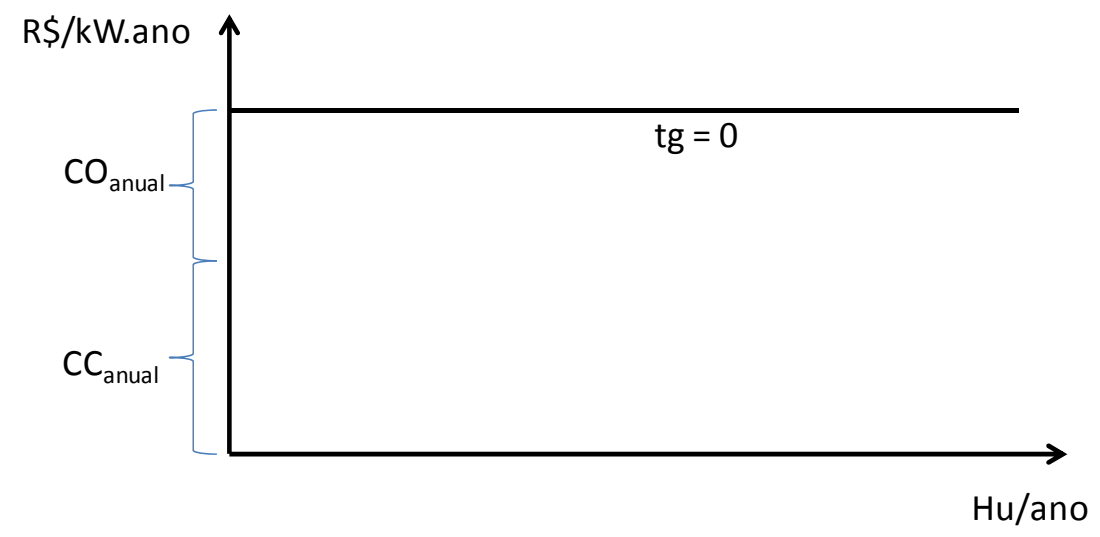

Figura 67 - Curva da tarifa de uso do sistema de distribuição, em função apenas da demanda máxima registrada

Embora a modalidade tarifária final contenha os custos da commodity (energia) e demais encargos repassados aos consumidores e faturados em $M W h$, o exemplo da Figura 67 ilustra apenas a parcela de uso da tarifa, referente aos custos do transporte da energia.

Em um sistema desverticalizado, consequentemente, a atividade de distribuição de energia não possui custos operacionais diretamente relacionados ao consumo de energia, mas sim à capacidade colocada à disposição dos consumidores (disponibilidade de potência).

Como a cobrança de todos os custos de uso do sistema através da potência máxima não poderia ser feita de outra forma, a não ser por um valor fixo mensal independente do consumo de energia, observa-se o mesmo problema da tarifa de acesso discutido no item 2.1.2. Ou seja, consumidores de menor consumo (menor renda) podem ser excluídos do mercado, gerando ineficiência econômica.

Assim, a construção de um esquema de modalidades tarifárias não lineares deve justificar-se muito melhor pela tentativa de aumentar a eficiência econômica do sistema tarifário do que propriamente refletir os custos operacionais da geração, como ocorre claramente para uma empresa verticalizada.

Uma proposta bastante simplificadora, mas consistente economicamente, seria a construção de um esquema de modalidades a partir do desenho de uma tarifa inicial $T_{0}$, com custos totalmente associados à energia, passado por modalidades $T_{1}, T_{2}, \ldots$, $T_{n-1}$, nas quais os custos seriam associados de forma decrescente à energia (variável) 
e de forma crescente à potência (fixo), até a modalidade final $T_{n}$, em que todos os custos seriam associados à potência, como na Figura 67.

As modalidades intermediárias $\left(T_{1}, T_{2}, \ldots, T_{n-1}\right)$ poderiam ser construídas a partir da análise da distribuição de freqüências dos fatores de carga dos consumidores atendidos por este esquema de tarifação, proporcionando assim, de forma aderente, o enquadramento dos consumidores aos níveis de consumo.

A Figura 68 ilustra um esquema de tarifação com 3 modalidades, $T_{0}, T_{1} e T_{2}$, de tal forma que, para a construção de $T_{0}$, todos os custos são divididos pelo mercado agregado de energia, exatamente como o cálculo de uma tarifa média monômia. Como já mencionado, a modalidade final $T_{2}$ é obtida pela alocação dos custos totais na potência máxima faturada neste mercado, sem nenhuma componente variável em energia.

Por fim, a modalidade $T_{1}$ é construída de tal forma que, num exemplo hipotético, as intersecções entre $T_{1}$ e $T_{0}$, e $T_{1}$ e $T_{2}$ proporcionem a divisão do mercado consumidor em três blocos de consumo com igual quantidade de consumidores.

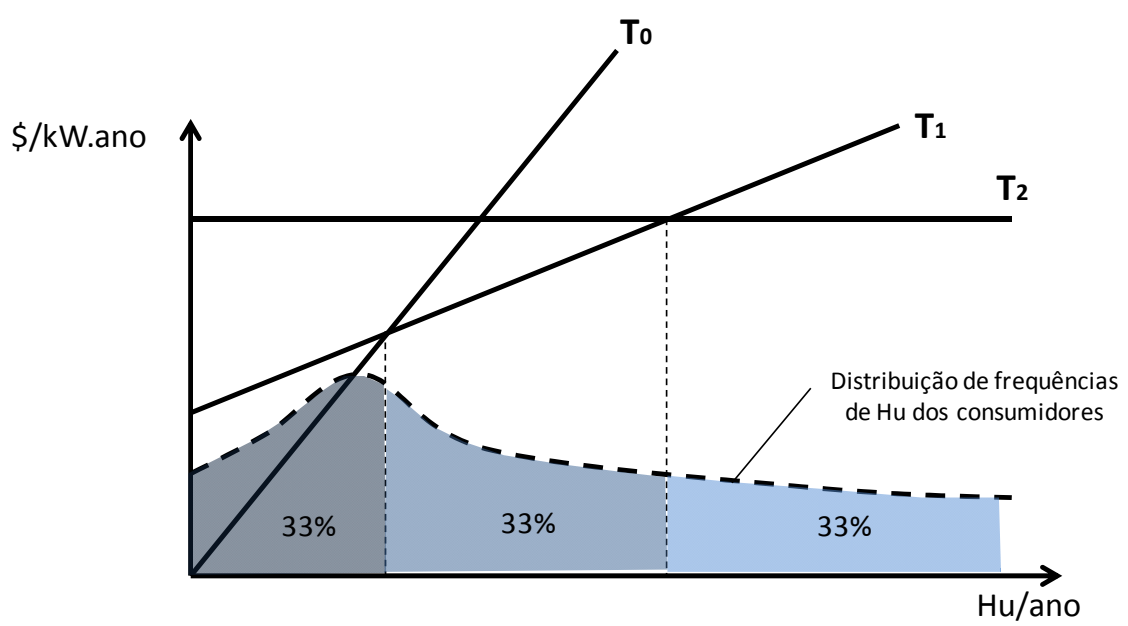

Figura 68 - Esquema de tarifação com 3 modalidades, de tal forma que o mercado é dividido em 3 faixas de consumo com igual número de consumidores.

A distribuição de freqüências real dos fatores de carga dos consumidores, que são as variáveis utilizadas para o cálculo das horas de utilização, pode naturalmente não se assemelhar a nenhuma função padrão de distribuição de probabilidades. No entanto, a construção das modalidades poderia ser realizada objetivando-se a quantidade esperada de consumidores optantes em cada "plano" tarifário. 
A Figura 69 ilustra um caso real, com a distribuição de freqüências dos fatores de carga no posto tarifário de ponta para toda a população de consumidores do nível A4 de uma distribuidora nacional. Como é possível verificar na figura, medidas estatísticas como a média e a mediana poderiam orientar a determinação de modalidades tarifárias para este grupo de consumidores.

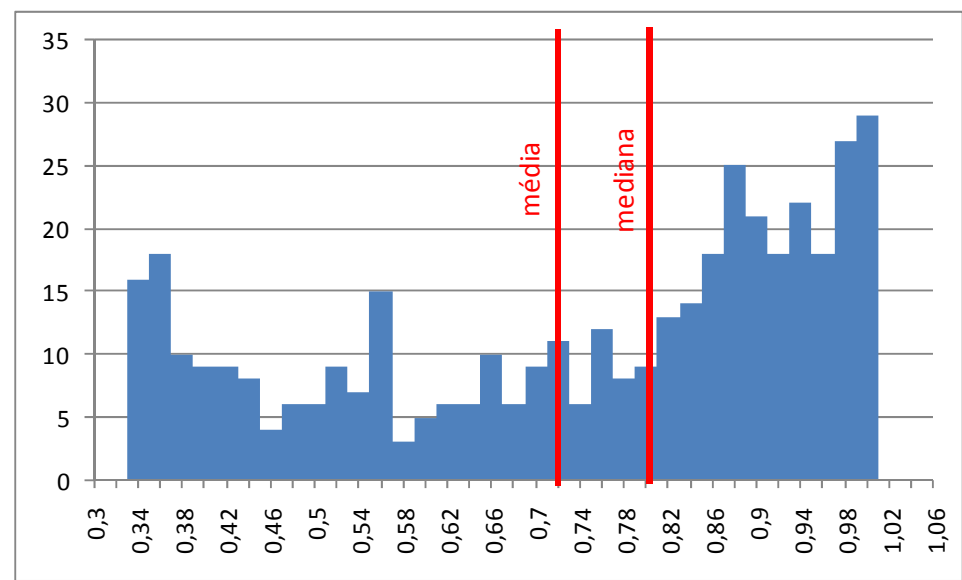

Figura 69 - Distribuição de freqüências dos fatores de carga no posto de ponta para todos os consumidores A4 de uma distribuidora nacional.

\subsection{Alguns resultados para a estrutura vertical}

Serão apresentados resultados de simulações realizadas para três empresas brasileiras de distribuição de energia elétrica. O objetivo das simulações foi o de avaliar exclusivamente o processo de cálculo proposto para a estrutura vertical de preços frente a atual metodologia, implementada do sistema computacional Tardist.

A estrutura horizontal de preços, bem como o desenvolvimento de modalidades tarifárias, apresentados nos itens 6.5 e 0 , dependem de avaliações regulatórias e análises de comportamento do mercado, muitas delas subjetivas. Assim, pela abordagem destas questões ter sido mais indicativa do que determinativa neste trabalho, elas não serão tratadas nas simulações apresentadas.

Para que se avaliem corretamente os resultados da estrutura vertical proposta em comparação a atual metodologia, os valores dos Custos Marginais Isolados foram considerados iguais aos valores dos chamados custos marginais de expansão utilizados pela ANEEL no segundo ciclo de revisões tarifárias (Os valores são apresentados na Tabela 15). 
Tabela 15 - Custos Marginais Isolados (denominados custos marginais de expansão) utilizados pela ANEEL no $2^{\circ}$ ciclo de revisões tarifárias. Fonte: ANEEL.

Custos Marginais Isolados

\begin{tabular}{l|l} 
Nivel de Tensão & $\mathrm{R} \$ / \mathrm{kW}$.ano
\end{tabular}

\begin{tabular}{c|l} 
A2 & 29,13 \\
A3 & 30,56 \\
A3a & 36,63 \\
A4 & 41,63 \\
BT & 57,10
\end{tabular}

É importante lembrar que a metodologia proposta levou em consideração as perdas técnicas de energia calculadas segundo a metodologia regulatória especificada nos Procedimentos da Distribuição - PRODIST (ANEEL-C, 2008).

As curvas de carga utilizadas nas campanhas de medidas das três distribuidoras foram utilizadas para o cálculo de uma curva média amostral para cada nível de tensão, de forma a possibilitar o cálculo dos Custos Marginais Compostos também por nível de tensão, tornando possível a comparação com os custos de capacidade, calculados pelo Tardist.

Os resultados para cada empresa foram divididos em dois grupos de tabelas. As primeiras (Tabela 16, Tabela 18 e Tabela 20) contém os resultados absolutos e relativos dos Custos Marginais Compostos, sendo a base para os valores relativos os custos do nível de tensão A217. Nestas tabelas, são apresentadas também as somas, por nível de tensão, dos custos de capacidade de ponta e fora-ponta.

No segundo grupo de tabelas (Tabela 17, Tabela 19 e Tabela 21), são apresentados os resultados das tarifas finais de aplicação (Anexo II da resolução homologatória que publica as tarifas no momento das revisões tarifárias) de algumas modalidades tarifárias Azuis, Verdes e Convencionais.

\footnotetext{
${ }^{17}$ Geralmente, o nível de tensão A2 se refere aos níveis de tensão de $88 \mathrm{kV}$ ou $230 \mathrm{kV}$.
} 
Tabela 16 - Resultado da aplicação da metodologia proposta ao sistema da CPFL Paulista, utilizando-se dados de curvas de carga e fluxo de energia do segundo ciclo de revisões tarifárias da empresa. Fonte de dados: ANEEL.

\begin{tabular}{|c|c|c|}
\hline & METODOLOGIA PROPOSTA & TARDIST 2a. RTP \\
\hline & $\begin{array}{c}\text { Custos Marginais Compostos } \\
\mathrm{R} \$ / \mathrm{kW} \text {.ano }\end{array}$ & $\begin{array}{c}\text { (Ccap P + Ccap FP) } \\
\mathrm{R} \$ / \mathrm{kW} \text {.ano } \\
\end{array}$ \\
\hline A2 & 28,38 & 28,86 \\
\hline$\overline{\mathrm{A} 3}$ & 50,70 & 52,79 \\
\hline$\overline{A 3 a}$ & 61,39 & 56,70 \\
\hline A4 & 59,48 & 70,48 \\
\hline BT & 139,71 & 126,35 \\
\hline & Estrutura em relação ao A2 & Estrutura em relação ao A2 \\
\hline $\mathrm{A} 2$ & $100,00 \%$ & $100,00 \%$ \\
\hline $\mathrm{A} 3$ & $178,63 \%$ & $182,92 \%$ \\
\hline A3a & $216,29 \%$ & $196,47 \%$ \\
\hline A4 & $209,54 \%$ & $244,21 \%$ \\
\hline$\overline{\mathrm{BT}}$ & $492,23 \%$ & $437,80 \%$ \\
\hline
\end{tabular}

Tabela 17 - Tarifas finais (Anexo II) da CPFL Paulista nos dois cenários: Metodologia proposta e resultados do Tardist. Fonte de dados: ANEEL.

\begin{tabular}{|c|c|c|c|}
\hline & \multicolumn{3}{|c|}{ TARIFAS FINAIS ANEXO II } \\
\hline & METODOLOGIA PROPOSTA & TARDIST & VARIAÇÃO \\
\hline A2 AZUL TDP & 12,93 R\$/kW.mês & $13,55 \mathrm{R} \$ / \mathrm{kW}$.mês & $-4,58 \%$ \\
\hline A2 AZUL TDFP & 1,59 R\$/kW.mês & 1,73 R\$/kW.mês & $-8,25 \%$ \\
\hline A4 AZUL TDP & 20,42 R\$/kW.mês & 23,08 R\$/kW.mês & $-11,52 \%$ \\
\hline A4 AZUL TDFP & 4,74 R\$/kW.mês & 5,62 R\$/kW.mês & $-15,76 \%$ \\
\hline A4 VERDE TD & 4,74 R\$/kW.mês & 5,62 R\$/kW.mês & $-15,76 \%$ \\
\hline A4 VERDE TEPS & $701,82 \mathrm{R} \$ / \mathrm{MWh}$ & $763,58 \mathrm{R} \$ / \mathrm{MWh}$ & $-8,09 \%$ \\
\hline B1 & $275,63 \mathrm{R} \$ / \mathrm{MWh}$ & $268,84 \mathrm{R} \$ / M W h$ & $2,52 \%$ \\
\hline
\end{tabular}

Tabela 18 - Resultado da aplicação da metodologia proposta ao sistema da RGE, utilizando-se dados de curvas de carga e fluxo de energia do segundo ciclo de revisões tarifárias da empresa. Fonte de dados: ANEEL.

\begin{tabular}{|c|c|c|}
\hline & METODOLOGIA PROPOSTA & TARDIST 2a. RTP \\
\hline & $\begin{array}{l}\text { Custos Marginais Compostos } \\
\text { R\$/kW.ano }\end{array}$ & $\begin{array}{c}\text { (Ccap P + Ccap FP) } \\
R \$ / k W \text {.ano }\end{array}$ \\
\hline A2 & 25,59 & 27,55 \\
\hline $\bar{A} 3$ & 35,97 & 36,61 \\
\hline A3a & 37,78 & 46,22 \\
\hline A4 & 51,01 & 74,14 \\
\hline \multirow[t]{2}{*}{ BT } & 141,85 & 127,48 \\
\hline & Estrutura em relação ao A2 & Estrutura em relação ao A2 \\
\hline $\mathrm{A} 2$ & $100,00 \%$ & $100,00 \%$ \\
\hline A3 & $140,58 \%$ & $132,89 \%$ \\
\hline A3a & $147,65 \%$ & $167,77 \%$ \\
\hline $\mathrm{A} 4$ & $199,38 \%$ & $269,11 \%$ \\
\hline BT & $554,39 \%$ & $462,72 \%$ \\
\hline
\end{tabular}


Tabela 19 - Tarifas finais (Anexo II) da RGE nos dois cenários: Metodologia proposta e resultados do Tardist. Fonte de dados: ANEEL.

\begin{tabular}{|c|c|c|c|}
\hline & \multicolumn{3}{|c|}{ TARIFAS FINAIS ANEXO II } \\
\hline & METODOLOGIA PROPOSTA & TARDIST & VARIAÇÃO \\
\hline A3 AZUL TDP & 20,15 R\$/kW.mês & $21,10 \mathrm{R} \$ / \mathrm{kW}$.mês & $-4,50 \%$ \\
\hline A3 AZUL TDFP & 3,86 R\$/kW.mês & 4,12 R\$/kW.mês & $-6,31 \%$ \\
\hline A4 AZUL TDP & 27,87 R\$/kW.mês & $34,80 \mathrm{R} \$ / \mathrm{kW}$.mês & $-19,91 \%$ \\
\hline A4 AZUL TDFP & 7,07 R\$/kW.mês & 9,38 R\$/kW.mês & $-24,63 \%$ \\
\hline A4 VERDE TD & 7,07 R\$/kW.mês & 9,38 R\$/kW.mês & $-24,63 \%$ \\
\hline A4 VERDE TEPS & $892,14 \mathrm{R} \$ / \mathrm{MWh}$ & $1053,30 \mathrm{R} \$ / \mathrm{MWh}$ & $-15,30 \%$ \\
\hline B1 & $339,78 \mathrm{R} \$ / \mathrm{MWh}$ & $318,66 \mathrm{R} \$ / \mathrm{MWh}$ & $6,63 \%$ \\
\hline
\end{tabular}

Tabela 20 - Resultado da aplicação da metodologia proposta ao sistema da ESCELSA, utilizando-se dados de curvas de carga e fluxo de energia do segundo ciclo de revisões tarifárias da empresa. Fonte de dados: ANEEL.

\begin{tabular}{|c|c|c|}
\hline \multicolumn{2}{|r|}{ METODOLOGIA PROPOSTA } & TARDIST 2a. RTP \\
\hline & Custos Marginais Compostos & (Ccap P + Ccap FP) \\
\hline & $\mathrm{R} \$ / \mathrm{kW} . \mathrm{ano}$ & $\mathrm{R} \$ / \mathrm{kW}$.ano \\
\hline $\mathrm{A} 2$ & 26,91 & 28,10 \\
\hline A3 & 43,62 & 53,44 \\
\hline A3a & 51,85 & 65,99 \\
\hline A4 & 82,51 & 87,11 \\
\hline BT & 135,27 & 127,48 \\
\hline & Estrutura em relação ao $\mathrm{A} 2$ & Estrutura em relação ao A2 \\
\hline $\mathrm{A} 2$ & $100,00 \%$ & $100,00 \%$ \\
\hline A3 & $162,09 \%$ & $190,18 \%$ \\
\hline A3a & $192,68 \%$ & $234,84 \%$ \\
\hline A4 & $306,60 \%$ & $310,00 \%$ \\
\hline$\overline{\mathrm{BT}}$ & $502,65 \%$ & $453,67 \%$ \\
\hline
\end{tabular}

Tabela 21 - Tarifas finais (Anexo II) da ESCELSA nos dois cenários: Metodologia proposta e resultados do Tardist. Fonte de dados: ANEEL.

\begin{tabular}{|c|c|c|c|}
\hline & \multicolumn{3}{|c|}{ TARIFAS FINAIS ANEXO II } \\
\hline & METODOLOGIA PROPOSTA & TARDIST & VARIAÇÃO \\
\hline A2 AZUL TDP & $18,03 \mathrm{R} \$ / \mathrm{kW}$.mês & $18,94 \mathrm{R} \$ / \mathrm{kW}$.mês & $-4,80 \%$ \\
\hline A2 AZUL TDFP & $2,41 \mathrm{R} \$ / \mathrm{kW}$.mês & 2,62 R\$/kW.mês & $-7,87 \%$ \\
\hline A3 AZUL TDP & $22,23 \mathrm{R} \$ / \mathrm{kW}$.mês & $26,90 \mathrm{R} \$ / \mathrm{kW}$.mês & $-17,37 \%$ \\
\hline A3 AZUL TDFP & 3,97 R\$/kW.mês & 5,25 R\$/kW.mês & $-24,40 \%$ \\
\hline A3a AZUL TDP & 29,23 R\$/kW.mês & 35,28 R\$/kW.mês & $-17,15 \%$ \\
\hline A3a AZUL TDFP & 7,14 R\$/kW.mês & 9,16 R\$/kW.mês & $-22,03 \%$ \\
\hline A4 AZUL TDP & 41,06 R\$/kW.mês & 43,37 R\$/kW.mês & $-5,32 \%$ \\
\hline A4 AZUL TDFP & 11,06 R\$/kW.mês & $11,82 \mathrm{R} \$ / \mathrm{kW}$.mês & $-6,46 \%$ \\
\hline A4 VERDE TD & 11,06 R\$/kW.mês & 11,82 R\$/kW.mês & $-6,46 \%$ \\
\hline A4 VERDE TEPS & $1201,48 \mathrm{R} \$ / \mathrm{MWh}$ & $1255,00 \mathrm{R} \$ \mathrm{MWh}$ & $-4,26 \%$ \\
\hline B1 & $331,45 \mathrm{R} \$ / \mathrm{MWh}$ & $324,80 \mathrm{R} \$ / \mathrm{MWh}$ & $2,05 \%$ \\
\hline
\end{tabular}


Como resultado geral, é possível verificar, nas três empresas analisadas, uma transferência estrutural de recursos dos níveis de alta e média tensão para o nível da baixa tensão (tarifa $\mathrm{B} 1^{18}$ ), caso a atual proposta metodológica substituísse a atual metodologia implementada no sistema Tardist.

Este fenômeno se dá, em parte, pela consideração das perdas técnicas de energia na atual metodologia, as quais não foram consideradas no cálculo da estrutura vigente no momento da $2^{\mathrm{a}}$ revisão tarifária periódica.

Naturalmente, a consideração das perdas resultará, como observado, em um acúmulo maior de custos compostos nos níveis mais a jusante dos pontos de suprimento do sistema, como é o caso do nível de baixa tensão.

Por outro lado, existem também condições matemáticas circunstanciais verificadas na atual metodologia, descritas com detalhes no capítulo 4, que são também responsáveis pelas diferenças observadas nos resultados.

As comparações realizadas entre as duas metodologias não tem como objetivo a avaliação de qual delas estaria ou não correta, mesmo porque este julgamento não poderia ser objetivo. As comparações, por outro lado, tem por desígnio prático avaliar qual seria o efeito da substituição da atual metodologia sobre as tarifas finais aos consumidores. De forma geral, nota-se que as diferenças quantitativas observadas entre as duas metodologias não são sobremaneira expressivas.

Considerando-se, assim, a simplificação do processo metodológico proposto somada à sua maior fundamentação econômica, parecem aceitáveis, sob a ótica da aplicação, as diferenças de resultados por ela proporcionados em relação à metodologia vigente, muito mais complexa e carente de fundamentação teórica.

${ }^{18}$ A tarifa B1 se refere à classe residencial em baixa tensão. 


\section{Conclusões}

Análises mais aprofundadas e discussões críticas a respeito da atual metodologia de estrutura tarifária de uso das redes de distribuição de energia não tem ocorrido com freqüência no Brasil desde a sua formulação e implantação, em meados da década de 1980.

Como pôde ser observado através das análises do capítulo 4, a atual metodologia é bastante caracterizada por uma excessiva complexidade operacional em sua aplicação, sem, no entanto, alicerçar-se em consistentes fundamentos econômicos e estatísticos.

De outro modo, constatou-se falta de rigor a definições encontradas na literatura que documenta a atual metodologia, tornando frágil a aplicação de um dos principais preceitos desejados no desenho de estruturas de preços regulados: a sólida fundamentação teórica.

Exatamente no sentido de preencher esta lacuna, foram apresentados, nos capítulos 2 e 3, os resultados da pesquisa bibliográfica sobre o tema. Notadamente, a teoria econômica clássica tem muito a oferecer sobre a questão da precificação eficiente em sistemas caracterizados por monopólios naturais regulados.

Assim, o ferramental teórico encontrado nos modelos de precificação linear, precificação não linear e precificação de pico (ou ponta) serviu de ponto de partida para a análise crítica da atual metodologia, bem como para a proposição metodológica apresentada.

Como relatado no capítulo 1 , as contribuições do trabalho para o tema da estrutura tarifária de uso das redes de distribuição de energia elétrica ocorreram em três frentes principais:

i. O trabalho ofereceu uma compreensão mais clara e melhor estruturada da atual metodologia de cálculo da estrutura de preços de uso dos sistemas de distribuição de energia no Brasil. Foram avaliadas as hipóteses implicitamente consideradas no modelo vigente, redefinidas algumas de suas variáveis e processos segundo uma interpretação própria do autor, além de analisada a origem dos principais 
mecanismos de diferenciação de preços entre níveis de tensão e períodos de faturamento.

ii. Apresentou-se uma análise crítica da atual metodologia, identificando questões relativas à sua fundamentação econômica, à sua validade mediante investigações numéricas empíricas e, por fim, à sua complexidade operacional frente à qualidade de seus resultados.

iii. Foi proposta uma nova metodologia simplificadora alternativa para o cálculo das estruturas de preços entre níveis de tensão e entre períodos tarifários de ponta e fora-ponta. Embora simplificadora, a proposta fundamentou-se em um alicerce teórico mais sólido e consubstanciado, permitindo aliar estes dois objetivos principais e concorrentes entre si.

Basicamente, a metodologia proposta abarcou e redefiniu os conceitos relativos: ao modelo de custos da distribuidora; ao custo marginal de longo prazo; à estrutura entre níveis de tensão (vertical); e à estrutura entre períodos do dia (horizontal).

O modelo econômico da curva de custos totais de uma distribuidora, apresentado no item 6.1, é próprio da característica inata da atividade econômica do negócio, resumida no produto oferecido aos consumidores de energia pela distribuidora, qual seja, a disponibilidade de capacidade de potência.

Com base neste conceito, pelo fato da energia em si não fazer parte dos insumos de custeio da distribuidora (pelo menos de forma direta), foi proposta a sinalização de preços entre os períodos de ponta e fora-ponta como resultado da relação entre os preços-sombra nos dois períodos. Mesmo não sendo possível determiná-los devido ao desconhecimento das curvas de demanda por potência no curto prazo, é possível controlar e aferir a máxima eficiência quando os diferentes preços proporcionam a equalização das demandas de ponta e fora-ponta do sistema ou sub-sistema objeto da otimização.

No tocante à estrutura vertical de preços, a proposta apresentada foi mais objetiva e determinativa, definindo processos e variáveis de forma rigorosa. Como resultado, a metodologia proposta poderia substituir integralmente o complexo 
mecanismo implementado no sistema computacional Tardist, sem, no entanto, alterar radicalmente a estrutura atual de preços.

Os resultados apresentados no item 6.7 demonstram, sob a ótica da aplicação, uma aceitável divergência entre os resultados da atual metodologia em relação aos resultados da metodologia proposta. Em prol de um resultado melhor fundamentado e bastante mais simples, avalia-se que os benefícios aos agentes do sistema, incluindo principalmente o órgão regulador e, em última instância, os consumidores, são notórios.

Por fim, o trabalho abre novas possibilidades de investigação acadêmica para a ampliação ou o aprofundamento do assunto, tão importantes para o enriquecimento das discussões acerca da estrutura tarifaria da distribuição de energia. Algumas possibilidades principais de investigações futuras, dentre muitas outras, envolvem as seguintes questões:

a. A proposição de métodos de determinação dos custos marginais de longo prazo por nível de tensão, seja através do planejamento de investimentos, seja pela determinação dos custos médios. É fato que em alguns países, como Chile e Espanha, utilizam-se modelos de simulação geográfica de redes otimizadas para o cálculo dos custos marginais, o que poderia reduzir o grau de arbitrariedade e subjetividade existentes nos processos atualmente utilizados no Brasil para a determinação destas variáveis.

De todo modo, esta é uma linha de pesquisa bastante importante para a consolidação de um ferramental consistente e objetivo no desenho de uma estrutura tarifária eficiente e justa, uma vez que estas variáveis são efetivamente as mais significativas em qualquer abordagem marginalista.

b. A proposição de outro contexto metodológico alternativo ao atual diagrama unifilar de fluxo de potência ou energia. Com o advento da geração distribuída, e até mesmo da microgeração, torna-se necessária a consideração de variáveis locacionais para a determinação da estrutura de preços para geradores conectados ao sistema. No entanto, seria desejável uma alternativa diferente da já existente metodologia nacional para o cálculo da tarifa de uso das redes de transmissão, 
devido não somente ao seu caráter estático com relação ao comportamento da carga e da rede, mas também devido à complexidade topológica das redes de distribuição.

c. A prospecção e análise do comportamento dos consumidores para a quantificação das elasticidades-preço da demanda por potência elétrica contratada, e também por energia, em horizontes de curto prazo. $O$ conhecimento destas variáveis pode trazer ganhos expressivos na avaliação das estruturas de preços entre períodos diários de faturamento, e também nas estimativas de reconciliação de receita regulatória devido à sensibilidade do mercado.

A usual quantificação das elasticidades-preço do consumo de energia no longo prazo não são adequadas ao desenho de uma estrutura de preços que é recalculada, em média, a cada período tarifário de quatro anos.

d. Por fim, seria bastante promissora uma abordagem econômica mais holística sobre a estrutura da tarifa de energia no Brasil, analisando-se todas as suas componentes, tanto na tarifa de uso quanto na tarifa de energia. Como ficou claro, este trabalho somente considerou a parcela relativa à cobertura dos custos da distribuição, não havendo análises ou propostas para a estrutura tarifária das componentes de uso da transmissão, perdas ou encargos parafiscais, tão significativas em termos quantitativos. 


\section{Referências Bibliográficas}

ABRAMOWIZ, M., \& STEGUN, I. A. (1964). Handbook of Mathematical Functions. National Bureau of Standards.

ANDRADE, T., \& LOBÃO, W. J. (1997). Elasticidade-Renda e Preço da Demanda Residencial de Energia Elétrica no Brasil. IPEA Texto para Discussão n. 489.

ANEEL-A. (2009). Nota Técnica n. 271/2009-SRE-SRD/ANEEL. Brasília, Brasil.

ANEEL-B. (Outubro de 2006). Nota Técnica n. 262/2006SRE/SFF/SRD/SFE/SRC/ANEEL. Acesso em 25 de 11 de 2009, disponível em www.aneel.gov.br: http://www.aneel.gov.br/cedoc/nren2006234.pdf

ANEEL-C. (2008). Procedimentos de Distribuição de Energia Elétrica no Sistema Elétrico Nacional - PRODIST - Módulo 2. Procedimentos Técnicos . Brasília, Brasil.

ANEEL-D. (2005). Programa de Simulação de Tarifas de Uso do Sistema Elétrico. Manual do Usuário. Aneel.

ANEEL-E. (2008). Projeto Estratégico: Metodologia para Estabelecimento de Estrutura Tarifária para o Serviço de Distribuição de Energia Elétrica. Chamada No. 008/2008 .

ANEEL-F. (2001). Resolução n. 90. Brasília, Brasil.

ANEEL-G. (2005). Tarifas de Fornecimento de Energia Elétrica. Brasília: Aneel.

ANTUNES, A. U. (2004). Análise Crítica e Proposições Metodológicas para Avaliação dos Custos Marginais de Expansão de Redes de Distribuição de Energia Elétrica. Tese de Doutorado. Escola Politécnica da Universidade de São Paulo .

BOITEUX, M. (1960). Peak-Load Pricing. The Journal of Business , p. 157-179.

BROWN, S. J., \& SIBLEY, D. S. (1986). The Theory of Public Utility Pricing. Cambridge University Press.

CARLTON, D. W. (1977). Peak Load Pricing with Stochastic Demand. The American Economic Review , 67 (5), p. 1006-1010.

COASE, R. H. (1946). The Marginal Cost Controversy. Economica, 13, p. 169-189.

COCHRAN, W. G. (1977). Sampling Techniques. Wiley.

COSTA NETO, P. L. (2002). Estatística (2a. ed.). Editora Edgard Blucher.

CREW, M. A., \& KLEINDFORFER, P. R. (1986). The Economics of Public Utility Regulation. Cambridge: MIT Press.

DE SALVIA, D. N. (1969). An Application of Peak-Load Pricing. The Journal of Business - The University of Chicago Press , p. 458 - 476. 
DNAEE. (1985). Nova Tarifa de Energia Elétrica - Metodologia e Aplicação ("Livro Verde"). MME/DNAEE.

DNAEE. (1994). PRT - Programa de Revisão Tarifária - Projeto 3 - Tarifas de Referência. MME/SE/DNAEE.

DNAEE. (1994). PRT - Programa de Revisão Tarifária - Projetos 1, 2 e 3. MME/SE/DNAEE.

DRĖZE, J. H. (1964). Some Postwar Contributions of French Economists to Theory and Public Policy; With Special Emphasis on Problems of Resourse Allocation. The American Economic Review, 54 (Surveys of Foreign Postwar Developments in Economic Thought), p. 2-64.

ECKEL, C. C. (1987). Customer-Class Discrimination by Electric Utilities. Journal of Economics and Business , 39, p. 19-33.

EL HAGE, F. S. (2009). Avaliação da elasticidade-preço da demanda por energia elétrica. Trabalho de Conclusão de Curso - EESP/FGV . São Paulo.

GREUB, W. (1981). Linear Algebra. Nova York: Springer.

GUJARATI, D. (2006). Econometria Básica. Campus.

HÄRDLLE, W., \& SIMAR, L. (2007). Applied Multivariate Statistical Analysis. Berlin: Spri nger.

IZENMAN, A. J. (2008). Modern Multivariate Statistical Techniques. Nova York: Springer.

JOSKOW, P. L. (2005). Regulation of Natural Monopolies. In: Elsevier, \& MIT (Eds.), Handbook of Law and Economics. Elsevier.

KACHIGAN, S. K. (1991). Multivariate Statistical Analysis. A conceptual introduction. Nova York: Radius Press.

KAGAN, N., OLIVEIRA, C. C., \& ROBBA, E. J. (2005). Introdução aos Sistemas de Distribuição de Energia Elétrica. São Paulo: Editora Edgard Blucher Ltda.

KAHN, A. E. (1970). The Economics of Regulation: Principles and Institutions (Vol. I). New York: Wiley.

KREPS, D. M. (2004). Microeconomics for Managers. New York: W.W. Nortn \& Company.

LAFFONT, J. J., \& TIROLE, J. (1990). The Regulation of Multiproduct Firms, Part I: Theory. Journal of Public Economics (43), p. 1-36.

LIPSCHUTZ, S. (1994). Álgebra Linear. São Paulo: Schaum.

LOOTTY, M., \& SZAPIRO, M. (2002). Economias de Escala e Escopo. In: D. KUPFER, \& L. HASENCLEVER, Economia Industrial (p. 43-70). Rio de Janeiro: Elsevier. 
MACQUEEN, J. B. (1967). Some Methods for Classification and Analysis of Multivariate Observations. Proceedings of 5th Berkeley Symposium on Mathematical Statistics and Probability (p. 281-297). University of California Press.

MAGALHÃES, M. N., \& LIMA, A. C. (2004). Noções de Probabilidade e Estatística. São Paulo: Edusp.

MANLY, B. F. J. (2000). Multivariate Statistical Methods. A primer. Boca Raton: Chapman \& Hall/CRC.

MANLY, B. F. (2005). Multivariate Statistical Methods. A primer. CRC Press.

MODIANO, E. M. (1984). Elasticidade renda e preços da demanda de energia elétrica no Brasil. Rio de Janeiro: Departamento de Economia da PUC- RJ.

NELSON, J. R. (1964). Marginal Cost Pricing in Practice. Englewood Cliffs: PrenticeHall.

PANZAR, J. C. (1976). A Neoclassical Approach to Peak Load Pricing. The Bell Journal of Economics , 7, p. 521-530.

PIRES, J., \& PICCININI, M. S. (1998). Modelos de Regulação Tarifária do Setor Elétrico. Revista do BNDES (junho).

RAMSEY, F. (1927). A Contribution to the Theory of Taxation. Economic Journal , 37, p. 47-61.

SCHMIDT, C. A., \& LIMA, M. (2004). A demanda por energia elétrica no Brasil. Revista Brasileira de Economia , p. 68-98.

SHARKEY, W. W. (1982). The Theory of Natural Monopoly. Cambridge: Cambridge University Press.

STEINER, P. O. (1957). Peak Loads and Efficient Pricing. The Quarterly Journal of Economics , 71, p. 585-610.

STOFT, S. (2002). Power System Economics. IEEE Press \& WILEY-INTERSCIENCE.

SUN, W., \& YUAN, Y.-X. (2006). Optimization Theory and Methods. Nonlinear Programming. Springer.

TAYLOR, L. D. (1975). The Demand for electricity: a Survey. The Bell Journal of Economics , p. 74-110.

TURVEY, R. (1968). Optimal Pricing and Investment in Electricity Supply: An Essay in Applied Welfare Economics. Cambridge, MA: MIT Press.

VISCUSI, W. K., HARRINGTON JR, J. E., \& VERMON, J. M. (2005). Economics of Regulation and Antitrust. Cambridge, MA: MIT Press.

WENDERS, J. T. (1976). Peak Load Pricing in the Electric Utility Industry. The Bell Journal of Economics , p. 232-241. 
WILLIAMSON, O. E. (1966). Peak-Load Pricing and Optimal Capacity under Indivisibility Constraints. The American Economic Review , p. 810-827.

WILSON, R. B. (1993). Nonlinear Pricing. New York: Oxford University Press.

\section{Bibliografia}

ANEEL-H. (2010). Nota Técnica n. 265/2010-SRE/ANEEL. AP040/2010. Brasília: ANEEL.

AUERBACH, A. J., \& HINES JR, J. R. (2001). Taxation and Economic Efficiency. In: A. J. AUERBACH, \& J. R. HINES JR, Handbook of Public Economics.

BITU, R., \& BORN, P. (1993). Tarifas de Energia Elétrica. Aspectos Conceituais e Metodológicos. MM Editora.

BORENSTEIN, S., JASKE, M., \& ROSENFELD, A. (2002). Dynamic Pricing, Advanced Metering and Demand Response in Electricity Markets. Berkeley: University of California Energy Institute.

BRAEUTIGAM. (1980). An Analysis of Fully Distributed Cost Pricing in Regulated Industries. The Bell Journal of Economics , p. 182-196.

COELLI, T. J., RAO, D., O'DONNELL, C. J., \& BATTESE, J. E. (2005). An Introduction to Efficiency and Productivity Analysis. Springer.

DIDAY, E. (1982). Optimisation en Classification Automatique. INRIA .

EL HAGE, F., \& KAGAN, N. (2009). Tariff structure based on a new definition of customer responsibility in power distribution systems. Electricity Distribution - Part 1, 2009. CIRED 2009. 20th International Conference.

FRIEDMAN, L. S. (2002). The Microeconomics of Public Policy Analysis. Oxfordshire: Princeton University Press.

GUARDIA, E. C. (2007). Metodologia para o Cálculo da Elasticidade da Tipologia de Carga Frente à Tarifa de Energia Elétrica. Dissertação de Mestrado. Departamento de Engenharia da Energia da Universidade Federal de Itajubá .

HAIR, J. F., TATHAN, R. L., ANDERSON, R. E., \& BLACK, W. (1998). Análise Multivariada de Dados. São Paulo: Artmed Editora S.A.

HOUTHAKKER, H. S. (1951). Electricity Tariffs in Theory and Practice. The Economic Journal , p. 1-25.

IPEA. (2010). Setor Elétrico: Desafios e Oportunidades. Comunicados do IPEA - n.51. 
KUBRUSLY, L. S. (2002). Modelos Estatísticos. In: D. KUPFER, \& L. HASENCLEVER, Economia Industrial (p. 593-618). Rio de Janeiro: Elsevier Editora Ltda.

KUPFER, D., \& HASENCLEVER, L. (2002). Economia Industrial. Rio de Janeiro: Elsevier.

KURZ, H. D., \& SALVADORI, N. (2003). Classical Economics and Modern Theory. Malta: Gutemberg Press Ltda.

LANDSBURG, S. E. (2008). Price Theory and Applications. Thomson - South Wertern.

LEGEMANN, E. (2004). Tributação Ótima. Ensaios FEE, v.25, n.2, p. 403-426. Porto Alegre.

LI, F. (2009). Recent Development in Distribution Tariff Structure in the UK and New Challenges. Seminário Internacional de Estrutura Tarifária , junho. Brasília, DF, Brasil.

LITTLECHILD, S. C. (1970). Marginal-Cost Pricing with Joint Costs. The Economic Journal , p. 323-335.

ORTEGA, M. P., PEREZ-ARRIAGA, J. I., ABBAD, J. R., \& GONZALES, J. P. (2008). Distribution network tariffs: A closed question? Energy Policy, p. 1712-1725.

SCHARFHAUSEN, F. M. (2009). Tariff Structure: The Spanish Case. junho. Brasília, DF, Brasil: Seminário Internacional de Estrutura Tarifária.

SEETO, D., WOO, C. K., \& HOROWITZ, I. (1997). Time-of-use rates vs. Hopkinson tariffs redux: An analysis of the choice of rate structures in a regulated electricity distribution company. Energy Economics (19), p. 169-185.

SIMAR, L., \& WILSON, P. W. (2007). Estimation and inference in two-stage, semiparametric models of production processes. Journal of Econometrics , p. 31-64.

SLEMROD, J. (1990). Optimal Taxation and Optimal Tax Systems. The Journal of Economic Perspectives Vol. 4, No. 1 , p. 157-178.

VANHANEN, J., VEHVILAINEN, I., VIRTANEN, E., AGRELL, P., \& BOGETOFT, P. (2010). Scientific Review on Regulation Models for Electricity Distribution Networks Final Report. Helsinki - Finland: Energy Market Authority.

VERDELHO, P. (2009). Atividade Tarifária do Setor Elétrico. junho . Brasília, DF, Brasil: Seminário Interancional de Estrutura Tarifária. 


\section{ANEXO I}

\section{Teoria de Monopólios Naturais}

\section{Definição de um monopólio natural}

A produção de um único produto homogêneo é caracterizada por um Monopólio Natural se, para qualquer volume de produção, o custo da indústria é minimizado quando apenas uma firma produz. Em particular, esta relação de dominância de custo deve valer para qualquer que seja o nível de demanda $q=D(p)$ do mercado.

Um monopólio natural pode ser permanente ou temporário. No primeiro caso, os custos médios de longo prazo da firma monopolista serão sempre decrescentes. Esta condição é assegurada quando o custo marginal de produção é sempre inferior ao custo médio, qualquer que seja o volume produzido. No segundo caso, os custos médios de longo prazo serão decrescentes até um determinado nível de produção. A partir de então, passam a ser constantes. Se a demanda do mercado for suficientemente elevada ao ponto em que a firma monopolista atinja custos médios constantes, estará descaracterizado o caso de um monopólio natural, podendo-se, em princípio, incentivar-se a competição neste mercado, visando-se a melhoria do bemestar social. A Figura 70 e a Figura 71 apresentam as situações de monopólio natural permanente e temporário, respectivamente.

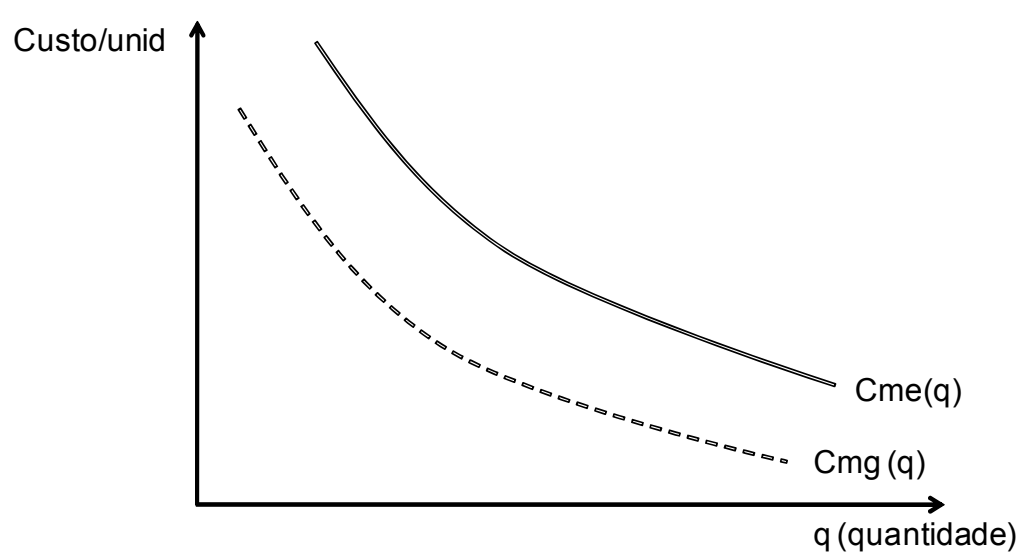

Figura 70 - Caso do Monopólio Natural Permanente 


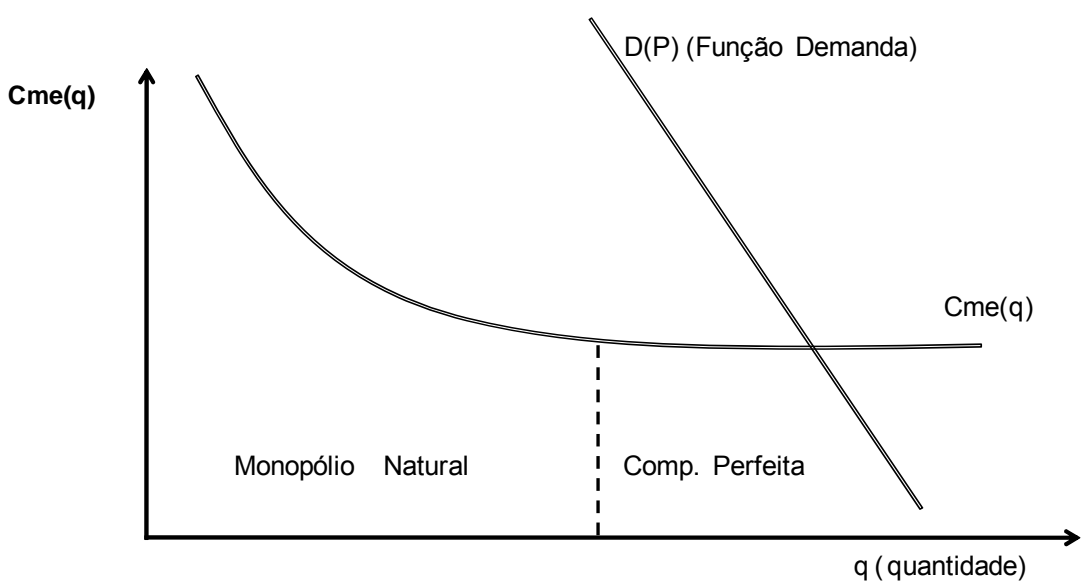

Figura 71 - Caso do Monopólio Natural Temporário

\section{Geometria de custos}

Os custos totais de uma empresa qualquer, no curto prazo, construída para atender a uma demanda q, podem ser representados pela Equação (67). É importante enfatizar que custos fixos só se caracterizam no curto prazo, uma vez que, no longo prazo, a empresa poderia escolher a quantidade de todos os fatores que são utilizados (LOOTTY \& SZAPIRO, 2002).

$C T(q)=C f+C v(q)$

Onde:

CT: Custos totais.

Cf: $\quad$ Custos fixos.

Cv: Custos variáveis.

q: Quantidade atendida pela empresa. 
Dada a Equação (67), o custo marginal desta empresa para o atendimento a um incremento de demanda a partir do ponto q, será dado pela Equação (68).

$\operatorname{Cmg}(q)=\frac{d C T(q)}{d q}=\frac{d C v(q)}{d q}$

Da mesma forma, o custo médio observado nesta empresa, ao nível de produção q, será dado pela Equação (69).

$\operatorname{Cme}(q)=\frac{C f}{q}+\frac{C v(q)}{q}$

Da teoria econômica, o nível de produção eficiente ocorre quando os custos médios em função da quantidade produzida forem mínimos, o que para funções Cme $(q)$ convexas e positivas, pode ser determinado pela Equação (70).

$\frac{d C m e(q)}{d q}=0$

Desta forma, derivando-se a Equação (69) e igualando-a a zero, obtém-se algebricamente o seguinte resultado:

$\frac{d C m e(q)}{d q}=-\frac{C f}{q^{2}}+\frac{d C v(q)}{d q} \cdot \frac{1}{q}-\frac{C v(q)}{q^{2}}=0$

$\frac{C f}{q^{2}}+\frac{C v(q)}{q^{2}}=\frac{d C v(q)}{d q} \cdot \frac{1}{q}$

Multiplicando-se ambos os lados da equação por $q$, tem-se que:

$\frac{C f}{q}+\frac{C v(q)}{q}=\frac{d C v(q)}{d q}$ 
$\operatorname{Cme}\left(q_{e f}\right)=\operatorname{Cmg}\left(q_{e f}\right)$

Da mesma forma, para $\frac{d C m e(q)}{d q}<0$, tem-se que:

$\operatorname{Cme}\left(q_{e f}\right)>\operatorname{Cmg}\left(q_{e f}\right)$

Assim como para $\frac{d C m e(q)}{d q}>0$, tem-se que:

$\operatorname{Cme}\left(q_{e f}\right)<\operatorname{Cmg}\left(q_{e f}\right)$

Como resultado, observado nas Equações (71), (72) e (73), conclui-se que na escala de produção eficiente, $q_{e f}$, o custo médio de produção, que é mínimo, é igual ao custo marginal neste mesmo nível, definindo assim duas regiões de produção bastante discutidas na teoria micro-econômica.

Para a região à esquerda do ponto de escala eficiente, considerando-se que a curva de custo médio é convexa, o custo marginal é sempre menor que o custo médio, o que caracteriza a economia de escala. À direita da quantidade eficiente de produção, o inverso ocorre, caracterizando assim a deseconomia de escala. O gráfico da Figura 72 ilustra as regiões de economias e deseconomias de escala, para um exemplo genérico de função de custo médio convexa.

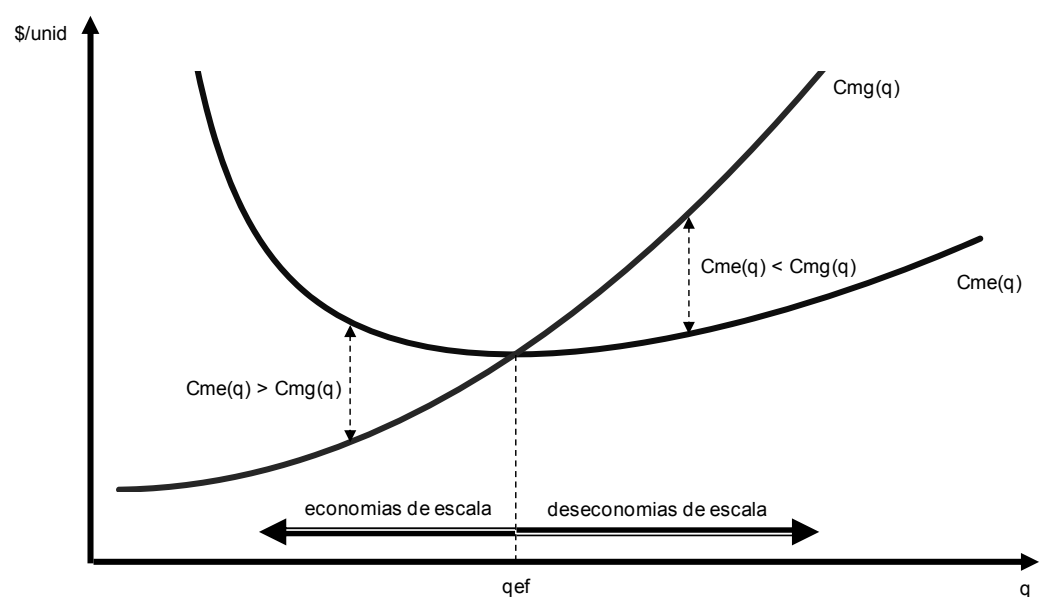

Figura 72 - Definição das regiões de economias e deseconomias de escala 


\section{Incluindo a curva de demanda: O bem-estar social}

Para um determinado mercado, o preço de equilíbrio, bem como a quantidade de equilíbrio, decorrem da intersecção entre a curva de oferta, ou curva de custo marginal, e a curva de demanda, ou curva de utilidade marginal (KREPS, 2004).

Em (BROWN \& SIBLEY, 1986), são discutidos princípios econômicos básicos relacionados à teoria econômica do bem-estar social, formado pelos excedentes dos consumidores e dos produtores. A discussão do bem-estar social é bastante considerada na literatura relacionada à regulação de monopólios naturais, uma vez que um dos principais objetivos do regulador é, teoricamente, a maximização deste bem-estar.

Resumidamente, iniciando-se pelo excedente do produtor, sua definição é dada pela Equação (74). O excedente do produtor nada mais é do que o lucro de sua atividade, composto pela diferença entre a receita obtida ao nível de produção qe e os custos de produção, também ao nível qe. Matematicamente, o custo total é obtido através da integral do custo marginal, prevendo-se a consideração de uma constante, que para o caso em questão, é igual ao custo fixo, $C f$.

$E P=P(q e) \cdot q e-\int_{0}^{q e} C m g(q) d q$

Onde:

EP: $\quad$ Excedente do produtor.

$\operatorname{Cmg}(q)$ : Custo marginal em função do nível de produção q.

qe: $\quad$ Quantidade de equilíbrio

O excedente do consumidor, por sua vez, não é obtido através de uma definição tão intuitiva quanto o excedente do produtor. Segundo (KREPS, 2004), o excedente do consumidor é um conceito matemático que busca mensurar de forma 
aproximada o benefício dos consumidores em consumir um produto, e esta mensuração é realizada em unidades monetárias.

Existem muitas considerações e discussões teóricas complexas sobre a natureza da função demanda por um produto. Contudo, para o caso particular de serviços de utilidade pública (BROWN \& SIBLEY, 1986), como é o caso da energia elétrica, pode-se, por hipótese, considerar que as funções demanda são quasilineares, para as quais a elasticidade-renda para o consumo do produto em questão é desprezível. Desta forma, o excedente do consumidor torna-se uma boa aproximação de seu bem-estar.

A Equação (75) apresenta o excedente do consumidor, formado pela diferença entre a sua utilidade em consumir uma quantidade qe e o custo para o consumidor, composto pelo produto entre quantidade e preço, ambos ao nível de consumo qe.

$E C=\int_{0}^{q e} P(q) d q-P(q e) \cdot q e$

Onde:

EC: $\quad$ Excedente do consumidor.

$P(q e): \quad$ Função inversa da demanda.

qe: $\quad$ Quantidade de equilíbrio.

Desta forma, retomando-se a Figura 72, e considerando a existência de uma função inversa da demanda qualquer $P(q)$, Obtém-se a Figura 73. Nela, são ilustrados os excedentes do consumidor e do produtor em um ambiente particular de competição perfeita, no qual a quantidade de equilíbrio e o preço de equilíbrio são dados pelo cruzamento das funções demanda, custo marginal e custo médio. 


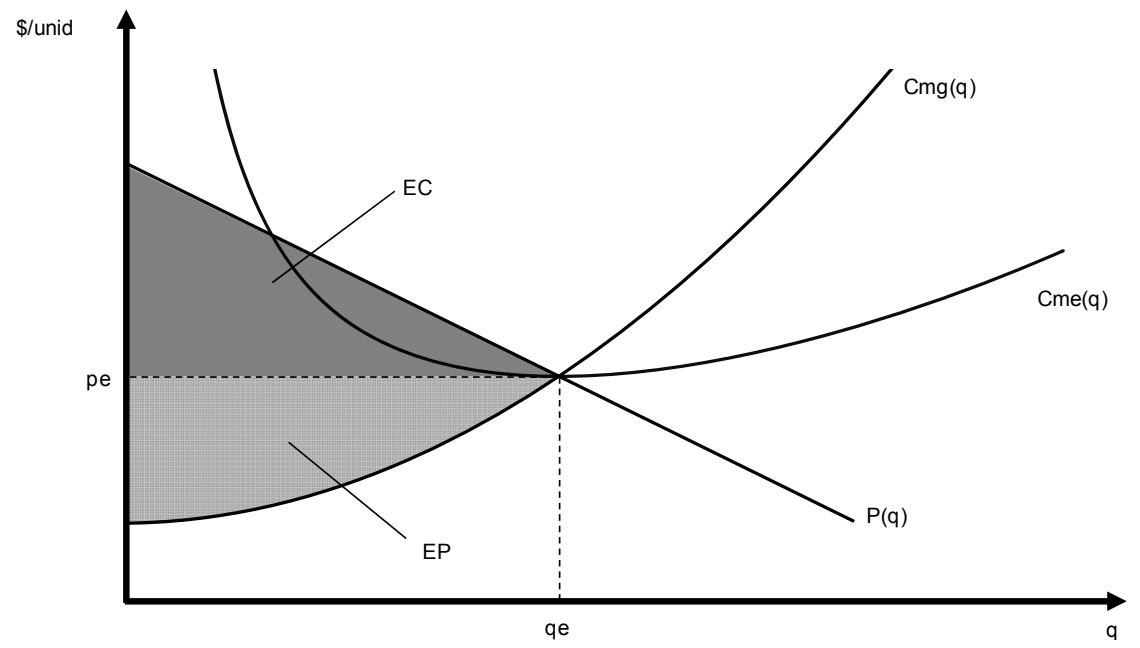

Figura 73 - Representação gráfica dos excedentes do consumidor e do produtor

Para o caso exemplo observado na Figura 73, ao excedente do produtor ilustrado, é necessário subtrair os custos fixos. Para o caso da concorrência perfeita, estes custos são exatamente iguais à área representada por "EP", resultando em excedente líquido do produtor nulo.

Para observar esta situação, pode-se considerar novamente a Equação (67), $C T(q)=C f+\operatorname{Cv}(q)$.

Como o custo total é dado pela relação $C T(q)=C m e(q) \cdot q$, e também como o custo variável é dado por $C V(q)=\int_{0}^{q} C m g(q) d q$, desconsiderando-se a constante da integração, chega-se à Equação (76), que nada mais é do que a definição do custo fixo como sendo a diferença entre os custos totais e os custos variáveis, ambos ao nível de produção $q$.

$C f=C m e(q) \cdot q-\int_{0}^{q} \operatorname{Cmg}(q) d q$

A Figura 74 ilustra graficamente a interpretação do custo fixo, $C f$, do variável, $C v(q)$ e do custo total $C T(q)$, para um determinado volume de produção $q$. 


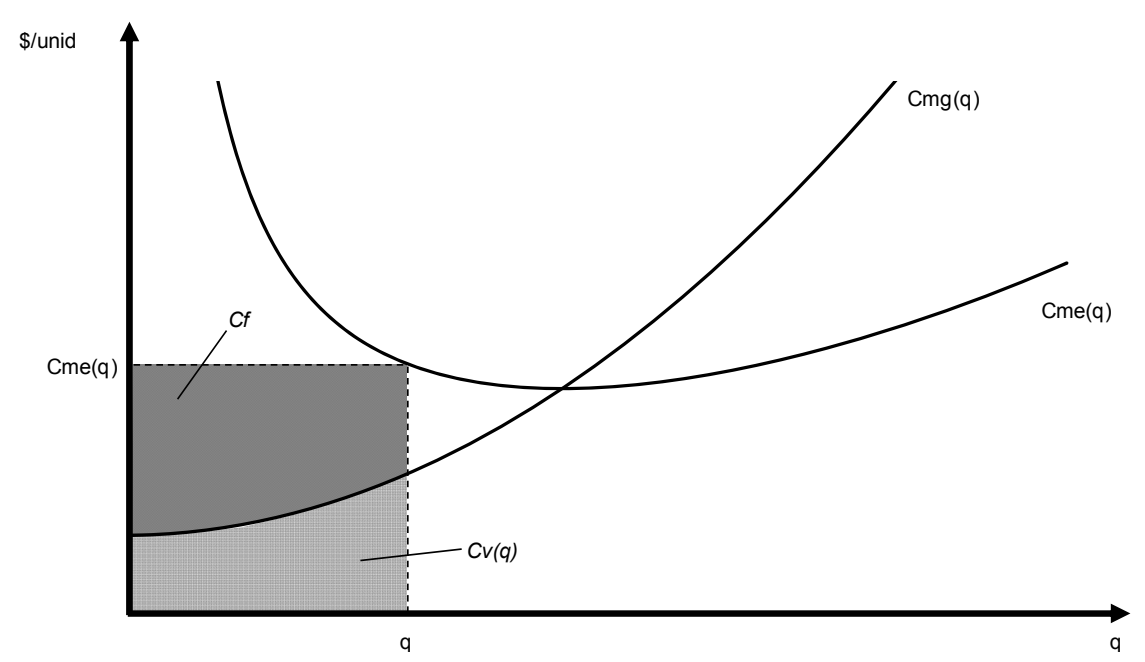

Figura 74 - Interpretação gráfica do custo fixo, variável e total

Para o caso de um monopólio natural, como inicialmente tratado no item 2.1, a demanda atendida encontra-se na região de economias de escala. Nesta região, os custos marginais para qualquer nível de produção são menores que os custos totais, indicando que qualquer precificação a custos marginais não garante o equilíbrio econômico-financeiro do produtor.

Desta forma, para o caso exemplo de um monopólio natural que produz um único produto (monoproduto), os preços devem ser, no mínimo, iguais ao custo médio de produção para que se cumpra a restrição de cobertura total dos custos. Neste contexto, trabalha-se com o conceito de lucro econômico nulo, considerando-se a remuneração dos ativos já incluída nos custos totais da empresa.

Para o exemplo da Figura 73, ao se cobrar um preço igual ao custo médio de produção na região de economias de escala, haverá alteração nos montantes dos excedentes do consumidor, $E C$, e produtor, $E P$, bem como o surgimento do chamado "peso-morto", que equivale à perda de bem-estar social.

A Figura 75 ilustra o resultado da precificação a custos médios, bem como os montantes dos excedentes do consumidor, produtor e o "peso-morto". 


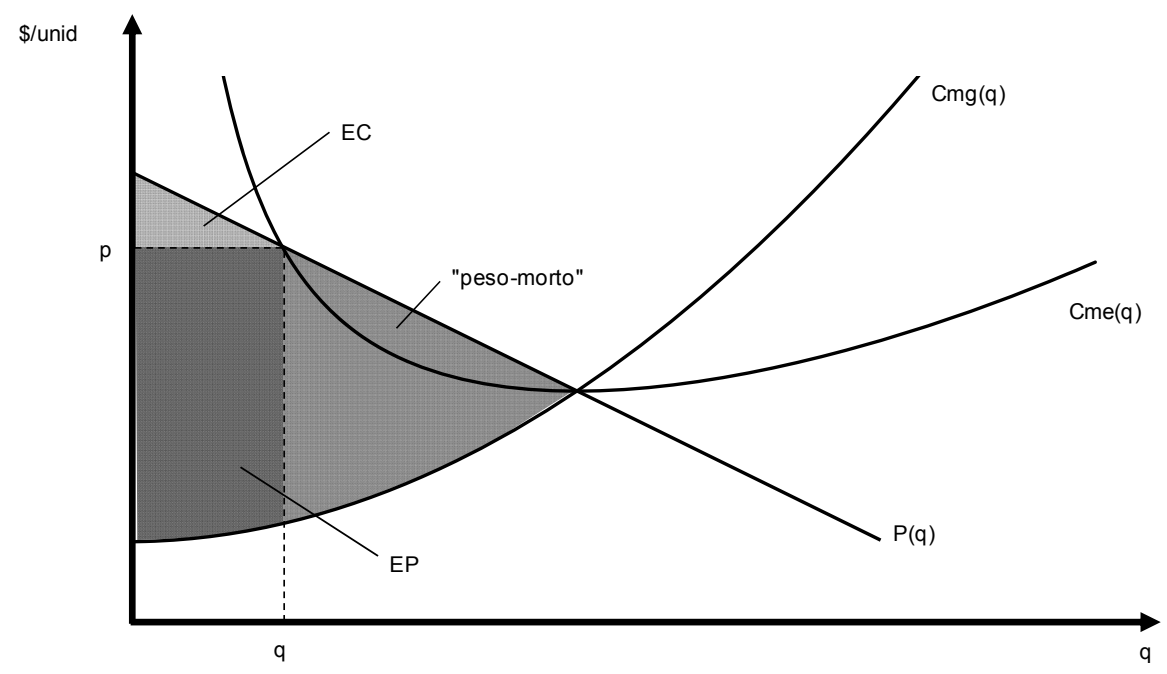

Figura 75 - Resultados para a precificação à custos médios, com a ilustração dos excedentes do consumidor, EC, do produtor, EP e do "peso-morto", que é a perdłâdde bem-estar social.

O resultado obtido pela precificação a custos médios pode generalizar a interpretação de que toda vez que o preço se distanciar do custo marginal (essa distância também é conhecida como markup), haverá perda de bem-estar social. É por esse motivo que a precificação a custo marginal é conhecida na economia como a condição de primeiro ótimo (first-best), para a qual o "peso-morto" não existe.

A tentativa de minimização deste "peso-morto", quando ele necessariamente existir, levará a uma condição de segundo ótimo (second-best), que é conseguida para um caso de restrição de equilíbrio econômico, através da segmentação do mercado (múltiplos produtos) e aplicação da regra de Ramsey, a ser discutida mais adiante neste capítulo.

\section{A caracterização da sub-aditividade}

\section{O caso monoproduto}

Seja o mercado para um único produto homogêneo onde $k$ firmas produzem um determinado nível de output qi, sendo o volume total de produção dado por $Q=\sum_{i=1}^{k} q_{i}$. Suponha que todas as firmas operem com a mesma tecnologia de 
produção, com preços de insumos constantes, sendo a função custo (de longo prazo) de uma dada firma $i$ igual a $C(q i)$. O nível de produção $Q$ será caracterizado como um monopólio natural quando:

$C(Q)<C\left(q_{1}\right)+C\left(q_{2}\right)+\cdots+C\left(q_{k}\right)$

A desigualdade (77) demonstra que o custo de produzir $Q$ unidades será minimizado quando apenas uma firma produzir, ao invés de duas firmas ou mais. Funções de custo com esta característica são conhecidas como "sub-aditivas" ao nível de produção Q (SHARKEY, 1982). Quando esta propriedade é válida para qualquer nível de produção $Q$, em particular para todos os níveis de produção demandados pelo mercado $Q=D(p)$, diz-se que a função $C(Q)$ será globalmente sub-aditiva. Desta forma, uma condição necessária para a existência de um monopólio natural ao nível de produção $Q$ de um bem qualquer, é que o custo de produzi-lo seja sub-aditivo em $Q$.

Para o caso de um único produto, o conceito de monopólio natural está fortemente relacionado à existência de uma tecnologia de retornos crescentes de escala. Esta tecnologia, por sua vez, dará origem a economias de escala no âmbito da firma. Suponha que para produzir unidades de produto, são necessários $n$ insumos nas quantidades $y_{1}, y_{2}, \ldots, y_{n}$. Uma função de produção $q_{i}=f\left(y_{1}, y_{2}, \ldots, y_{n}\right)$ apresentará retornos crescentes de escala se, $\forall a>1$, quando:

$f\left(a \cdot y_{1}, a \cdot y_{2}, \ldots, a \cdot y_{n}\right) \geq a \cdot f\left(y_{1}, y_{2}, \ldots, y_{n}\right)$

Uma interpretação didática para a inequação (78) pode ser a seguinte: Ao aumentar, por exemplo, todos insumos $y_{1}, y_{2}, \ldots, y_{n}$ utilizados na produção em $10 \%$, a quantidade resultante aumentará numa proporção maior ou igual a 10\%.

A existência de economias de escala em um processo produtivo está relacionada à ocorrência de custos médios decrescentes com o volume de produção. Por sua vez, a um dado volume de produção $q_{i}$, o custo médio será decrescente sempre que for maior que o respectivo custo marginal em $q_{i}$. Como exemplo, seja a função custo dada pela Equação (79). 
$C\left(q_{i}\right)=F+c \cdot q_{i}$

$F$ é um custo fixo afundado e $c$ é o custo marginal (suposto constante). Desta forma, o custo médio relativo à produção de $q_{i}$ unidades de produto pode ser descrito pela Equação (80).

$\operatorname{Cme}\left(q_{i}\right)=\frac{F}{q_{i}}+c$

Em (80), vê-se claramente que o custo marginal $c$ será sempre menor que o custo médio $C m e\left(q_{i}\right), \forall q_{i}$. Portanto, os custos médios serão decrescentes em toda a extensão possível para $q_{i}$, como ilustrado na Figura 76, caracterizando a existência de economias de escala no âmbito da firma.

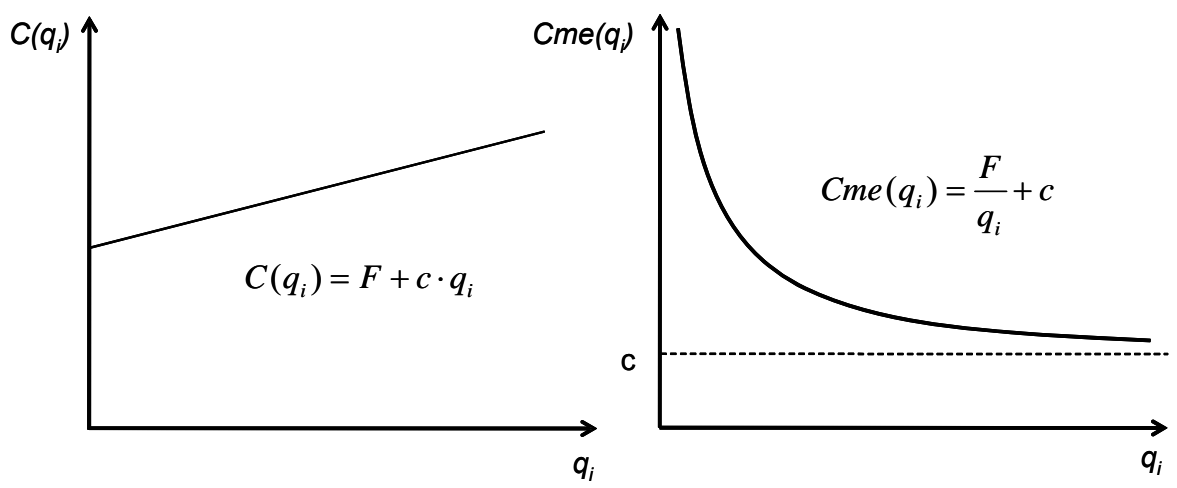

Figura 76 - Curva de custos caracterizando Economias de Escala no âmbito da firma

Em particular, para o caso de custos totais lineares, o custo médio será tão mais próximo do custo marginal, quanto maior for o volume de produção $q_{i}$. No limite, para $q_{i} \rightarrow+\infty$, ambos os custos serão iguais.

De maneira geral, quando o custo médio de uma firma decresce com o aumento do volume produzido, sua tecnologia de produção será caracterizada por 
economias de escala ou, de forma equivalente, sua função de produção exibirá retornos crescentes de escala.

A equivalência entre economias de escala e retornos crescentes de escala no âmbito da firma pode ser demonstrada de maneira simples. Suponha a seguinte função custo para a firma $k$, a qual opera com retornos crescentes de escala.

$C\left(q_{i}\right)=r_{1} \cdot y_{1}^{*}+r_{2} \cdot y_{2}^{*}+\cdots+r_{n} \cdot y_{n}^{*}$

$\mathrm{Na}$ Equação (81), $r_{i}$ representa o preço do insumo $i$ e $y_{i}^{*}$ representa a demanda ótima por este insumo, para $i=1 \ldots n$. Suponha que esta firma deseje aumentar sua escala de produção para $a \cdot q_{i}$, com $a>1$. Dada a existência de retornos crescentes de escala, é possível afirmar que o vetor de insumos $\left(a \cdot y_{1}^{*}, a \cdot y_{2}^{*}, \ldots, a \cdot y_{n}^{*}\right)$ produzirá, no mínimo, $a \cdot q_{i}$. Portanto, o custo de se produzir $a \cdot q_{i}$ não pode ser maior que $a \cdot C\left(q_{i}\right)$, pois, como mostra a Equação (82).

$$
\begin{aligned}
r_{1} \cdot\left(a \cdot y_{i}^{*}\right)+r_{2} \cdot\left(a \cdot y_{2}^{*}\right)+\cdots+r_{n} \cdot\left(a \cdot y_{n}^{*}\right) \\
=a \cdot\left(r_{1} \cdot y_{1}^{*}+r_{2} \cdot y_{2}^{*}+\cdots+r_{n} \cdot y_{n}^{*}\right)=a \cdot C\left(q_{i}\right)
\end{aligned}
$$

Ou seja, o custo total para produzir, por exemplo, $10 \%$ mais unidades tem que ser, no máximo, o custo total considerando que haverá um acréscimo de $10 \% \mathrm{em}$ todos os insumos utilizados. Logo, se a firma possui retornos crescentes de escala, tem-se que, $\forall q_{i}$ e $a>1$,

$C\left(a \cdot q_{i}\right) \leq a \cdot C\left(q_{i}\right)$

Supondo $q_{i}$ e $q_{i}^{*}$ arbitrários, de tal forma que $q_{i}^{*}>q_{i}$, e seja $a=\frac{q_{i}^{*}}{q_{i}}$, o que resulta em $a>1$, tem-se que: 
Dividindo-se ambos os membros da desigualdade representada em (84) por $q_{i}^{*}=a$. $q_{i}$, tem-se que:

$\operatorname{Cme}\left(q_{i}^{*}\right)=\frac{C\left(q_{i}^{*}\right)}{q_{i}^{*}} \leq \frac{a \cdot C\left(q_{i}\right)}{a \cdot q_{i}}=\operatorname{Cme}\left(q_{i}\right)$

O que demonstra que, quanto maior a escala de produção, menor será o custo médio para uma dada firma com tecnologia de retornos crescentes de escala. Para a desigualdade forte, bastaria assumir retornos de escala estritamente crescentes.

Para o caso monoproduto, uma firma caracterizada por custos médios decrescentes em um dado intervalo de produção, também apresentará sub-aditividade em sua função custo para este mesmo intervalo. Desta forma, para o caso monoproduto, a existência de economias de escala é condição suficiente para a caracterização de um monopólio natural.

A relação entre economias de escala e sub-aditividade também pode ser demonstrada de maneira simples. Seja $Q=\sum_{i=1}^{k} q_{i}$. Supondo a existência de economias de escala, tem-se que:

$\frac{C\left(q_{i}\right)}{q_{i}} \geq \frac{C(Q)}{Q}$

Aplicando-se a somatória em ambos os membros da desigualdade em (86), tem-se que:

$\sum_{i=1}^{k} C\left(q_{i}\right) \geq \sum_{i=1}^{k} \frac{q_{i} \cdot C(Q)}{Q}=C(Q)$ 
O que demonstra a sub-aditividade da função custo $C$, sob a hipótese de economias de escala.

É importante ressaltar que, para o caso monoproduto, a existência de economias de escala é uma condição suficiente para a caracterização de um monopólio natural, mas não é uma condição necessária. É possível, pois, a ocorrência de sub-aditividade em um intervalo de produção caracterizado por deseconomias de escala ou retornos decrescentes de escala. De outra forma, é possível que seja ainda mais barata a produção de apenas uma firma, em relação a duas firmas ou mais, mesmo em um volume de produção onde já inexistem economias de escala a serem exploradas. Este é particularmente o caso quando a demanda de mercado $P=D(Q)$ não é grande o suficiente para suportar a produção eficiente de duas firmas.

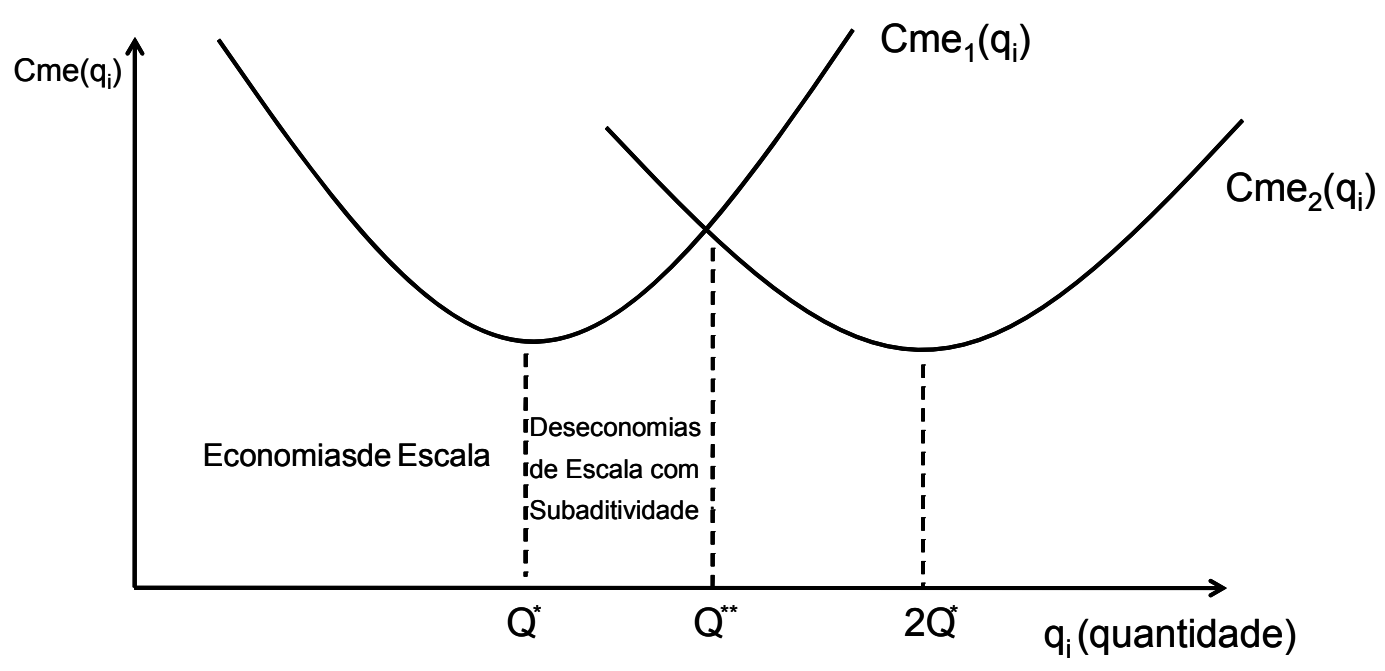

Figura 77 - Economias de Escala x Sub-aditividade da função custo

A Figura 77 faz um comparativo entre as curvas de custos médios para os casos de uma única firma $\left(C m e_{1}\right)$ e para o caso de duas firmas idênticas, com produção conjunta $\left(\mathrm{Cme}_{2}\right)$. O nível de produção $Q^{*}$ representa a escala eficiente de produção (custo médio mínimo), valor a partir do qual os retornos de escala passam a ser decrescentes. De acordo com a Figura 77, para o intervalo de produção entre 0 e $Q^{* *}$, a eficiência produtiva será alcançada com a produção de apenas uma firma, ainda que o intervalo específico entre $Q^{*}$ e $Q^{* *}$ seja caracterizado por deseconomias de escala ou retornos decrescentes. 
Em síntese, o conjunto de funções custo sub-aditivas compreende um conjunto ainda mais amplo de funções, além das que exibem economias de escala. Para o caso monoproduto, a função custo de uma firma pode exibir economias de escala em um determinado intervalo de produção, mas ainda ser sub-aditiva a partir de um ponto onde inexistem economias de escala a serem exploradas e até um volume de produção grande o suficiente para comportar uma firma adicional neste mercado.

\section{O caso multiproduto}

A definição de monopólio natural pode ser generalizada para o caso onde firmas produzem vários bens. Neste caso, é mais eficiente para uma dada firma a produção de dois ou mais bens em uma mesma planta, ao invés de produzi-los em plantas individuais. Este tipo de tecnologia de produção é caracterizado pela existência de economias de escopo.

Para a intuição do conceito de sub-aditividade no caso multiproduto, suponha dois produtos $q_{1}$ e $q_{2}$ que podem ser produzidos por uma única firma com função custo dada por $C\left(q_{1}, q_{2}\right)$. Defina $q_{i}$ como um vetor de duas dimensões tal que $q_{i}=$ $\left(q_{1 i}, q_{2 i}\right)$. Suponha que existam $N$ vetores de tal forma que $\sum_{i=1}^{N} q_{1 i}=q_{1}$ e $\sum_{i=1}^{N} q_{2 i}=$ $q_{2}$. Assim, a função custo $C\left(q_{1}, q_{2}\right)$ será sub-aditiva se, $\forall N$,

$C\left(q_{1}, q_{2}\right)<\sum_{i=1}^{N} C\left(q_{1 i}, q_{2 i}\right)$

A definição em (88) pode ser generalizada para qualquer que seja o número de produtos produzidos por uma firma. Contrariamente ao caso monoproduto, onde a ocorrência de economias de escala garante a sub-aditividade da função custo, no caso multiproduto a tecnologia deverá ser caracterizada por algum nível de economias de escopo associada a economias de escala. 
Em uma tecnologia de produção com economias de escopo, será sempre mais econômico produzir dois produtos quaisquer em uma única firma do que em duas firmas distintas. A inequação (89) garante economias de escopo.

$C\left(q_{1}, q_{2}\right)<C\left(q_{1}, 0\right)+C\left(0, q_{2}\right)$

Há basicamente duas formas de conceituar economias de escala para o caso multiproduto, dependendo da análise que é feita sobre a função custo de uma firma. São elas: a) Custo incremental médio decrescente para um produto específico; b) Custo médio radial decrescente para quantidades variáveis de um conjunto de produtos analisados em proporções fixas.

No enfoque pelo custo incremental médio decrescente, define-se o custo incremental de produzir $\mathrm{q}_{1}$, mantendo-se $\mathrm{q}_{2}$ constante, como:

$C I\left(q_{1} / q_{2}\right)=C\left(q_{1}, q_{2}\right)-C\left(0, q_{2}\right)$

A partir de (90), define-se o custo médio incremental de produzir o mesmo produto como:

$\operatorname{CMI}\left(q_{1} / q_{2}\right)=\frac{\left[C\left(q_{1}, q_{2}\right)-C\left(0, q_{2}\right)\right]}{q_{1}}$

Caso a função $C M I$ seja decrescente em $q_{1}$, tem-se uma medida de economias de escala de um único produto, para o caso multiproduto. O mesmo exercício pode ser feito para o produto $q_{2}$ e, em caso de custos médios também decrescentes, pode-se afirmar que a função custo possui custos médios incrementais decrescentes para ambos os produtos, caracterizando a existência de economias de escala.

No enfoque pelo custo médio radial decrescente para quantidades variáveis de um conjunto de produtos analisados em proporções fixas, considera-se que, de maneira geral, dados os volumes de produção $q_{1}$ e $q_{2}$, haverá economias de escala para o caso multiproduto quando, $\forall \lambda>1$ :

$C\left(\lambda \cdot q_{1}, \lambda \cdot q_{2}\right)<\lambda \cdot C\left(q_{1}, q_{2}\right)$ 
No caso multiproduto, a sub-aditividade da função custo só poderá ser garantida na presença de economias de escala e de escopo. Para melhor exemplificar este ponto, considere a seguinte função custo (SHARKEY, 1982):

$C\left(q_{1}, q_{2}\right)=q_{1}+q_{2}+\left(q_{1} \cdot q_{2}\right)^{\frac{1}{3}}$

A função custo descrita em (93) apresenta economias de escala na medida em que:

$\lambda \cdot C\left(q_{1}, q_{2}\right)=\lambda \cdot q_{1}+\lambda \cdot q_{2}+\lambda \cdot\left(q_{1} \cdot q_{2}\right)^{\frac{1}{3}}$

$C\left(\lambda \cdot q_{1}, \lambda \cdot q_{2}\right)=\lambda \cdot q_{1}+\lambda \cdot q_{2}+\lambda^{\frac{2}{3}} \cdot\left(q_{1} \cdot q_{2}\right)^{\frac{1}{3}}$

Logo, $C\left(\lambda \cdot q_{1}, \lambda \cdot q_{2}\right)<\lambda \cdot C\left(q_{1}, q_{2}\right)$. Contudo, esta função custo apresenta deseconomias de escopo, uma vez que $C\left(q_{1}, 0\right)=q_{1}$ e $C\left(0, q_{2}\right)=q_{2}$. Portanto:

$C\left(q_{1}, 0\right)+C\left(0, q_{2}\right)=q_{1}+q_{2}<q_{1}+q_{2}+\left(q_{1} \cdot q_{2}\right)^{\frac{1}{3}}=C\left(q_{1}, q_{2}\right)$

Como conseqüência, a função custo descrita em (93) não é sub-aditiva, embora apresente economias de escala. Seria mais econômico produzir os dois produtos em plantas separadas que em uma única planta, dada a existência de deseconomias de escopo. Já, por exemplo, a função custo dada por $C\left(q_{1}, q_{2}\right)=q_{1}^{1 / 4}+$ $q_{2}^{1 / 4}-\left(q_{1} \cdot q_{2}\right)^{1 / 4} \quad$ apresenta economias de escala e escopo.

As condições necessárias e suficientes para a sub-aditividade global de uma função custo multiproduto são bastante complexas, fugindo ao escopo desta tese. De maneira geral, a existência de economias de escopo e economias de escala será uma condição suficiente para a sub-aditividade de uma função custo multiproduto. 


\section{Motivação teórica para a regulação de monopólios naturais}

É importante notar a existência de uma compensação natural entre eficiência alocativa e produtiva, para o caso de monopólios naturais. Eficiência produtiva requer que exista apenas uma firma produzindo, caso seja esta a forma de minimizar o custo da indústria. Por outro lado, se há apenas uma firma produzindo, esta exercerá seu poder de mercado e fixará seu preço acima do custo marginal, gerando perda de bemestar social (peso morto). De outra forma, se há mais de uma firma produzindo, o preço se aproximará do custo marginal, aumentando a eficiência alocativa, mas, por outro lado, piorando a eficiência produtiva. Portanto, considera-se que, para o monopólio natural, a melhor maneira de se alcançar eficiência produtiva e alocativa será por meio da regulação do governo.

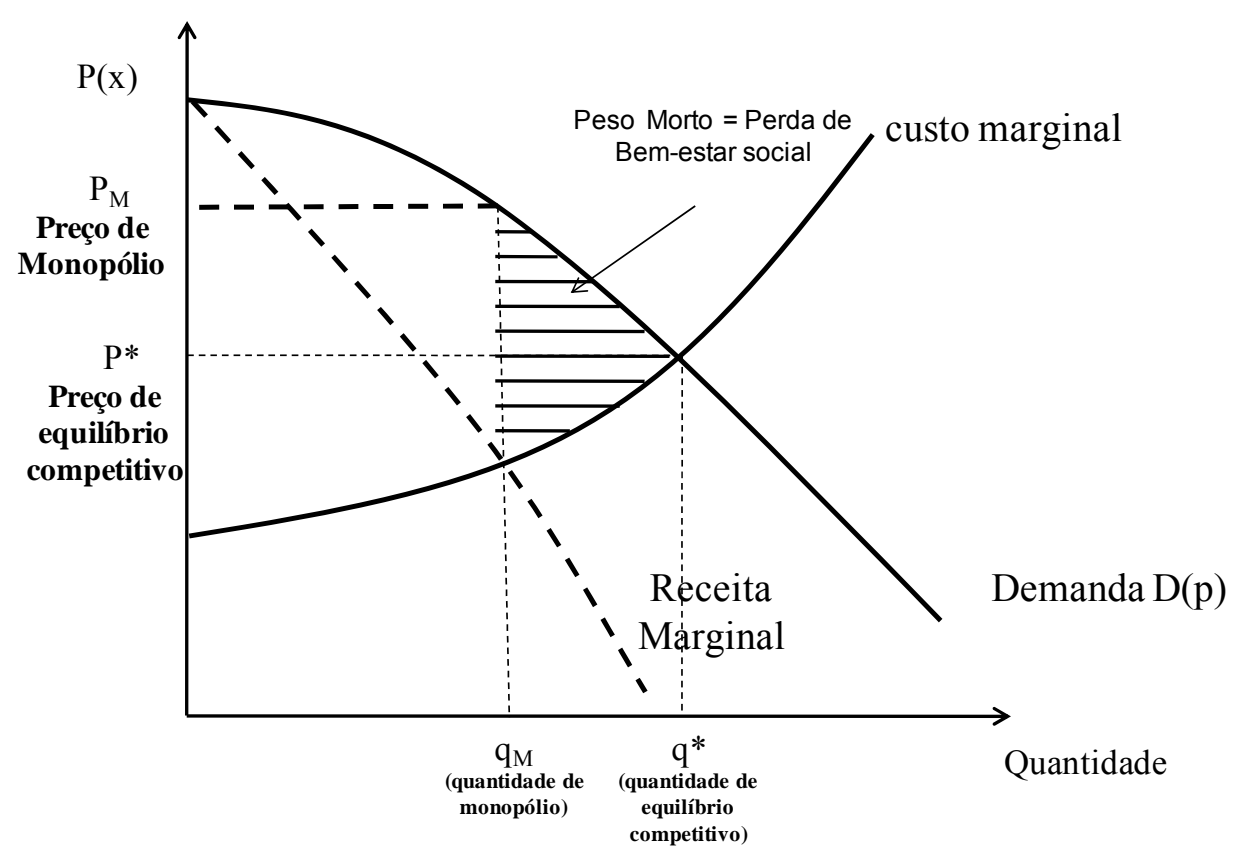

Figura 78 - Uma firma monopolista fixa seu preço acima do custo marginal

A Figura 78 ilustra o comportamento do monopolista, quando da tomada de decisão sobre o quanto produzir de forma a maximizar seu lucro. Por considerar o impacto negativo do volume ofertado em sua receita (perda infra-marginal), o monopolista tende a produzir uma quantidade menor que uma indústria perfeitamente competitiva, gerando perda de bem-estar social. O bem-estar social seria maximizado (eficiência alocativa máxima) caso a firma monopolista produzisse no volume de equilíbrio competitivo $q^{*}$. Contudo, a depender da intensidade dos custos fixos da 
indústria, caso o regulador imponha tal volume de produção para o monopolista, é possível que seu lucro econômico seja negativo. Faz-se necessário, pois, a compatibilização entre o aumento do excedente do consumidor e a viabilidade econômico-financeira da firma monopolista. 


\section{ANEXO II \\ Dados e Modelos Econométricos}

Foram avaliados os custos de capital e O\&M de 56 das 61 distribuidoras de energia elétrica no Brasil, com base nos resultados da metodologia da Empresa de Referência e da Base de Remuneração Regulatória para o $2^{\circ}$ ciclo de revisão tarifária 2007 - 2010. Não foi possível realizar a análise para todas distribuidoras devido à indisponibilidade de dados de algumas empresas, uma vez que o $2^{\circ}$ ciclo de revisão tarifária não havia sido encerrado até o momento das análises. As Tabela 22, Tabela 23 e Tabela 24 apresentam a relação de todas concessionárias analisadas neste estudo.

Tabela 22 - Calendário de Revisão Tarifária - 2007. Fonte: ANEEL.

\begin{tabular}{lcc}
\multicolumn{1}{c}{ Distribuidora } & Sigla & $\begin{array}{c}\text { Data da } \\
\text { Revisão }\end{array}$ \\
\hline Companhia Energética do Ceará & COELCE & $22 / 04 / 07$ \\
Eletropaulo Metropolitana Eletricidade de São Paulo S/A & ELETROPAULO & $04 / 07 / 07$ \\
Espírito Santo Centrais Elétricas S/A & ESCELSA & $07 / 08 / 07$ \\
Centrais Elétricas do Pará S/A & CELPA & $07 / 08 / 07$ \\
Elektro Eletricidade e Serviços S/A & ELEKTRO & $27 / 08 / 07$ \\
Bandeirante Energia S/A & BANDEIRANTE & $23 / 10 / 07$ \\
Companhia Piratininga de Força e Luz & CPFL PIRA & $23 / 10 / 07$ \\
\hline
\end{tabular}

Tabela 23 - Calendário de Revisão Tarifária - 2008. Fonte: ANEEL.

\begin{tabular}{llc}
\hline \multicolumn{1}{c}{ Distribuidora } & Sigla & $\begin{array}{c}\text { Data da } \\
\text { Revisão }\end{array}$ \\
\hline Companhia Jaguari de Energia & CJE & $03 / 02 / 08$ \\
Companhia Paulista de Energia Elétrica & CPEE & $03 / 02 / 08$ \\
Companhia Sul Paulista de Energia & CSPE & $03 / 02 / 08$ \\
Companhia Luz e Força Santa Cruz & CLFSC & $03 / 02 / 08$ \\
Companhia Força e Luz do Oeste & CFLO & $03 / 02 / 08$ \\
\hline
\end{tabular}




\begin{tabular}{|c|c|c|}
\hline Companhia Luz e Força Mococa & CLFM & $03 / 02 / 08$ \\
\hline Empresa Luz e Força Santa Maria S/A & ELFSM & 07/02/08 \\
\hline Companhia Campolarguense de Energia & COCEL & $30 / 03 / 08$ \\
\hline Empresa Força e Luz Urussanga Ltda & EFLUL & $30 / 03 / 08$ \\
\hline Empresa Força e Luz João Cesa Ltda & EFLJC & $30 / 03 / 08$ \\
\hline Companhia Paulista de Força e Luz & CPFL PAULISTA & 08/04/08 \\
\hline CEMIG Distribuição S/A & CEMIG-D & 08/04/08 \\
\hline Centrais Elétricas Matogrossenses S/A & CEMAT & 08/04/08 \\
\hline Empresa Energética Mato Grosso do Sul & ENERSUL & 08/04/08 \\
\hline AES SUL Distribuidora Gaúcha de Energia S/A & AES SUL & $19 / 04 / 08$ \\
\hline Rio Grande Energia S/A & RGE & $19 / 04 / 08$ \\
\hline Companhia de Eletricidade do Estado da Bahia & COELBA & $22 / 04 / 08$ \\
\hline Companhia Energética do Rio Grande do Norte & COSERN & $22 / 04 / 08$ \\
\hline Energisa Sergipe & ESE & $22 / 04 / 08$ \\
\hline Caiuá Distribuição de Energia S/A & CAIUÁ & $10 / 05 / 08$ \\
\hline Empresa Elétrica Bragantina & EEB & $10 / 05 / 08$ \\
\hline Empresa de Distribuição de Energia Vale Paranapanema & EDEVP & $10 / 05 / 08$ \\
\hline Companhia Nacional de Energia Elétrica & CNEE & $10 / 05 / 08$ \\
\hline Energisa Minas Gerais & EMG & $18 / 06 / 08$ \\
\hline Energisa Nova Friburgo & ENF & $18 / 06 / 08$ \\
\hline Copel Distribuição S/A & COPEL-D & $24 / 06 / 08$ \\
\hline Departamento Municipal de Eletricidade de Poços de Caldas & DMEPC & $28 / 06 / 08$ \\
\hline Companhia Elétrica do Estado de Tocantins & CELTINS & 04/07/08 \\
\hline Centrais Elétricas Santa Catarina S/A & CELESC & 07/08/08 \\
\hline Iguaçu Distribuidora de Energia Elétrica & IENERGIA & 07/08/08 \\
\hline CEB Distribuição S/A & CEB & $26 / 08 / 08$ \\
\hline Força e Luz Coronel Vivida Ltda & FORCEL & $26 / 08 / 08$ \\
\hline Companhia Hidroelétrica São Patrício & CHESP & $12 / 09 / 08$ \\
\hline Companhia Estadual de Distribuição de Energia Elétrica & CEEE-D & $25 / 10 / 08$ \\
\hline Light Serviços de Eletricidade S/A & LIGHT & $07 / 11 / 08$ \\
\hline Companhia Sul Sergipana de Eletricidade & SULGIPE & $14 / 12 / 08$ \\
\hline
\end{tabular}


Tabela 24 - Calendário de Revisão Tarifária - 2009. Fonte: ANEEL.

\begin{tabular}{lcc}
\hline \multicolumn{1}{c}{ Distribuidora } & Sigla & $\begin{array}{c}\text { Data da } \\
\text { Revisão }\end{array}$ \\
\hline Energisa Borborema - Distribuidora de Energia S.A. & EBO & $04 / 02 / 09$ \\
Ampla Energia e Serviços S/A & AMPLA & $15 / 03 / 09$ \\
Companhia Energética de Pernambuco & CELPE & $29 / 04 / 09$ \\
Muxfeldt Marin \& Cia Ltda & MUX-ENERGIA & $29 / 06 / 09$ \\
Hidroelétrica Panambi S/A & HIDROPAN & $29 / 06 / 09$ \\
Centrais Elétricas do Carazinho S/A & ELETROCAR & $29 / 06 / 09$ \\
Cooperativa Aliança & COOPERALIANÇA & $14 / 08 / 09$ \\
Companhia Energética de Alagoas & CEAL & $28 / 08 / 09$ \\
Energisa Paraíba & EPB & $28 / 08 / 09$ \\
Companhia Energética do Piauí & CEPISA & $28 / 08 / 09$ \\
Companhia Energética do Maranhão & CEMAR & $28 / 08 / 09$ \\
Boa Vista Energia S/A & BOA VISTA & $01 / 11 / 09$ \\
Manaus Energia S/A & MANAUS & $01 / 11 / 09$ \\
\hline
\end{tabular}

\section{Modelo para todo o Brasil}

Primeiramente, simulou-se um modelo econométrico de longo prazo a partir de dados de todas as 56 distribuidoras consideradas. Os valores de custos totais foram corrigidos pelo IGP-M da Fundação Getúlio Vargas, e estão em valores de outubro de 2009.

O gráfico da Figura 79 ilustra a regressão linear para o modelo econométrico de longo prazo, com função custo estimado $\widehat{C T_{l}}\left(q_{i}\right)=\hat{k}+\hat{\alpha} \cdot q_{i}+\varepsilon_{i}$, sendo $\hat{k}$ o estimador da constante, e $\hat{\alpha}$ o estimador de $B+\beta$. No modelo econômico apresentado no item 6.1 , a constante $k$ é supostamente nula. 


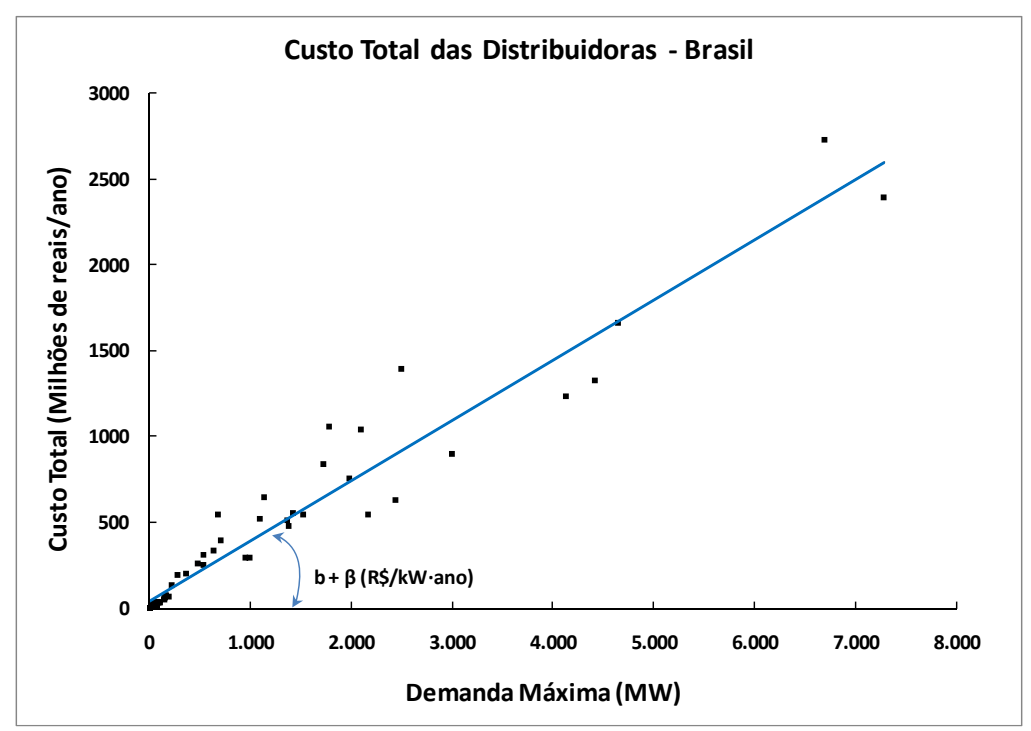

Figura 79 - Custo Total de Longo Prazo.

Os resultados das estimativas $\hat{k}$ e $\hat{\alpha}$ são apresentados na Tabela 25. Como é possível observar, o coeficiente de correlação ajustado foi significativamente alto, e as estatísticas de teste de hipótese nula dos estimadores corroboram com a expectativa de aderência ao modelo econômico proposto no item 6.1, ou seja, estatisticamente, $k=0$.

Tabela 25 - Dados da função de custos de longo prazo - Total.

\begin{tabular}{lcc}
\hline & Valor & t-statistic \\
\hline Coeficiente Angular (R\$/kW.ano) $(\widehat{\alpha})$ & 350,24 & 28,69468 \\
Coeficiente Linear (R\$/ano) $(\widehat{k})$ & 43.576 .816 & 1,837283 \\
& & \\
\hline
\end{tabular}

$r^{2}$ ajustado $=0,937314$

Contudo, deve-se considerar que, sendo o Brasil um país bastante diverso e heterogêneo, a análise de regressão considerando-se todas as empresas de distribuição em um mesmo grupo não é apropriada.

Optou-se por classificar as empresas em grupos através de um critério arbitrário de semelhança. Em uma análise preliminar e subjetiva, as empresas foram sub-divididas de acordo com a região geográfica a que pertencem. Assim, foram considerados os grupos: região Nordeste, região Norte/Centro Oeste, região Sul e 
região Sudeste. Posteriormente, como será observado, as empresas serão classificadas de acordo com um método de estatístico de classificação, reduzindo-se a subjetividade.

\section{Custos regionais - Nordeste}

Neste item será analisado um modelo com base nos custos das 11 distribuidoras de energia elétrica que operam na Região Nordeste do país. A Tabela 26 apresenta os valores dos custos de O\&M, capital e total publicados pela ANEEL durante o $2^{\circ}$ ciclo de revisões tarifárias, com os respectivos valores de demanda máxima agregada.

Tabela 26 - Dados das Distribuidoras - Nordeste. Dados a preços constantes de out/2009 - IGP-M. Fonte: ANEEL.

\begin{tabular}{lccccr}
\multicolumn{1}{c}{ Empresa } & UF & $\begin{array}{c}\text { Custo de O\&M } \\
\text { (R\$/ano) }\end{array}$ & $\begin{array}{c}\text { Custo de Capital } \\
\text { (R\$/ano) }\end{array}$ & $\begin{array}{c}\text { Custo de O\&M + } \\
\text { Capital (R\$/ano) }\end{array}$ & $\begin{array}{c}\text { Demanda } \\
\text { máxima } \\
\text { (kW/ano) }\end{array}$ \\
COELBA & BA & $155.587 .937,83$ & $94.549 .007,00$ & $250.136 .944,84$ & 2.499 .800 \\
CEPISA & PI & $709.882 .876,04$ & $686.457 .881,35$ & $1.396 .340 .757,40$ & 484.800 \\
CEAL & AL & $398.780 .512,95$ & $361.280 .673,86$ & $760.061 .186,81$ & 540.035 \\
COELCE & CE & $279.667 .555,04$ & $266.659 .828,99$ & $546.327 .384,03$ & 1.980 .880 \\
EBO & PB & $28.024 .190,02$ & $9.973 .490,76$ & $37.997 .680,78$ & 77.100 \\
EPB & PB & $201.637 .776,11$ & $113.761 .976,67$ & $315.399 .752,78$ & 538.300 \\
CEMAR & MA & $440.781 .325,98$ & $403.300 .942,04$ & $844.082 .268,02$ & 677.325 \\
ESE & SE & $184.877 .318,48$ & $79.896 .965,02$ & $264.774 .283,50$ & 371.201 \\
SULGIPE & SE & $189.434 .026,67$ & $149.301 .352,86$ & $338.735 .379,53$ & 50.060 \\
CELPE & PE & $118.402 .671,27$ & $81.538 .737,04$ & $199.941 .408,30$ & 1.717 .900 \\
COSERN & RN & $22.154 .057,13$ & $7.251 .382,01$ & $29.405 .439,13$ & 629.790
\end{tabular}

O gráfico da Figura 80 ilustra a regressão linear para o modelo econométrico de longo prazo, $\widehat{C T}_{l}\left(q_{i}\right)=\hat{k}+\hat{\alpha} \cdot q_{i}+\varepsilon_{i}$. Na Tabela 27 são apresentados os valores dos estimadores obtidos para o modelo de longo prazo. Nota-se que o teste de hipótese nula para o estimador da constante é bastante pequeno, corroborando assim com o modelo apresentado no item 6.1 . 


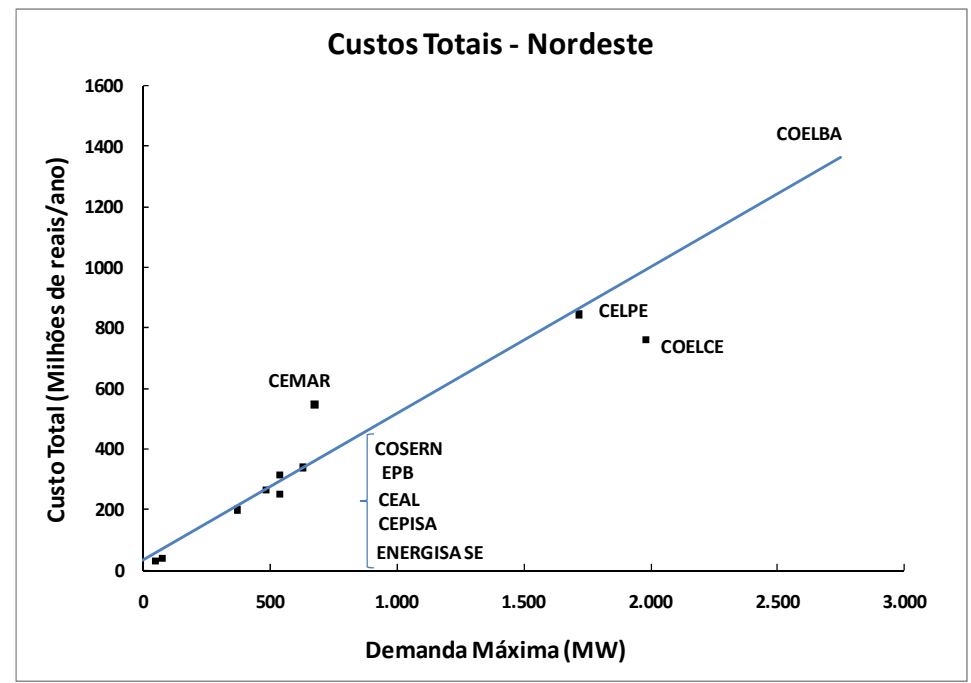

Figura 80 - Custo de Total de Longo Prazo.

Tabela 27 - Dados da função de custos de longo prazo - Total.

\begin{tabular}{lcc}
\hline & Valor & t-statistic \\
\hline Coeficiente Angular (R\$/kW.ano) $(\widehat{\alpha})$ & 484,41 & 10,95737 \\
Coeficiente Linear (R\$/ano) $(\widehat{k})$ & 31.708 .971 & 0,615416 \\
\hline $\mathbf{r}^{2}$ ajustado $=0,922519$ & \\
\hline
\end{tabular}

Na Tabela 28, é possível observar que o coeficiente de variação do custo médio, definido pela razão dos desvios padrão pelos valores médios de cada variável, é relativamente pequeno, o que torna o agrupamento proposto bastante aderente.

Tabela 28: Custos médios - Nordeste. Fonte: ANEEL.

$\begin{array}{lc}\text { Empresa } & \begin{array}{c}\text { Custo Médio } \\ (\boldsymbol{R} \$ \mathbf{k W} \boldsymbol{W} \cdot \mathbf{a n o})\end{array} \\ \text { CEAL } & 463,19 \\ \text { COELBA } & 558,58 \\ \text { COELCE } & 383,70 \\ \text { CEMAR } & 806,60 \\ \text { EBO } & 492,84 \\ \text { EPB } & 585,92\end{array}$




\begin{tabular}{lc} 
CELPE & 491,35 \\
CEPISA & 546,15 \\
COSERN & 537,85 \\
ESE & 538,63 \\
SULGIPE & 587,40 \\
\hline Média (R\$/kW·ano) & 544,75 \\
\hline Desvio Padrão (R\$/kW·ano) & 100,22 \\
Coeficiente de Variação (\%) & $18,40 \%$ \\
\hline
\end{tabular}

\section{Custos regionais - Norte / Centro-Oeste}

Neste item, foram agrupadas as distribuidoras de energia elétrica das regiões Norte e Centro-Oeste, pois em sua maioria, essas empresas possuem características semelhantes de operação e estrutura organizacional, como imensas áreas de concessão pouco povoadas, cargas fortemente concentradas em centros urbanos e maiores custos relativos à expansão de seus sistemas de distribuição. A Tabela 29 apresenta os dados referentes a 8 das 11 concessionárias que atendem essas duas regiões.

Tabela 29 - Dados das Distribuidoras - Nortel Centro-Oeste. Fonte: ANEEL.

\begin{tabular}{llrrrr}
\multicolumn{1}{c}{ Empresa } & UF & $\begin{array}{c}\text { Custo de O\&M } \\
\text { (R\$/ano) }\end{array}$ & $\begin{array}{c}\text { Custo de Capital } \\
\text { (R\$/ano) }\end{array}$ & $\begin{array}{c}\text { Custo de O\&M + } \\
\text { Capital (R\$/ano) }\end{array}$ & $\begin{array}{c}\text { Demanda } \\
\text { máxima } \\
\text { (kW/ano) }\end{array}$ \\
MANAUS & AM & $187.218 .960,24$ & $107.442 .317,14$ & $294.661 .277,38$ & 992.200 \\
CEB & DF & $170.267 .944,38$ & $123.180 .144,85$ & $293.448 .089,22$ & 950.425 \\
CHESP & GO & $8.562 .392,02$ & $4.507 .288,76$ & $13.069 .680,80$ & 19.100 \\
ENERSUL & MS & $197.514 .109,05$ & $194.806 .576,94$ & $392.320 .685,99$ & 710.380 \\
CEMAT & MT & $285.322 .727,09$ & $240.751 .601,28$ & $526.074 .328,37$ & 1.100 .489 \\
CELPA & PA & $427.555 .177,48$ & $222.601 .248,37$ & $650.156 .425,85$ & 1.143 .810 \\
BOA VISTA & RR & $19.338 .205,75$ & $19.615 .082,51$ & $38.953 .288,26$ & 84.374 \\
CELTINS & TO & $133.992 .120,81$ & $64.347 .764,36$ & $198.339 .885,18$ & 274.321
\end{tabular}


A Figura 81 e a Tabela 30 mostram os resultados da estimação do modelo de longo prazo para estas duas regiões.

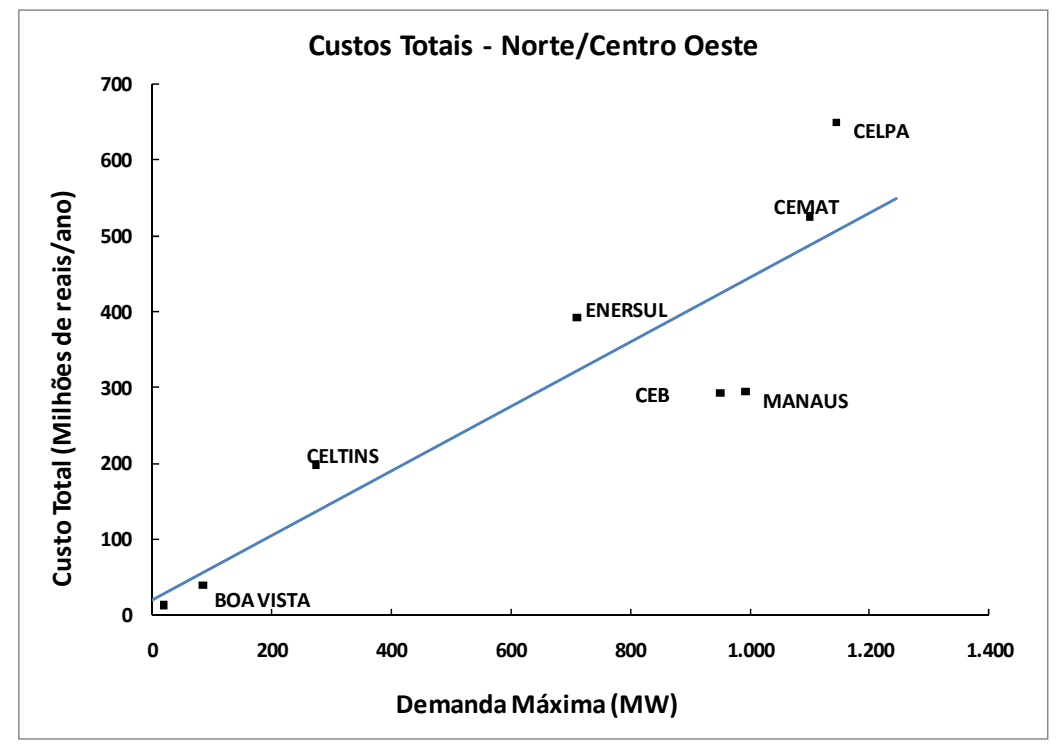

Figura 81 - Custo Total de Longo Prazo.

Tabela 30 - Dados da função de custos de longo prazo - Total.

\begin{tabular}{lcc}
\hline & Valor & t-statistic \\
\hline Coeficiente Angular $(\mathbf{R} \$ \mathbf{k W})(\hat{\boldsymbol{\alpha}})$ & 424,31 & 4,832337 \\
Coeficiente Linear $(\mathbf{R} \$ / \mathbf{a n o})(\widehat{\boldsymbol{k}})$ & 21.091 .142 & 0,303997 \\
\hline $\mathbf{r}^{2}$ ajustado $=0,761511$ & \\
\hline
\end{tabular}

Na Tabela 31, nota-se, para este agrupamento, que o coeficiente de variação é mais elevado, o que indicaria uma dispersão elevada, e uma equivalente ineficiência do agrupamento realizado.

Tabela 31: Custos médios - Norte/Centro-Oeste. Fonte: ANEEL.

$\begin{array}{lr}\text { Empresa } & \begin{array}{c}\text { Custo Médio } \\ (\boldsymbol{R} \$ \mathbf{k W} \cdot \mathbf{a n o})\end{array} \\ \text { MANAUS } & 296,98 \\ \text { CEB } & 308,75 \\ \text { CHESP } & 684,28\end{array}$




\begin{tabular}{lc} 
ENERSUL & 552,27 \\
CEMAT & 478,04 \\
CELPA & 568,41 \\
BOA VISTA & 461,67 \\
CELTINS & 723,02 \\
\hline Média (R\$/kW·ano) & 509,18 \\
\hline Desvio Padrão (R\$/kW·ano) & 145,85 \\
Coeficiente de Variação (\%) & $28,64 \%$ \\
\hline
\end{tabular}

\section{Custos regionais - Sul}

A região Sul do Brasil é atendida por 17 distribuidoras de energia, das quais 15 são objeto do presente estudo. Seus dados relativos aos custos e demandas encontram-se detalhados na Tabela 32.

Tabela 32 - Dados das Distribuidoras - Sul. Fonte: ANEEL.

\begin{tabular}{llrrrr}
\multicolumn{1}{c}{ Empresa } & UF & $\begin{array}{c}\text { Custo de O\&M } \\
\text { (R\$/ano) }\end{array}$ & $\begin{array}{c}\text { Custo de Capital } \\
\text { (R\$/ano) }\end{array}$ & $\begin{array}{c}\text { Custo de O\&M + } \\
\text { Capital (R\$ano) }\end{array}$ & $\begin{array}{c}\text { Demanda } \\
\text { máxima } \\
\text { (kW/ano) }\end{array}$ \\
COCEL & PR & $11.076 .835,15$ & $5.012 .278,79$ & $16.089 .113,93$ & 4.416 .100 \\
COPEL-D & PR & $729.120 .907,14$ & $597.418 .702,95$ & $1.326 .539 .610,08$ & 40.591 \\
CFLO & PR & $12.940 .789,73$ & $4.087 .951,71$ & $17.028 .741,44$ & 3.600 \\
FORCEL & PR & $2.954 .194,00$ & $952.017,45$ & $3.906 .211,45$ & 1.519 .000 \\
CEEE-D & RS & $257.747 .199,86$ & $288.280 .895,65$ & $546.028 .095,51$ & 1.374 .800 \\
AES SUL & RS & $251.919 .443,59$ & $229.630 .483,89$ & $481.549 .927,48$ & 1.416 .700 \\
RGE & RS & $268.642 .340,71$ & $290.286 .248,18$ & $558.928 .588,89$ & 8.862 \\
MUX-ENERGIA & RS & $2.469 .128,26$ & $1.213 .197,81$ & $3.682 .326,06$ & 16.618 \\
HIDROPAN & RS & $4.706 .557,75$ & $2.139 .793,33$ & $6.846 .351,08$ & 33.500 \\
ELETROCAR & RS & $11.399 .073,80$ & $2.633 .863,40$ & $14.032 .937,20$ & 28.558 \\
CELESC & SC & $477.315 .447,67$ & $422.601 .048,87$ & $899.916 .496,53$ & 3.001 .300
\end{tabular}




$\begin{array}{lrrrrr}\text { IENERGIA } & \text { SC } & 12.798 .520,25 & 2.767 .845,96 & 15.566 .366,21 & 52.300 \\ \text { EFLUL } & \text { SC } & 3.403 .408,80 & 954.493,32 & 4.357 .902,13 & 18.951 \\ \text { COOPERALIANÇA } & \text { SC } & 7.523 .145,08 & 2.781 .088,82 & 10.304 .233,90 & 9.800 \\ \text { EFLJC } & \text { SC } & 1.076 .891,93 & 183.280,72 & 1.260 .172,66 & 2.200\end{array}$

A Figura 82 e a Tabela 33 ilustram os resultados da estimação do modelo de longo prazo para a região Sul. Ressalta-se que a região Sul apresenta um significativo número de pequenas distribuidoras de energia, das quais muitas operam em caráter de cooperativas.

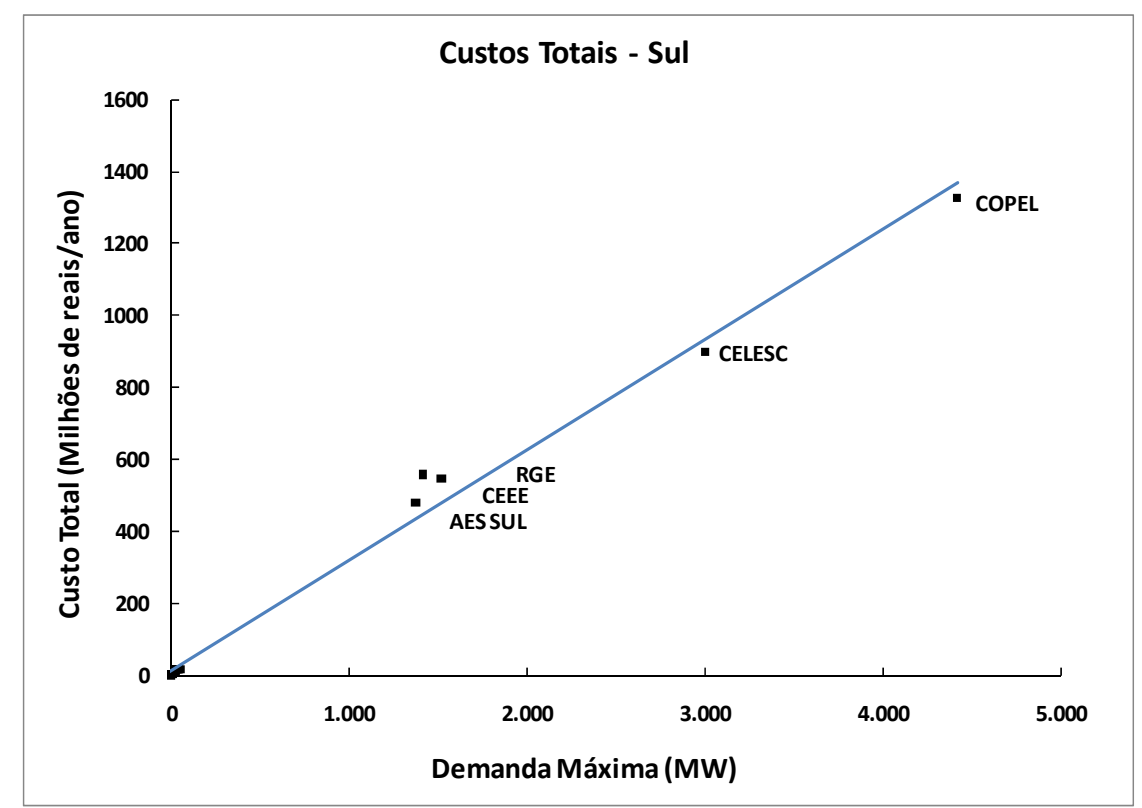

Figura 82 - Custo Total de Longo Prazo.

Tabela 33 - Dados da função de custos de longo prazo - Total.

\begin{tabular}{lcc}
\hline & Valor & t-statistic \\
\hline Coeficiente Angular $(\mathbf{R} \$ \mathbf{k W} \cdot \mathbf{a n o})(\hat{\boldsymbol{\alpha}})$ & 306,80 & 36,72856 \\
Coeficiente Linear $(\mathbf{R} \$ / \mathbf{a n o})(\widehat{\boldsymbol{k}})$ & 16.130 .117 & 1,269206 \\
\hline \multicolumn{2}{c}{$\mathbf{r}^{2}$ ajustado $=0,989721$} & \\
\hline
\end{tabular}


$\mathrm{Na}$ Tabela 34, nota-se que, para este agrupamento, o coeficiente de variação é bastante elevado, indicando também uma dispersão elevada e uma equivalente ineficiência do agrupamento realizado.

\begin{tabular}{lc} 
Tabela 34 - Custos médios $-\begin{array}{c}\text { Sul. Fonte: ANEEL } \\
\text { Empresa }\end{array}$ & $\begin{array}{c}\text { Custo Médio } \\
\text { (R\$/kW/ano) }\end{array}$ \\
COCEL & 480,27 \\
COPEL-D & 300,39 \\
CFLO & 419,52 \\
FORCEL & $1.085,06$ \\
CEEE-D & 359,47 \\
AES SUL & 350,27 \\
RGE & 394,53 \\
MUX-ENERGIA & 415,52 \\
HIDROPAN & 411,98 \\
ELETROCAR & 491,38 \\
CELESC & 299,84 \\
IENERGIA & 297,64 \\
EFLUL & 444,68 \\
COOPERALIANÇA & 543,73 \\
EFLJC & 572,81 \\
\hline Média (R\$/kW·ano) & 457,81 \\
Desvio Padrão (R\$/kW·ano) & 186,52 \\
Coeficiente de Variação (\%) & $40,74 \%$ \\
\hline
\end{tabular}

\section{Custos Regionais - Sudeste}

Este item envolve a região de maior consumo energético do Brasil, onde se concentram as principais econômicas do país e o maior número de habitantes. A Tabela 35 apresenta os valores de custos e de demandas apurados no ciclo de revisão tarifária 2007 - 2010 para as 22 distribuidoras analisadas. 
Tabela 35 - Dados das Distribuidoras - Sudeste. Fonte: ANEEL.

\begin{tabular}{|c|c|c|c|c|c|}
\hline Empresa & UF & $\begin{array}{l}\text { Custo de O\&M } \\
\text { (R\$/ano) }\end{array}$ & $\begin{array}{l}\text { Custo de Capital } \\
\text { (R\$/ano) }\end{array}$ & $\begin{array}{l}\text { Custo de O\&M + } \\
\text { Capital (R\$/ano) }\end{array}$ & $\begin{array}{c}\text { Demanda } \\
\text { máxima } \\
\text { (kW/ano) }\end{array}$ \\
\hline ESCELSA & ES & $260.841 .858,08$ & $251.743 .193,23$ & $512.585 .051,31$ & 1.366 .200 \\
\hline ELFSM & ES & $21.629 .284,83$ & $17.610 .956,69$ & $39.240 .241,51$ & 89.065 \\
\hline CEMIG-D & MG & $1.402 .570 .232,15$ & $1.326 .434 .818,15$ & $2.729 .005 .050,30$ & 6.687 .200 \\
\hline DMEPC & MG & $19.286 .592,32$ & $19.664 .065,98$ & $38.950 .658,28$ & 63.773 \\
\hline EMG & MG & $89.753 .520,84$ & $44.708 .548,42$ & $134.462 .069,26$ & 224.514 \\
\hline BANDEIRANTE & SP & $631.728 .364,61$ & $1.030 .041 .945,01$ & $1.661 .770 .309,63$ & 2.439 .300 \\
\hline CPFL PIRA & SP & $425.544 .073,79$ & $634.254 .796,89$ & $1.059 .798 .870,67$ & 2.167 .900 \\
\hline ELETROPAULO & SP & $22.971 .714,65$ & $16.746 .337,42$ & $39.718 .052,07$ & 7.283 .090 \\
\hline CPFL PAULISTA & SP & $305.163 .494,63$ & $323.332 .013,40$ & $628.495 .508,03$ & 4.134 .432 \\
\hline CJE & SP & $284.470 .412,20$ & $260.966 .337,54$ & $545.436 .749,74$ & 83.163 \\
\hline CPEE & SP & $1.032 .450 .978,39$ & $1.358 .829 .800,00$ & 2.391.280.778,39 & 82.300 \\
\hline CAIUÁ & SP & $604.968 .140,32$ & $632.702 .600,69$ & $1.237 .670 .741,01$ & 189.879 \\
\hline ELEKTRO & SP & $12.778 .546,16$ & $7.840 .701,50$ & $20.619 .247,64$ & 2.098 .200 \\
\hline EEB & SP & $17.834 .570,17$ & $17.036 .265,97$ & $34.870 .836,14$ & 147.950 \\
\hline CSPE & SP & $44.775 .709,02$ & $21.570 .747,59$ & $66.346 .456,61$ & 77.365 \\
\hline CLFSC & SP & $544.163 .413,17$ & $496.321 .236,31$ & $1.040 .484 .649,47$ & 161.000 \\
\hline EDEVP & SP & $35.237 .139,46$ & $19.894 .800,37$ & $55.131 .939,83$ & 148.233 \\
\hline CNEE & SP & $21.088 .331,44$ & $12.736 .058,81$ & $33.824 .390,26$ & 104.110 \\
\hline CLFM & SP & $46.817 .898,73$ & $27.108 .291,86$ & $73.926 .190,59$ & 40.900 \\
\hline LIGHT & RJ & $42.219 .744,70$ & $16.903 .923,16$ & $59.123 .667,88$ & 4.650 .261 \\
\hline AMPLA & RJ & $29.859 .010,55$ & $9.455 .315,43$ & $39.314 .325,99$ & 1.787 .959 \\
\hline ENF & RJ & $14.407 .716,66$ & $5.822 .859,00$ & $20.230 .575,66$ & 55.960 \\
\hline
\end{tabular}

A Figura 83 e a Tabela 36 ilustram os resultados da estimação do modelo de longo prazo para a região Sudeste. 


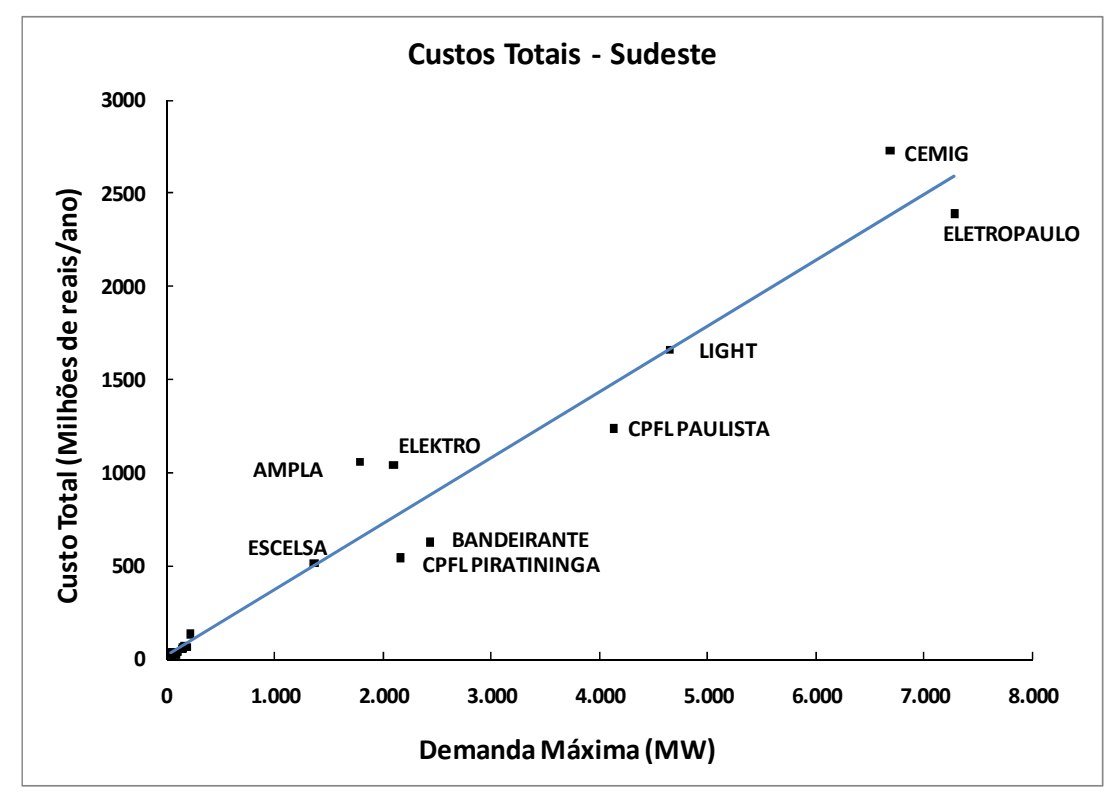

Figura 83 - Custo Total de Longo Prazo.

Tabela 36 - Dados da função de custos de longo prazo - Total.

\begin{tabular}{lcc}
\hline & Valor & t-statistic \\
\hline Coeficiente Angular (R\$/kW·ano) $(\widehat{\alpha})$ & 353,75 & 20,99671 \\
Coeficiente Linear (R\$/ano) $(\widehat{k})$ & 18.437 .001 & 0,409909 \\
\hline \multicolumn{2}{c}{$\mathbf{r}^{2}$ ajustado $=0,954433$} & \\
\hline
\end{tabular}

$\mathrm{Na}$ Tabela 37, observam-se os custos médios das distribuidoras. Para o agrupamento da região Sudeste, o coeficiente de variação é menos elevado, indicando um melhor agrupamento.

Tabela 37 - Custos marginais de curto prazo e custos médios - Sudeste. Fonte: ANEEL.

$\begin{array}{lc}\text { Empresa } & \begin{array}{c}\text { Custo Médio } \\ (\boldsymbol{R} \$ \mathbf{k W} \mathbf{k} \mathbf{a n o})\end{array} \\ \text { ESCELSA } & 375,19 \\ \text { ELFSM } & 440,58 \\ \text { CEMIG-D } & 408,09 \\ \text { DMEPC } & 610,77 \\ \text { EMG } & 598,90 \\ \text { LIGHT } & 357,35\end{array}$




\begin{tabular}{lc} 
AMPLA & 592,74 \\
ENF & 709,76 \\
BANDEIRANTE & 257,65 \\
CPFL PIRA & 251,60 \\
ELETROPAULO & 328,33 \\
CPFL PAULISTA & 299,36 \\
CJE & 247,94 \\
CPEE & 423,70 \\
CAIUÁ & 349,41 \\
ELEKTRO & 495,89 \\
EEB & 372,64 \\
CSPE & 437,21 \\
CLFSC & 459,17 \\
EDEVP & 398,86 \\
CNEE & 377,62 \\
CLFM & 494,64 \\
\hline Média (R\$/kW·ano) & $28,50 \%$ \\
Desvio Padrão (R\$/kW·ano) & \\
\hline Coeficiente de Variação (\%) & \\
\hline & \\
\hline
\end{tabular}

\section{Agrupamento por k-médias}

Neste item, será proposta uma classificação alternativa das 56 empresas distribuidoras através de um método estatístico bastante conhecido, denominado kmédias (MACQUEEN, 1967). Este método procura agrupar elementos por proximidade de suas variáveis descritoras.

É importante salientar que é demasiado complexa a definição de um processo classificatório para todo o universo das 61 distribuidoras brasileiras, o que poderia envolver a consideração de um modelo em painel com diversas variáveis descritoras. Como já descrito, propõe-se aqui um modelo bastante simplificado de causalidade entre custos e demandas. 
Embora existam certamente outras variáveis significativas para a modelagem da curva de custos, sua inclusão não aumentaria significativamente o poder explicativo dos modelos, haja vista os resultados obtidos, com elevados coeficientes de correlação.

A partir do modelo econômico proposto no item 6.1, considerando-se que os modelos de regressão se baseiam em dados organizados em seção cruzada (cross section), onde cada ponto representa uma empresa, o que se pretende é construir um modelo econométrico para o qual o coeficiente de correlação seja o maior possível.

Sendo assim, descreve-se uma empresa, para os propósitos pretendidos na classificação em grupos, através de duas variáveis, quais sejam, o seu custo marginal de operação no longo prazo, $B$, e o seu custo médio, Cme, segundo o modelo econômico proposto no item 6.1 , igual ao custo marginal de longo prazo, $B+\beta$. Neste processo de classificação, a medida de distância entre duas empresas será a distância euclidiana.

A Figura 84 ilustra o resultado do processo de classificação empregado. Nesta simulação, foram escolhidos, a priori, um total de seis grupos. Nota-se que a dispersão é bastante pequena nos grupos 1, 2, 3, 4 e 5, e relativamente maior no grupo 6 . Isso se deveu à existência de um ponto absolutamente "outlier", referente à empresa FORCEL, do Paraná.

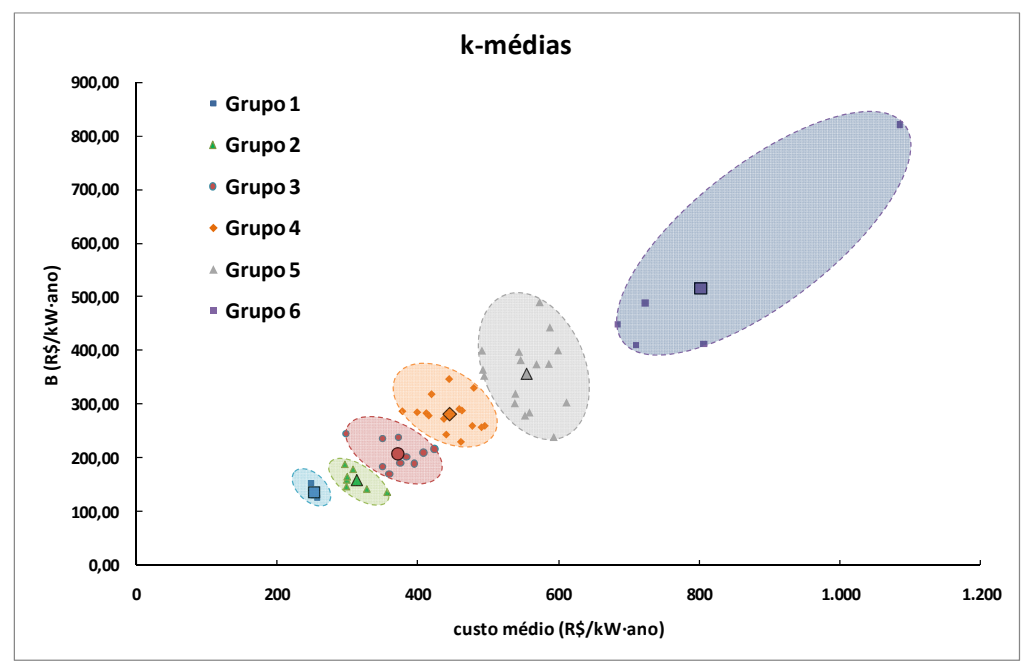

Figura 84: Agrupamentos resultantes - Método k-médias. 
Os gráficos e tabelas a seguir ilustram os resultados da regressão linear para os grupos 1 a 6 . Como será possível observar, o menor coeficiente de correção calculado foi de aproximadamente $98 \%$, o que mostra a relevância do adequado critério de classificação.

Este processo de classificação é resultado direto do que se espera obter para os modelos econômicos propostos neste trabalho. Não foi objeto de estudo a avaliação crítica dos grupamentos.

\section{- Grupo 1}

Tabela 38 - Custos marginais de operação e custos médios - Grupo 1.

\begin{tabular}{|c|c|c|}
\hline \multirow[b]{2}{*}{ Empresa } & \multirow[b]{2}{*}{$B(R \$ / k W \cdot a n o)$} & \multirow[b]{2}{*}{$\begin{array}{l}\text { Custo Médio } \\
\text { (R\$/kW-ano) }\end{array}$} \\
\hline & & \\
\hline BANDEIRANTE & 125,10 & 257,65 \\
\hline CPFL PIRA & 131,22 & 251,60 \\
\hline CJE & 153,66 & 247,94 \\
\hline Média (R\$/kW·ano) & 136,66 & 252,40 \\
\hline Desvio Padrão (R\$/kW·ano) & 12,28 & 4,01 \\
\hline Coeficiente de Variação (\%) & $8,98 \%$ & $1,59 \%$ \\
\hline
\end{tabular}

Tabela 39 - Dados da função de custos de longo prazo - Grupo 1.

\begin{tabular}{lcc}
\hline & Valor & t-statistic \\
\hline Coeficiente Angular $(\mathbf{R} \$ \mathbf{k W})(\hat{\boldsymbol{\alpha}})$ & 255,63 & 23,79254 \\
Coeficiente Linear $(\mathbf{R} \$ / \mathbf{a n o})(\widehat{\boldsymbol{k}})$ & -1.475 .523 & 0,308946 \\
\hline & $\mathbf{r}^{2}$ ajustado $=0,999129$ & \\
\hline
\end{tabular}




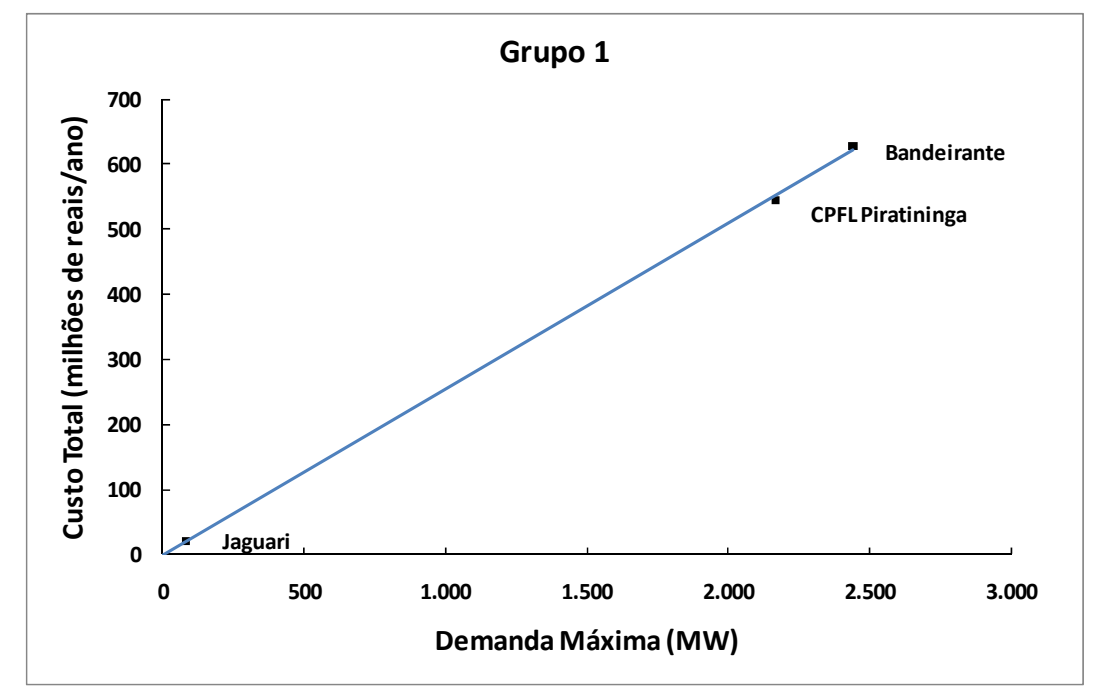

Figura 85: Gráfico de Custos Totais - Grupo 1.

\section{- Grupo 2}

Tabela 40 - Custos marginais de operação e custos médios - Grupo 2.

Empresa

LIGHT

ELETROPAULO

CPFL PAULISTA

CELESC

COPEL-D

CEB

MANAUS

Média (R\$/kW·ano)

Desvio Padrão (R\$/kW·ano)

Coeficiente de Variação (\%)
$B(R \$ / k W \cdot a n o)$

135,85

141,76

146,32

159,04

165,11

179,15

188,69

159,42

18,20

$11,41 \%$
Custo Médio

(R\$/kW·ano)

357,35

328,33

299,36

299,84

300,39

308,75

296,98

313,00

20,69

$6,61 \%$ 
Tabela 41: Dados da função de custos de longo prazo - Grupo 2.

\begin{tabular}{crc}
\hline & \multicolumn{1}{c}{ Valor } & t-statistic \\
\hline Coeficiente Angular (R\$/kW) & 333,92 & 18,79584 \\
Coeficiente Linear (R\$/ano) & -55.091 .908 & $-0,742316$ \\
\hline $\mathbf{r}^{2}$ ajustado $=0,983253$ & \\
\hline
\end{tabular}

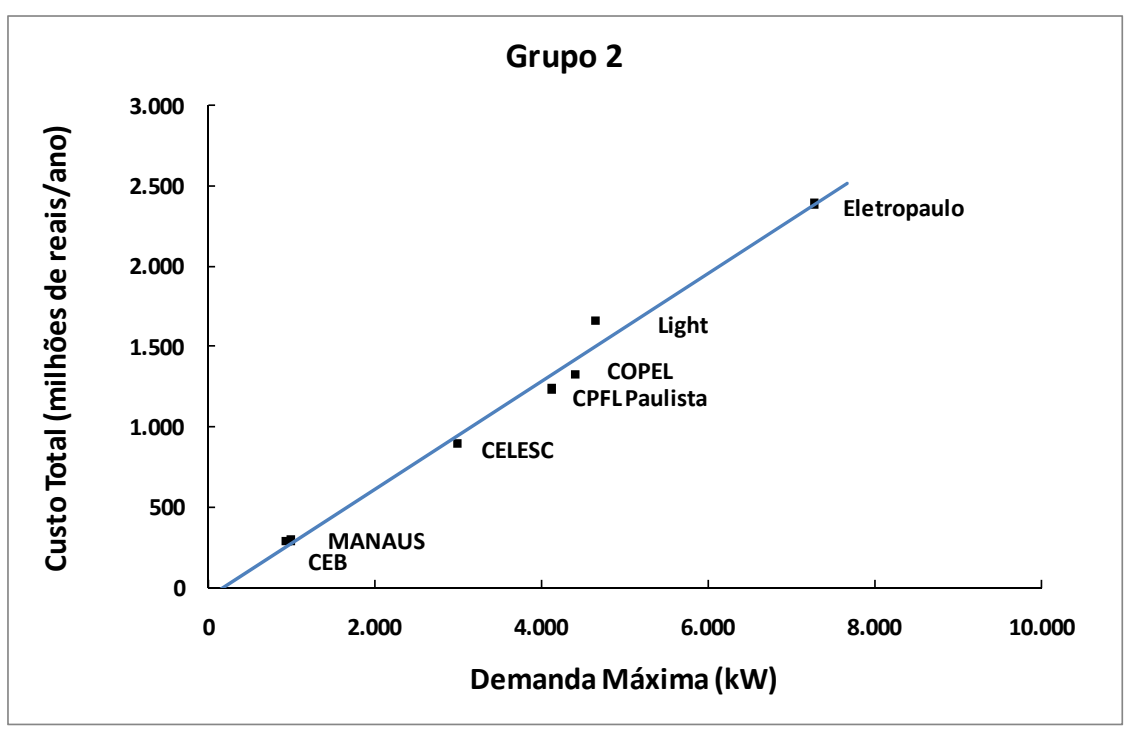

Figura 86: Gráfico de Custos Totais - Grupo 2.

\section{- Grupo 3}

Tabela 42 - Custos marginais de operação e custos médios - Grupo 3.

Empresa

CEEE-D

AES SUL

RGE

ESCELSA

COELCE

CEMIG-D

CPEE

CAIUÁ
$B(R \$ / k W \cdot a n o)$

169,68

183,24

189,63

190,93

201,31

209,74

216,70

235,81
Custo Médio

(R\$/kW-ano)

359,47

350,27

394,53

375,19

383,70

408,09

423,70

349,41 


\begin{tabular}{lcc} 
EEB & 238,17 & 372,64 \\
IENERGIA & 244,71 & 297,64 \\
\hline Média (R\$/kW·ano) & 207,99 & 371,46 \\
Desvio Padrão (R\$/kW·ano) & 24,22 & 33,61 \\
Coeficiente de Variação (\%) & $11,64 \%$ & $9,05 \%$ \\
\hline
\end{tabular}

Tabela 43 - Dados da função de custos de longo prazo - Grupo 3.

\begin{tabular}{lrr}
\hline & \multicolumn{1}{l}{ Valor } & t-statistic \\
\hline Coeficiente Angular $(\mathbf{R} \$ \mathbf{k W})(\hat{\boldsymbol{\alpha}})$ & 408,55 & 74,14572 \\
Coeficiente Linear $(\mathbf{R} \$ \mathbf{a n o})(\widehat{k})$ & -29.351 .036 & $-2,235435$
\end{tabular}

$r^{2}$ ajustado $=0,998365$

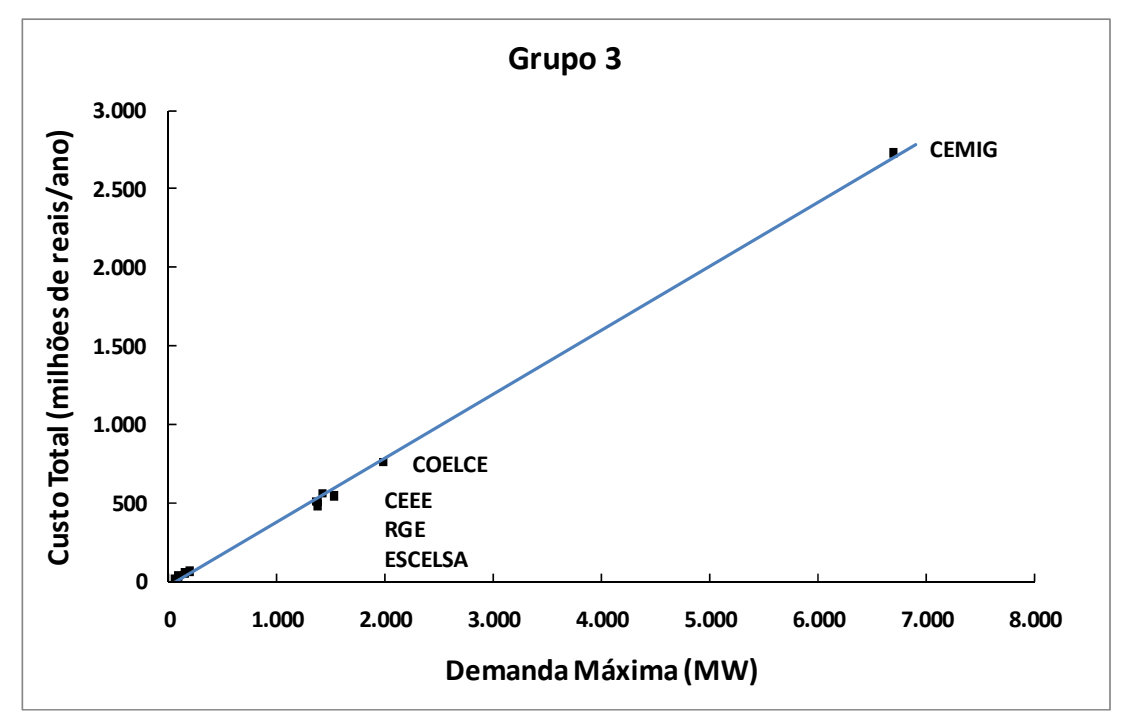

Figura 87: Gráfico de Custos Totais - Grupo 3.

\section{- Grupo 4}

Tabela 44 - Custos marginais de operação e custos médio - Grupo 4.

$$
\begin{array}{lll}
\text { Empresa } & B(R \$ / \mathrm{kW} \cdot \mathrm{ano}) & \begin{array}{l}
\text { Custo Médio } \\
(R \$ / \mathrm{kW} \cdot \mathrm{ano})
\end{array}
\end{array}
$$

BOA VISTA

ELFSM
229,20

242,85 


\begin{tabular}{lcc} 
CELPE & 256,58 & 491,35 \\
CEMAT & 259,27 & 478,04 \\
ELEKTRO & 259,35 & 495,89 \\
CSPE & 272,58 & 437,21 \\
MUX-ENERGIA & 278,62 & 415,52 \\
HIDROPAN & 283,22 & 411,98 \\
EDEVP & 284,82 & 398,86 \\
CNEE & 286,80 & 377,62 \\
CEAL & 288,11 & 463,19 \\
CLFSC & 290,79 & 459,17 \\
CFLO & 318,81 & 419,52 \\
COCEL & 330,65 & 480,27 \\
EFLUL & 347,29 & 444,68 \\
\hline Média (R\$/kW·ano) & 281,93 & $43,62 \%$ \\
Desvio Padrão (R\$/kW·ano) & 30,80 & \\
Coeficiente de Variação (\%) & $10,92 \%$ & \\
\hline & & 34,04 \\
\hline
\end{tabular}

Tabela 45 - Dados da função de custos de longo prazo - Grupo 4.

$\frac{\text { Tabela 45 - Dados da função de custos de longo prazo - Grupo }}{\text { t-statistic }}$

\begin{tabular}{lrr}
\hline Coeficiente Angular (R\$/kW) $(\widehat{\alpha})$ & 494,29 & 185,9113 \\
& & \\
Coeficiente Linear (R\$/ano) $(\widehat{k})$ & -5.757 .407 & $-2,805046$ \\
\hline
\end{tabular}

$r^{2}$ ajustado $=0,999595$ 


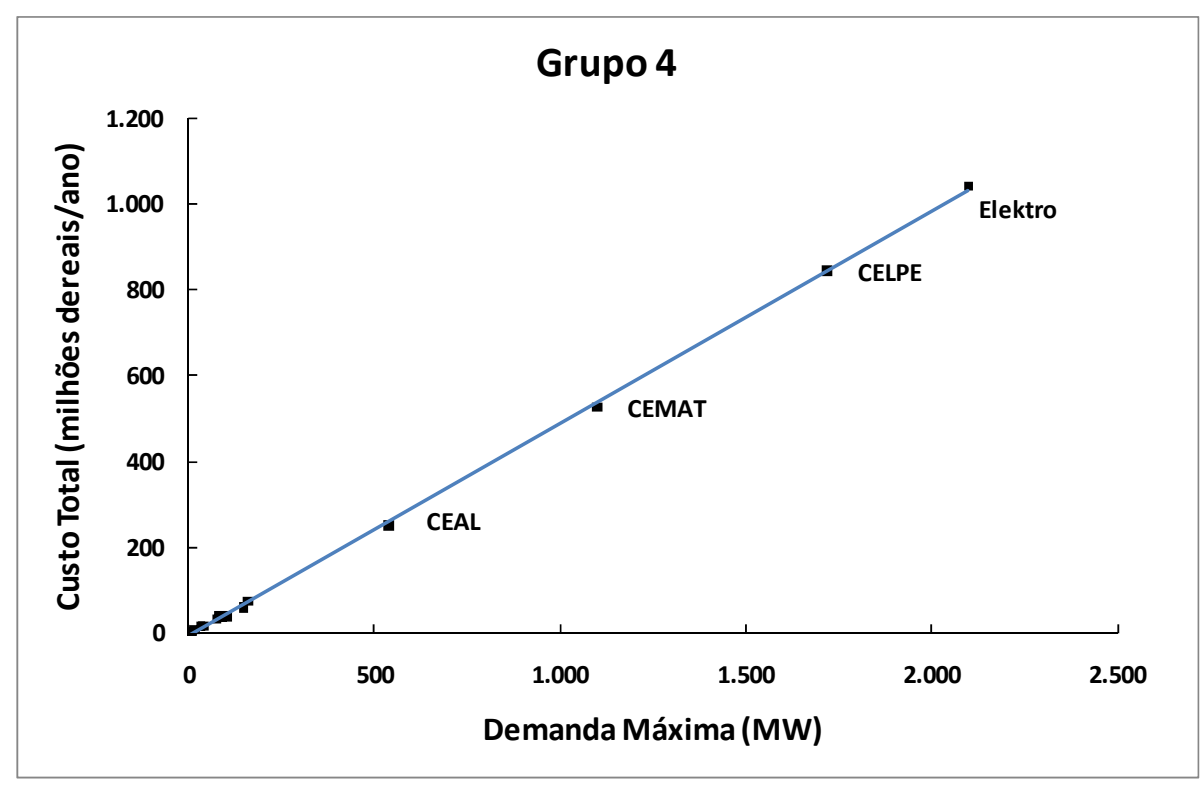

Figura 88: Gráfico de Custos Totais - Grupo 4.

- Grupo 5

Tabela 46 - Custos marginais de operação e custos médio - Grupo 5.

Empresa

AMPLA

ENERSUL

COELBA

COSERN

DMEPC

ESE

CLFM

EBO

CELPA

EPB

CEPISA

COOPERALIANÇA

ELETROCAR

EMG

SULGIPE
$B$ (R\$/kW.ano)

238,01

278,04

283,98

300,79

302,43

318,97

352,27

363,48

373,80

374,58

381,35

396,98

399,16

399,77

442,55
Custo Médio (R\$/kW·ano)

592,74

552,27

558,58

537,85

610,77

538,63

494,64

492,84

568,41

585,92

546,15

543,73

491,38

598,90

587,40 


\begin{tabular}{lcc} 
EFLJC & 489,50 & 572,81 \\
\hline Média (R\$/kW·ano) & 355,98 & 554,56 \\
Desvio Padrão (R\$/kW·ano) & 63,55 & 36,49 \\
Coeficiente de Variação (\%) & $17,85 \%$ & $6,58 \%$ \\
\hline
\end{tabular}

Tabela 47 - Dados da função de custos de longo prazo - Grupo 5.

\begin{tabular}{lrr}
\hline & \multicolumn{1}{c}{ Valor } & t-statistic \\
\hline Coeficiente Angular (R\$/kW) $(\hat{\boldsymbol{\alpha}})$ & 569,27 & 101,5031 \\
Coeficiente Linear (R\$/ano) $(\widehat{\boldsymbol{k}})$ & -2.040 .966 & $-0,413648$
\end{tabular}

$r^{2}$ ajustado $=0,998546$

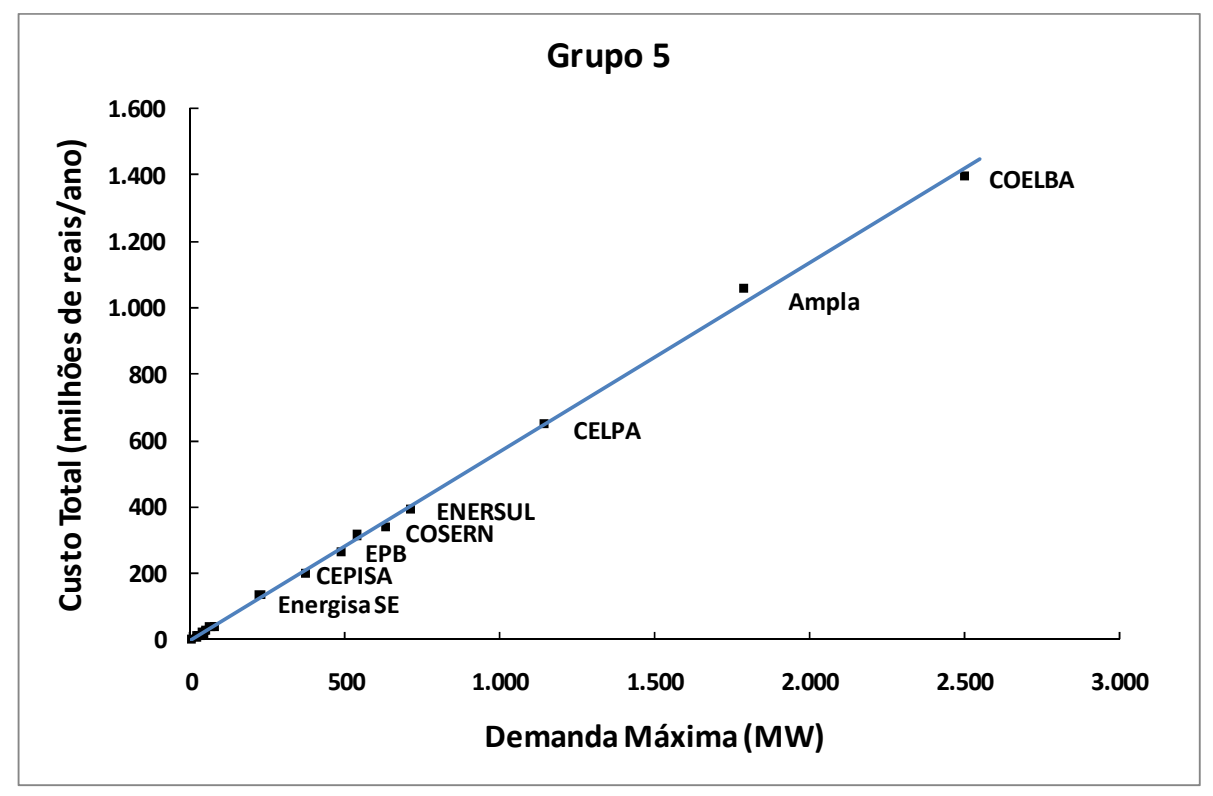

Figura 89: Gráfico de Custos Totais - Grupo 5.

- Grupo 6

Tabela 48 - Custos marginais de operação e custos médios - Grupo 6.

Empresa

ENF

CEMAR

CHESP
$B(R \$ / k W \cdot a n o)$

410,50

412,90

448,29
Custo Médio

(R\$/kW·ano)

709,76

806,60

684,28 


\begin{tabular}{lcc} 
CELTINS & 488,45 & 723,02 \\
FORCEL & 820,61 & $1.085,06$ \\
\hline Média (R\$/kW·ano) & 516,15 & 801,74 \\
Desvio Padrão (R\$/kW·ano) & 154,85 & 147,48 \\
Coeficiente de Variação (\%) & $30,00 \%$ & $18,39 \%$ \\
\hline
\end{tabular}

Tabela 49 - Dados da função de custos de longo prazo - Grupo 6.

\begin{tabular}{lcc}
\hline & \multicolumn{1}{c}{ Valor } & t-statistic \\
\hline Coeficiente Angular $(\mathbf{R} \$ \mathbf{k W})(\hat{\boldsymbol{\alpha}})$ & 805,00 & 40,55380 \\
Coeficiente Linear $(\mathbf{R} \$ / \mathbf{a n o})(\widehat{\boldsymbol{k}})$ & -5.607 .807 & $-0,861609$ \\
\hline \multicolumn{2}{c}{$\mathbf{r}^{2}$ ajustado $=0,997572$} & \\
\hline
\end{tabular}

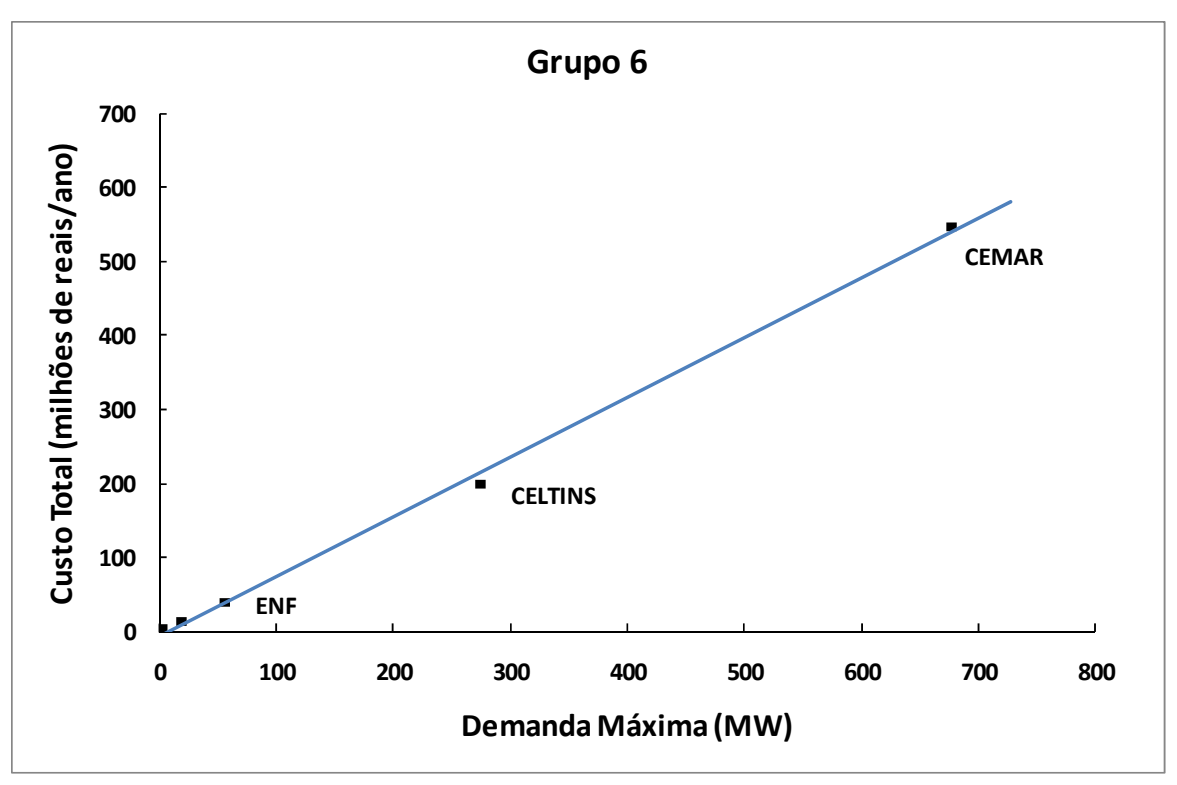

Figura 90: Gráfico de Custos Totais - Grupo 6. 


\section{ANEXO III}

\section{Relações entre as variáveis $\pi$ e $\beta$}

Dada e existência de dois eventos quaisquer, por exemplo $A$ e $B$, a teoria de probabilidades (COSTA NETO, 2002) define a probabilidade condicionada do evento $A$ ocorrer, dado que o evento B ocorreu, de acordo com a Equação (95).

$$
P(A / B)=\frac{P(A \cap B)}{P(B)}
$$

Algebricamente, pode-se demonstrar que a probabilidade condicionada $P(A / B)$ pode ser representada pela Equação (96). Esta equação é conhecida como Teorema de Bayes.

$$
P(A / B)=\frac{P(B / A) \cdot P(A)}{P(B)}
$$

O Teorema de Bayes é complementarmente definido através do Teorema da Probabilidade Total (COSTA NETO, 2002), conforme pode ser observado na Equação (97). A notação $\bar{A}$ se refere ao evento complementar a $A$.

$P(B)=P(A \cap B)+P(\bar{A} \cap B)$

A partir das equações (97) e (96), é possível demonstrar que:

$$
P(A / B)=\frac{P(B / A) \cdot P(A)}{P(B / A) \cdot P(A)+P(B / \bar{A}) \cdot P(\bar{A})}
$$


Genericamente, para qualquer partição complementar $A_{i}$ do evento $A$, o Teorema de Bayes mostra que:

$P\left(A_{i} / B\right)=\frac{P\left(B / A_{i}\right) \cdot P\left(A_{i}\right)}{\sum_{j} P\left(B / A_{j}\right) \cdot P\left(A_{j}\right)}$

Desde que $\sum_{j} P\left(A_{j}\right)=1$.

A partir da Equação (99), e das definições das probabilidades de associação $\pi_{j i}$ e $\beta_{i j}$ apresentadas, obtém-se imediatamente a Equação (100).

$P\left(C_{j} / T_{i}\right)=\frac{P\left(T_{i} / C_{j}\right) \cdot P\left(C_{j}\right)}{\sum_{j} P\left(T_{i} / C_{j}\right) \cdot P\left(C_{j}\right)}$

Ou ainda, substituindo-se os termos da Equação (100) pelas variáveis correspondentes, são obtidas as Equações (101) e (102), lembrando que $\sum_{j} \gamma_{j}=1$ e $\sum_{i} \alpha_{i}=1$.

$\beta_{i j}=\frac{\pi_{j i} \cdot \gamma_{j}}{\sum_{j} \pi_{j i} \cdot \gamma_{j}}$

$\pi_{j i}=\frac{\beta_{i j} \cdot \alpha_{i}}{\sum_{i} \beta_{i j} \cdot \alpha_{i}}$

Observando-se as equações (96) e (99), imediatamente pode-se verificar que:

$$
\begin{aligned}
& \sum_{j} \pi_{j i} \cdot \gamma_{j}=\alpha_{i} \\
& \sum_{i} \beta_{i j} \cdot \alpha_{i}=\gamma_{j}
\end{aligned}
$$


Até aqui, foram apenas definidas as relações entre as probabilidades $P\left(T_{i} / C_{j}\right)$, $P\left(C_{j} / T_{i}\right), P\left(C_{j}\right)$ e $P\left(T_{i}\right)$. É importante observar que as probabilidades $P\left(C_{j}\right)$ e $P\left(T_{i}\right)$ são conhecidas a priori, através do processo de caracterização da carga, responsável pela construção das tipologias representativas.

Contudo, as probabilidades $P\left(T_{i} / C_{j}\right)$ e $P\left(C_{j} / T_{i}\right)$ são desconhecidas a priori, o que torna necessária a formulação de um problema matemático para a sua determinação. Estas probabilidades estão, vale lembrar, intimamente relacionadas ao conceito de responsabilidade de potência, abordado no item 4.1.4. A Figura 91 e a Figura 92 representam graficamente a interpretação das variáveis $\pi_{j i}$ e $\beta_{i j}$.

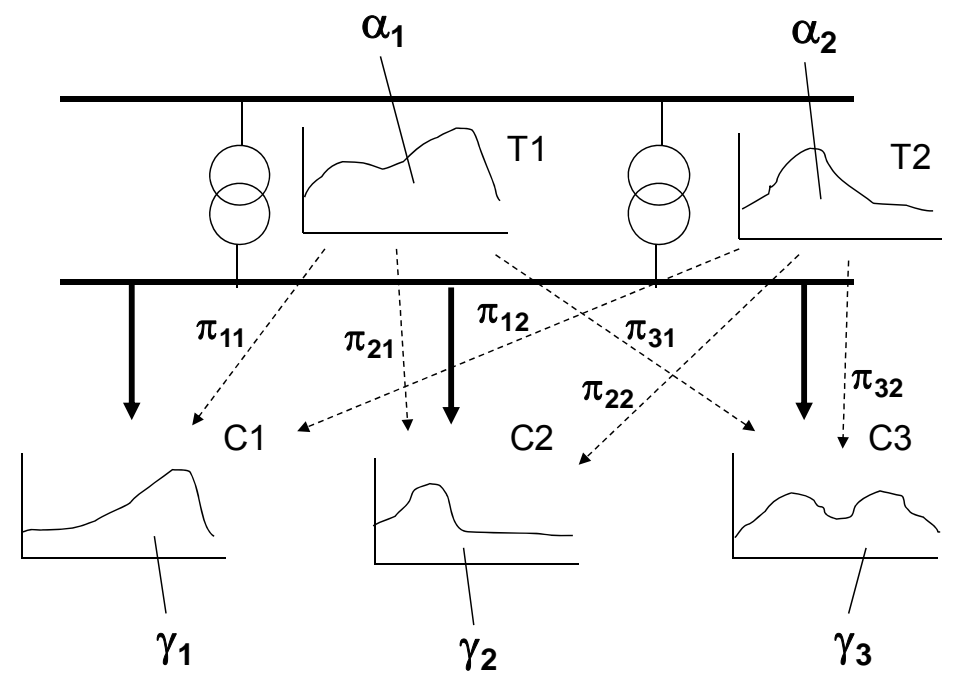

Figura 91 - Representação gráfica das variáveis $\pi_{j i}$

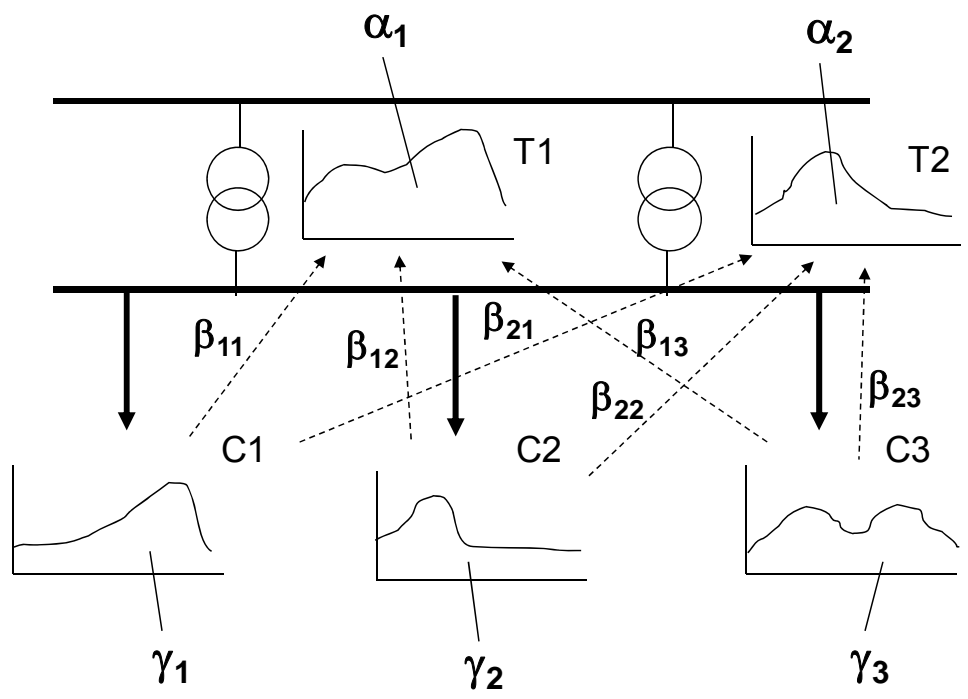

Figura 92 - Representação gráfica das variáveis $\boldsymbol{\beta}_{i j}$ 


\section{ANEXO IV \\ Determinação das Probabilidades de Associação}

\section{Considerações sobre a solução do problema}

A seguir, será demonstrado que o problema proposto em (31) pode ser expresso na forma de um problema de programação quadrática. Em seguida, demonstrar-se-á também que o problema é de otimização convexa, apresentando apenas um mínimo global.

Considere que um problema de programação quadrática pode ser colocado na forma:

$\min \left\{Q(x)=\frac{1}{2} x^{T} G x+g^{T} x\right\}$

Sujeito $a$ :

$a_{i}^{T} x=b_{i}, i \in E$

$a_{i}^{T} x \geq b_{i}, i \in I$

Sendo $\mathrm{x}$ o vetor de variáveis com $\mathrm{n}$ elementos, $\mathrm{G}$ uma matriz $\mathrm{n} \times \mathrm{n}$ simétrica e $\mathrm{E}$ e I conjuntos finitos de índices com $\mathrm{E}=\left\{1, \ldots, \mathrm{m}_{\mathrm{e}}\right\}$ e $\mathrm{I}=\left\{\mathrm{m}_{\mathrm{e}}+1, \ldots, \mathrm{m}\right\}$ (SUN \& YUAN, 2006). Deste modo, o problema tem $m_{e}$ restrições de igualdade e $m-m_{e}$ restrições de desigualdade.

Como as restrições observadas em (31) são lineares, da mesma forma que as do equacionamento genérico de programação quadrática (105), o problema consiste em mostrar que a função objetivo em (31) também pode ser escrita na forma do equacionamento genérico.

$\mathrm{O}$ número total de redes-tipo será indicado por $\mathrm{N}$ e o número total de consumidores tipo será indicado por M. As variáveis do problema são os valores $\beta_{\mathrm{ij}}$. Dessa forma o vetor de variáveis do problema será dado por: 
$x=\left[\begin{array}{c}{\left[\beta_{1}\right]} \\ \vdots \\ {\left[\beta_{N}\right]}\end{array}\right]$

Sendo que cada matriz $\left[\beta_{i}\right]$ é dada por:

$\beta_{i}=\left[\begin{array}{c}\beta_{i 1} \\ \vdots \\ \beta_{i M}\end{array}\right]$

Dessa forma, o vetor $\mathrm{x}$ tem N.M elementos, e a função objetivo do problema (31) pode ser expressa na seguinte forma:

$f=\sum_{i=1}^{N} \sum_{t=1}^{24}\left[t_{i}(t)^{2}-2 t_{i}(t)\left(\sum_{j=1}^{M} \beta_{i j} c_{j}(t)\right)+\left(\sum_{j=1}^{M} \beta_{i j} c_{j}(t)\right)^{2}\right]$

O primeiro termo da função (108) é uma constante de forma que não altera as características da função objetivo, podendo ser desprezado.

Sendo assim, a função objetivo pode ser escrita na forma:

$\bar{f}=\sum_{i=1}^{N} \sum_{t=1}^{24}\left[-2 t_{i}(t)\left(\sum_{j=1}^{M} \beta_{i j} c_{j}(t)\right)\right]+\sum_{i=1}^{N} \sum_{t=1}^{24}\left(\sum_{j=1}^{M} \beta_{i j} c_{j}(t)\right)^{2}$

E o primeiro termo da expressão de $\overline{\mathrm{f}}$ pode ser reescrito na forma:

$\sum_{i=1}^{N}\left[\sum_{j=1}^{M}\left(-2 \sum_{t=1}^{24} t_{i}(t) c_{j}(t)\right) \beta_{i j}\right]$

Denominando-se

$g_{i j}=-2 \sum_{t=1}^{24} t_{i}(t) c_{j}(t)$

A expressão (110) pode ser escrita na forma:

$\sum_{i=1}^{N}\left[\sum_{j=1}^{M} g_{i j} \beta_{i j}\right]=\sum_{i=1}^{N} g_{i}^{T} \beta_{i}=g^{T} x$ 
Sendo $g_{i}^{T}=\left[g_{i 1} \ldots g_{i M}\right]$ e $g^{T}=\left[\left[g_{1}^{T}\right] \ldots\left[g_{N}^{T}\right]\right]$. Para completar a demonstração, observa-se que o segundo termo da Equação (110) pode ser escrito na forma 1/ $2 x^{T} G x$. Para isso, esse segundo termo é escrito conforme (113), com $c(t)=$ $\left[c_{1}(t) \ldots c_{M}(t)\right]$.

$\sum_{i=1}^{N} \sum_{t=1}^{24}\left(\sum_{j=1}^{M} \beta_{i j} c_{j}(t)\right)^{2}=\sum_{i=1}^{N}\left[\sum_{t=1}^{24}\left(\beta_{i}^{T}\left(c(t)^{T} c(t)\right) \beta_{i}\right)\right]$

Como os vetores $\beta_{\mathrm{i}}$ não dependem de $t$, a expressão (113) pode ser escrita conforme (114):

$\sum_{i=1}^{N} \beta_{i}^{T}\left[\sum_{t=1}^{24} c(t)^{T} c(t)\right] \beta_{i}=\sum_{i=1}^{N} \beta_{i}^{T} C \beta_{i}=\frac{1}{2} x^{T} G x$

Onde $\mathrm{C}=\sum_{\mathrm{t}=1}^{24} \mathrm{c}(\mathrm{t})^{\mathrm{T}} \mathrm{c}(\mathrm{t})$ e a matriz $\mathrm{G}$ dada por:

$G=2\left[\begin{array}{cccc}C & 0 & \ldots & 0 \\ 0 & C & \ldots & 0 \\ 0 & \vdots & \ddots & 0 \\ 0 & \ldots & 0 & C\end{array}\right]$

Finalmente, demonstrou-se que a expressão (109) pode ser escrita na forma da função objetivo do problema (105), concluindo-se que o problema (31) é um problema de programação quadrática.

\section{Convexidade do problema}

O próximo passo consiste em mostrar que a matriz G é positiva semi-definida. Nesse caso, pode-se garantir que um mínimo local da função objetivo é solução global do problema (SUN \& YUAN, 2006). Esse fato é de suma importância para a determinação do método de solução computacional a ser utilizado para o problema.

Uma matriz $\mathrm{G}$ é positiva semi-definida se, para qualquer vetor $\mathrm{x}, \mathrm{x}^{\mathrm{T}} \mathrm{Gx} \geq 0$. Uma das maneiras de mostrar que uma matriz é positiva semi-definida é mostrar que todos os seus auto-valores são não negativos (LIPSCHUTZ, 1994). Para determinar os autovalores da matriz G resolve-se a equação: 
$\operatorname{det}(\lambda I-G)=0$

Sendo os valores de $\lambda$ que satisfazem a equação os autovalores de Ge I a matriz identidade de ordem igual a ordem de G. Como a matriz G é diagonal em blocos, a matriz $\lambda I-G$ também será, e pode ser escrita na forma:

$\lambda I-G=2\left[\begin{array}{cccc}\lambda I-C & 0 & \ldots & 0 \\ 0 & \lambda I-C & \ldots & 0 \\ 0 & \vdots & \ddots & 0 \\ 0 & \ldots & 0 & \lambda I-C\end{array}\right]$

É um fato conhecido também que nesse caso pode-se escrever (GREUB, 1981):

$\operatorname{det}(\lambda I-G)=2 \operatorname{det}(\lambda I-C) \cdot \operatorname{det}(\lambda I-C) \ldots \operatorname{det}(\lambda I-C)$

E, por esse motivo, a Equação (32) pode ser escrita na forma:

$\operatorname{det}(\lambda I-C) \cdot \operatorname{det}(\lambda I-C) \ldots \operatorname{det}(\lambda I-C)=0$

Isso mostra que o conjunto dos autovalores da matriz $G$ é dado pelos autovalores da matriz $\mathrm{C}$, sendo que cada um deles terá multiplicidade igual ao número de matrizes C. Sendo assim, para mostrar que G é uma matriz positiva semi-definida, basta mostrar que a matriz C é positiva semi-definida.

Para isso, deve-se notar que a matriz C pode ser escrita da seguinte forma:

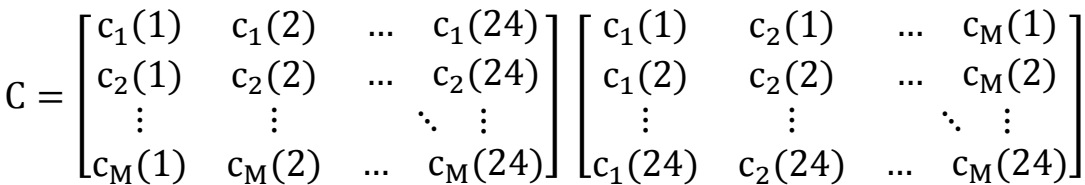

Dessa forma, C é dada pelo produto de uma matriz transposta por ela mesa, ou seja:

$\mathrm{C}=\mathrm{S}^{\mathrm{T}} \mathrm{S}$

Assim, $x^{\mathrm{T}} \mathrm{Cx}=\mathrm{x}^{\mathrm{T}}\left(\mathrm{S}^{\mathrm{T}} \mathrm{S}\right) \mathrm{x}=(\mathrm{S} \mathrm{x})^{\mathrm{T}}(\mathrm{S} \mathrm{x})=|| \mathrm{S} \mathrm{x} \|^{2} \geq 0$, para qualquer $\mathrm{x}$, o que completa a demonstração de que o problema (31) é um problema de programação quadrática convexo, de forma que um minimizador local para o problema é também um minimizador global. 


\section{Algoritmo para a solução do problema}

Como demonstrado nas seções anteriores, o problema de otimização a ser resolvido é um problema convexo. Como também apresenta restrições de desigualdade, pode ser resolvido pelo método do gradiente projetado com restrições ativas (SUN \& YUAN, 2006). A implementação do algoritmo mostrou que problemas de tamanho típico podem ser resolvidos com tempo de computação viável. 


\section{ANEXO V \\ Inferência Estatística de Uma Curva de Carga}

\section{O problema}

Para uma dada população de consumidores, deseja-se encontrar sua curva de carga agregada de consumo durante um dia típico. É importante perceber, neste caso, que não há interesse na determinação do total de energia consumida pela população, já que esse dado é conhecido. Objetiva-se, assim, determinar a forma da curva agregada da população.

Pretende-se, para este fim, determinar o tamanho da amostra $n$, ou seja, o número de consumidores cujas curvas de consumo devem ser medidas. Como requisitos, deve-se estabelecer qual o erro máximo aceitável na curva determinada e qual a sua confiabilidade. A precisão será dada pela letra $\alpha$, de forma que a confiabilidade será dada por $1-\alpha$. Ou seja, para uma confiabilidade de $95 \%$, deve-se escolher $\alpha=5 \%$. Já a questão de como definir o erro da curva obtida para a amostra e para a população exige uma discussão mais cuidadosa.

Considere-se o caso em que se queira determinar o valor da média de uma variável unidimensional para uma população. Chama-se $\mu$ a média da variável para a população toda e $\bar{x}$ a média obtida para uma amostra da população. É simples definir o erro obtido nesse caso por $|\overline{\mathrm{x}}-\mu|$. Pode-se também definir o erro de forma relativa por $R=|\bar{x}-\mu| /|\mu|$, também chamado de erro amostral.

Para o caso tratado nesse documento, o problema é mais complexo. Cada elemento da população corresponde a um vetor de, no mínimo, 24 valores, sendo cada valor o consumo médio do consumidor durante uma hora do dia. Dessa forma, a média da população é dada por um vetor $\mu=\left(\mu_{1}, \ldots, \mu_{24}\right)$, e a média da amostra por outro vetor $\overline{\mathrm{x}}=\left(\overline{\mathrm{x}}_{1}, \ldots, \overline{\mathrm{x}}_{24}\right)$. Sendo $n$ o tamanho da amostra e $\mathrm{x}_{\mathrm{i}}^{\mathrm{j}}$ o valor da i-ésima variável do j-ésimo elemento da amostra, a média da i-ésima variável é definida por (122). 
$\bar{x}_{i}=\frac{\sum_{j=1}^{n} x_{i}^{j}}{n}, \quad i=1 \ldots 24$

Um questão bastante importante reside em como definir o erro dado pela comparação entre os vetores $\mu \mathrm{e} \overline{\mathrm{x}}$. Este problema está intimamente associado à medida de distância entre dois vetores. A primeira opção frequentemente escolhida seria utilizar a distância euclidiana entre eles, que é dada por (123).

$d(\bar{x}, \mu)=\sqrt{\sum_{i=1}^{24}\left(\bar{x}_{i}-\mu_{i}\right)^{2}}$.

Dessa forma, a definição natural do erro amostral seria $R=d(\bar{x}, \mu) /|\mu|$, sendo que a norma da média da população é dada por $|\mu|=d(0, \mu)$. O problema da utilização da distância euclidiana é que ela não garante a forma da curva. Na Figura 93, é ilustrado um exemplo em que a distância euclidiana entre duas curvas é pequena, porém a forma da curva com erro não é parecida com a forma da curva de referência. Isso ocorre porque nesse caso os erros ocorreram em apenas três pontos da curva, fazendo com que o erro total seja pequeno, apesar de ser efetivamente grande nesses pontos.

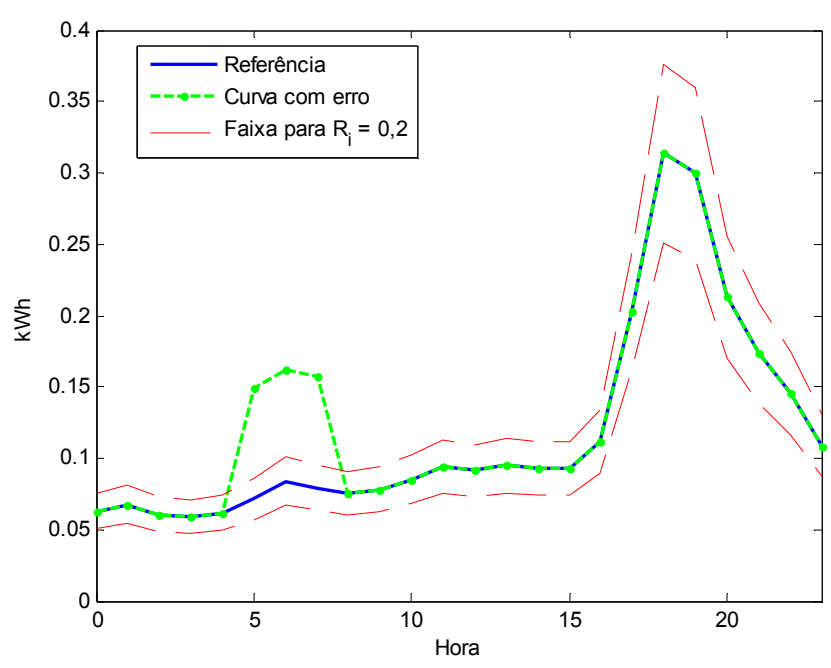

Figura 93 - Na figura, está indicada uma curva de referência. A curva "com erro" é um exemplo de curva com pequena distância euclidiana em relação à curva de referência. Apesar da pequena distância euclidiana, vê-se que a forma da curva não mantida. A linha tracejada em indica uma faixa em torno da curva de referência de forma que os erros amostrais para cada uma das variáveis é igual a 0,2. 
Uma segunda possibilidade seria a determinação do erro amostral para cada variável. Nesse caso, o erro amostral em cada uma das variáveis seria dado por:

$R_{i}=\frac{\left|\bar{x}_{i}-\mu_{i}\right|}{\left|\mu_{i}\right|}$

A conseqüência natural dessa definição seria determinar o tamanho da amostra para que todos os erros amostrais fossem menores que um valor prédeterminado. A dificuldade natural dessa abordagem é que a faixa de tolerância em torno da curva de referência seria mais estreita exatamente nos pontos em que o consumo é o menor, e, portanto, nos pontos de menor importância na determinação da forma da curva de carga. Em outras palavras, essa abordagem levaria a faixas de erro mais largas nos pontos de maior relevância e a faixas mais estreitas nos pontos de menor relevância. Esse efeito pode ser observado também na Figura 93.

Por esse motivo, procurou-se uma forma alternativa de definição de erro amostral. $\mathrm{O}$ autor propõe uma nova definição de erro amostral para o valor médio da curva, dado por (125).

$\mu_{\text {médio }}=\frac{\sum_{i=1}^{24} \mu_{i}}{24}$

De forma análoga, o valor médio da curva amostrada é observado em (126).

$\bar{x}_{\text {médio }}=\frac{\sum_{i=1}^{24} \bar{x}_{i}}{24}$.

O erro amostral da curva é, então, definido por (127).

$\mathfrak{R}=\frac{\left|\mu_{\text {médio }}-\bar{x}_{\text {médio }}\right|}{\left|\mu_{\text {médio }}\right|}$.

Define-se, a partir de então, uma faixa de largura $2 \mathrm{e}=2 \Re\left|\mu_{\text {médio }}\right|$ em torno da curva média da população. Neste contexto, o problema consiste em determinar o tamanho da amostra n de tal forma que a curva média da amostra esteja dentro desta faixa, com confiabilidade $1-\alpha$. 
Sendo $\mathrm{e}_{\mathrm{i}}=\left|\overline{\mathrm{x}}_{\mathrm{i}}-\mu_{\mathrm{i}}\right|$ o erro para cada variável e $\mathrm{P}_{\mathrm{i}}=\mathrm{P}\left(\mathrm{e}_{\mathrm{i}}<e\right)$ a confiabilidade para cada variável, a amostra de tamanho n deve garantir que:

$$
\prod_{i=1}^{24} P_{i}>1-\alpha
$$

\section{Comentário sobre amostragem multivariada}

Pelo que foi discutido até aqui, pode-se perceber que o problema foi colocado de forma que as 24 variáveis a serem amostradas são tratadas independentemente, não se levando em consideração as correlações entre elas.

Essa colocação objetiva-se a obter uma amostra que leve a determinação de uma curva média com formato semelhante ao formato da curva média da população. Sendo assim, é importante que o valor de cada uma das variáveis seja controlado de forma independente. Para uma descrição mais detalhada dos métodos de amostragem multivariada, consultar (HÄRDLLE \& SIMAR, 2007), (MANLY, B. F. J., 2000) ou (IZENMAN, 2008).

\section{Determinação da confiabilidade para o caso unidimensional}

A partir da formulação proposta na seção anterior, é possível perceber que para a determinação do tamanho da amostra com o objetivo de se obter uma curva agregada amostral semelhante à curva agregada da população, têm-se um conjunto de 24 problemas de estimação para variáveis unidimensionais. A relação entre eles é dada pelo fato de que as confiabilidades individuais devem ser tais que seus produtos forneçam um valor maior que a confiabilidade requerida de $1-\alpha$. Por esse motivo, nesta seção será tratado o problema da amostragem unidimensional, de forma que se possa determinar o valor das probabilidades $\mathrm{P}_{\mathrm{i}}=\mathrm{P}\left(\mathrm{e}_{\mathrm{i}}<e\right)$.

O problema a ser considerado consiste em determinar, para um determinado tamanho de amostra n, qual a probabilidade do erro amostral obtido ser menor que um certo valor pré-determinado e. Sendo $\mu$ o valor da média da população e $\overline{\mathrm{x}}$ a média da amostra, essa probabilidade será dada por $\mathrm{P}(|\overline{\mathrm{x}}-\mu|<e)$. 
Para isso, é necessária a utilização de um importante teorema, conhecido como teorema do limite central (KACHIGAN, 1991).

\section{Teorema do limite central}

Se uma variável $\mathrm{x}$ tem distribuição com média $\mu$ e desvio padrão $\sigma$, então a distribuição da média amostral $\overline{\mathrm{x}}$, obtida através de amostras de tamanho $\mathrm{n}$ sorteadas aleatoriamente a partir de uma população de tamanho $N$, considerando-se que $N \gg n$ (COSTA NETO, 2002), terá média igual a $\mu$ e desvio padrão $\sigma_{\bar{x}}=\sigma / \sqrt{ }$ n. A distribuição de $\overline{\mathrm{x}}$ tenderá a uma distribuição normal quanto maior o tamanho da amostra $\mathrm{n}$.

Uma questão importante a respeito do teorema acima descrito é que, em geral, assume-se que a distribuição da média da amostra será normal para amostras com tamanho a partir de $n=30$ (KACHIGAN, 1991), (MANLY, 2005).

Sabendo-se que a variável $\overline{\mathrm{x}}$ tem distribuição normal com média $\mu$ e desvio padrão $\sigma_{\bar{x}}=\sigma / \sqrt{n}$, conclui-se que a variável $z=\frac{\bar{x}-\mu}{\sigma_{\bar{x}}}$ terá distribuição normal com média zero e desvio padrão unitário, também chamada de normal reduzida (MAGALHÃES \& LIMA, 2004).

Voltando-se à probabilidade da diferença entre a média da amostra e a média da população ser menor que um determinado erro absoluto e, pode-se escrever $P(|\bar{x}-\mu|<e)=P(-e<\bar{x}-\mu<e)$.

Dividindo-se todos os temos por $\sigma_{\bar{x}}$, tem-se que $P\left(\frac{-e}{\sigma_{\bar{x}}}<\frac{\bar{x}-\mu}{\sigma_{\bar{x}}}<\frac{e}{\sigma_{\bar{x}}}\right)=$ $P\left(\frac{-e}{\sigma_{\bar{\chi}}}<z<\frac{e}{\sigma_{\bar{\chi}}}\right)=P\left(\frac{-e \sqrt{ } n}{\sigma}<z<\frac{e \sqrt{n}}{\sigma}\right)$.

Assim, assumindo-se que a população é consideravelmente maior que o tamanho da amostra, a partir de uma estimativa para o valor do desvio padrão $\sigma$ da população, bem como do tamanho da amostra $\mathrm{n}$ e do erro absoluto requerido, é possível determinar a probabilidade P desejada.

Outro aspecto a ser observado é que, para amostras com tamanho superior a $30, \sigma_{x}$ (desvio padrão da amostra) é uma boa aproximação de $\sigma$ (desvio padrão da 
população), o que justifica a utilização da distribuição normal reduzida ao invés da distribuição T de Student para avaliar o intervalo de confiança (COSTA NETO, 2002).

\section{Um exemplo}

Supondo que se deseje determinar a confiabilidade de um erro de 0,1 , para a determinação da média de uma população com estimativas iniciais $\mu=0,5$ e $\sigma=0,3$ para uma amostra de tamanho $\mathrm{n}=100$, chega-se à expressão $P(-3.3333 \ldots<z<$ $3.3333 \ldots$ ), sendo que $z$ tem distribuição normal com média nula e desvio padrão unitário.

A função densidade de probabilidade para a normal reduzida é dada por (129).

$f(z)=\frac{1}{\sqrt{2 \pi}} e^{\left(-\frac{z^{2}}{2}\right)}$

A Figura 94 ilustra o gráfico da função densidade de probabilidade em (129). A área abaixo da curva indica a probabilidade de um número sorteado aleatoriamente estar dentro dos limites definidos. Assim, se tomarmos um valor crítico para z, por exemplo, $\mathrm{z}_{\mathrm{c}}=1,96$, é possível verificar que a área abaixo da curva $\mathrm{f}(\mathrm{z})$ entre os limites $-1,96$ e 1,96 é igual a, aproximadamente, 0,95 . Isso significa que a probabilidade de um número sorteado para uma variável com distribuição normal de média zero e desvio padrão unitário estar entre -1,96 e 1,96 é de aproximadamente 95\%. 


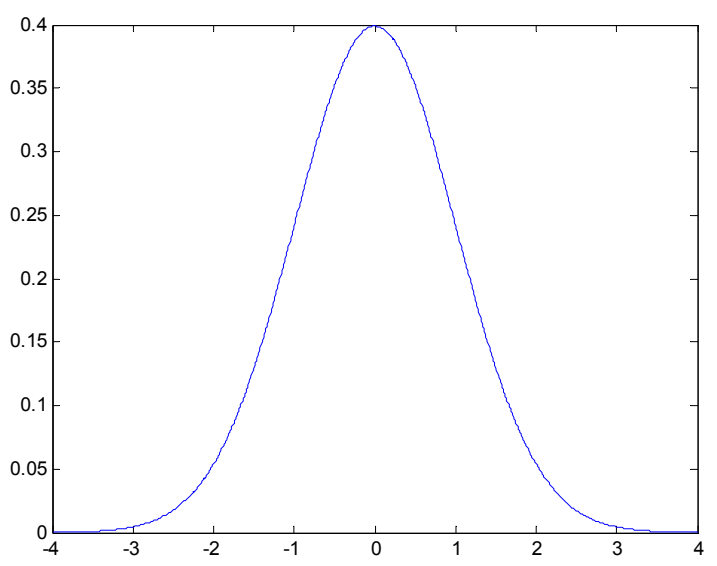

Figura 94 - Função densidade de probabilidade da distribuição normal com média 0 e desvio padrão unitário

Voltando ao exemplo apresentado, dados os limites $-3,33 \ldots$ e $3,33 \ldots$, qual a probabilidade de um número sorteado estar dentro desses valores? Para responder a esta questão, pode-se utilizar a definição da função distribuição acumulada, apresentada em (130).

$F\left(z_{c}\right)=\int_{-\infty}^{z_{c}} f(z) d z=P\left(z<z_{c}\right)$.

Pela definição de $\mathrm{F}\left(\mathrm{z}_{\mathrm{c}}\right)$, é possível perceber que $\mathrm{F}\left(\mathrm{z}_{\mathrm{c}}\right)=1-\alpha / 2$, já que a distribuição normal é simétrica. Dessa forma, a probabilidade procurada é dada por (131).

$P\left(-z_{c}<z<z_{c}\right)=2 F\left(z_{c}\right)-1$

Deste modo, o problema se resume em calcular o valor de $\mathrm{F}(3,33 \ldots)$. Esse valor pode ser obtido a partir de tabelas usuais, porém para a melhor automatização, torna-se interessante o cálculo através de um algoritmo computacional.

Como a função $\mathrm{F}(\mathrm{z})$ não tem forma analítica definida, somente é possível obter seu valor calculado por uma aproximação, e a aproximação usada será dada pela 
equação proposta em (ABRAMOWIZ \& STEGUN, 1964). A expressão numérica desta equação é dada em (132).

$F(z) \approx 1-c \cdot e^{-z^{2} / 2} \cdot\left(b_{1} t+b_{2} t^{2}+b_{3} t^{3}+b_{4} t^{4}+b_{5} t^{5}\right)$,

com

$b_{1}=0,319381530$,

$b_{2}=-0,356563782$,

$b_{3}=1,781477937$,

$b_{4}=-1,821255978$,

$b_{5}=1,330274429$,

$c=\frac{1}{\sqrt{2 \pi}}$

$p=0,2316419$,

$t=\frac{1}{1+p \cdot z}$

A partir da expressão (132), é possível obter, para $\mathrm{z}_{\mathrm{c}}=3,33 \ldots$, o valor $\mathrm{F}\left(\mathrm{z}_{\mathrm{c}}\right) \approx$ 0,9995708 , o que corresponde a uma probabilidade $\mathrm{P}=99,91417 \%(2 F(Z c)-1)$.

A partir do que foi descrito anteriormente, propõe-se um procedimento expedito para o cálculo da probabilidade $P$. Deve-se lembrar que os dados de entrada são o erro desejado $e$, a estimativa para o desvio padrão da população $\sigma$ e o tamanho da amostra $n$.

Assim, calcula-se o valor de $\mathrm{z}_{\mathrm{c}}$ pela expressão (133).

$z_{c}=\frac{e \sqrt{n}}{\sigma}$.

E a partir desse valor, calcula-se a confiabilidade $\mathrm{P}$ a partir de (134).

$P=2 F\left(z_{c}\right)-1$.

Conhecendo-se o valor da probabilidade $P$ a partir de um valor $n$, referente ao número de amostras, pode-se propor um algoritmo bastante simples, no qual incrementa-se de forma unitária o número de amostras até que a probabilidade seja maior ou igual à confiabilidade desejada. 


\section{Estratificação da população}

Nesta seção, será tratado o problema da estratificação da população com o objetivo de reduzir o tamanho da amostra garantindo o mesmo erro amostral e a mesma confiabilidade desejados para a média amostral agregada. No problema em questão, é possível definir estratos em função do consumo total mensal dos usuários. Entretanto, deve-se ter clareza que o objetivo da estratificação não é o conhecimento da curva agregada por estrato, e sim da curva agregada total da população. Inicialmente será discutido o caso de amostragem unidimensional e em seguida será proposta a aplicação do método para o problema multidimensional.

\section{Estratificação para caso unidimensional}

O texto desta seção está baseado no capítulo 5 de (COCHRAN, 1977). Primeiramente estabelecemos a notação a ser utilizada. $O$ sobrescrito $h$ indica $O$ estrato.

- $\quad L$ : Número de estratos.

- $\quad N$ : Tamanho da população.

- $N_{h}$ : Número de elementos no estrato $\mathrm{h}$.

- $W_{h}=\frac{N_{h}}{N}$ : Fração do estrato na população.

- $\sigma_{h}$ : Desvio padrão do estrato $\mathrm{h}$.

- $n$ : Tamanho total da amostra.

- $n_{h}$ : Tamanho da amostra do estrato $\mathrm{h}$.

- $\bar{x}_{h}$ : Média da amostra no estrato $\mathrm{h}$.

- $\bar{x}_{e s t}$ : Média da amostra estratificada.

- $\sigma_{\bar{x}_{e s t}}$ : Desvio padrão da média da amostra estratificada.

A média da amostra estratificada $\overline{\mathrm{x}}_{\text {est }}$ é a estimativa para a média da população e é dada por:

$\bar{x}_{e s t}=\sum_{h=1}^{L} W_{h} \bar{x}_{h}$.

A variância do estimador, $\overline{\mathrm{x}}_{\mathrm{est}}$, pode ser calculada por: 
$\left(\sigma_{\bar{x}_{e s t}}\right)^{2}=\sum_{h=1}^{L} \frac{W_{h}^{2} \sigma_{h}^{2}}{n_{h}}$.

Para a expressão (136), as relações $n_{h} / N_{h}$ foram desprezadas.

O teorema fundamental a ser utilizado nessa seção trata da alocação do total de amostras em diferentes estratos. A idéia consiste em determinar quantas amostras devem ser escolhidas em cada estrato de forma que $\left(\sigma_{\overline{\mathrm{x}}_{\mathrm{est}}}\right)^{2}$ seja minimizado.

Teorema: Em uma amostragem estratificada aleatória, o valor de $\left(\sigma_{\overline{\mathrm{x}}_{\text {est }}}\right)^{2}$ é minimizado para um tamanho fixo de amostras n se:

$$
\begin{gathered}
n_{h}=n \frac{W_{h} \sigma_{h}}{\sum_{h=1}^{L} W_{h} \sigma_{h}}=n F_{h}, \\
\text { com } \mathrm{F}_{\mathrm{h}}=\mathrm{W}_{\mathrm{h}} \sigma_{\mathrm{h}} / \sum_{\mathrm{h}=1}^{\mathrm{L}} \mathrm{W}_{\mathrm{h}} \sigma_{\mathrm{h}} .
\end{gathered}
$$

Essa alocação, conhecida como alocação de Neymann, substituída na Equação (136), leva ao seguinte valor para o desvio padrão do estimador $\overline{\mathrm{x}}_{\mathrm{est}}$ :

$\sigma_{\bar{x}_{e s t}}=\frac{\sum_{h=1}^{L} W_{h} \sigma_{h}}{n}$

A conclusão principal sobre a estratificação é que para aumentar a precisão do estimador da média da população, estratos com maiores variabilidades e tamanhos devem ter amostras maiores.

\section{Aplicação para o caso multidimensional}

A maior dificuldade da aplicação do procedimento de estratificação para o caso multidimensional é que a alocação ótima para uma das variáveis pode não ser ótima para as outras. Para resolver esse problema, sugere-se o cálculo da alocação ótima para a variável mais crítica do problema.

Para a determinação da variável mais crítica, retoma-se a Equação (133), que define o valor de $\mathrm{z}_{\mathrm{c}}$ a ser usado no cálculo da confiabilidade da amostragem. Usando 
a definição dada na Equação (127) para o erro amostral desejado, chega-se à expressão de $\mathrm{z}_{\mathrm{c}}$ para cada variável $\mathrm{i}$ :

$z_{c}^{i}=\frac{\Re\left|\mu_{\text {médio }}\right| \sqrt{\mathrm{n}}}{\sigma_{i}}$

Como, quanto maior for o valor de $\mathrm{z}_{\mathrm{c}}$, maior a confiabilidade da amostragem, a variável mais crítica do problema é aquela que apresenta o menor valor de $z_{c}$. Como esperado, isso ocorre para a variável com maior variabilidade.

\section{Resolução do problema}

O problema a ser resolvido tem como dados de entrada os seguintes itens:

$\mu$ : Vetor com as estimativas iniciais para as médias de cada uma das variáveis para a população.

$\sigma_{\mathrm{h}}$ : Matriz com as estimativas para os desvios padrão de cada uma das variáveis da população em cada estrato.

$\mathfrak{R}$ : Erro amostral da curva desejado para a amostra.

$\alpha$ : Precisão amostral. A confiabilidade desejada para a amostra é igual a $1-\alpha$.

$\mathrm{W}_{\mathrm{h}}$ : Fração de cada estrato em relação à população total.

L: Número de estratos utilizados.

Para cada uma das variáveis, calcula-se o valor do desvio padrão da média da amostra estratificada por:

$\sigma_{\bar{x}_{e s t}}^{i}=\frac{\sum_{h=1}^{L} W_{h} \sigma_{h}^{i}}{n}$ 
Além disso, para cada estrato, calcula-se o valor de $\mathrm{F}(\mathrm{h})$ usado para a alocação ótima da amostra por estrato. O valor é calculado para a variável com maior desvio padrão k, através da Equação (141):

$F_{h}=\frac{W_{h} \sigma_{h}^{k}}{\sum_{h=1}^{L} W_{h} \sigma_{h}^{k}}$

O que se deseja é determinar o tamanho da amostra n, de forma que:

$\prod_{i=1}^{24} P_{i}>1-\alpha$,

Sendo $\mathrm{P}_{\mathrm{i}}=\mathrm{P}\left(\mathrm{e}_{\mathrm{i}}<e\right)$ e $\mathrm{e}=\mathfrak{R}\left|\mu_{\text {médio }}\right|$, com $\mathfrak{R}$ dado pela Equação (127), caracterizando o máximo erro permitido para cada uma das variáveis. Para resolver o problema, é utilizado o seguinte algoritmo:

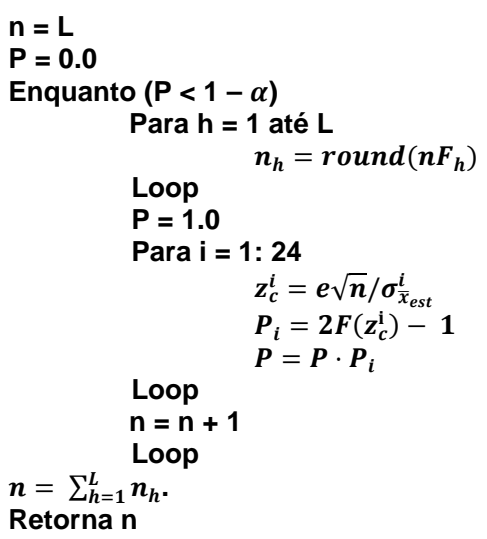

\section{Verificação dos resultados}

Para a verificação do procedimento proposto, algumas simulações numéricas são sugeridas. No item 0 , são apresentados resultados para o caso unidimensional com dados gerados artificialmente. No item ii é apresentado um caso multidimensional com dados artificiais e, finalmente, no item iii, apresentam-se resultados obtidos a partir de dados de campanhas de medição de anos anteriores, realizadas no segundo ciclo de revisões tarifárias. 


\section{i. Caso unidimensional com dados artificiais}

Para validar o procedimento de cálculo da confiabilidade para a média amostral no caso unidimensional, será tomado um conjunto de dados gerados artificialmente.

Num primeiro exemplo, gerou-se uma população de 20.000 elementos que seguem uma distribuição uniforme entre os valores 0 e 1. A Figura 95 mostra o histograma da população gerada. Nesta simulação, a média obtida para a população foi $\mu=0,4993$, com desvio padrão $\sigma=0,2888$.

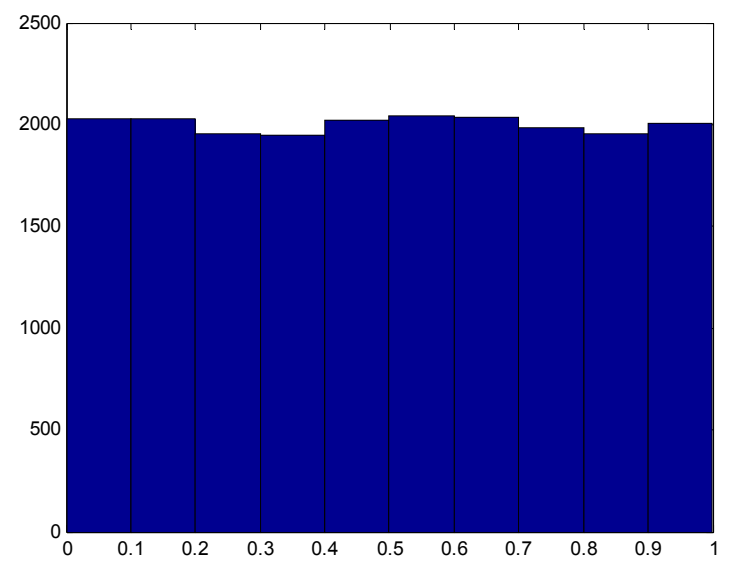

Figura 95 - Histograma da população com distribuição uniforme entre 0 e 1 com 20.000 elementos

Uma primeira verificação importante é a validade do teorema do limite central. Para isso, foram geradas 5000 sorteios aleatórios, sendo que para cada uma delas calculou-se a média da amostra, permitindo assim a determinação da distribuição da média amostral. O procedimento foi repetido para amostras de tamanhos iguais a 20 , 50 e 100 elementos. A Figura 96 ilustra as distribuições das médias amostrais nestes três casos, respectivamente.

Neste contexto, dois resultados são observados. O primeiro demonstra que a distribuição das médias amostrais é normal com média igual à média da população, e o segundo comprova a diminuição do desvio padrão da distribuição da média amostral com o aumento do tamanho da amostra, validando assim o teorema do limite central. 

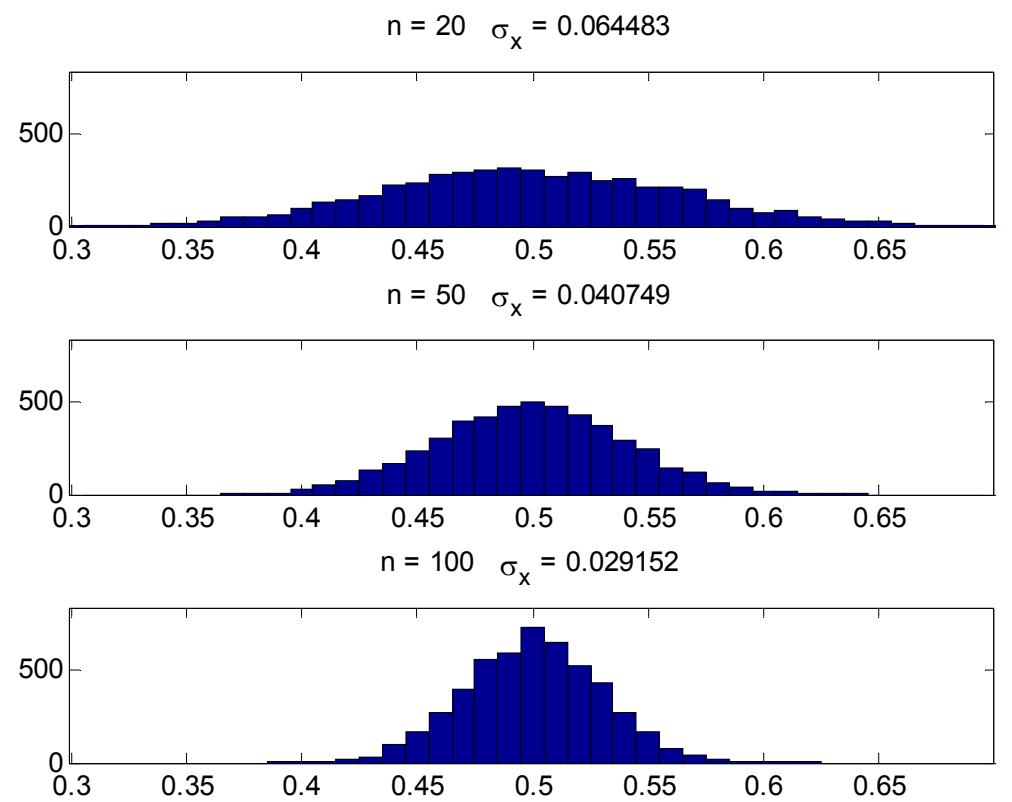

Figura 96 - Verificação do teorema do limite central. Distribuição da média amostral para 5000 amostras aleatórias, para amostras de tamanhos iguais a 20, 50 e 100 elementos.

Como neste caso a média da população e seu desvio padrão são conhecidos, pode-se testar o procedimento para o cálculo da confiabilidade do valor da média amostral obtida para um determinado tamanho de amostra e um determinado erro amostral pré-estabelecido. Como exemplo, toma-se um erro amostral de $10 \%$ e uma amostra de 50 elementos. Assim, retomando-se o erro amostral $\mathrm{R}=\frac{\mathrm{e}}{|\mu|}$, tem-se que $\mathrm{e}=\mathrm{R} \cdot|\mu|$.

Nesse caso, a confiabilidade é dada por $\mathrm{P}=2 \mathrm{~F}\left(\mathrm{z}_{\mathrm{c}}\right)-1$. Sendo $\mathrm{z}_{\mathrm{c}}=(\mathrm{R} \cdot|\mu| \cdot \sqrt{\mathrm{n}}) / \sigma=1,2133$, a confiabilidade será $\mathrm{P}=0,7750=77,50 \%$. Isso significa que, para cada 1000 sorteios de 50 amostras a partir da população, 775 deverão ter erros amostrais menores ou iguais a 10\%, em média. A Figura 97 ilustra a distribuição da média amostral para um total de 50.000 sorteios com 50 amostras. Em 77,452\% dos casos o erro amostral foi menor que $10 \%$, confirmando a validade do cálculo apresentado. 


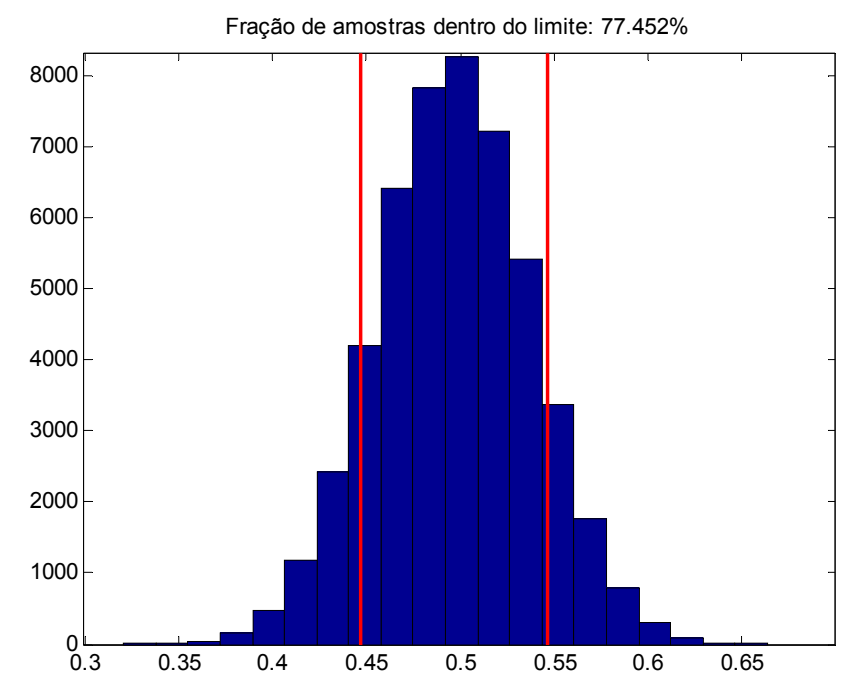

Figura 97 - Para 50.000 amostras calculou-se a média amostral e o número de vezes em que a média amostral esteve a uma distância de menos de $10 \%$ da média da população.

\section{ii. Caso Multidimensional com dados artificiais}

Para avaliar o procedimento proposto no caso multidimensional, foram geradas 4 populações de dados independentes, o que equivale a gerar um vetor populacional de quatro variáveis. Neste exemplo, cada população possui um total de 10.000 elementos. A

Tabela 50 indica os parâmetros de cada uma das populações e a Figura 98 ilustra os histogramas das 4 populações geradas.

Tabela 50 - Características das populações geradas para simulação de caso multidimensional.

\begin{tabular}{|c|c|c|c|}
\hline Índice & Distribuição & $\begin{array}{l}\text { Média } \\
\text { calculada }\end{array}$ & $\begin{array}{l}\text { Desvio Padrão } \\
\text { calculado }\end{array}$ \\
\hline 1 & Uniforme entre 0 e 1 & 0,49995 & 0,28829 \\
\hline 2 & Uniforme entre 7 e 12 & 9,5009 & 1,4481 \\
\hline 3 & $\begin{array}{l}\text { Normal com média } 0 \text { e desvio } \\
\text { unitário }\end{array}$ & 0,0010574 & 1,0011 \\
\hline 4 & $\begin{array}{l}\text { Normal com média } 5 \text { e desvio } \\
\text { igual a } 3\end{array}$ & 5,0199 & 3,0109 \\
\hline
\end{tabular}



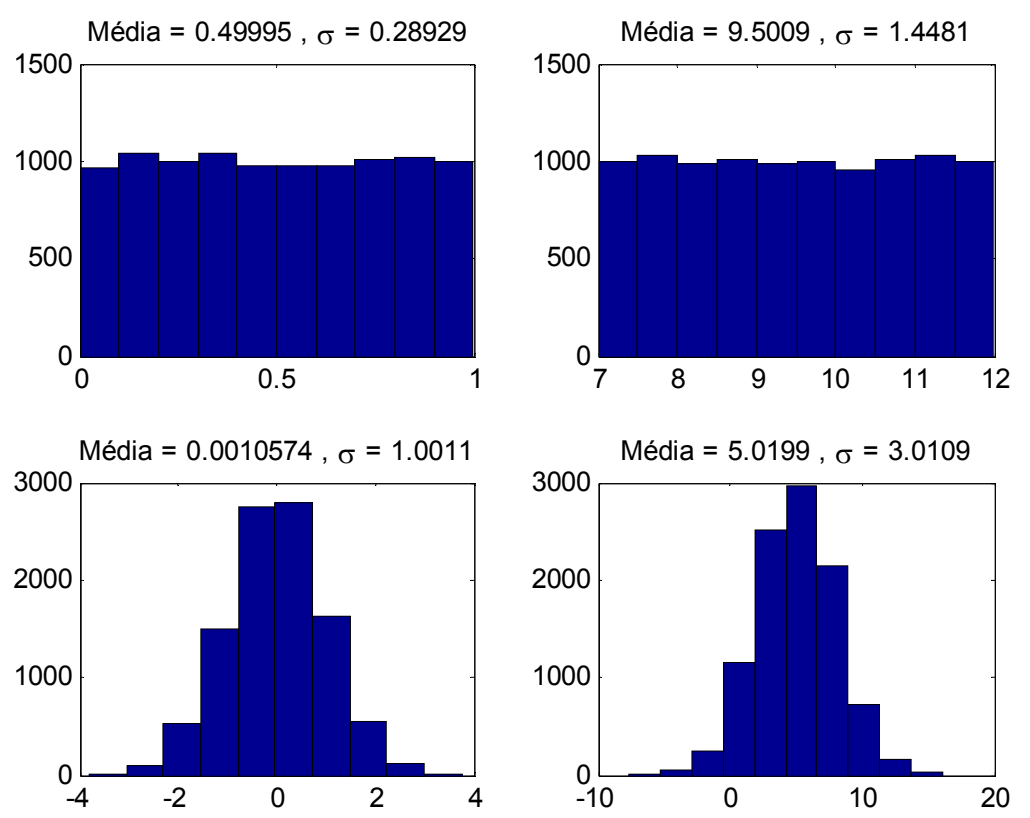

Figura 98 - Distribuições das populações geradas para simulação do caso multidimensional.

Como as médias populacionais são:

$\mu_{1}=0,49995$

$\mu_{2}=9,5009$

$\mu_{3}=0,0010574$

$\mu_{4}=5,0199$

A partir da notação apresentada, pode-se escrever:

$\mu_{\text {médio }}=\frac{0,49995+9,5009+0,0010574+5,0199}{4}=3,7555$

Escolhendo-se um erro amostral de 10\%, por exemplo, a largura da faixa a ser utilizada para a determinação do tamanho da amostra será dada por:

$2 \mathrm{e}=2 \mathrm{R} \mu_{\text {médio }}=2 \cdot 0,37555$

$\mathrm{e}=0,37555$ 
Escolhendo-se, então, uma confiabilidade a priori de $75 \%$, o algoritmo proposto, para um único estrato, apresenta como resultado um valor de n igual a 90 . As confiabilidades $\mathrm{P}_{\mathrm{i}}$ associadas a cada variável são, então, dadas por:

$\mathrm{P}_{1} \approx 1$

$\mathrm{P}_{2}=0,9861$

$\mathrm{P}_{3}=0,9996$

$\mathrm{P}_{4}=0,7633$

Nota-se que o produto das probabilidades $\mathrm{P}_{\mathrm{i}}$ é igual a 75,24\%, como esperado. Pode-se notar que a confiabilidade associada à primeira variável é a mais alta, dado que seu desvio padrão é o menor. De forma análoga, a confiabilidade associada à variável 4 é a menor, já que seu desvio padrão é o maior.

Para verificar a validade desse procedimento, foram gerados 10.000 sorteios contendo 90 amostras com 4 elementos de cada uma das 4 populações. Em seguida, verificou-se em quantas delas pelo menos um dos pontos esteve fora da faixa definida pelo erro absoluto e. Em exatamente 7552 casos, a faixa não foi violada, levando a uma confiabilidade de $75,52 \%$.

\section{iii. Caso Multidimensional com dados reais}

A partir de dados obtidos em campanhas de medidas do segundo ciclo de revisões tarifárias, foram tomadas 5893 curvas de consumo como elementos de uma população fictícia. A Figura 99 ilustra a curva média obtida para essa população. $\mathrm{Na}$ figura, estão também representadas faixas para valores de erro amostral $\mathrm{R}$ iguais a 20 e $40 \%$. 


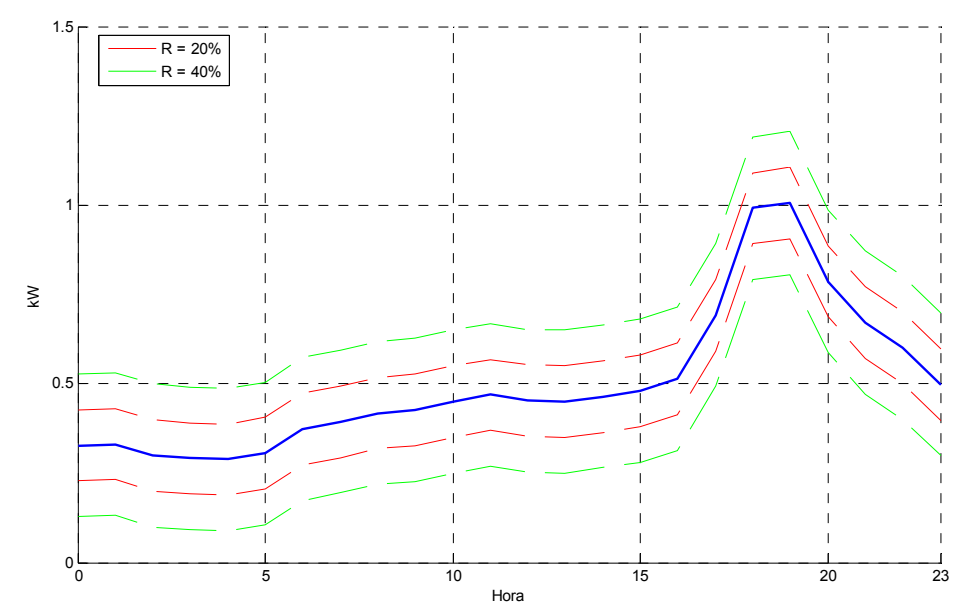

Figura 99 - Curva média para uma população de 5893 consumidores. Estão indicadas as faixas correspondentes a erros amostrais de 20 e $40 \%$

Escolhendo-se uma confiabilidade de 95\%, o procedimento proposto, sem estratificação $(L=1)$, indica a necessidade de 694 amostras para um erro amostral de $20 \%$. Para verificar a validade dos resultados, foram realizados 10.000 sorteios aleatórios de 694 amostras. Para cada sorteio, foi escolhida a variável que apresentava a maior distância em relação à curva média. Essa distância foi denominada $e_{\max }$, e seu histograma pode ser visto na Figura 100. A confiabilidade calculada foi de $95,53 \%$, e o resultado comprova a eficácia do procedimento apresentado.

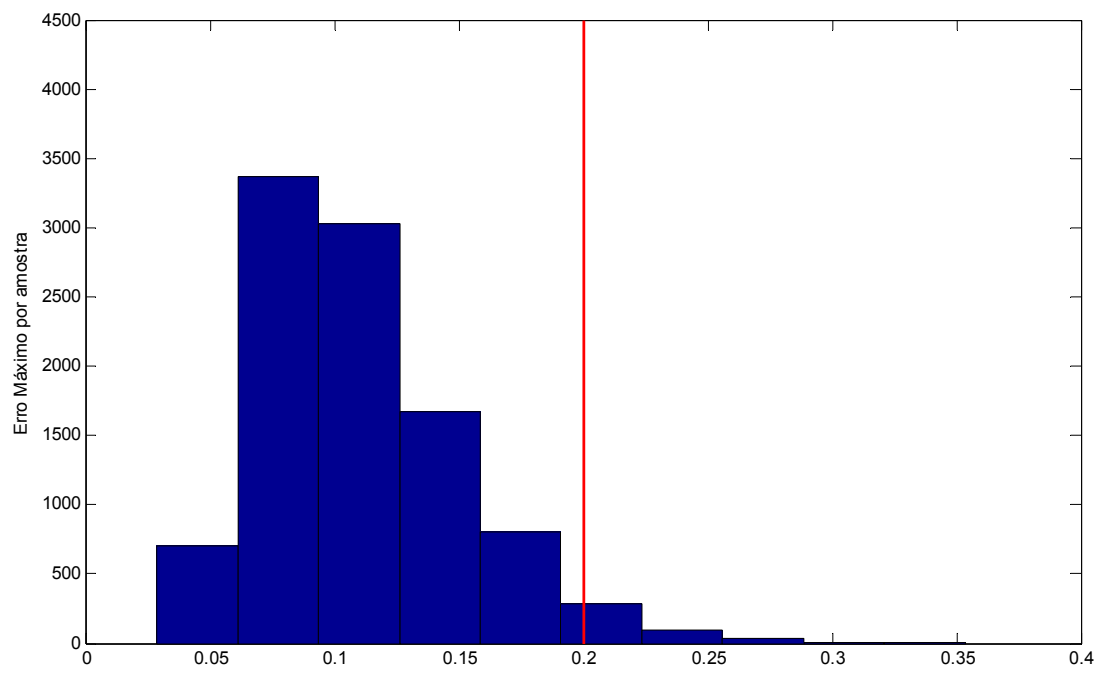

Figura 100 - Histograma para o valor de $e_{\max }$ para amostras de 694 elementos. Ao centro, o limite de erro determinado pelo erro amostral requerido (20\%). 
Com o objetivo de diminuir o tamanho necessário de elementos da amostra, a população foi estratificada de acordo com o valor de energia consumida em um dia. A Tabela 51 mostra as características de cada estrato e o tamanho da amostra para cada um deles. Os tamanhos das amostras nos estratos foram obtidos também a partir do algoritmo proposto.

Tabela 51 - Definição dos estratos utilizados e número de amostras para cada estrato.

\begin{tabular}{|l|l|l|}
\hline Estrato 1 & De 0 a $5 \mathrm{kWh} / \mathrm{dia}$ & 41 amostras \\
\hline Estrato 2 & De 5 a $15 \mathrm{kWh} / \mathrm{dia}$ & 62 amostras \\
\hline Estrato 3 & De 15 a $25 \mathrm{kWh} / \mathrm{dia}$ & 44 amostras \\
\hline Estrato 4 & De 35 a $50 \mathrm{kWh} / \mathrm{dia}$ & 35 amostras \\
\hline Estrato 5 & Mais de $50 \mathrm{kWh} / \mathrm{dia}$ & 23 amostras \\
\hline
\end{tabular}

Somando-se as amostras de cada estrato, chega-se a um valor de 205 amostras totais. Esse valor é muito inferior ao obtido para o caso sem estratificação. A Figura 101 ilustra o histograma do erro máximo obtido para um total de 10.000 sorteios considerando os números de amostras apresentadas na Tabela 51. A confiabilidade obtida foi de $95,03 \%$, e esse resultado mostra que a estratificação é bastante vantajosa para o problema em questão.

Um último comentário deve ser feito sobre a escolha da estratificação adotada. Experiências feitas com outras possibilidades mostraram que o resultado final não é muito sensível à estratificação adotada. Por esse motivo, torna-se pouco relevante a utilização de outras estratificações diferentes das já adotadas nos Procedimentos da Distribuição (ANEEL-C, 2008).

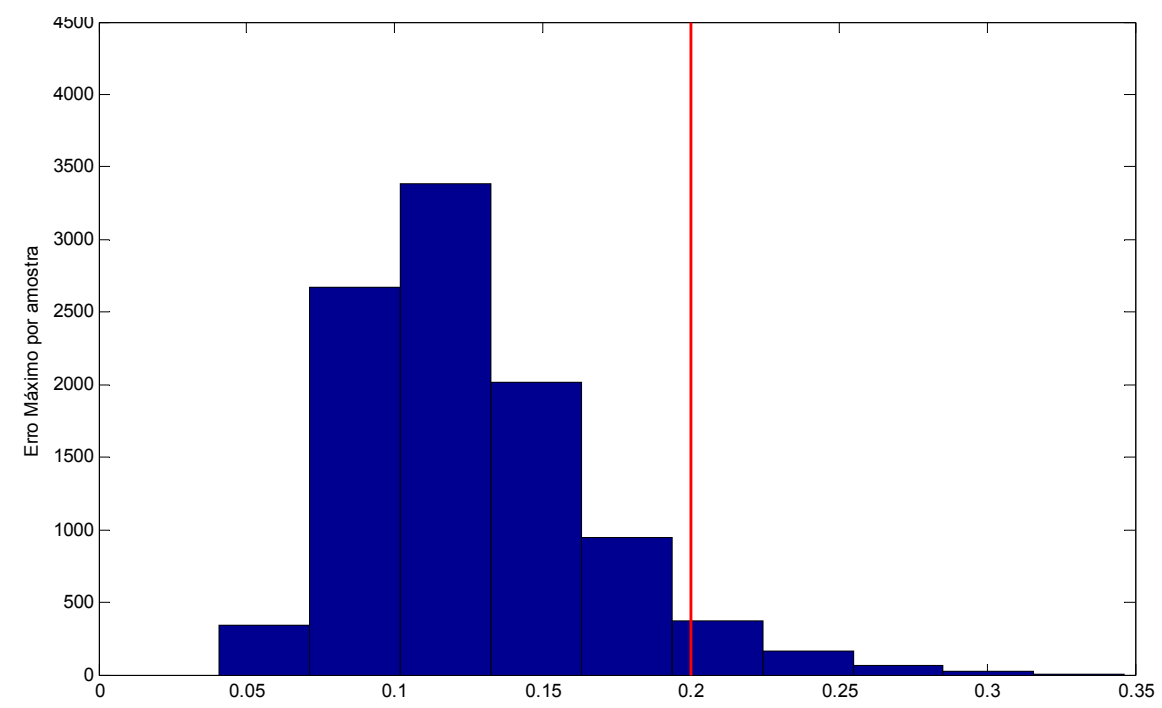

Figura 101 - Histograma para o valor de $e_{\max }$ para amostras estratificadas de 205 elementos. Ao centro, o limite de erro determinado pelo erro amostral requerido (20\%). 